Agrupamento de séries temporais em fluxos contínuos de dados 

SERVIÇO DE PÓS-GRADUAÇÃO DO ICMC-USP

Data de Depósito:

Assinatura:

\title{
Agrupamento de séries temporais em fluxos contínuos de dados
}

\author{
Cássio Martini Martins Pereira
}

Orientador: Prof. Dr. Rodrigo Fernandes de Mello

Tese apresentada ao Instituto de Ciências Matemáticas e de Computação - ICMC-USP, como parte dos requisitos para obtenção do título de Doutor em Ciências - Ciências de Computação e Matemática Computacional. VERSÃO REVISADA. 
Ficha catalográfica elaborada pela Biblioteca Prof. Achille Bassi e Seção Técnica de Informática, ICMC/USP, com os dados fornecidos pelo(a) autor(a)

Pereira, Cássio Martini Martins

P436a Agrupamento de séries temporais em fluxos contínuos de dados / Cássio Martini Martins Pereira; orientador Rodrigo Fernandes de Mello. -- São Carlos, 2013.

$140 \mathrm{p}$.

Tese (Doutorado - Programa de Pós-Graduação em Ciências de Computação e Matemática Computacional) -Instituto de Ciências Matemáticas e de Computação, Universidade de São Paulo, 2013.

1. Aprendizado de máquina. 2. Agrupamento. 3. Séries temporais. 4. Fluxos contínuos de dados. I. de Mello, Rodrigo Fernandes, orient. II. Título. 


\section{Agradecimentos}

Agradeço a meus pais pelo apoio, paciência e suporte.

Ao professor Rodrigo Mello, por sua orientação presente e cuidadosa do trabalho.

Aos professores e funcionários do ICMC-USP, que colaboraram direta e indiretamente para a conclusão deste trabalho.

Aos colegas Marcelo Albertini, Paulo Henrique Gabriel, Ricardo Rios e Vinícius Reis, pelas críticas e sugestões que auxiliaram na melhoria deste trabalho.

À FAPESP pelo auxílio financeiro (processo \# 2010/05062-6). 


\section{Resumo}

Recentemente, a área de mineração de fluxos contínuos de dados ganhou importância, a qual visa extrair informação útil a partir de conjuntos massivos e contínuos de dados que evoluem com o tempo. Uma das técnicas que mais se destaca nessa área é a de agrupamento de dados, a qual busca estruturar grandes volumes de dados em hierarquias ou partições, tais que objetos mais similares estejam em um mesmo grupo. Diversos algoritmos foram propostos nesse contexto, porém a maioria concentrou-se no agrupamento de fluxos compostos por pontos em um espaço multidimensional. Poucos trabalhos voltaramse para o agrupamento de séries temporais, as quais se caracterizam por serem coleções de observações coletadas sequencialmente no tempo. Técnicas atuais para agrupamento de séries temporais em fluxos contínuos apresentam uma limitação na escolha da medida de similaridade, a qual na maioria dos casos é baseada em uma simples correlação, como a de Pearson. Este trabalho mostra que até para modelos clássicos de séries temporais, como os de Box e Jenkins, a correlação de Pearson não é capaz de detectar similaridade, apesar das séries serem provenientes de um mesmo modelo matemático e com mesma parametrização. Essa limitação nas técnicas atuais motivou este trabalho a considerar os modelos geradores de séries temporais, ou seja, as equações que regem sua geração, por meio de diversas medidas descritivas, tais como a Autoinformação Mútua, o Expoente de Hurst e várias outras. A hipótese considerada é que, por meio do uso de medidas descritivas, pode-se obter uma melhor caracterização do modelo gerador de séries temporais e, consequentemente, um agrupamento de maior qualidade. Nesse sentido, foi realizada uma avaliação de diversas medidas descritivas, as quais foram usadas como entrada para um novo algoritmo de agrupamento baseado em árvores, denominado TS-Stream. Experimentos com bases sintéticas compostas por diversos modelos de séries temporais foram realizados, mostrando a superioridade de TS-Stream sobre ODAC, a técnica mais popular para esta tarefa encontrada na literatura. Experimentos com séries reais provenientes de preços de ações da NYSE e NASDAQ mostraram que o uso de TS-Stream na escolha de ações, por meio da criação de uma carteira de investimentos diversificada, pode aumentar os retornos das aplicações em várias ordens de grandeza, se comparado a estratégias baseadas somente no indicador econômico Moving Average Convergence Divergence. 


\section{Abstract}

Recently, the data streams mining area has gained importance, which aims to extract useful information from massive and continuous data sources that evolve over time. One of the most popular techniques in this area is clustering, which aims to structure large volumes of data into hierarchies or partitions, such that similar objects are placed in the same group. Several algorithms were proposed in this context, however most of them focused on the clustering of streams composed of multidimensional points. Few studies have focused on clustering streaming time series, which are characterized by being collections of observations sampled sequentially along time. Current techniques for clustering streaming time series have a limitation in the choice of the similarity measure, as most are based on a simple correlation, such as Pearson. This thesis shows that even for classic time series models, such as those from Box and Jenkins, the Pearson correlation is not capable of detecting similarity, despite dealing with series originating from the same mathematical model and the same parametrization. This limitation in current techniques motivated this work to consider time series generating models, i.e., generating equations, through the use of several descriptive measures, such as Auto Mutual Information, the Hurst Exponent and several others. The hypothesis is that through the use of several descriptive measures, a better characterization of time series generating models can be achieved, which in turn will lead to better clustering quality. In that context, several descriptive measures were evaluated and then used as input to a new tree-based clustering algorithm, entitled TS-Stream. Experiments were conducted with synthetic data sets composed of various time series models, confirming the superiority of TS-Stream when compared to ODAC, the most successful technique in the literature for this task. Experiments with real-world time series from stock market data of the NYSE and NASDAQ showed that the use of TS-Stream in the selection of stocks, by the creation of a diversified portfolio, can increase the returns of the investment in several orders of magnitude when compared to trading strategies solely based on the Moving Average Convergence Divergence financial indicator. 


\section{Sumário}

Lista de Figuras . . . . . . . . . . . . . . . . . . . . . xvii

Lista de Tabelas . . . . . . . . . . . . . . . . . . . $\mathrm{xx}$

Lista de Abreviaturas . . . . . . . . . . . . . . . . . . . . . xxii

Lista de Algoritmos . . . . . . . . . . . . . . . . . . . . . . . . xxiii

1 Introdução 1

1.1 Contextualização . . . . . . . . . . . . . . . . . . . . 1

1.2 Hipótese e Objetivo . . . . . . . . . . . . . . . . . . . . . . . . . . . . 12

1.3 Organização . . . . . . . . . . . . . . . . . . . . . . 14

2 Algoritmos para agrupamento de séries temporais em fluxos contínuos 17

2.1 Considerações Iniciais . . . . . . . . . . . . . . . . . . . . . 17

2.2 K-Means Incremental . . . . . . . . . . . . . . . . . . . . 17

2.3 Online Divisive-Agglomerative Clustering . . . . . . . . . . . . . . . . . . . 19

2.4 Probability and Distribution-based Clustering . . . . . . . . . . . 22

2.5 Evolving Clustering Method . . . . . . . . . . . . . . . . 24

2.6 Weighted Clustering Ensemble with Different Representations . . . . . . . 25

2.7 Considerações Finais . . . . . . . . . . . . . . . . . . . . . . . . . . . . . . 29

3 Medidas descritivas de séries temporais $\quad 31$

3.1 Considerações iniciais . . . . . . . . . . . . . . . . . . . . . . . . . 31

3.2 Medidas descritivas de séries temporais . . . . . . . . . . . . . . . . 31

3.2.1 Medidas de Análise de Quantificação de Recorrência . . . . . . . . . . 32

3.2 .2 Expoente de Lyapunov . . . . . . . . . . . . . . . . . . . . . . 35

3.2 .3 Expoente de Hurst . . . . . . . . . . . . . . . . . . . . . . . 37

3.2.4 Detrended Fluctuation Analysis . . . . . . . . . . . . . . . . . . 38

3.2.5 Transformada de Fourier . . . . . . . . . . . . . . . . . . . . 39

3.2.6 Transformada discreta de cossenos . . . . . . . . . . . . . . . . . . 40

3.2.7 Transformada Wavelet . . . . . . . . . . . . . . . . . . . . . . 40

3.2.8 Empirical Mode Decomposition . . . . . . . . . . . . . . . . 43 
3.2.9 Modelos paramétricos de Box e Jenkins . . . . . . . . . . . . . 45

3.2 .10 Autocorrelação . . . . . . . . . . . . . . . . . 46

3.2 .11 Autoinformação Mútua . . . . . . . . . . . . . . . . 46

3.3 Considerações finais . . . . . . . . . . . . . . . . . . . . . . . . . . . . 48

4 Experimentos com medidas descritivas de séries temporais $\quad 51$

4.1 Considerações Iniciais . . . . . . . . . . . . . . . . . . . . . . 51

4.2 Experimentos com séries sintéticas . . . . . . . . . . . . . . . . 52

4.2.1 Resultados - Cenário sem ruído . . . . . . . . . . . . . . . . 59

4.2.2 Resultados - Cenário com ruído . . . . . . . . . . . . . . . . 62

4.3 Experimentos com séries reais . . . . . . . . . . . . . . . . . . . 64

4.4 Considerações Finais . . . . . . . . . . . . . . . . . . . . . . . . . 68

5 TS-Stream: uma abordagem para o agrupamento de séries temporais $\begin{array}{ll}\text { em fluxos contínuos de dados } & 69\end{array}$

5.1 Considerações iniciais . . . . . . . . . . . . . . . . . . . . . . . . . . . 69

5.2 Objetivo . . . . . . . . . . . . . . . . . . . . . . . . . . 69

5.3 TS-Stream - Abordagem proposta . . . . . . . . . . . . . 71

5.4 Discussão sobre o algoritmo . . . . . . . . . . . . . . . . . . . . . 78

5.5 Análise de complexidade . . . . . . . . . . . . . . . . . . . . 82

5.6 Análise de sensibilidade dos parâmetros . . . . . . . . . . . . . 85

5.7 Experimentos com TS-Stream . . . . . . . . . . . . . . . . 87

5.7.1 Experimentos com modelos AR e AR com não linearidade adicionada 88

5.7.2 Experimentos com modelos AR e $\operatorname{ARIMA}(1,1,0)$, ambos com não linearidade adicionada . . . . . . . . . . . . . . 88 88

5.7.3 Experimentos com modelos AR e mapas logísticos . . . . . . . . . 89

5.7.4 Experimentos com modelos AR e ARIMA $(1,1,0) \ldots . . .90$

5.7.5 Experimentos com evolução de grupos . . . . . . . . . . . . . . . . 90

5.7.6 Experimentos com dados reais do setor financeiro . . . . . . . . . . 93

5.7.7 Experimento com dados reais de áudio . . . . . . . . . . . . . . . . 101

5.8 Adaptação automática de parâmetros . . . . . . . . . . . . . . . . . . . . 104

5.9 Análise dos resultados . . . . . . . . . . . . . . . . . 110

5.10 Considerações finais . . . . . . . . . . . . . . . . . . . . . . . . 112

6 Conclusão 113

6.1 Conclusões . . . . . . . . . . . . . . . . . . . . . . . 113

6.2 Atividades futuras . . . . . . . . . . . . . . . . . . 115

$\begin{array}{ll}\text { A Ranking das medidas descritivas de séries temporais } & 117\end{array}$

B Execuções de ODAC utilizando as medidas descritivas 121

C Análise do comportamento da correlação de Pearson $\quad 125$ 
D Lista de músicas utilizadas

Referências

140

xiii 


\section{Lista de Figuras}

1.1 Exemplo do problema de agrupamento de séries temporais em fluxos. . . . 3

1.2 Evolução das ações da Vale e Cielo. . . . . . . . . . . . . . . . . . . . . . . 4

1.3 Séries seguindo um modelo AR(1) . . . . . . . . . . . . . . . . . . 7

1.4 Correlação de Pearson incremental e RNOMC . . . . . . . . . . . . . . . . . 7

1.5 Séries mapas logísticos. . . . . . . . . . . . . . . . . . . . . 9

1.6 Taxonomia de séries temporais. . . . . . . . . . . . . . . . 10

1.7 Reconstrução da série mapa logístico da Figura 1.5b. . . . . . . . . . . . . 11

1.8 Passos da abordagem. . . . . . . . . . . . . . . . . . . . . 15

2.1 Série seguindo modelo ARIMA e seu histograma. . . . . . . . . . . . . 22

3.1 Taxonomia de séries temporais. . . . . . . . . . . . . . . . . . 32

3.2 Séries base para ilustração do Recurrence Plot. . . . . . . . . . . . . . . . 33

3.3 Recurrence Plot para a série determinística $S_{1}$ da Figura 3.2a. . . . . . . . 34

3.4 Recurrence Plot para a série estocástica $S_{2}$ da Figura 3.2b. . . . . . . . . . 34

3.5 Exemplos de séries com o valor do expoente de Lyapunov. . . . . . . . . . 36

3.6 Série de Lorenz com Lyapunov positivo. . . . . . . . . . . . . . . . . . 37

3.7 Série com expoente de Hurst $=1 \ldots \ldots \ldots$. . . . . . . . . 38

3.8 Série com expoente de Hurst $=0 \ldots \ldots \ldots \ldots$. . . . . . . . 38

3.9 Série com expoente de Hurst $=0,5 \ldots \ldots$. . . . . . . . . . . . . . . . 39

3.10 Plano complexo com o círculo unitário. . . . . . . . . . . . . . . . . . . 40

3.11 Wavelet $\psi(u)$ conhecida como "chapéu mexicano". . . . . . . . . . . . . . . 41

3.12 Exemplos de translações e escalas de uma Wavelet. . . . . . . . . . . . . . 42

3.13 Série com duas frequências localizadas no tempo. . . . . . . . . . . . . . 42

3.14 Periodograma para a série da Figura 3.13. . . . . . . . . . . . . . . 43

3.15 Transformada Wavelet contínua da série da Figura 3.13. . . . . . . . . . . 44

3.16 Exemplo da aplicação da transformada Wavelet de Haar em vários níveis. . 44

3.17 Série AR(3) juntamente com sua Autocorrelação. . . . . . . . . . . . . . . 47

3.18 Série de Lorenz juntamente com sua Autoinformação Mútua. . . . . . . . . 48 
4.1 Histograma séries UCR. . . . . . . . . . . . . . . . . . . . . 52

4.2 Configuração experimental no cenário com séries simuladas. . . . . . . . . 54

4.3 Exemplo de série mapa Logístico . . . . . . . . . . . . . . . . . . 54

4.4 Exemplo de série de Lorenz. . . . . . . . . . . . . . . . . . . . . . . . . . 54

4.5 Exemplo de série MA(1) . . . . . . . . . . . . . . . . . . . 55

4.6 Exemplo de série $\mathrm{AR}(1) \ldots \ldots \ldots \ldots \ldots$

4.7 Exemplo de série $\operatorname{IMA}(1,1) \ldots \ldots \ldots \ldots \ldots \ldots$

4.8 Exemplo de série $\operatorname{ARI}(1,1) \ldots \ldots \ldots \ldots$. . . . . . . . . . . . 56

4.9 Exemplo de série $\mathrm{MA}(1)+\mathrm{N} \ldots \ldots \ldots$. . . . . . . . . . 56

4.10 Exemplo de série $\mathrm{AR}(1)+\mathrm{N}$. . . . . . . . . . . . . . . 56

4.11 Exemplo de série $\operatorname{IMA}(1,1)+\mathrm{N}$. . . . . . . . . . . . . . . 57

4.12 Exemplo de série $\operatorname{ARI}(1,1)+$ N. . . . . . . . . . . . . . . 57

4.13 Árvore de decisão induzida nos experimentos sem adição de ruído. . . . . . 61

4.14 Histogramas dos resultados para o cenário sem adição de ruído. . . . . . . 61

4.15 Histogramas dos resultados para o cenário com adição de ruído. . . . . . . 63

4.16 Exemplo de árvore induzida nos experimentos com adição de ruído. . . . . . 64

4.17 Resultados experimentos com séries extraídas de músicas. . . . . . . . . . . 65

5.1 Exemplo de Entropia para caso com duas segmentações. . . . . . . . . . 73

5.2 Exemplo de uma árvore com três folhas, representando três grupos. . . . . 78

5.3 Exemplo de uma árvore induzida em uma base de dados com 3 grupos. . . 79

5.4 Árvore obtida por TS-Stream para o experimento com um fluxo $S=$ $\left\{S_{1}, S_{2}, S_{3}, S_{4}, S_{5}\right\}$. As folhas $N 3, N 4, N 5$ indicam os grupos. FOU1 e FOU2 são os coeficientes de Fourier (primeiro e segundo, respectivamente) identificados pelo critério de minimização de variância de TS-Stream como os melhores para realizar a divisão. . . . . . . . . . . . . . . . . 80

5.5 Cortes ortogonais realizados por TS-Stream no espaço projetado dos coeficientes de Fourier, separando com sucesso os grupos. As dimensões apropriadas (FOU1 e FOU2), juntamente com os pontos de corte, foram identificados pelo critério de minimização de variância de TS-Stream. Os números de 1 a 5 indicam os pontos correspondentes às séries do fluxo. . . . . . . . 81

5.6 Pontos de corte. . . . . . . . . . . . . . . . . . 83

5.7 Avaliação de desempenho da implementação de TS-Stream em R. . . . . . 85

5.8 Avaliação de sensibilidade do parâmetro $\alpha \ldots \ldots$. . . . . . . . 86

5.9 Avaliação de sensibilidade do parâmetro $\lambda . \ldots$. . . . . . . . . . 86

5.10 Avaliação de sensibilidade do tamanho de janela $w$. . . . . . . . . . . . 87

5.11 Experimentos com AR e AR com não linearidade. . . . . . . . . . . . . 88

5.12 Experimentos com $\operatorname{AR}$ e $\operatorname{ARIMA}(1,1,0)$, ambos com não linearidade. . . . 89

5.13 Experimentos com AR e mapa logístico. . . . . . . . . . . . . . 89

5.14 Experimentos com $\mathrm{AR}$ e $\operatorname{ARIMA}(1,1,0) \ldots \ldots \ldots$

5.15 Função usada para modelar evolução de grupos. . . . . . . . . . . . . . . . 91 
5.16 Exemplos de trechos da série $S_{2}$ do experimento de evolução de grupos. . 92

5.17 Resultados experimentos com evolução de grupos. . . . . . . . . . . . . . 93

5.18 Exemplo do MACD para uma série de preços de fechamento do Google. . . 94

5.19 Resultados das políticas para a primeira base do setor financeiro. . . . . . . 96

5.20 Resultados de Top-1 para a primeira base do setor financeiro. . . . . . . . 96

5.21 Gráficos quantil-quantil para as políticas de negociação. . . . . . . . . . . . 99

5.22 Periodograma para arquivo N30.wav, do grupo Alarmes e sirenes. . . . . . 101

5.23 Periodograma para arquivo N56.wav, do grupo Água. . . . . . . . . . . . . 102

5.24 Periodograma para arquivo N1.wav, do grupo Aglomerações de pessoas. . . 102

5.25 Árvore obtida por TS-Stream sobre a base de dados reais de áudio. . . . . 103

5.26 Matriz de similaridade de Pearson e ideal para experimento com áudio. . . 104

5.27 Exemplo de árvore do método inspirado em Darbellay e Vajda (2006). . . . 105

5.28 Exemplo 2 de árvore do método inspirado em Darbellay e Vajda (2006). . . 106

5.29 Histograma acurácia TS-Stream com adaptação para AR e AR + N. . . . . 108

5.30 Histograma acurácia TS-Stream com adaptação para AR e $\operatorname{ARIMA}(1,1,0) .109$

5.31 Histograma acurácia TS-Stream com adaptação para AR e $\operatorname{ARIMA}(1,1,0)$ ambos com não linearidade adicionada. . . . . . . . . . . . . . . . . 109

5.32 Histograma acurácia TS-Stream com adaptação para mapa logístico e AR. 109

5.33 Análise de resultados do TS-Stream. . . . . . . . . . . . . . . . . 110

5.34 Exemplo de duas séries geradas segundo o modelo proposto por ODAC Equação 5.13 - com parâmetro $\beta=0,3 \ldots$. . . . . . . . . . . . . . 111

B.1 Histograma acurácia ODAC com medidas para AR e AR + N. . . . . . . . 122

B.2 Histograma acurácia ODAC com medidas para $\operatorname{AR}$ e $\operatorname{ARIMA}(1,1,0)$. . . . 122

B.3 Histograma acurácia ODAC com medidas para $\operatorname{AR}$ e $\operatorname{ARIMA}(1,1,0)$ ambos com não linearidade adicionada. . . . . . . . . . . . . . . . . . . . . 122

B.4 Histograma acurácia ODAC com medidas para mapa logístico e AR. . . . . 123

C.1 Resultados dos experimentos da divergência de McDiarmid para a correlação de Pearson, alterando um único valor $x_{i}^{\prime}$ da série a cada iteração. . . . 129

C.2 Correlação de Pearson entre duas séries AR(1) conforme o valor de $\sigma$ aumenta. 129

C.3 Desvio padrão da Correlação de Pearson entre duas séries AR(1) conforme

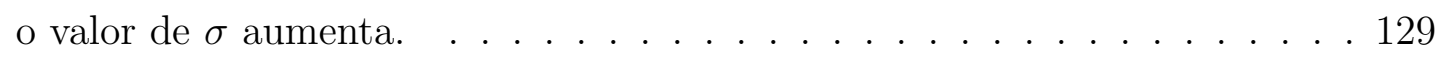

C.4 Lado direito da desigualdade de McDiarmid para vários valores de $\epsilon$. . . 130 


\section{Lista de Tabelas}

2.1 Comparativo dos algoritmos com relação à cobertura de modelos de representação de séries temporais. . . . . . . . . . . . . . . . . . . . . . . . 29

4.1 Classes e modelos usados para geração das séries temporais sintéticas. . . . 52

4.2 Resultados experimentais com 10-fold Cross-validation para 30 bases no cenário sem adição de ruído. . . . . . . . . . . . . . . . . . . . . . 59

4.3 Resultados experimentais com 10-fold Cross-validation para as 30 bases no cenário com adição de ruído. . . . . . . . . . . . . . . . . . . . 62

4.4 Resultados experimentais com 10-fold Cross-validation sobre as bases do Free Music Archive. . . . . . . . . . . . . . . . . . . . . . . . . 66

5.1 Partições encontradas a cada iteração de TS-Stream e ODAC para o conjunto de dados com evolução de grupos ao longo do tempo. As linhas em negrito indicam as iterações (13-25) em que o Modelo 2 apresentava maior peso do que o Modelo 1. Observa-se que na iteração 15 TS-Stream já está adaptado à nova estrutura de grupos. . . . . . . . . . . . . . . . . . . . . . 92

5.2 Comparação de TS-Stream e Top-1 nas bases do setor financeiro. . . . . . 97

5.3 Comparação de TS-Stream e Top-K nas bases do setor financeiro. . . . . . 98

5.4 Porcentagem de tempo em que o resgate total ficou acima do capital inicial investido. . . . . . . . . . . . . . . . . . . . . 98

5.5 Comparação de TS-Stream e ODAC nas bases do setor financeiro. . . . . . 100

5.6 Sons utilizados no experimento com a base de dados reais de áudio. . . . . 101

5.7 Resultados do experimentos com a base de dados reais de áudio. . . . . . . 103

A.1 Ranking das medidas descritivas de séries temporais de acordo com Ganho de Informação para as 30 bases no cenário sem adição de ruído. . . . . . . 118

A.2 Ranking das medidas descritivas de séries temporais de acordo com Ganho de Informação para as 30 bases no cenário com adição de ruído. . . . . . . 119

A.3 Ranking das medidas descritivas de séries temporais de acordo com Ganho de Informação para as 30 bases de músicas. . . . . . . . . . . . . . . . . . . 119 
D.1 Músicas utilizadas nos experimentos de classificação com séries temporais reais. . . . . . . . . . . . . . . . . . . . . 132 


\section{Lista de Abreviaturas}

1-NN One Nearest Neighbor

ACF Autocorrelation Function

AMI Auto Mutual Information

AR Autoregressive model

ARI Adjusted Rand Index

ARI Integrated Autoregressive model

ARIMA Autoregressive Integrated Moving Average model

ARMA Autoregressive Moving Average model

CWT Continuous Wavelet Transform

D Determinística

DCT Discrete Cosine Transform

DET Determinism

DFA Detrended Fluctuation Analysis

DFT Discrete Fourier Transform

DIV Divergence

DMS Distribution Management Systems

DSPA Dendrogram-based Similarity Partitioning Algorithm

DVI Dunn Validity Index

DWT Discrete Wavelet Transform 
ECM Evolving Clustering Method

ELE Estocástica, Linear, Estacionária

ELN Estocástica, Linear, Não Estacionária

EMD Empirical Mode Decomposition

ENE Estocástica, Não Linear, Estacionária

ENN Estocástica, Não Linear, Não Estacionária

FFT Fast Fourier Transform

IF Instantaneous Frequency

IMA Integrated Moving Average model

IMF Intrinsic Mode Function

MA Moving Average model

MACD Moving Average Convergence Divergence

МНГ Modified Hubert $\Gamma$

NMI Normalized Mutual Information

ODAC Online Divisive-Agglomerative Clustering

PACF Partial Autocorrelation Function

PCF Polynomial Curve Fitting

PDWT Piecewise Discrete Wavelet Transform

PLS Piecewise Local Statistics

POD-Clus Probability and Distribution-based Clustering

RNOMC Rooted Normalized One-Minus-Correlation

RP Recurrence Plot

RQA Recurrence Quantification Analysis

SCADA Supervisory Control and Data Acquisition

TS-Stream Time Series Stream

WCE Weighted Clustering Ensemble with Different Representations 


\section{Lista de Algoritmos}

1 K-Means Incremental . . . . . . . . . . . . . . . . . . . 18

2 Online Divisive-Agglomerative Clustering (ODAC) . . . . . . . . . . 21

3 Probability and Distribution-based Clustering (POD-Clus) . . . . . . . . 23

4 Evolving Clustering Method (ECM) . . . . . . . . . . . . . . 24

5 Weighted Clustering Ensemble (WCE) with Different Representations . . . 28

$6 \quad$ Indução da árvore de decisão . . . . . . . . . . . . . . . . . . . . . . 58

7 Classificador $1-\mathrm{NN} \ldots \ldots \ldots \ldots \ldots \ldots$

$8 \quad$ TS-Stream . . . . . . . . . . . . . . . . . . . . 75

9 encontraAtributoSignificativo(membros, entrada, $\beta) \ldots \ldots \ldots \ldots$

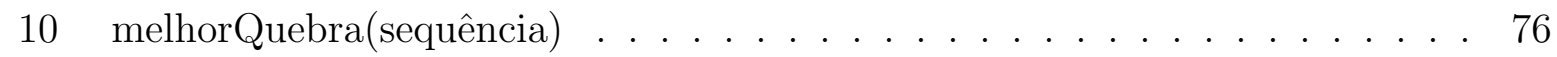

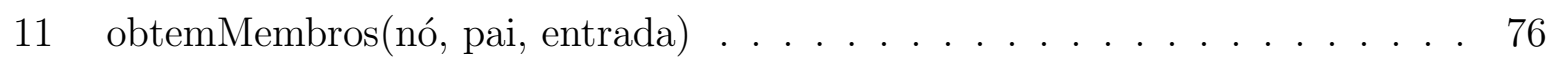

12 calculaVariancia(nó, entrada) . . . . . . . . . . . . . . . . . 77

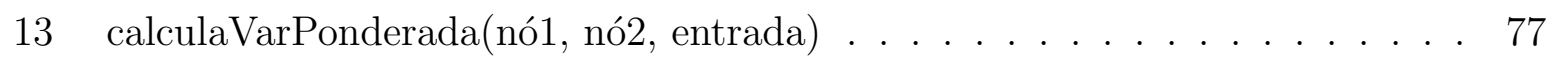




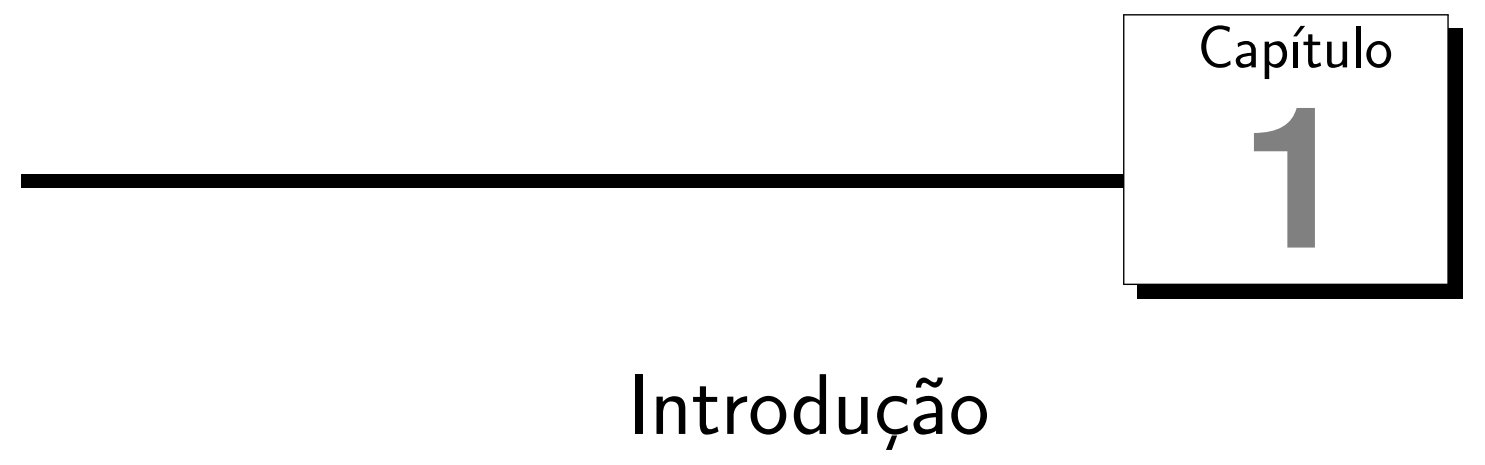

\subsection{Contextualização}

Recentemente, os avanços em termos de hardware e software permitiram a captura contínua de dados em diversos campos da ciência (Gaber et al., 2005). Por exemplo, redes de sensores, tráfego de redes de computadores, informações de satélites, fluxos de clicks em páginas $W e b$, e outros, são geradores contínuos de dados. Essas sequências, possivelmente infinitas, são denominadas fluxos contínuos de dados, do inglês data streams (Gama, 2010). A principal característica desses fluxos, além de serem contínuos e infinitos, é que os dados podem se modificar ao longo do tempo, efeito denominado mudança de conceito (Aggarwal, 2006).

Tradicionalmente, a área de Aprendizado de Máquina se concentrou na extração de conhecimento a partir de conjuntos finitos e que seguem uma distribuição estacionária (Gama, 2010). Nesse contexto, os dados ficam disponíveis de forma integral para o treinamento do algoritmo de aprendizado, o qual realiza, em geral, várias passadas para gerar um modelo. Essa abordagem tradicional de aprendizado, denominada batch learning, mostrou-se eficaz para vários domínios (Tong e Koller, 2000; Baldi e Brunak, 2001; Pang et al., 2002). Entretanto, a comunidade observou que os algoritmos desenvolvidos para o cenário batch não são capazes de lidar adequadamente com dados que se modificam ao longo do tempo e são produzidos continuamente (Gama, 2010).

Por exemplo, considere o algoritmo de classificação C4.5 (Quinlan, 1993b), que gera hipóteses com base em árvores de decisão. Não se conhece uma forma trivial de alterá-lo para lidar com fluxos contínuos, a não ser armazenando todo o fluxo e induzindo uma nova árvore a cada exemplo que chega, o que na prática é inviável em função da sua complexidade de tempo e espaço. Outros algoritmos, como $K$-vizinhos mais próximos 
(Cover e Hart, 1967), apresentam uma natureza incremental, simplificando seu uso em fluxos de dados. Entretanto, ainda sofrem com problemas de espaço, pois requerem o armazenamento de todo o fluxo, o que não é possível na prática.

As limitações dos algoritmos concebidos para o cenário batch motivaram o desenvolvimento de uma nova área de pesquisa, denominada mineração de fluxos contínuos de dados, do inglês data streams mining. Bifet e Kirby (2009) enumeram quatro características importantes que algoritmos desenvolvidos para mineração de fluxos contínuos buscam respeitar: 1) processar e inspecionar cada exemplo no máximo uma vez e na ordem de chegada. Porém, nada impede que o algoritmo use uma memória de curta duração para armazenar um subconjunto dos dados, o qual deve ser eventualmente descartado; 2) usar uma quantidade limitada de memória (complexidade de espaço); 3) operar em tempo limitado, preferencialmente com complexidade de tempo linear ou sublinear; 4) responder a qualquer momento (anytime), ou seja, realizar uma predição ou produzir um agrupamento a qualquer instante.

Entre as técnicas de mineração de fluxos contínuos, uma das que mais se destaca é a de agrupamento de dados (O'Callaghan et al., 2002). Ela é definida como o processo de segmentar objetos em diferentes grupos, tal que os pertencentes a um mesmo grupo são mais similares entre si do que aos outros objetos (Jain e Dubes, 1988). Isso é útil para compreender a distribuição de grandes volumes de dados quando não se dispõe de rotulações. Um exemplo tradicional de aplicação é dado pela segmentação de mercado, a fim de encontrar nichos de clientes, dados seus hábitos de compra. O agrupamento pode servir também como uma fase de pré-processamento para algoritmos com alta complexidade de tempo, por exemplo reduzindo sua entrada a poucos exemplos representativos.

Segundo Gama (2010), a dificuldade da tarefa de agrupamento no cenário de fluxos de dados reside em sua chegada contínua e na necessidade de processá-los utilizando complexidade de tempo linear ou sub-linear. Essas características demandam que o algoritmo de agrupamento seja capaz de trabalhar de forma incremental, mantendo um modelo adaptável que evolui com o tempo. Como a natureza dos dados pode se modificar, é necessário que o algoritmo seja capaz de lidar também com grupos que apareçam, desapareçam, se unam, se separem ou se modifiquem.

Apesar de existirem na literatura diversos algoritmos para agrupamento em fluxos contínuos, tais como STREAM (O'Callaghan et al., 2002), CluStream (Aggarwal et al., 2003), HPStream (Aggarwal et al., 2004), DenStream (Cao, 2006), MR-Stream (Wan et al., 2009) e PKS-Stream (Ren et al., 2011), eles se voltaram para fluxos constituídos por pontos em espaços multidimensionais. Assim, essas técnicas funcionam recebendo, a cada instante, um ponto multidimensional oriundo de uma única fonte geradora.

Poucos trabalhos exploraram o conceito de agrupamento de séries temporais em fluxos de dados, ou seja, fluxos constituídos por várias fontes geradoras ou séries temporais, as quais produzem uma nova observação a cada instante. Isso motiva novas propostas nessa área, dado que existem muitas aplicações práticas (Gama, 2010), tais como agrupamento 
de séries de consumo de energia e ações de bolsa de valores (Gama e Rodrigues, 2007).

Uma série temporal é definida como uma coleção de observações coletadas sequencialmente no tempo (Chatfield, 2001). Por exemplo, seja $S_{i}=\left(s_{i 1}, s_{i 2}, \ldots, s_{i n}\right)$ uma série em que $s_{i t}, t \in\{1,2, \ldots, n\}$, representa o número de vendas de um determinado produto no mês $t$ de um mesmo ano $(n=12)$.

Assim, o problema de agrupamento de séries temporais em fluxos contínuos de dados é definido da seguinte forma neste trabalho. Seja $S=\left\{S_{1}, S_{2}, \ldots, S_{m}\right\}$ o conjunto de $m$ séries temporais que compõem o fluxo contínuo e $S_{i}=\left(s_{i 1}, s_{i 2}, \ldots, s_{i n}\right)$ a $i$-ésima série, com $n \rightarrow \infty$. A cada instante de tempo $t \in\{1,2, \ldots, n\}$ recebem-se simultaneamente novas observações $s_{i t}, \forall S_{i} \in S$. Para um dado $t$ deseja-se obter uma partição $P=\left\{\pi_{1}, \pi_{2}, \ldots, \pi_{k}\right\}$ de $S$ tal que $\pi_{i}$ é o i-ésimo grupo da partição $P, k$ é o número de grupos, $\pi_{i} \cap \pi_{j}=\varnothing, \forall i \neq j$ e $\cup_{i=1}^{k} \pi_{i}=S$.

A Figura 1.1 ilustra o agrupamento de um fluxo de séries $S=\left\{S_{1}, S_{2}, S_{3}, S_{4}\right\}$. Suponha que o usuário deseja obter partições nos instantes $t=500$ e $t=1500$. Observa-se que até o instante $t=1000$ as séries $\left\{S_{1}, S_{2}\right\}$ e $\left\{S_{3}, S_{4}\right\}$ apresentam comportamento semelhante, formando os dois grupos da partição $P=\left\{\pi_{1}, \pi_{2}\right\}$ no instante $t=500$. Já a partir de $t=1000$, as séries $S_{1}$ e $S_{3}$ modificam seus comportamentos, fazendo com que os grupos evoluam para $\left\{S_{1}, S_{4}\right\}$ e $\left\{S_{2}, S_{3}\right\}$ no instante $t=1500$.

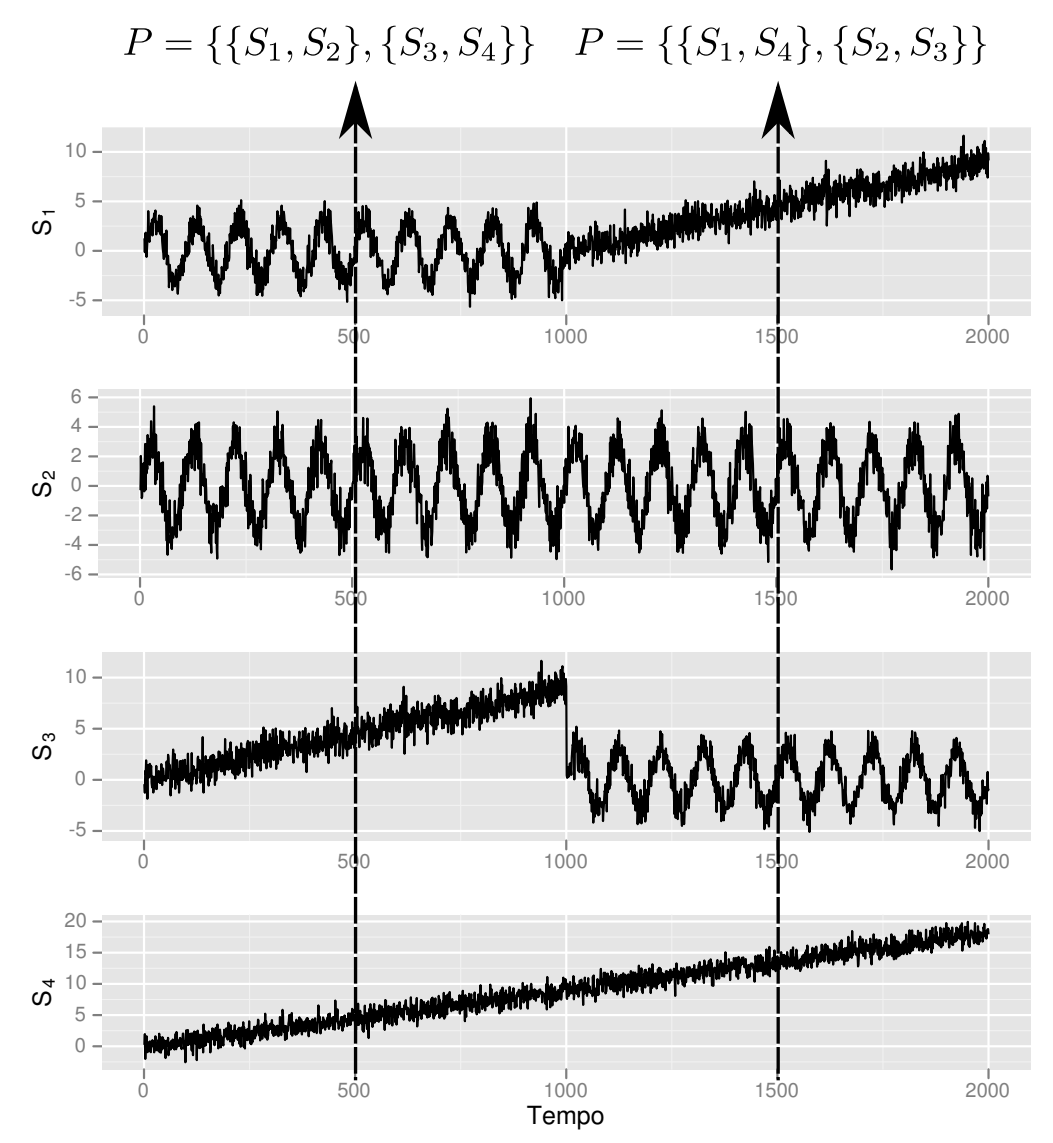

Figura 1.1: Exemplo do problema de agrupamento de séries temporais em fluxos contínuos de dados.

O agrupamento de séries temporais em fluxos contínuos apresenta várias aplicações. Por exemplo, companhias de distribuição de energia utilizam ferramentas SCADA/DMS 
(Supervisory Control and Data Acquisition/Distribution Management Systems) para controlar os dados de abastecimento (Gama, 2010). Nesse cenário, o agrupamento de séries de consumo pode fornecer informações relevantes, tais como o perfil de uso de uma região, i.e., industrial, urbano ou rural, e os momentos de pico. O agrupamento pode, também, detectar alterações de comportamento em uma mesma região, como um perfil industrial durante o dia e um perfil urbano durante a noite. Essas informações podem auxiliar gestores a tomarem decisões sobre como ampliar ou melhor distribuir a rede de abastecimento de energia.

Considere agora o cenário de ações na bolsa de valores. Um investidor deseja escolher as melhores ações para compor sua carteira de investimentos. Idealmente, a carteira deverá ser diversificada, sendo composta por várias companhias de diversos setores econômicos (Athanassiou, 2012). A diversificação permite que as eventuais perdas em um determinado segmento sejam compensadas pelos ganhos de outro, minimizando a margem de risco.

A Figura 1.2 ilustra as vantagens da diversificação. Ela apresenta a evolução do preço de fechamento ajustado das ações de duas empresas brasileiras, uma do setor de mineração (Vale) e a outra do segmento de serviços financeiros (Cielo) no período de 03/01/2011 a $06 / 01 / 2012$.

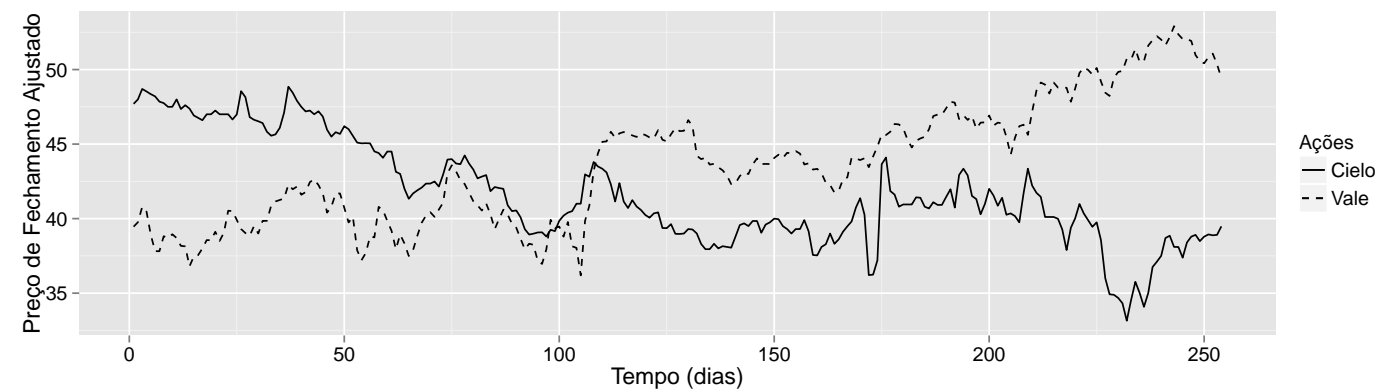

Figura 1.2: Evolução do preço das ações de duas empresas brasileiras. Os preços apresentados são relativos ao fechamento ajustado.

É possível observar na Figura 1.2 que em um primeiro período (dias 1 a 100) as ações da Cielo superaram as da Vale, enquanto no período final ocorre o inverso. Uma carteira de investimentos diversificada, que contivesse ambas as ações, teria suas perdas minimizadas.

O agrupamento de séries temporais, considerando o cenário de investimentos, fornece um entendimento intuitivo das relações entre a evolução dos preços. Isso pode auxiliar um investidor a escolher uma ou mais ações de cada grupo encontrado, diversificando sua carteira e minimizando sua margem de perdas.

Considerando outro cenário de aplicação, o agrupamento de séries temporais é útil no estudo de uma série com características desconhecidas. Por exemplo, dada uma série de crescimento populacional de indivíduos, oriundos de uma espécie desconhecida, podese agrupá-la a um conjunto de séries conhecidas para identificar com quais ela mais se assemelha. Assim, é possível melhor compreender a dinâmica comportamental da série e até mesmo modelá-la e fazer previsões mais acuradas.

No cenário de fluxos contínuos, poucos trabalhos se voltaram para o agrupamento de 
séries temporais. Uma das primeiras propostas encontradas que aborda esse problema é a de Beringer e Hüllermeier (2006), os quais criaram uma versão online do algoritmo K-Means que utiliza como passo de pré-processamento o cálculo incremental das distâncias entre séries temporais, usando uma aproximação obtida via DFT (Discrete Fourier Transform) (Fourier, 1888). O algoritmo conta também com uma versão fuzzy, em que cada série tem um grau de pertinência aos grupos. Isso permite, por exemplo, modelar a mudança de conceito de uma série que se move lentamente de um grupo para outro. Os autores não compararam sua técnica a nenhuma outra, pois de acordo com eles trata-se do primeiro trabalho a abordar o cenário de agrupamento de séries temporais em fluxos contínuos. A desvantagem do uso exclusivo da DFT é que algumas informações são perdidas, como a localização das frequências no tempo, característica que não pode ser capturada pela transformada (Graps, 1995).

Rodrigues et al. (2008) propuseram ODAC (Online Divisive-Agglomerative Clustering), um algoritmo que mantém uma hierarquia, na forma de árvore, dos grupos encontrados. ODAC utiliza uma estratégia top-down, iniciando com todas as séries em um mesmo grupo e realizando divisões quando detecta que o raio do grupo está maior do que o esperado, de acordo com o limite de Hoeffding (1963). Esse algoritmo emprega ainda a correlação de Pearson (1894) para determinar a similaridade entre as séries. Isso traz a forte vantagem de permitir o cálculo incremental das similaridades, conforme novas observações das séries são recebidas, porém tem a desvantagem de restringir a técnica às limitações inerentes da correlação de Pearson, como a capacidade de detectar somente relacionamentos lineares e sua sensibilidade a ruídos e outliers (Fujita et al., 2009).

Chaovalit (2009) propôs o algoritmo POD-Clus (Probability and Distribution-based Clustering), que funciona com dois modos de representação de dados. O primeiro baseiase na caracterização das séries por meio de suas observações, utilizando valores como média e desvio padrão. O segundo modo de representação utiliza parâmetros de modelos, tais como coeficientes ARIMA (Box e Jenkins, 1994). A cada nova observação recebida das séries, suas medidas de caracterização são atualizadas e comparadas com as dos grupos criados, associando cada série a seu grupo mais próximo. O nome POD-Clus deve-se ao uso de uma função Gaussiana para determinar a pertinência de objetos a grupos quando o algoritmo opera sobre pontos multidimensionais de um único fluxo. Essa função não é empregada na versão para agrupamento de séries, pois a premissa de normalidade não é viável, já que pontos de uma mesma série apresentam dependência. A limitação do algoritmo encontra-se na escolha de poucas representações e medidas muito triviais, tais como média e desvio padrão para caracterizar as séries.

Widiputra et al. (2011) propuseram uma metodologia para predição de múltiplas séries temporais. Para obter uma caracterização dos relacionamentos entre séries, o método utiliza um algoritmo de agrupamento que emprega a mesma medida de distância usada por ODAC (Rodrigues et al., 2008), baseada na correlação de Pearson. Essa escolha apresenta as mesmas limitações que ODAC, em função dessa medida ser capaz de representar 
somente dependências lineares e ser sensível a ruídos e outliers. O algoritmo permite a criação, remoção, junção e divisão de grupos, assim como ODAC, porém sem utilizar uma estrutura hierárquica de árvore. O foco da metodologia, entretanto, é na predição de observações das séries, empregando como base os relacionamentos encontrados via agrupamento.

Yang e Chen (2011) apresentaram um método para agrupamento de séries temporais baseado em ensembles. Inicialmente, várias representações distintas são utilizadas para gerar um conjunto de partições, as quais são submetidas a uma função de consenso que produz a partição final. A função de consenso realiza uma ponderação da importância de cada partição usando os valores de critérios de validação de agrupamento como pesos. A ideia intuitiva dos autores é de que representações, tais como DFT (Discrete Fourier Transform) e PCF (Polynomial Curve Fitting) (Chen e Chang, 1999), capturam somente parte das informações presentes nas séries. Assim, o uso de diversas representações complementares pode auxiliar a obter um agrupamento de maior qualidade, de acordo com critérios de validação como o Índice $\Gamma$ de Hubert Modificado (МHГ) (Halkidi et al., 2001), a Informação Mútua Normalizada (NMI) (Strehl e Ghosh, 2003) e o Índice de Validação de Dunn (DVI) (Halkidi et al., 2001).

No cenário de fluxos contínuos, os autores empregaram o algoritmo ODAC (Rodrigues et al., 2008) para gerar as partições iniciais dos dados com as diferentes representações. Consequentemente, o custo computacional do método proposto por Yang e Chen (2011) é maior, devido às várias execuções de ODAC necessárias para a obtenção das várias partições. Além disso, o método fica limitado pelas restrições provenientes da correlação de Pearson empregada por ODAC.

As diversas abordagens apresentadas, no contexto de agrupamento de séries temporais em fluxos contínuos, optaram pelo uso de correlações, como a de Pearson, ou de modelos lineares para as séries temporais, e.g., regressão linear. Enquanto vários fenômenos podem ser adequadamente descritos por modelos lineares, muitos outros requerem o uso de modelos mais complexos, envolvendo componentes não lineares. Além disso, as abordagens não consideram várias propriedades do modelo gerador, ou seja, a equação usada para produzir as observações de uma série temporal, tais como sua estocasticidade/determinismo, estacionariedade/não estacionariedade e linearidade/não linearidade.

Considere as séries ilustradas na Figura 1.3. As duas seguem um modelo Autorregressivo (AR) de Box e Jenkins (1994), de acordo com a equação $s_{t}=\phi s_{t-1}+a_{t}$, em que $\phi$ é o coeficiente regressivo e $a_{t}$ é um ruído branco distribuído de acordo com uma Normal de média 0 e desvio padrão 1 . Apesar de ambas as séries seguirem o mesmo modelo, inclusive com a mesma parametrização $\phi=0,5$, elas apresentam diferenças em sua realização, devido à natureza estocástica envolvida em seu modelo gerador.

Analisando o exemplo apresentado e observando como a maioria dos trabalhos em séries temporais utiliza-se da distância Euclidiana ou da correlação de Pearson para determinar a similaridade entre séries, é possível identificar uma das principais limitações das 

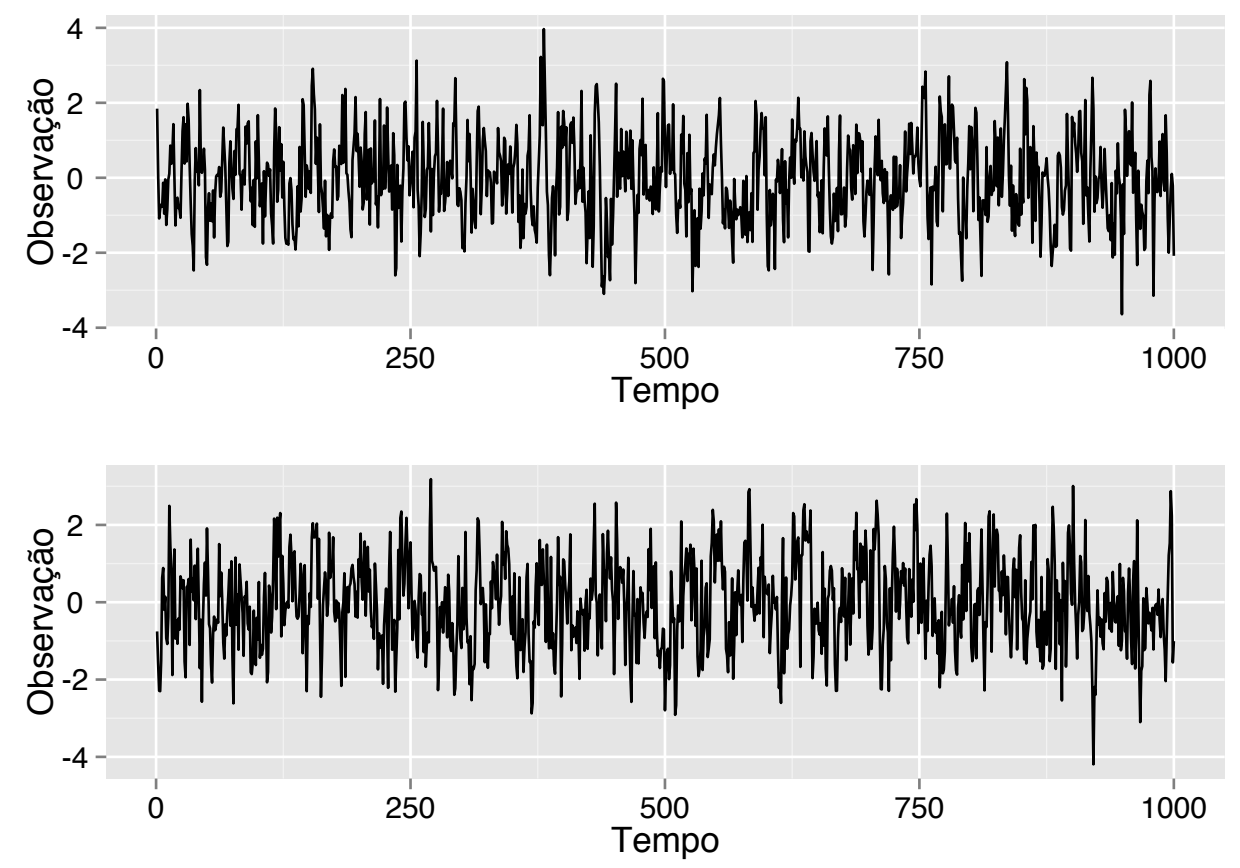

Figura 1.3: Séries seguindo o mesmo modelo $\operatorname{AR}(1): s_{t}=\phi s_{t-1}+a_{t} \operatorname{com} \phi=0,5$.

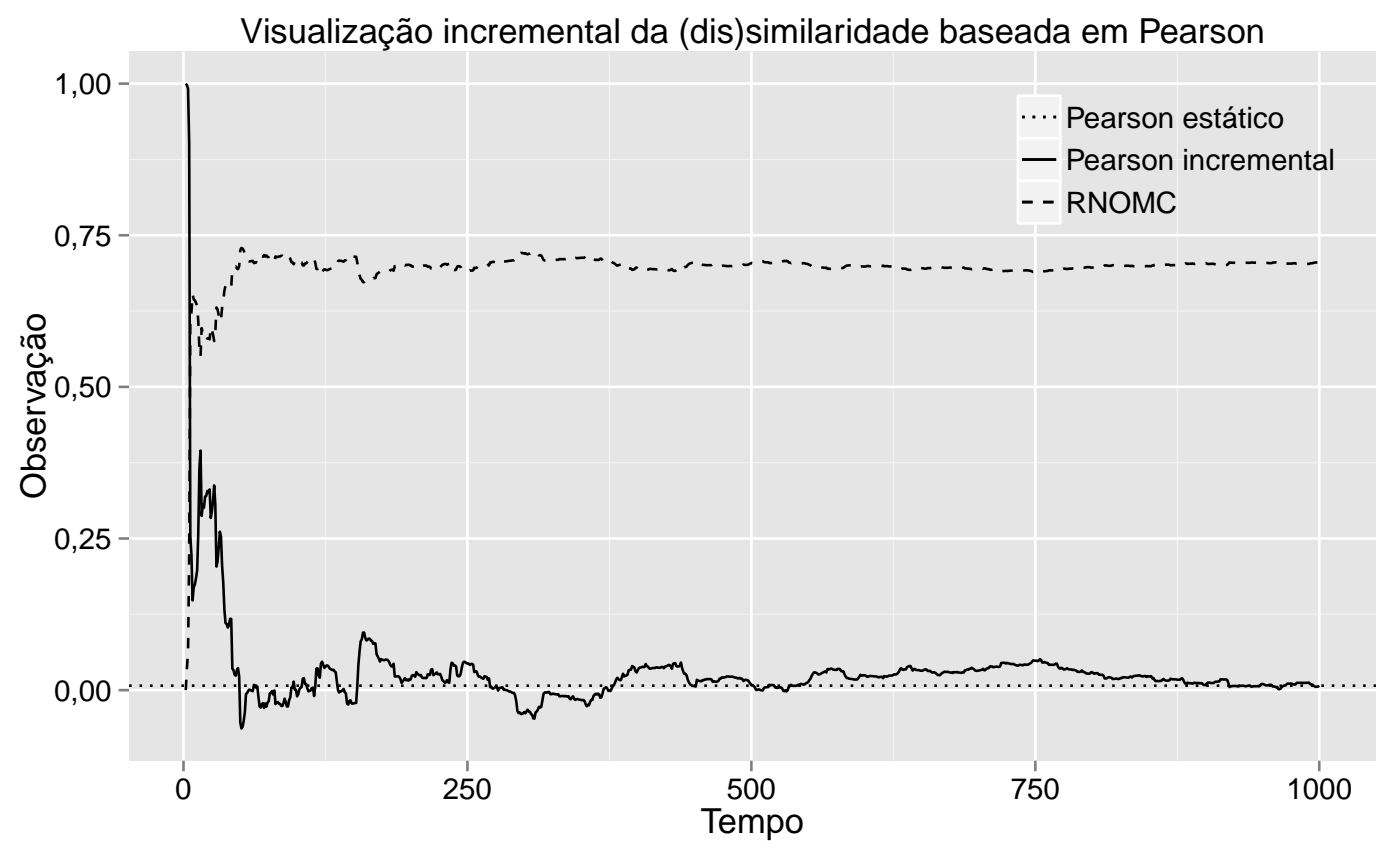

Figura 1.4: Correlação de Pearson incremental e dissimilaridade RNOMC para as séries AR da Figura 1.3 
técnicas de aprendizado voltadas para séries temporais. Ao calcular a distância Euclidiana entre as séries da Figura 1.3, obtém-se o valor 52 (alta distância), enquanto a correlação de Pearson é de apenas 0,0073 (indicativo de ausência de correlação - baixa similaridade). Isso demonstra que técnicas como ODAC e ECM (Evolving Clustering Method) ${ }^{1}$ identificam que ambas as séries são completamente distintas (correlação $\approx 0$ ), apesar de terem sido criadas utilizando o mesmo modelo gerador, inclusive com mesma parametrização. De fato, observando os cálculos da correlação de Pearson incremental e da dissimilaridade RNOMC usada por ODAC, conforme ilustrado na Figura 1.4, fica claro que para o algoritmo as séries são altamente diferentes (aproximadamente 69\% diferentes para a distância que ODAC usa), apesar de serem oriundas do mesmo modelo matemático. O Apêndice C (p. 125) apresenta um estudo analítico e experimental sobre o comportamento da correlação de Pearson, especialmente considerando modelos Autorregressivos.

Essa deficiência nas técnicas atuais ocorre devido à limitada importância atribuída ao modelo gerador de séries temporais. As técnicas realizam essa caracterização, em geral, sob um ponto de vista muito específico, utilizando uma única medida de similaridade. Isso restringe o escopo de modelos caracterizáveis aos que são englobados pela medida de similaridade escolhida. Por exemplo, a correlação de Pearson só é capaz de detectar e medir relacionamentos lineares (Fujita et al., 2009).

Considere agora um segundo exemplo, dado por uma série temporal gerada pelo mapa logístico $s_{t+1}=r \cdot s_{t} \cdot\left(1-s_{t}\right)$, um modelo não linear simples, originalmente proposto para análise demográfica (Alligood et al., 1997). A Figura 1.5 apresenta duas realizações do mesmo mapa, porém com uma pequena variação de parâmetro. Na Figura 1.5a, a série foi gerada com $r=3,0$, enquanto na Figura 1.5b com $r=3,8$. Na primeira, observase uma natureza convergente, o que não ocorre na segunda. Assim, pequenas variações de parâmetros em séries que seguem modelos não lineares podem ocasionar realizações completamente distintas. Técnicas que abordam somente modelos lineares, ou utilizam correlações simples, não são capazes de adequadamente caracterizar tais tipos de séries. Por exemplo, considerando as séries descritas, a correlação de Pearson entre as duas é $-0,05$, ou seja, praticamente inexistente, apesar de serem oriundas do mesmo modelo matemático.

Considere agora a medida de Determinismo (DET) proposta por Marwan et al. (2007), que será detalhada posteriormente (Seção 3.2.1). Ela computa o nível de determinismo de uma série, ou seja, retorna 1 para uma série puramente determinística e 0 para uma puramente aleatória. Para ambas as séries geradas seguindo o mapa logístico e diferindo apenas no parâmetro $r$, o valor de DET obtido é 1 . Isso significa que ambas as séries são altamente determinísticas, como de fato o modelo gerador o é. Isso evidencia que o uso de medidas descritivas de séries temporais, não restritas a modelos lineares ou puramente determinísticos, pode auxiliar em uma melhor caracterização e, consequentemente, em um melhor agrupamento.

\footnotetext{
${ }^{1}$ Ambas detalhadas no Capítulo 2, páginas 19 e 24, respectivamente.
} 


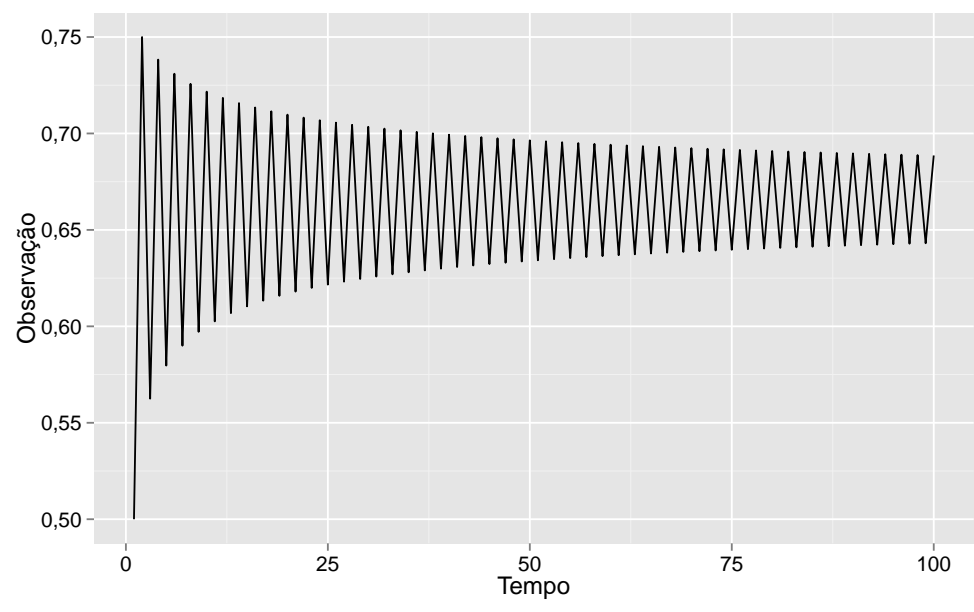

(a) Mapa logístico com $r=3,0$.

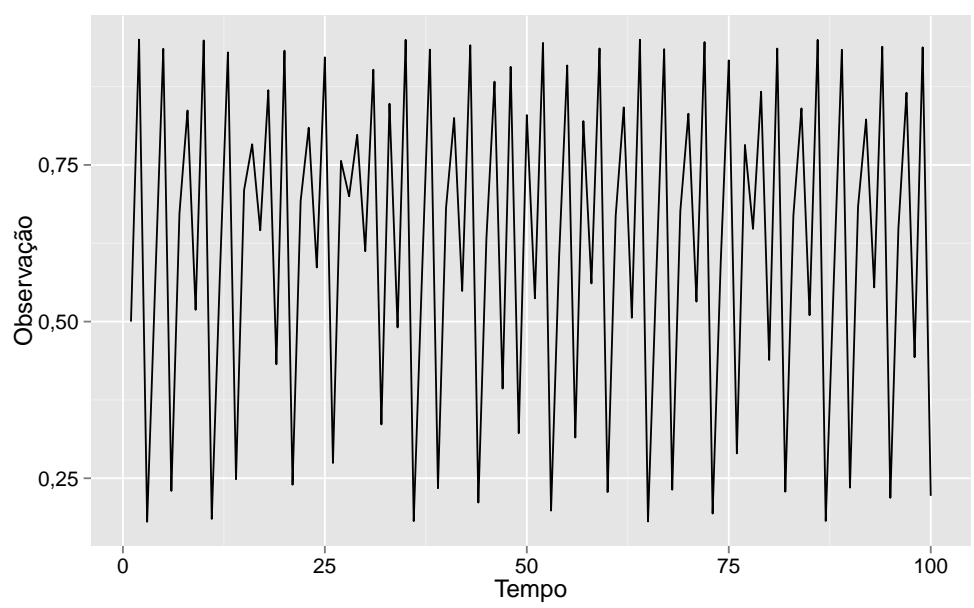

(b) Mapa logístico com $r=3,8$.

Figura 1.5: Ambas as figuras apresentam séries temporais geradas a partir do mesmo mapa logístico $s_{t+1}=r \cdot s_{t} \cdot\left(1-s_{t}\right)$, e com a mesma condição inicial $s_{0}=0,5$. Apenas os primeiros 100 pontos de um total de 1000 são apresentados. A pequena variação no parâmetro $r$ levou a duas realizações completamente distintas das séries.

A busca pela compreensão de modelos geradores levou a estudos de análise, modelagem e predição de séries temporais que têm sido desenvolvidos no grupo de pesquisa do ICMCUSP, do qual o aluno faz parte. O trabalho voltou-se, em uma de suas frentes, para a modelagem de séries temporais por meio de sua reconstrução utilizando os teoremas de Whitney (1936) e Takens (1981).

Nessa mesma linha, Dodonov (2009) investigou a compreensão e predição de dinâmicas comportamentais de processos, utilizando abordagens de sistemas dinâmicos, inteligência artificial e teoria do caos no desenvolvimento de uma política de escalonamento distribuído.

Pereira (2011), no contexto de tolerância a faltas, avaliou a reconstrução de séries de faltas de sistemas computacionais, separando o comportamento normal do comportamento faltoso em processos executando em sistemas UNIX.

Estudos como esses, realizados pelo grupo, motivaram a criação de uma categorização sistemática do modelo gerador de séries temporais, ou seja, o modelo que rege a equação matemática usada para produzir a série. Por exemplo, para a série ilustrada na Figura 
1.5a, seu modelo gerador é $s_{t+1}=3,0 \cdot s_{t} \cdot\left(1-s_{t}\right)$. Nesse sentido, foi proposta uma taxonomia no trabalho de Ishii et al. (2011) que leva em conta três propriedades: i) estocasticidade, que determina se a série provém de um modelo puramente determinístico ou se contém componentes aleatórios seguindo determinada distribuição; ii) linearidade, que verifica se a série segue um modelo linear ou não; e iii) estacionariedade, que determina se a série orbita em torno de média e variância constantes. Levando em conta essas características, os autores criaram uma hierarquia que apresenta as diferentes possibilidades, como ilustrado na Figura 1.6.

De acordo com Ishii et al. (2011), é possível identificar cinco classes básicas de séries: 1) Determinística; 2) Estocástica Linear Estacionária; 3) Estocástica Linear Não Estacionária; 4) Estocástica Não Linear Estacionária e 5) Estocástica Não Linear Não Estacionária.

Dentro da classe Determinística, também é possível subdividi-la em linear e não linear. Porém, caso a equação que rege a geração da série seja puramente determinística, com o ferramental matemático proveniente da área de sistemas dinâmicos (Alligood et al., 1997), como a reconstrução da série no espaço fase com os teoremas de Whitney (1936) e Takens (1981), é possível obter com certo sucesso uma equação que descreva a dinâmica da série, ou seja, como valores futuros são determinados a partir de valores passados. Assim, para os propósitos deste trabalho não se subdivide o ramo da classe Determinística.

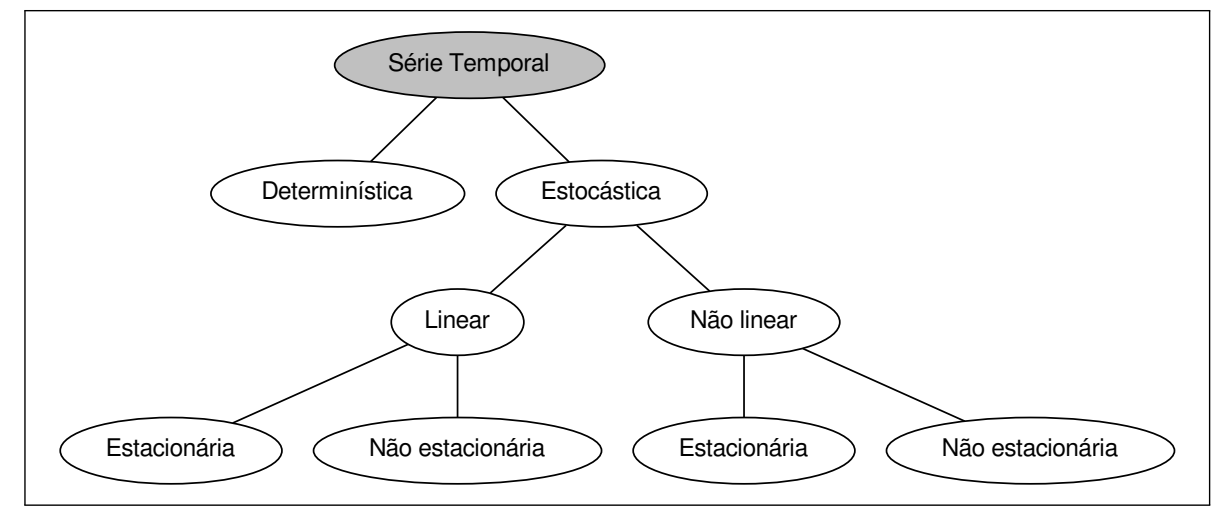

Figura 1.6: Taxonomia de séries temporais proposta por Ishii et al. (2011). Ela identifica as possíveis combinações de características básicas de séries temporais: estocasticidade, linearidade e estacionariedade.

A taxonomia proposta por Ishii et al. (2011) auxilia a determinar as várias classes de séries existentes, ou seja, quais combinações diferentes de características podem estar presentes no modelo gerador de uma série temporal. A compreensão desse modelo, ou seja, da equação que rege a geração da série estudada, é importante para que seja possível, de fato, analisar a similaridade entre um conjunto de séries.

Essa análise de similaridade, baseada em modelos geradores, pode se dar em diferentes campos. Por exemplo, uma das características a analisar é a dependência com o passado, ou seja, como o valor atual de uma série é influenciado por valores passados e qual a extensão dessa influência.

Outro campo de análise envolve os componentes determinísticos e estocásticos presentes nas séries. Caso ela seja estocástica, é possível utilizar ferramentas estatísticas para 
sua modelagem. Por outro lado, caso a série seja puramente determinística, o ferramental matemático da área de sistemas dinâmicos (Alligood et al., 1997) pode auxiliar na modelagem.

Nesse contexto de análise de séries determinísticas com sistemas dinâmicos, foram desenvolvidos estudos importantes, tais como o de Takens (1981), que baseado no teorema de imersão de Whitney (1936), mostrou que uma série temporal $S_{i}=\left(s_{1}, s_{2}, \ldots, s_{n}\right)$ pode ser reconstruída em um espaço de várias dimensões, também conhecido por espaço fase, $o_{n}(m, \tau)=\left(s_{n}, s_{n+\tau}, \ldots, s_{n+(m-1) \tau}\right)$, em que $o$ é um ponto do espaço fase formado por observações da série, $m$ é a dimensão embutida e $\tau$ a dimensão de separação.

Essa técnica de reconstrução permite transformar as observações de uma série temporal em um conjunto de pontos $\left\{o_{1}, o_{2}, \ldots, o_{j}\right\}$ em um espaço Euclidiano de $m$ dimensões, também chamado de espaço fase. Takens (1981) mostrou que essa reconstrução pode auxiliar na obtenção da regra, ou equação, geradora da série.

Por exemplo, considere o mapa logístico ilustrado na Figura 1.5b. Aparentemente, seu comportamento é complexo e de difícil determinação baseando-se somente nas observações da série. Porém, realizando sua reconstrução no espaço fase com dimensão embutida $m=2$ e de separação $\tau=1$, obtém-se a ilustração da Figura 1.7. É possível observar que, após a reconstrução, o comportamento de difícil compreensão na Figura 1.5b foi simplificado, de fato permitindo que, com uma simples equação do segundo grau (uma parábola), seja possível descrever com alta acurácia o valor de $s_{t+1}$ dada uma observação atual $s_{t}$.

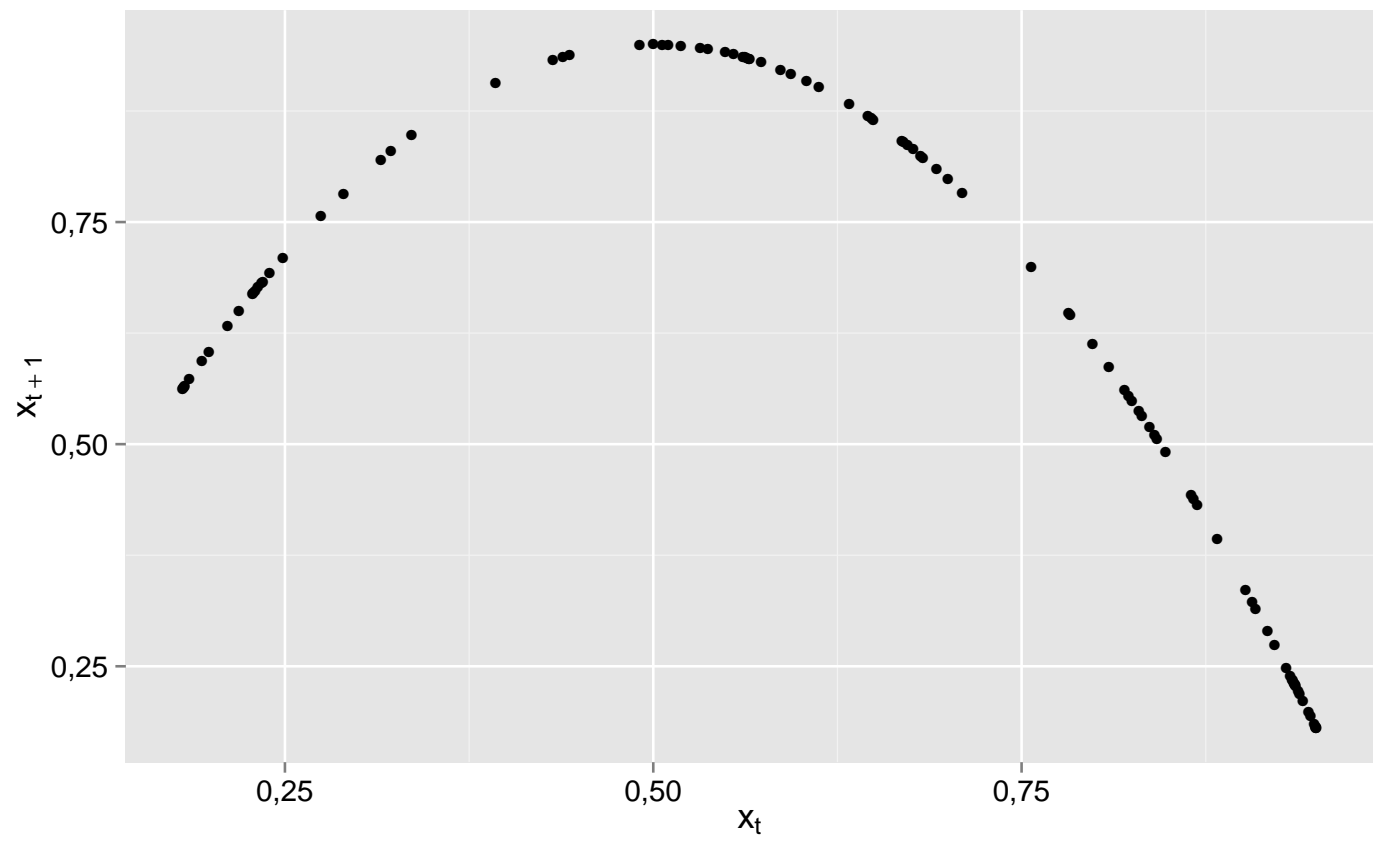

Figura 1.7: Reconstrução da série oriunda do mapa logístico da Figura 1.5b com dimensão embutida $m=2$ e de separação $\tau=1$. É possível observar que, após a reconstrução no espaço fase, torna-se mais simples a compreensão do comportamento da série, facilitando sua modelagem.

Os estudos de Whitney (1936) e Takens (1981) auxiliam na modelagem de séries temporais determinísticas, em que a reconstrução no espaço fase simplifica a compreensão 
da regra geradora da série. No entanto, muitas séries apresentam não só comportamento determinístico, mas também algum nível de estocasticidade. Por exemplo, o modelo $A R(p)=\sum_{i=1}^{p} \phi_{i} x_{t-i}+a_{t}$ proposto por Box e Jenkins (1994), que tem o componente determinístico $\phi_{i} x_{t-i}$, ou seja, dependente somente dos próprios valores passados da série, e apresenta também o ruído branco $a_{t}$, que introduz um elemento de incerteza nas observações.

Para caracterizar o modelo gerador de uma série, faz-se necessário, portanto, considerar também seus componentes estocásticos. Medidas como média, variância, curtose e outras podem auxiliar na caracterização do comportamento estocástico. Outras medidas como a Autocorrelação (Box e Jenkins, 1994) e a Autoinformação Mútua (Fraser e Swinney, 1986) também auxiliam a descobrir a relação entre observações atuais e passadas de séries, mesmo na presença de componentes estocásticos.

Esses estudos mostraram que, para uma caracterização adequada de uma série temporal, faz-se necessária uma compreensão do modelo gerador, ou seja, a equação que rege a geração da série. No entanto, as técnicas atuais de agrupamento de séries temporais em fluxos contínuos não consideram propriedades essenciais do modelo gerador, tais como sua estocasticidade, linearidade e estacionariedade. Essa lacuna levou à proposta deste trabalho, descrita na seção seguinte.

\subsection{Hipótese e Objetivo}

Informações relevantes para a fase de agrupamento de séries temporais são descartadas por abordagens atuais, notadamente por não considerarem propriedades essenciais que caracterizam o modelo gerador de séries temporais. O foco deste trabalho consiste, portanto, na busca por medidas descritivas de séries temporais que auxiliem na caracterização de seu modelo gerador, ou seja, a equação que produz suas observações.

Nesse sentido, foi definido um conjunto de medidas que auxiliam na caracterização das diversas propriedades elencadas na taxonomia de Ishii et al. (2011). Tomando as três propriedades básicas, notadamente, estocasticidade, linearidade e estacionariedade, podese citar algumas das medidas utilizadas neste trabalho para caracterização de modelos geradores.

Por exemplo, o coeficiente de integração do modelo ARIMA de Box e Jenkins (1994) permite identificar se uma série é estacionária. A transformada de Fourier (1888) auxilia na modelagem de componentes não lineares por meio da combinação de senóides, permitindo identificar quais frequências estão contidas em uma série. A medida de Determinismo (DET) proposta por Marwan et al. (2007) ajuda a medir o grau do componente determinístico presente em uma série.

A partir dessas medidas e outras discutidas posteriormente, espera-se obter uma melhor caracterização do modelo gerador de uma série temporal, consequentemente aumentando a qualidade de seu agrupamento. Assim, a hipótese deste trabalho é enunciada da 
seguinte maneira:

O uso de medidas descritivas auxilia na tarefa de agrupamento de séries temporais, em função de uma melhor caracterização de seus modelos geradores.

A hipótese colocada é justificada por meio de diversas pesquisas concebidas na área de análise de sinais. Ao longo da história, diversos pesquisadores buscaram, em diferentes domínios, modelar séries temporais por meio da compreensão de sua equação ou regra geradora.

Fourier (1888) estendeu resultados de Leonhard Euler, permitindo que se representasse um sinal por meio da combinação de senos e cossenos, empregando a fórmula $e^{i x}=\cos (x)+$ $i \operatorname{sen}(x)$ desenvolvida por Euler (Feynman et al., 1965). Posteriormente, Hilbert (1912) generalizou ainda mais e possibilitou estimar as frequências e amplitudes instantâneas de um sinal com o Hilbert Spectrum.

Diversos outros modelos foram criados para descrever o comportamento de séries temporais. No setor financeiro, um dos modelos mais conhecidos é o de Black e Scholes (1973), que precifica uma opção ${ }^{2}$ baseando-se somente no preço do ativo negociado e em outras variáveis conhecidas.

No campo determinístico, Whitney (1936) e Takens (1981) desenvolveram teoremas que permitem reconstruir uma série temporal em um espaço Euclidiano com mais dimensões, simplificando a modelagem e a compreensão do modelo que deu origem à série.

Já no campo estocástico, os modelos autorregressivos de Box e Jenkins (1994) determinam de forma muito clara como a observação atual de uma série é influenciada por observações passadas (por meio de uma combinação linear) e quais os componentes estocásticos envolvidos no processo. Por exemplo, em um modelo AR(1) o valor atual da série é completamente determinado por seu valor anterior, multiplicado por um escalar e somado a um ruído branco, oriundo de uma distribuição de probabilidades Normal.

Esses estudos buscaram compreender séries temporais por meio de modelos que descrevem a equação geradora da série, e não simplesmente pelas observações finais obtidas. Isso resulta em uma modelagem mais precisa, que permite descobrir relacionamentos dificilmente detectados ao se calcular diretamente uma distância ou correlação sobre as observações das séries.

Nesse contexto, para comprovar a hipótese colocada, o objetivo deste trabalho é melhorar o agrupamento de séries temporais em fluxos contínuos por meio do uso de medidas descritivas, que melhor caracterizem o modelo gerador das séries em questão.

Com esse intuito, foi desenvolvido um algoritmo de agrupamento que leva em conta as diversas medidas de caracterização analisadas. Nesse desenvolvimento, também foram considerados aspectos importantes no cenário de fluxos contínuos, tais como o surgimento, desaparecimento, união, divisão e modificação de grupos.

\footnotetext{
${ }^{2}$ Uma opção é um contrato que dá ao investidor o direito de comprar ou vender determinado ativo, dadas certas condições, em um prazo determinado (Black e Scholes, 1973).
} 
Os experimentos realizados para avaliar a abordagem utilizaram séries temporais sintéticas, geradas a partir de modelos bem conhecidos, que cobrem todas as combinações apresentadas na taxonomia de Ishii et al. (2011) - Figura 1.6. Também foram empregadas séries reais provenientes de músicas ${ }^{3}$, bem como de ações de bolsa de valores ${ }^{4}$. A validação da abordagem foi feita por meio de critérios como o Adjusted Rand Index (ARI) (Hubert e Arabie, 1985).

Para melhor ilustrar os passos envolvidos neste trabalho, produziu-se a Figura 1.8. Seja $S=\left\{S_{1}, S_{2}, S_{3}, S_{4}\right\}$ o conjunto de séries temporais que compõem o fluxo contínuo que se deseja agrupar. A cada instante, novas observações são recebidas. Considere uma janela fixa ${ }^{5}$ de $w$ observações que, quando completa, é submetida para o cálculo de medidas descritivas de séries temporais (passo 1). Após a obtenção de medidas relevantes para caracterizá-las, em termos de suas propriedades básicas como estocasticidade, linearidade e estacionariedade, os valores são fornecidos como entrada para a técnica de agrupamento incremental (passo 2). Essa é responsável pela manutenção dos grupos, tratando o desaparecimento, surgimento, união, divisão e modificação dos mesmos. No exemplo da figura, a partição $P=\left\{\left\{S_{1}, S_{2}\right\},\left\{S_{3}, S_{4}\right\}\right\}$ foi obtida. A cada instante, a partição atual é avaliada de acordo com critérios de validação de agrupamento (passo 3).

As contribuições deste trabalho podem ser sumarizadas da seguinte forma: 1) a avaliação e ranking de diversas medidas descritivas quanto ao seu poder discriminativo, considerando vários modelos e classes de séries temporais; 2) a proposta de um critério de minimização de variância que funciona de maneira similar ao Ganho de Informação; 3) a proposta e avaliação de um algoritmo de agrupamento que leva em conta as medidas estudadas para uma melhor caracterização do modelo gerador de séries temporais, consequentemente obtendo um agrupamento de melhor qualidade em cenários em que outras técnicas da literatura atualmente falham; 4) um estudo teórico e experimental que evidencia a sensibilidade da correlação de Pearson.

\subsection{Organização}

Esta tese está organizada conforme detalhado a seguir. No próximo capítulo, as técnicas já mencionadas para agrupamento de séries temporais em fluxos contínuos de dados são detalhadas. No Capítulo 3, apresenta-se uma revisão sobre diversas medidas descritivas de séries temporais, as quais foram avaliadas para uso na abordagem proposta. No Capítulo 4, experimentos com essas medidas são apresentados, a fim de avaliar seu impacto sobre o aprendizado considerando séries temporais. No Capítulo 5, é apresentada a

\footnotetext{
${ }^{3}$ Obtidas a partir do repositório público Free Music Archive - http://freemusicarchive.org/. Último acesso: 11 de junho de 2012.

${ }^{4}$ Obtidas a partir do serviço Yahoo! Finance - http://finance.yahoo.com/. Último acesso: 11 de junho de 2012.

${ }^{5}$ É importante enfatizar que não se trata de uma janela deslizante, que inclui uma nova observação e descarta uma antiga a cada iteração. A janela é completamente esvaziada e novamente preenchida com $w$ novas observações a cada iteração.
} 


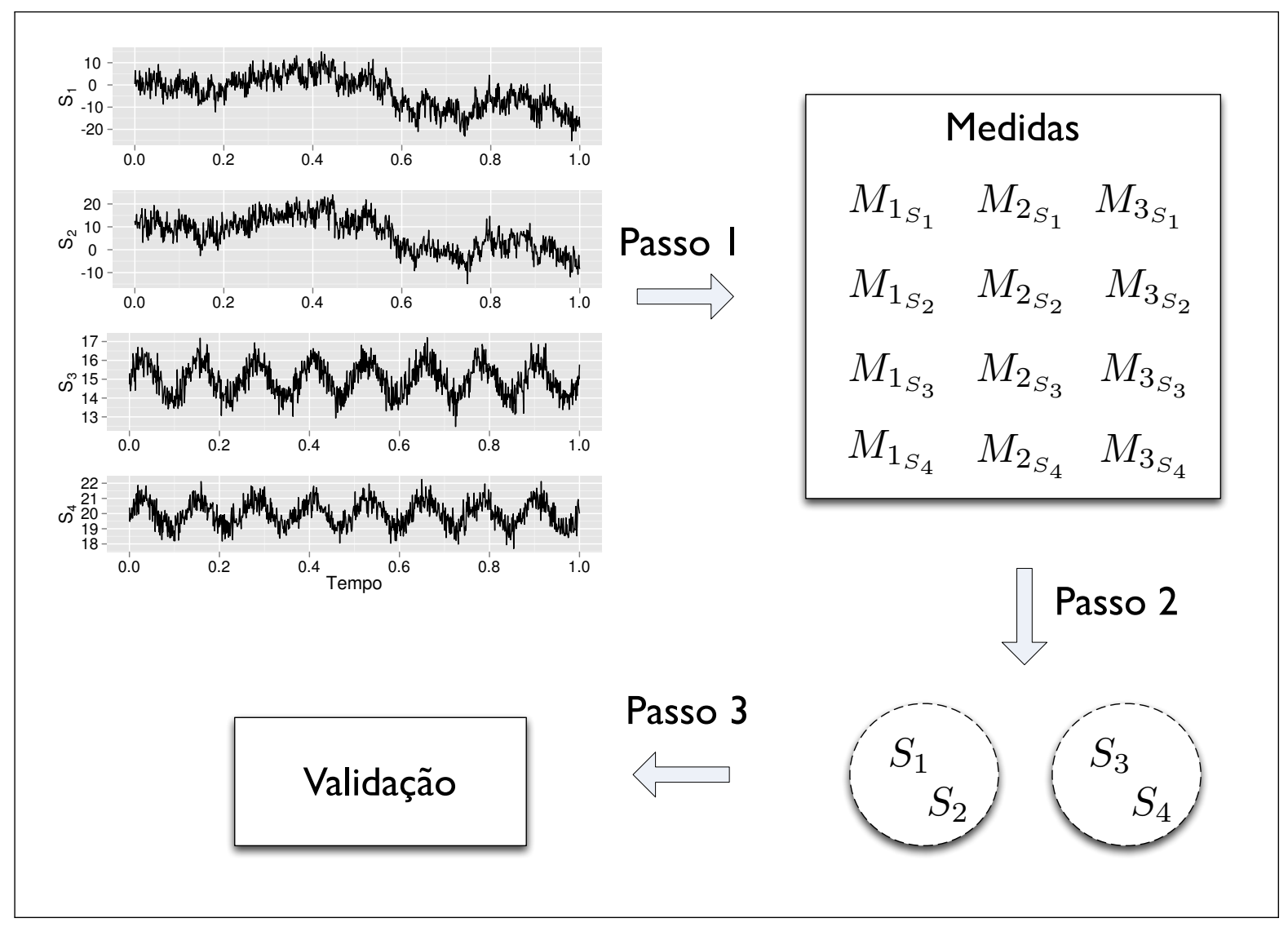

Figura 1.8: Passos da abordagem.

abordagem proposta, bem como sua avaliação. A seguir, são apresentadas as conclusões no Capítulo 6. Ao final, três apêndices trazem um rank das medidas descritivas analisadas, execuções adicionais de ODAC com as medidas e um estudo do comportamento da correlação de Pearson. 


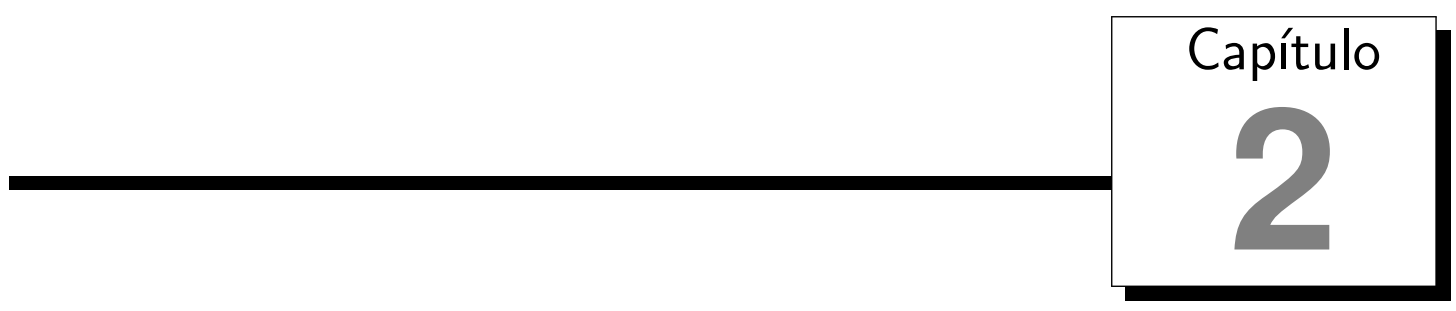

\section{Algoritmos para agrupamento de séries temporais em fluxos contínuos}

\subsection{Considerações Iniciais}

Este capítulo aborda propostas para agrupamento de séries temporais em fluxos contínuos de dados. Os algoritmos são apresentados em ordem cronológica e suas limitações são discutidas. É importante observar que, na maioria das propostas, prevalece o uso de modelos lineares e estacionários ou o emprego de correlações lineares, o que ocasiona limitações quando essas propostas são aplicadas a fluxos de dados constituídos por séries que apresentam comportamento não linear ou não estacionário, conforme exemplificado na Seção 1.1. É importante ressaltar também que algoritmos como STREAM (O'Callaghan et al., 2002) e CluStream (Aggarwal et al., 2003), apesar de populares e citados na Seção 1.1, tratam somente do agrupamento de pontos em espaços multidimensionais e não do agrupamento de séries temporais, como os algoritmos descritos neste capítulo.

\subsection{K-Means Incremental}

Beringer e Hüllermeier (2006) propuseram uma versão online do algoritmo K-Means, a qual utiliza uma janela deslizante composta pelas $w$ observações mais recentes. Cada janela é então novamente particionada em $m$ blocos de tamanho $v$, tal que $w=m \cdot v$, conforme mostrado a seguir para uma série $S_{x}$ do fluxo de dados. As séries são atualizadas a cada $v$ novas observações recebidas. 


$$
S_{x}=(\underbrace{s_{x 0}, s_{x 1}, \ldots, s_{x v-1}}_{B_{1}}|\underbrace{s_{x v}, s_{x v+1}, \ldots, s_{x 2 v-1}}_{B_{2}}| \ldots \mid \underbrace{s_{x(m-1) v}, s_{x(m-1) v+1}, \ldots, s_{x w-1}}_{B_{m}})
$$

As $w$ observações são multiplicadas (produto interno) por um vetor de pesos $C=$ $\left(c^{w-1}, c^{w-2}, \ldots, c^{0}\right)$ com crescimento exponencial, $0<c \leq 1$. Isso permite dar maior importância a pontos mais recentes do fluxo. As séries são então normalizadas, de forma que fiquem com média 0 e desvio padrão 1 . Isso corresponde à subtração de sua média e divisão pelo desvio padrão. Conforme novas observações do fluxo chegam, as médias e desvios são atualizados por meio de equações incrementais.

Um segundo passo de pré-processamento do algoritmo consiste na substituição das séries ponderadas e normalizadas por suas transformadas discretas de Fourier, conforme a Equação 2.1, em que $i=\sqrt{-1}$.

$$
\operatorname{DFT}_{f}\left(S_{x}\right)=\frac{1}{\sqrt{w}} \sum_{j=0}^{w-1} s_{x j} \cdot \exp \left(\frac{-i 2 \pi f j}{w}\right), f=0,1, \ldots, w-1 .
$$

Como a distância Euclidiana é preservada pela DFT (Beringer e Hüllermeier, 2006), ou seja, $\left\|S_{1}-S_{2}\right\|=\left\|D F T\left(S_{1}\right)-D F T\left(S_{2}\right)\right\|$, e as frequências mais baixas estão contidas nos primeiros coeficientes do vetor transformado, os autores empregam $u \ll w$ coeficientes das DFTs para aproximar a distância entre as séries. Isso permite suavizar séries que contenham várias observações ruidosas, já que apenas as frequências mais baixas são retidas.

Após a obtenção das distâncias entre séries, o algoritmo emprega uma versão modificada do K-Means, conforme listado no Algoritmo 1.

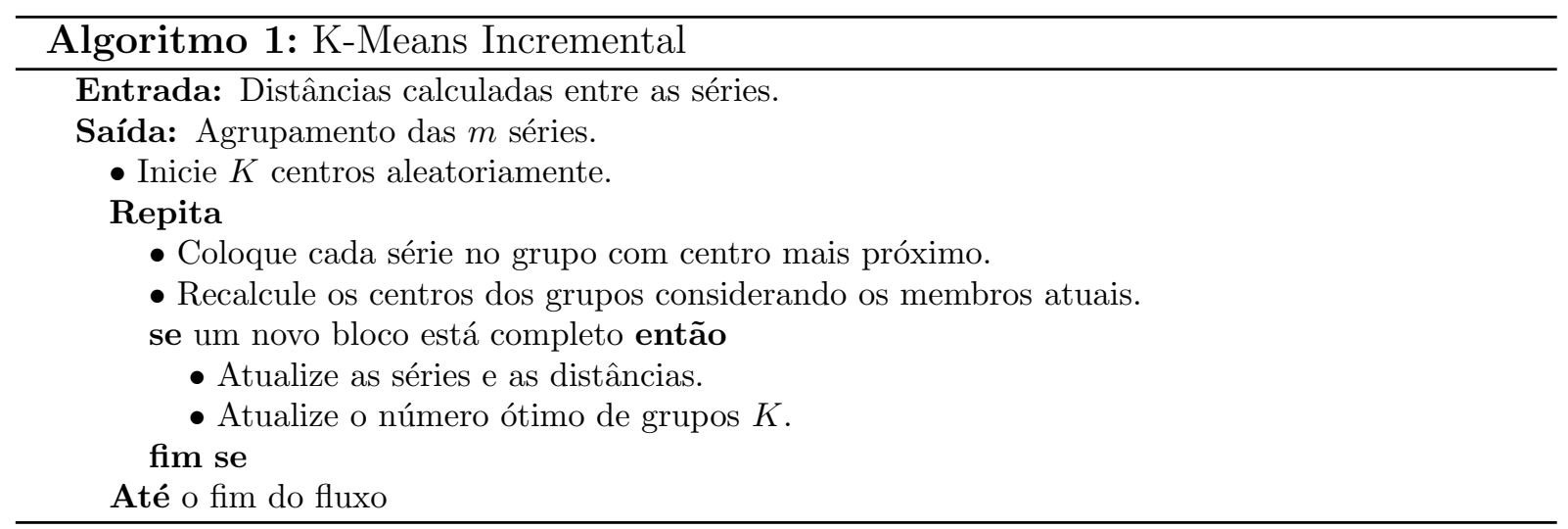

A principal diferença do procedimento proposto por Beringer e Hüllermeier (2006) em relação ao K-Means tradicional, é a adaptação automática do número de grupos $K$. Os autores a empregam no contexto da evolução de grupos ao longo do tempo, o que pode modificar o número de grupos existente em um dado momento.

O processo adaptativo do número de grupos é feito avaliando, a cada iteração, se há melhora modificando $K$ para mais ou menos um. Os autores consideram que usualmente 
a estrutura de grupos não se modifica abruptamente, e por isso a avaliação se restringe a $K \pm 1$. Isso nem sempre é verdade na prática, já que mudanças abruptas também são possíveis (Bifet e Kirby, 2009). Para avaliar se há melhora, o algoritmo emprega o Índice de Separação $Q$, proposto por Xie e Beni (1991) - Equação 2.2 - para obter o número $K^{*}$ ótimo de grupos.

$$
K^{*}=\arg \max \{Q(K-1), Q(K), Q(K+1)\}
$$

Caso $K-1$ obtenha o melhor resultado, deve-se remover um dos grupos existentes. Isso é feito retirando de maneira provisória um dos grupos e atribuindo todos os seus membros aos respectivos grupos remanescentes mais próximos. A qualidade da estrutura obtida é então novamente avaliada. Esse processo é repetido $K$ vezes, testando a remoção de cada um dos grupos, até que se obtenha a escolha que fornece o melhor índice de qualidade. $\mathrm{O}$ grupo selecionado a partir do método descrito é então designado para remoção definitiva.

Por outro lado, caso se detecte que deva haver um incremento no número de grupos, ou seja, $K+1$, então o algoritmo cria um novo grupo selecionando como centro uma das séries do fluxo, escolhida aleatoriamente, tal que a probabilidade de seleção é definida como uma função crescente da distância da série a seu centro atual.

A complexidade de tempo do algoritmo é quadrática em $K$, ou seja, $O\left(K^{2}\right)$, pois, para operações de remoção, o algoritmo testa cada um dos grupos, a fim de encontrar o que fornece o maior valor do índice de qualidade. Os autores desenvolveram também uma versão fuzzy do algoritmo, em que as séries apresentam níveis de pertinência aos grupos.

É possível identificar várias limitações na proposta de Beringer e Hüllermeier (2006). Em primeiro lugar, a distância Euclidiana é usada, o que pode mascarar a proximidade de séries que não apresentam alinhamento no eixo do tempo (Keogh e Ratanamahatana, 2005). Em segundo lugar, é necessário realizar uma busca exaustiva para escolher o grupo que fornece o melhor índice de qualidade na operação de remoção, enquanto no procedimento de adição seleciona-se aleatoriamente qual série deve ser o centro do novo grupo.

\subsection{Online Divisive-Agglomerative Clustering}

Rodrigues et al. (2008) propuseram o algoritmo Online Divisive-Agglomerative Clustering (ODAC), que cobre algumas das limitações encontradas na proposta prévia de Beringer e Hüllermeier (2006), como o tratamento mais adequado para o aparecimento e remoção de grupos. ODAC utiliza uma estratégia top-down, iniciando com todas as séries em um mesmo grupo e realizando divisões de acordo com um critério de quebra. A estrutura induzida corresponde a uma árvore, na qual os grupos são representados pelas folhas.

O algoritmo utiliza uma medida de distância incremental, baseada na correlação de Pearson (1894). Para isso, as estatísticas suficientes de cada uma das séries que compõem 
o fluxo são armazenadas. Concretamente, a dissimilaridade entre duas séries $S_{1}$ e $S_{2}$ é calculada por ODAC como a Rooted Normalized One-Minus-Correlation (RNOMC) Equação 2.3 - em que $\operatorname{corr}\left(S_{1}, S_{2}\right)$ é a correlação de Pearson entre $S_{1}$ e $S_{2}$. O método considera o diâmetro de um grupo como a maior dissimilaridade entre um par de membros, ou a variância da série no caso de grupos com somente um elemento.

$$
\operatorname{RNOMC}_{\left(S_{1}, S_{2}\right)}=\sqrt{\frac{1-\operatorname{corr}\left(S_{1}, S_{2}\right)}{2}}
$$

A matriz de dissimilaridades entre as séries é computada por ODAC somente no momento de teste de divisão ou agregação de folhas. Isso ocorre quando se identifica que um número suficiente de exemplos foi recebido, o que é calculado de acordo com o limite de Hoeffding (1963).

A decisão sobre a agregação ou divisão baseia-se na máxima e mínima variação do diâmetro de um grupo, o que é calculado com base no limite de Hoeffding, o qual diz que para $n$ observações independentes da variável $v_{k}$ com média $\overline{v_{k}}$ e intervalo $R$, sua média verdadeira é pelo menos $\overline{v_{k}}-\epsilon$ com probabilidade $1-\delta$ e $\epsilon$ dado pela Equação 2.4.

$$
\epsilon=\sqrt{\frac{R^{2} \ln (1 / \delta)}{2 n}}
$$

Como cada folha pode conter um número diferente de exemplos, cada uma tem um valor de $\epsilon$, designado $\epsilon_{k}$ para a $k$-ésima folha. ODAC considera que duas distâncias são diferentes somente se sua separação é maior do que $\epsilon_{k}$. Se a diferença entre o diâmetro $d_{1}$ e a segunda maior distância ${ }^{1} d_{2}=\max \left(D \backslash d_{1}\right)$ no grupo for estatisticamente significativa, de acordo com o limite de Hoeffding, então a primeira é o diâmetro real do grupo. Assim, ODAC só aplica o teste de divisão quando o diâmetro verdadeiro do grupo é conhecido.

A heurística aplicada para decisão de divisão baseia-se na ideia de que se a série segue uma distribuição simétrica, e.g., Normal ou Uniforme, então seu máximo e mínimo devem estar aproximadamente equidistantes da média. Assim, com alta probabilidade, dado um número $e \in \mathbb{R}$ deve-se observar $|(\max -\mu)-(\mu-\min )|<e$ com $e \ll(\mu-\min )$. Dada essa premissa, ODAC realiza a divisão de um nó folha caso a diferença entre $\left(d_{1}-\bar{d}\right)$ e $\left(\bar{d}-d_{0}\right)$ seja alta, sendo $d_{0}$ a menor distância entre séries do nó, $d_{1}$ a maior e $\bar{d}$ a média. Uma folha $C_{k}$ é dividida caso a Equação 2.5 seja atendida.

$$
\left(d_{1}-d_{0}\right)\left|\left(d_{1}-\bar{d}\right)-\left(\bar{d}-d_{0}\right)\right|>\epsilon_{k}
$$

Quando uma divisão é realizada, as séries que apresentam maior distância entre si, denominadas pivôs, formam novos grupos. As séries remanescentes são atribuídas aos grupos com pivôs mais próximos.

É possível que, ao longo do tempo, os nós filhos gerados a partir de uma operação de divisão voltem a fazer parte de um mesmo grupo, causando uma operação de agregação. ODAC utiliza uma heurística baseada nos diâmetros dos grupos para decidir se dois nós

\footnotetext{
${ }^{1} \mathrm{~A}$ maior distância no conjunto $D$ desconsiderando o elemento $d_{1}$.
} 
folhas devem ser agregados. A Equação 2.6 apresenta o teste realizado, caso ele seja verdadeiro, então os nós folhas são unidos e o nó pai volta a ser rotulado como um nó folha. Na Equação 2.6, $C_{k}$ e $C_{s}$ são dois nós folhas irmãos e $C_{j}$ o pai deles. O limite de Hoeffding $\epsilon_{j}$ refere-se ao nó pai.

$$
2 \cdot \operatorname{diam}\left(C_{j}\right)-\left(\operatorname{diam}\left(C_{k}\right)+\operatorname{diam}\left(C_{s}\right)\right)<\epsilon_{j}
$$

A partir das definições das operações de agregação e divisão, e também da medida de dissimilaridade, é possível apresentar o procedimento principal de ODAC, conforme ilustrado no Algoritmo 2.

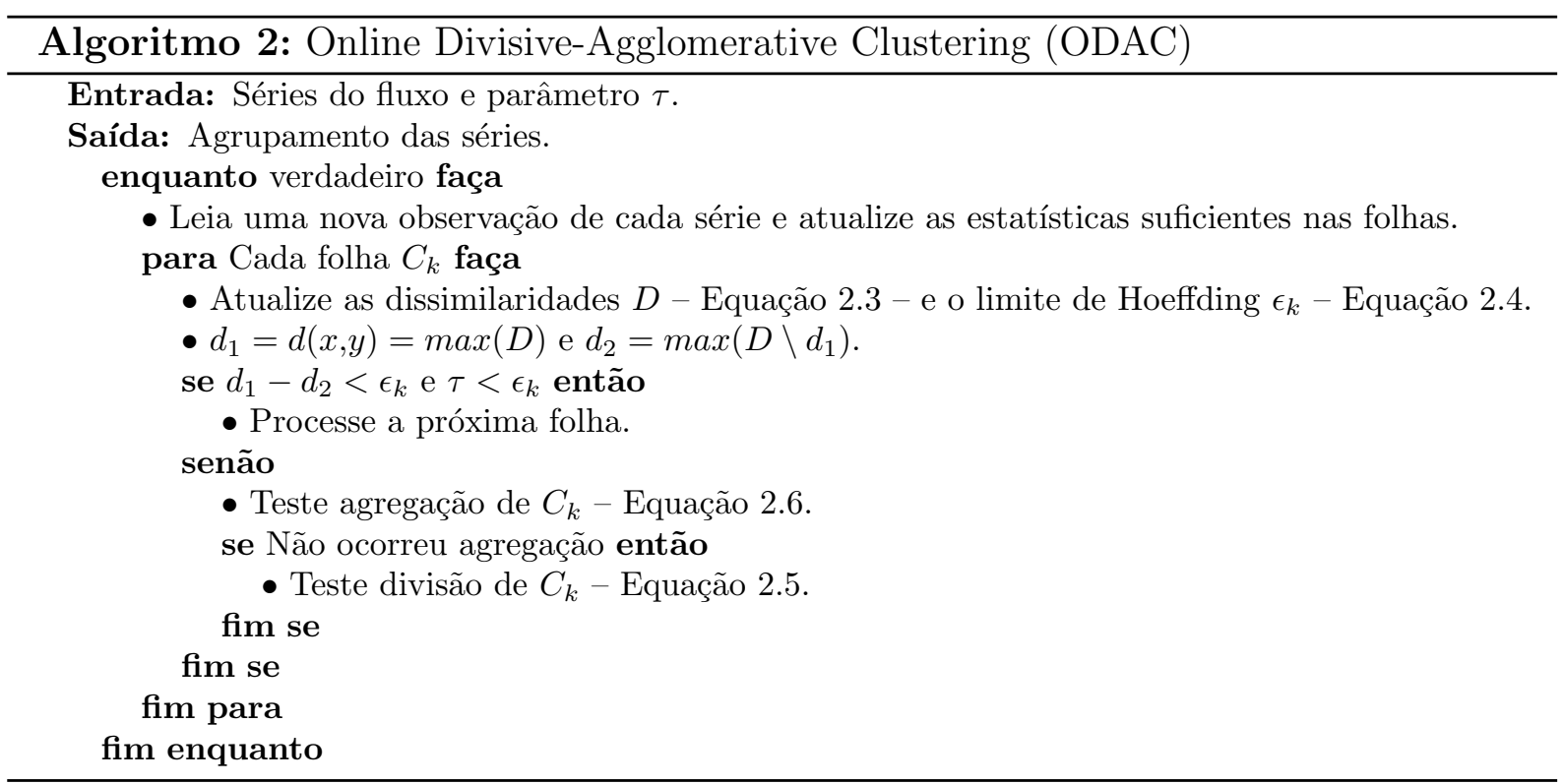

A cada iteração, o algoritmo recebe uma nova observação de todas as séries que compõem o fluxo. Isso permite atualizar as estatísticas suficientes nas folhas e as dissimilaridades. O parâmetro $\tau$, fornecido pelo usuário, controla o quanto o algoritmo poderá esperar para determinar o diâmetro real, até que se force o teste de agregação e divisão.

A complexidade de tempo do algoritmo ODAC é da ordem de $O\left(n^{2}\right)$, em que $n$ é o número de séries que compõem o fluxo. Várias premissas consideradas pelo algoritmo, como o uso do Limite de Hoeffding, o qual só é válido para variáveis aleatórias independentes oriundas de uma distribuição fixa, não se aplicam em geral para séries temporais.

Outra premissa considerada por ODAC que, em geral, não se verifica para vários modelos de séries temporais é a de distribuições simétricas, como Normal ou Uniforme. A Figura 2.1a ilustra uma série que segue um modelo $\operatorname{ARIMA}(1,1,0)$ de Box e Jenkins (1994), um exemplo comum de série com comportamento linear e não estacionário. O histograma da série é ilustrado na Figura 2.1b. É possível observar que o formato da distribuição não é de uma Normal, o que é confirmado executando o teste de normalidade Shapiro-Wilk (Royston, 1982), o qual retorna um p-valor de $5,1 \times 10^{-15}$, confirmando que não existem evidências para aceitar a hipótese de que a série segue uma distribuição Normal.

O uso da correlação de Pearson também limita o algoritmo, já que ela só é capaz 


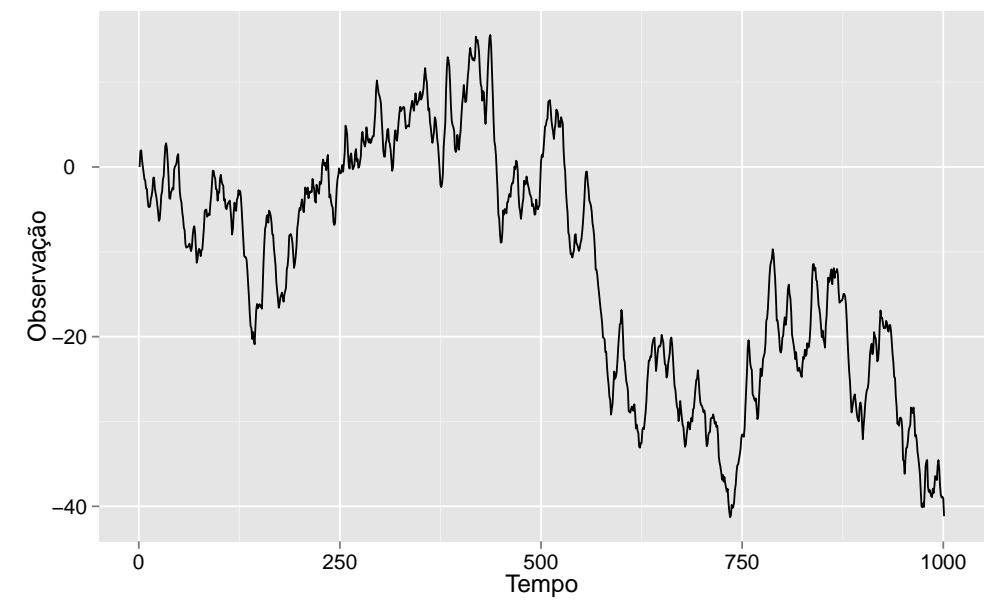

(a) Exemplo de uma série temporal seguindo um modelo $\operatorname{ARIMA}(1,1,0)$.

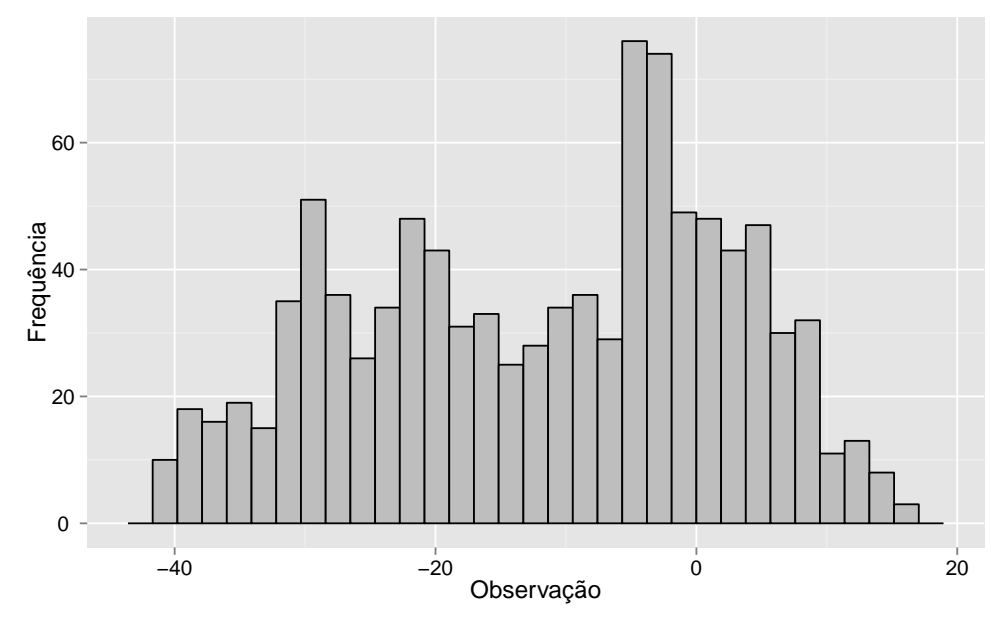

(b) Histograma da série.

Figura 2.1: A Figura 2.1a apresenta uma série seguindo um modelo ARIMA de Box e Jenkins (1994). Na Figura 2.1b, o histograma da série mostra que a suposição de normalidade não seria adequada para esta série, o que é confirmado pelo teste de normalidade Shapiro-Wilk (Royston, 1982) com p-valor $5,1 \times 10^{-15}$.

de detectar relacionamentos lineares, conforme exposto na Seção 1.1. Além disso, ela é sensível a ruídos e outliers (Fujita et al., 2009).

Apesar dessas limitações, ODAC é uma das propostas de agrupamento mais aceitas na literatura, sendo que outras basearam-se em sua medida de dissimilaridade RNOMC para propor novos algoritmos, como no trabalho de Widiputra et al. (2011). Nesta tese, mostra-se que essa medida de dissimilaridade não é adequada para vários modelos de séries temporais devido a restrições inerentes à correlação de Pearson, que serve como base para a medida RNOMC. Maiores detalhes são apresentados no Apêndice C (p. 125).

\subsection{Probability and Distribution-based Clustering}

Chaovalit (2009) propôs Probability and Distribution-based Clustering (POD-Clus), um método para agrupamento de séries temporais que faz uso de dois meios de representação. O primeiro baseia-se na sumarização de observações, por meio de média e desvio padrão, 
enquanto o segundo faz uso de coeficientes obtidos por regressão linear.

POD-Clus emprega a medida de dissimilaridade proposta por Kumar e Patel (2007), conforme mostra a Equação 2.7, na qual $S_{i}$ é uma série do fluxo, $C$ é um grupo, $f$ denota um atributo (e.g., média, desvio, coeficiente angular), $\mu_{\text {Sif }}$ é a média do atributo $f$ para a série $S_{i}, \mu_{C f}$ é a média do atributo $f$ para o grupo $C$ e $\sigma_{S i f}$ é o desvio padrão do atributo $f$ da série $S_{i}$. Essa medida calcula a soma das diferenças quadráticas entre as médias de atributos da série $S_{i}$ e do centro do grupo $C$, divididas pelas respectivas variâncias dos atributos. Essa medida é similar à distância Euclidiana, diferindo apenas na normalização pela variância.

$$
d_{S_{i} C}=\sum_{f=1}^{F} \frac{\left(\mu_{S i f}-\mu_{C f}\right)^{2}}{\sigma_{S i f}^{2}}
$$

O procedimento principal de POD-Clus é ilustrado no Algoritmo 3. Ele começa recebendo um agrupamento inicial das séries, pois supõe que desde o ponto de partida existe uma estrutura de grupos. Os autores sugerem que esse agrupamento inicial seja obtido por meio de outro algoritmo. A seguir, as informações sobre as séries, tais como média e desvio padrão, são atualizadas de forma incremental. As distâncias dos grupos em relação às séries são calculadas por meio da Equação 2.7. Cada série é atribuída a seu grupo mais próximo, permitindo que os centros sejam atualizados. O procedimento se repete a cada nova observação das séries do fluxo.

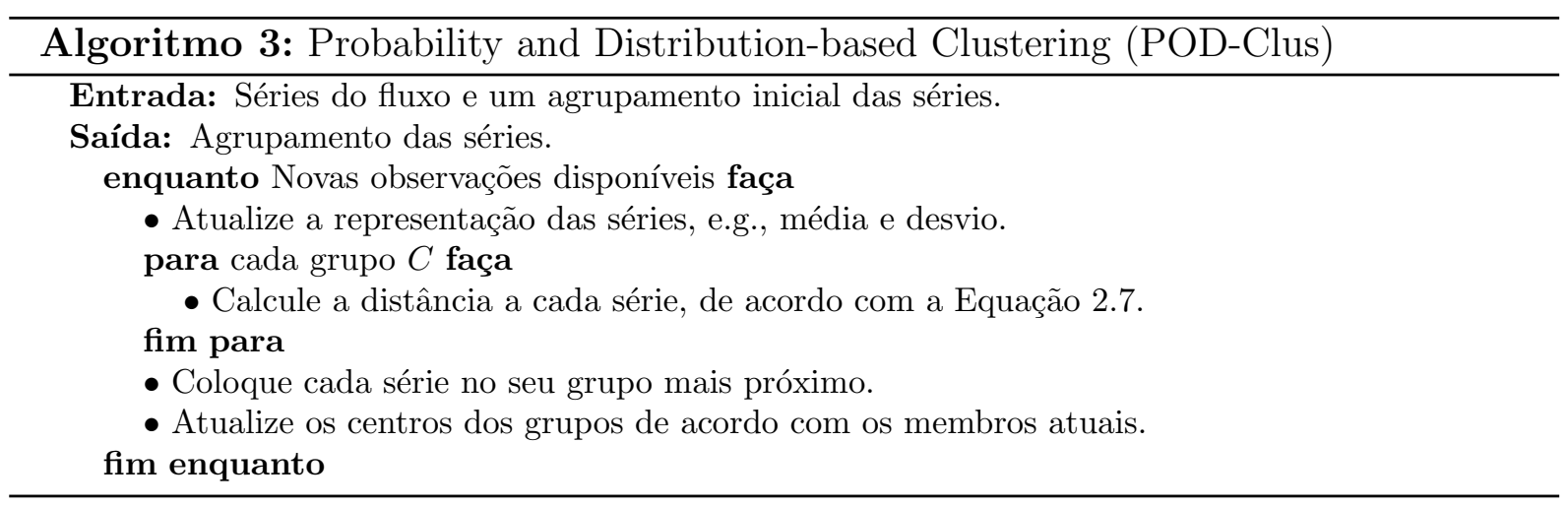

A complexidade de tempo de POD-Clus é da ordem de $O(M T)$, em que $M$ é o número de séries no fluxo e $T$ é o número de observações das séries. Uma das limitações do algoritmo é o uso exclusivo de coeficientes de regressão linear e medidas simples como média e desvio padrão. Além disso, POD-Clus requer o uso de outro algoritmo para gerar a estrutura inicial de grupos.

Apesar do nome do algoritmo se referir a distribuições de probabilidade, ele se remete à versão do algoritmo para agrupamento de pontos em um espaço multidimensional, na qual distribuições Gaussianas são usadas para determinar a pertinência de pontos a grupos. Entretanto, essa modelagem não é empregada na versão do algoritmo para séries temporais.

Chaovalit (2009) também propôs uma modificação para tratar a evolução de grupos, 
entretanto ela utiliza vários parâmetros que limitam a aplicação do algoritmo. Por exemplo, os limites de um grupo $C$ são determinados como $\mu_{C} \pm 3 \sigma_{C}$, o que se baseia na ideia de que se as observações seguirem uma distribuição Normal, então 99,73\% delas devem estar neste intervalo entre mais ou menos três desvios padrão. Entretanto, como o próprio autor aponta, a suposição de normalidade para séries temporais não é acurada, já que as observações tendem a ser correlacionadas e não independentes.

\subsection{Evolving Clustering Method}

Widiputra et al. (2011) propuseram o método Evolving Clustering Method (ECM) para predição de múltiplas séries temporais. Como base para o modelo preditivo, o método utiliza um algoritmo de agrupamento para caracterizar o relacionamento entre séries. O procedimento principal está ilustrado no Algoritmo 4.

Segundo esse algoritmo, ECM inicia calculando as correlações entre as séries utilizando a medida RNOMC - Equação 2.3 - proposta por Rodrigues et al. (2008). Apesar desses cálculos não serem feitos de forma online, pois utilizam as séries temporais completas já no início do algoritmo, eles poderiam ser facilmente adaptados para atualizarem as correlações de forma incremental, como feito em ODAC (Rodrigues et al., 2008).

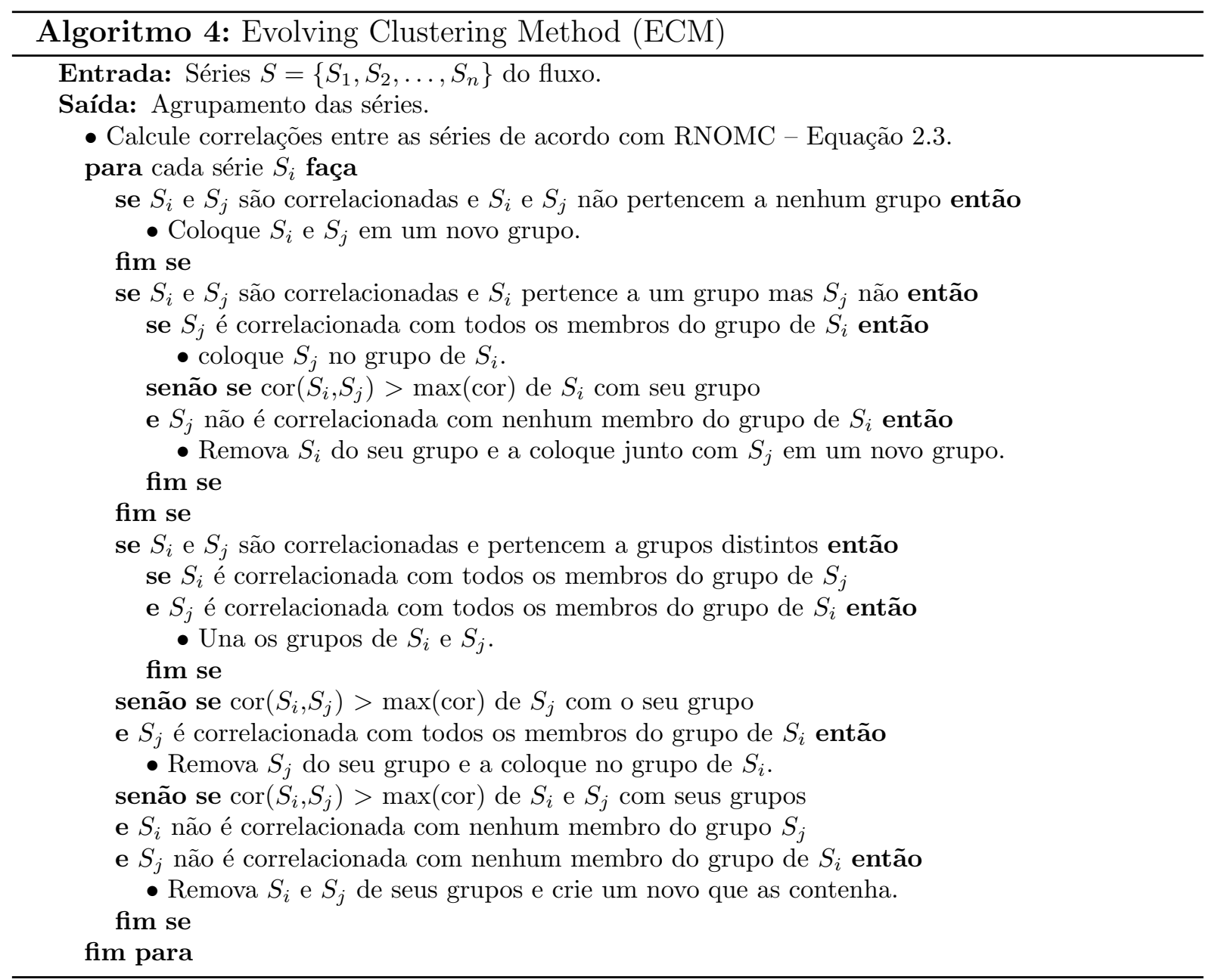


No passo seguinte, o algoritmo verifica se existe correlação entre pares de séries e quais suas correlações com os membros de seus grupos. Considera-se que existe correlação caso o valor retornado por RNOMC (Equação 2.3) seja estatisticamente significativo, de acordo com um Teste T (Walpole et al., 1998) com nível de confiança de 95\%. Baseando-se em um conjunto de regras de decisão, o algoritmo decide como agrupar as séries e opta por criar, remover ou unir grupos.

A complexidade de tempo de ECM é da ordem de $O\left(n^{2}\right)$, sendo $n$ o número de séries presentes no fluxo. Além disso, duas limitações podem ser identificadas no ECM. A primeira refere-se ao uso da mesma medida de dissimilaridade de ODAC (Rodrigues et al., 2008), que se baseia na correlação de Pearson, capaz de detectar somente relacionamentos lineares. Nesse sentido, Widiputra et al. (2011) dizem que como trabalho futuro pretendem avaliar o uso de correlações que capturem também relacionamentos não lineares.

Uma segunda limitação do ECM refere-se às decisões tomadas pelo algoritmo, que se baseiam em regras muito sensíveis. Por exemplo, para unir dois grupos é necessário que o par de séries em avaliação, $S_{i}$ e $S_{j}$, seja significativamente correlacionado com todas as séries de ambos os grupos. Esse tipo de regra torna o algoritmo muito sensível, pois caso $S_{i}$ seja correlacionada com todas as séries do grupo de $S_{j}$ menos uma, a união dos grupos será descartada, quando na verdade a decisão pela união seria provavelmente a correta.

\subsection{Weighted Clustering Ensemble with Different Representations}

Yang e Chen (2011) propuseram o método Weighted Clustering Ensemble with Different Representations (WCE) para agrupamento de séries temporais. O método divide-se em três fases: a primeira extrai diferentes representações das séries, baseando-se em características locais e globais. A segunda fase usa como entrada as representações extraídas na primeira etapa e obtém diversas partições das séries utilizando um ensemble de agrupadores. Finalmente, a terceira fase consiste em uma função de conciliação, a qual reúne as várias partições em um agrupamento final, ponderando cada uma com medidas de validação de agrupamento.

Inicialmente, o algoritmo transforma as séries para um conjunto de representações que fornece uma melhor caracterização, a fim de servir como entrada para a fase de agrupamento. Os autores dividem as representações em piecewise e global, buscando modelar tanto aspectos locais de pontos críticos, como também aspectos globais das séries.

Nas simulações apresentadas por Yang e Chen (2011), para a primeira fase de extração de características, foram utilizadas duas representações locais. A primeira, Piecewise Local Statistics (PLS) (Yang e Chen, 2007) divide a série em vários blocos. Para cada um, as estatísticas de primeira e segunda ordem são usadas como características do segmento. Para o $n$-ésimo bloco, sua média $\mu_{n}$ e desvio $\sigma_{n}$ são computados de acordo com as Equações 2.8 e 2.9 , respectivamente, em que $|w|$ é o tamanho do bloco. 


$$
\begin{gathered}
\mu_{n}=\frac{1}{|w|} \sum_{t=1+(n-1)|w|}^{n|w|} x_{t} \\
\sigma_{n}=\sqrt{\frac{1}{|w|} \sum_{t=1+(n-1)|w|}^{n|w|}\left[x_{t}-\mu_{n}\right]^{2}}
\end{gathered}
$$

A segunda representação local utilizada é a Piecewise Discrete Wavelet Transform (PDWT) (Yang e Chen, 2007), usada para decompor cada segmento utilizando filtros de passa-alta e passa-baixa. No nível $j$, filtros passa-alta $\Psi_{H}^{j}$ codificam as informações detalhadas, enquanto os filtros passa-baixa $\Psi_{L}^{j}$ caracterizam informações mais genéricas. Para o $n$-ésimo segmento, uma análise multiescala de $J$ níveis leva à representação indicada pela Equação 2.10.

$$
\left\{x_{t}\right\}_{t=1+(n-1)|w|}^{n|w|} \Rightarrow\left\{\Psi_{L}^{J},\left\{\Psi_{H}^{j}\right\}_{j=1}^{J}\right\}
$$

Os autores utilizam ainda a técnica de mapeamento não linear de Sammon (1969) para redução de dimensionalidade, pois o número de coeficientes gerado pela decomposição Wavelet é igual ao tamanho da janela $w$.

Para as representações globais, os autores também empregaram duas técnicas. A primeira, Polynomial Curve Fitting (PCF) (Chen e Chang, 1999) realiza o ajuste da série a uma função polinomial paramétrica, conforme a Equação 2.11, na qual $\alpha_{r}$ com $r=(0,1, \ldots, R)$, são os coeficientes de um polinômio de ordem $R$. O ajuste é feito utilizando um critério de erro baseado em mínimos quadrados. Os coeficientes obtidos por meio da técnica de otimização constituem a representação PCF.

$$
x_{t}=\alpha_{R} t^{R}+\alpha_{R-1} t^{R-1}+\ldots+\alpha_{1} t+\alpha_{0}
$$

A segunda técnica utilizada para representação global é a Transformada Discreta de Fourier (DFT) (Fourier, 1888). Ela permite transformar as séries para o domínio das frequências, fornecendo informações interessantes que não são evidentes no domínio do tempo. A transformada de uma série $\left\{x_{t}\right\}_{t=1}^{T}$ gera o conjunto de coeficientes indicados na Equação 2.12, em que $i=\sqrt{-1}$. Somente os primeiros $f$ coeficientes são retidos (com $f$ muito menor que o número total de $T$ coeficientes), a fim de desconsiderar informações ruidosas, e selecionando somente as frequências mais baixas do sinal.

$$
A_{f}=\frac{1}{T} \sum_{t=1}^{T} x_{t} \cdot e^{\frac{-2 \pi i f t}{T}}, f=0,1, \ldots, T-1
$$

Durante a segunda fase do algoritmo, vários agrupadores são aplicados sobre cada uma das representações para gerar várias partições. É importante notar que, na proposta de Yang e Chen (2011), cada representação dá origem a uma ou mais partições distintas, porém não é feita uma união das diversas representações como entrada consolidada para 
um algoritmo.

$\mathrm{Na}$ terceira fase, as partições geradas a partir das várias representações são consolidadas em uma partição final. Para isso, uma função de consenso, ponderada por três critérios de validação de agrupamento, estima a contribuição de cada partição.

Seja $X=\left\{X_{n}\right\}_{n=1}^{N}$ um conjunto de dados com $N$ objetos e $M$ partições $P=\left\{P_{m}\right\}_{m=1}^{M}$ de $X$, nas quais o número de grupos pode diferir. O sistema de ponderação de partições atribui um peso $w_{m}^{\pi}$ a cada $P_{m}$ com base no critério de validação $\pi$, conforme a Equação 2.13, em que $w_{m}^{\pi}>0, \sum_{m=1}^{M} w_{m}^{\pi}=1$ e $\pi\left(P_{m}\right)$ é o valor retornado pelo índice do critério $\pi$.

$$
w_{m}^{\pi}=\frac{\pi\left(P_{m}\right)}{\sum_{m=1}^{M} \pi\left(P_{m}\right)}
$$

Nas simulações realizadas pelos autores, três critérios de validação foram selecionados: o Índice $\Gamma$ de Hubert Modificado (МHГ) (Halkidi et al., 2001), o Índice de Dunn (DVI) (Halkidi et al., 2001) e a Informação Mútua Normalizada (NMI) (Strehl e Ghosh, 2003). Assim, três vetores de pesos são obtidos, $w^{\mathrm{MH} \Gamma}, w^{\mathrm{DVI}}$ e $w^{\mathrm{NMI}}$.

A seguir, a matriz de similaridade $\Theta_{m}=\{0,1\}^{N \times N}$ para a partição $P_{m}$ é construída, de forma que o objeto na posição $(i, j)$ da matriz é 1 caso $i$ e $j$ estejam no mesmo grupo e 0 caso contrário. Finalmente, uma matriz de similaridade ponderada $\Theta^{\pi}$ é obtida, que considera todas as partições geradas, conforme a Equação 2.14. Em função das simulações dos autores terem empregado três vetores de pesos, baseados em três critérios de validação de agrupamento, também se obtém um conjunto de três matrizes de similaridade ponderadas: $\Theta^{\mathrm{MH \Gamma}}, \Theta^{\mathrm{DVI}}$ e $\Theta^{\mathrm{NMI}}$.

$$
\Theta^{\pi}=\sum_{m=1}^{M} w_{m}^{\pi} \Theta_{m}
$$

As três matrizes de similaridade ponderadas são então submetidas ao algoritmo hierárquico DSPA (Dendrogram-based Similarity Partitioning Algorithm) proposto pelos autores em outro trabalho (Yang e Chen, 2007), o qual gera três partições de consenso candidatas $P^{\pi}, \pi=\{\mathrm{MH}$,DVI,NMI $\}$.

Finalmente, a terceira e última fase do algoritmo é executada, a qual computa a partição final a partir das três partições candidatas geradas ao fim da segunda fase. Para realizar essa consolidação, o algoritmo cria três matrizes binárias $H^{\pi}$ a partir das partições $P^{\pi}$, em que as linhas contêm os dados e as colunas os grupos. O elemento $(i, j)$ corresponde a 1 caso a série $i$ pertença ao grupo $j$ e 0 caso contrário.

Concatenando as três matrizes binárias $H^{\pi}$, obtém-se uma matriz de adjacência consistindo dos dados versus as partições de consenso candidatas, $H=\left[H^{\mathrm{MH \Gamma}}\left|H^{\mathrm{DVI}}\right| H^{\mathrm{NMI}}\right]$. A matriz de similaridade $\bar{\Theta}$ é então obtida de acordo com a Equação 2.15 .

$$
\bar{\Theta}=\frac{1}{3} H H^{T}
$$

Finalmente, a matriz $\bar{\Theta}$ é fornecida como entrada para o algoritmo DSPA (Yang e 
Chen, 2007) e a partição de consenso final $\bar{P}$ é obtida. O método completo, descrito em detalhes nesta seção, é listado no Algoritmo 5.

Como WCE depende de quais algoritmos são utilizados para compor o ensemble da segunda fase, não é possível atribuir-lhe uma complexidade de tempo. Porém, observa-se que o custo do algoritmo não é trivial, pois além da execução de vários algoritmos de agrupamento, também existem execuções intermediárias de DSPA (Yang e Chen, 2007) sobre as matrizes ponderadas de similaridade e a matriz final $\bar{\Theta}$, o que aumenta o custo do método.

Apesar das limitações de custo, o trabalho apresenta uma ideia interessante, a do emprego de várias representações de séries temporais para sua melhor caracterização e, consequentemente, agrupamento. Essa ideia também é explorada neste trabalho de doutorado.

As principais diferenças entre este trabalho de doutorado e o de Yang e Chen (2011) consistem em que o método proposto por Yang e Chen (2011) utiliza apenas quatro representações: PLS, PDWT, PCF e DFT, enquanto este trabalho explorou diversas outras, a partir de um estudo que avaliou a contribuição de cada medida descritiva para a caracterização de séries (ver Capítulos 3 e 4). Para o cenário de fluxos contínuos, Yang e Chen (2011) utilizaram o algoritmo ODAC (Rodrigues et al., 2008) para composição do ensemble, o que torna o método restrito às mesmas limitações apresentadas por ODAC, previamente discutidas na Seção 2.3. Outra diferença importante reside no fato de Yang e Chen (2011) não terem explorado a consolidação das diferentes representações em um único conjunto, permitindo ao algoritmo de agrupamento ter acesso ao mesmo tempo a uma visão local e global dos dados. No método proposto pelos autores, cada partição foi gerada separadamente sobre uma representação específica, para só posteriormente serem consolidadas em uma partição final por meio da ponderação com critérios de validação de agrupamento.

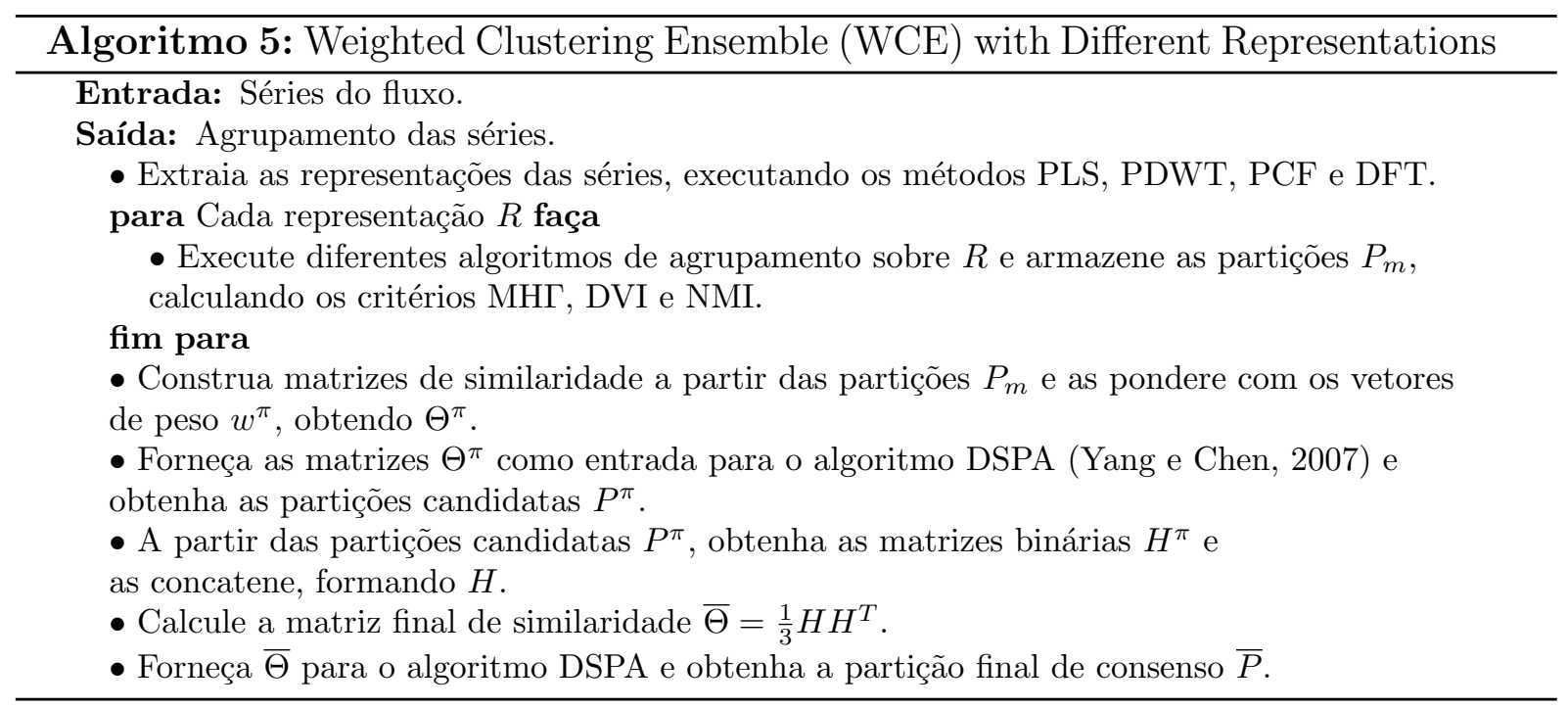


Tabela 2.1: Comparativo dos algoritmos apresentados neste capítulo com relação à cobertura de modelos de representação de séries temporais, conforme a taxonomia proposta por Ishii et al. (2011). A classe ELE refere-se a séries Estocásticas, Lineares, Estacionárias, enquanto ENE refere-se a séries Estocásticas, Não Lineares, Estacionárias.

\begin{tabular}{llll}
\hline \multicolumn{1}{c}{ Algoritmo } & \multicolumn{1}{c}{ Referência } & \multicolumn{1}{c}{ Medidas utilizadas } & Classes cobertas \\
\hline K-Means Incremental & Beringer e Hüllermeier (2006) & DFT & ELE \\
ODAC & Rodrigues et al. (2008) & Pearson & ELE \\
POD-Clus & Chaovalit (2009) & $\mu, \sigma$, regressão & ELE \\
ECM & Widiputra et al. (2011) & Pearson & ELE \\
WCE & Yang e Chen (2011) & PLS, PDWT, PCF, DFT & ELE, ENE \\
\hline
\end{tabular}

\subsection{Considerações Finais}

Neste capítulo foram apresentados diversos algoritmos propostos na literatura para o agrupamento de séries temporais em fluxos contínuos de dados. Pode-se observar que a maioria das técnicas baseia-se no uso de modelos lineares ou na correlação de Pearson para compor uma medida de dissimilaridade. Essas opções apresentam limitações quando o fluxo de dados contém séries com comportamento determinístico complexo ou não linear e não estacionário, os quais não são bem representados por modelos lineares simples.

A Tabela 2.1 apresenta, para cada algoritmo discutido neste capítulo, quais as medidas utilizadas para caracterizar séries temporais. É possível observar que prevalece o uso da correlação de Pearson e de modelos lineares. Isso faz com que essas técnicas sejam capazes de representar adequadamente, e consequentemente agrupar, somente séries que seguem a classe Estocástica, Linear, Estacionária (ELE), segundo a taxonomia de Ishii et al. (2011). A única exceção é o algoritmo WCE, que permite a modelagem também da classe Estocástica, Não Linear, Estacionária em função do mesmo usar múltiplas medidas de caracterização, inclusive com o ajuste de polinômios de ordem arbitrária (PCF).

A proposta de Yang e Chen (2011) traz características comuns às desta tese de doutorado, como o uso de diversas representações para caracterizar séries temporais. As principais diferenças se dão na escolha das medidas usadas para representação e em como elas são fornecidas para o algoritmo de agrupamento. Além disso, Yang e Chen (2011) exploram o uso de ensembles para realizar o agrupamento, fornecendo como entrada para diferentes algoritmos as diferentes representações extraídas das séries. Enquanto essas operações não apresentam necessariamente um alto custo no cenário batch, podem ser custosas no cenário de fluxos, já que a combinação da execução de vários algoritmos para várias representações e a conciliação das partições geradas podem, quando acumuladas, tornarem-se custosas em termos de tempo.

Em função das limitações encontradas nas propostas atuais para agrupamento de séries temporais, este trabalho de doutorado investigou o uso de diversas medidas descritivas para uma melhor caracterização de modelos geradores, incluindo comportamento não determinístico, não linear e não estacionário. 


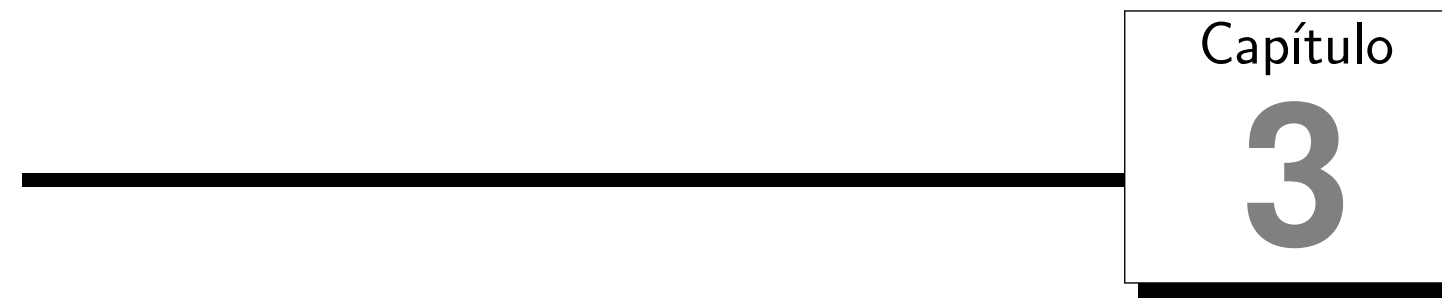

\section{Medidas descritivas de séries temporais}

\subsection{Considerações iniciais}

Conforme a revisão da literatura apresentada no capítulo anterior, observou-se que as técnicas atuais de agrupamento de séries temporais não consideram diversas propriedades do modelo gerador, tais como estocasticidade, linearidade e estacionariedade. Isso faz com que a caracterização das séries seja limitada, consequentemente prejudicando o resultado do agrupamento. Neste capítulo, são apresentadas as diversas medidas descritivas consideradas neste trabalho de doutorado para melhor caracterizar séries temporais.

\subsection{Medidas descritivas de séries temporais}

De acordo com a taxonomia de classes de séries temporais proposta por Ishii et al. (2011), apresentada no Capítulo 1, é possível listar propriedades básicas que caracterizam o modelo gerador de uma série: estocasticidade, linearidade e estacionariedade. Essas propriedades resultam na árvore apresentada na Figura 3.1, que permite identificar cinco classes de séries temporais: 1) Determinística; 2) Estocástica Linear Estacionária; 3 ) Estocástica Linear Não Estacionária; 4) Estocástica Não Linear Estacionária e 5) Estocástica Não Linear Não Estacionária. Para que seja possível caracterizar adequadamente o modelo gerador de uma série é importante que todas essas características sejam observadas.

Nesse sentido, diversas medidas descritivas de séries temporais foram escolhidas para avaliação, tais como medidas de Análise de Quantificação de Recorrência (RQA), Expoente de Lyapunov, Expoente de Hurst, Detrended Fluctuation Analysis, Transformada de Fourier, Transformada Discreta de Cossenos (DCT), Transformada Wavelet, Empirical Mode Decomposition, Modelos Box-Jenkins, Autocorrelação e Autoinformação Mútua, 
todas descritas a seguir.

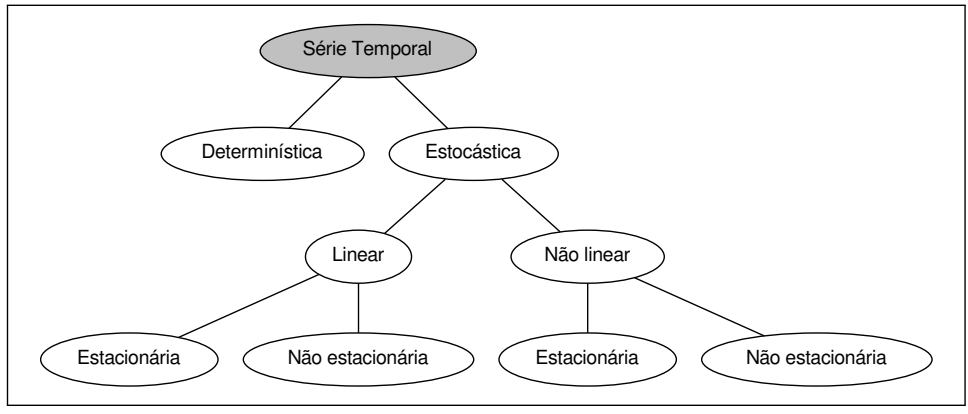

Figura 3.1: Taxonomia de séries temporais proposta por Ishii et al. (2011). Ela identifica as possíveis combinações de características básicas de séries temporais: estocasticidade, linearidade e estacionariedade.

\subsubsection{Medidas de Análise de Quantificação de Recorrência}

O primeiro conjunto de medidas utilizadas neste trabalho baseia-se na área de Análise de Quantificação de Recorrência (RQA) (Marwan et al., 2007; Marwan, 2008) e auxilia principalmente na determinação do nível de estocasticidade de uma série. Essas medidas utilizam como insumo a saída da técnica de Recurrence Plot (RP) (Eckmann et al., 1987), a qual permite a visualização de recorrências de um sistema dinâmico.

Seja $\left\{\vec{x}_{i}\right\}_{i=1}^{N}$ a trajetória de uma série com $N$ estados no espaço fase. Conforme explicado no Capítulo 1, pelo teorema de Takens (1981) é possível reconstruir uma série temporal no espaço fase, ou seja, um espaço Euclidiano com $m$ dimensões, sendo cada uma separada por $\tau$ unidades de tempo ${ }^{1}$. O RP da série baseia-se na matriz de recorrência definida na Equação 3.1, na qual $N$ é o número de estados no espaço fase e o símbolo $\approx$ significa igualdade dado um limiar $\epsilon$. Intuitivamente, a matriz de recorrência compara a proximidade de estados da série em instantes $i$ e $j$, e caso eles estejam em uma vizinhança$\epsilon$, então 1 é colocado na posição $(i, j)$ da matriz. Caso eles não sejam $\epsilon$-vizinhos, então 0 é colocado na posição $(i, j)$. Assim, a matriz indica instantes em que estados vizinhos da série são visitados.

$$
\mathbf{R}_{i, j}=\left\{\begin{array}{ll}
1: & \overrightarrow{x_{i}} \approx \overrightarrow{x_{j}}, \\
0: & \overrightarrow{x_{i}} \not \overrightarrow{x_{j}},
\end{array} \quad i, j,=1, \ldots, N .\right.
$$

O RP é definido de acordo com a Equação 3.2, na qual $N$ e $\epsilon$ foram previamente descritos, $\Theta(\cdot)$ é uma função degrau (Abramowitz, 1974) e \| · || é uma norma, geralmente a $L_{2}$ (distância Euclidiana). A matriz resultante pode ser plotada com pontos brancos nos elementos iguais a zero e pontos pretos nos elementos iguais a um. Trata-se de uma matriz simétrica, assim $\mathbf{R}_{i, j}=\mathbf{R}_{j, i}$. Além disso, sua diagonal é igual a um, já que representa a similaridade entre estados em um mesmo instante.

\footnotetext{
${ }^{1}$ Para estimar a dimensão de separação $\tau$, Fraser e Swinney (1986) sugerem tomar o primeiro mínimo local encontrado no gráfico de $\tau$ versus a Autoinformação Mútua da série. Já a dimensão embutida $m$ pode ser estimada utilizando a técnica de Falsos Vizinhos mais Próximos proposta por Kennel et al. (1992), selecionando o valor que fornece a menor fração de falsos vizinhos.
} 


$$
\mathbf{R}_{i, j}(\epsilon)=\Theta\left(\epsilon-\left\|\overrightarrow{x_{i}}-\overrightarrow{x_{j}}\right\|\right), \quad i, j=1, \ldots, N .
$$

Considere a série puramente determinística $S_{1}=\operatorname{sen}(0,6 \cdot \pi t)-2 \cos (8 / 3 \pi t)$, ilustrada na Figura 3.2a, e a série puramente estocástica $S_{2}$, oriunda de uma distribuição Normal com média 0 e variância 1: $\mathcal{N}(0,1)$, ilustrada na Figura 3.2b. Ao fornecê-las como entrada para a técnica de Recurrence Plot, obtém-se os gráficos das Figuras 3.3 e 3.4, respectivamente. É possível observar que, para a série determinística $S_{1}$, existem várias estruturas formadas por linhas diagonais, um indicativo do determinismo da série. Já para a série puramente estocástica $S_{2}$, não existe estrutura no Recurrence Plot, visto que cada estado é determinado de forma independente e estocástica.

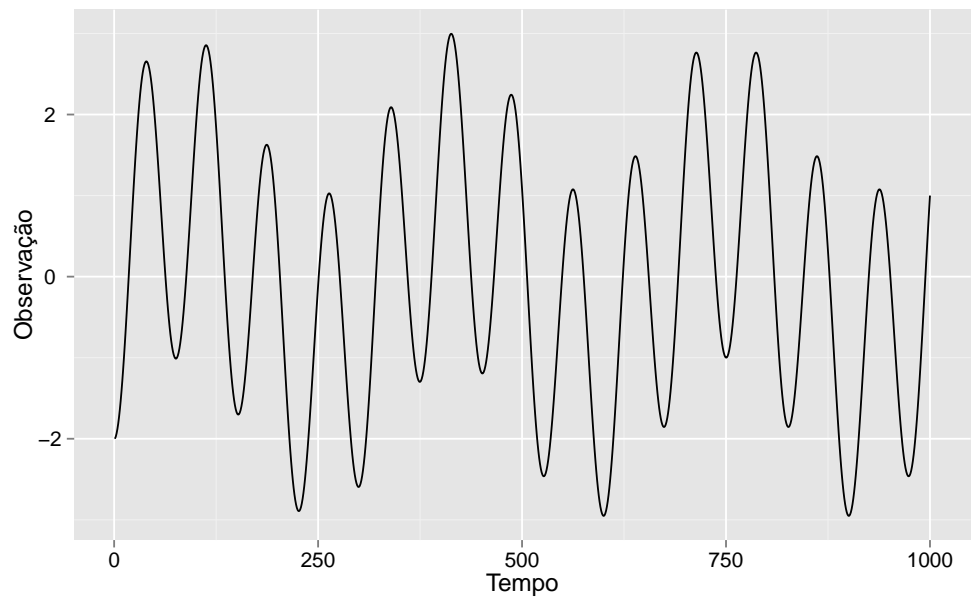

(a) Série determinística $S_{1}=\operatorname{sen}(0,6 \cdot \pi t)-2 \cos (8 / 3 \pi t)$

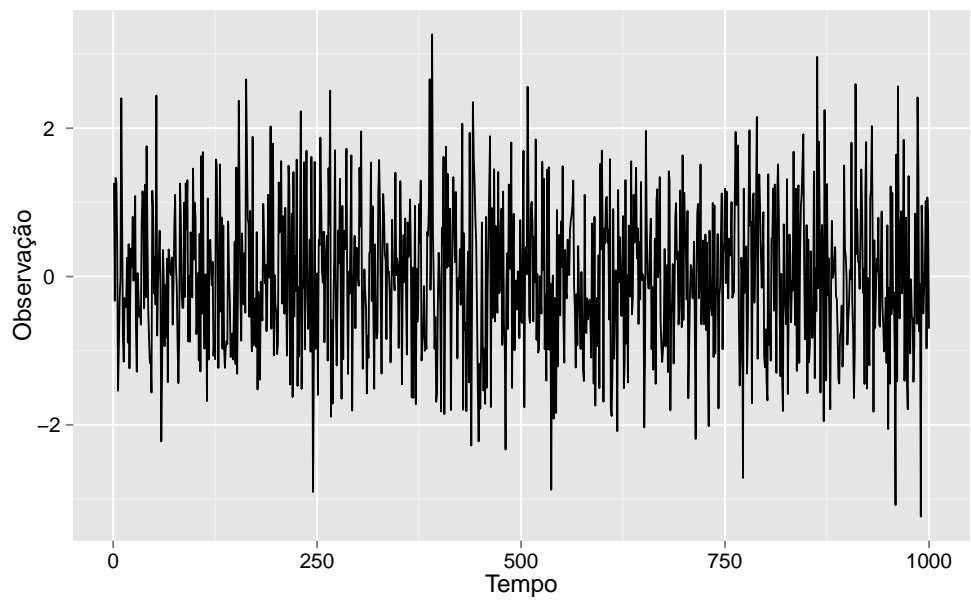

(b) Série estocástica $S_{2} \sim \mathcal{N}(0,1)$.

Figura 3.2: Séries utilizadas para ilustrar a técnica de Recurrence Plot.

Várias medidas podem ser calculadas usando como entrada o Recurrence Plot, as quais formam a área de Análise de Quantificação de Recorrência (RQA) (Marwan et al., 2007). Por exemplo, uma linha diagonal ocorre quando um segmento da trajetória no espaço fase é quase paralelo a outro durante $l$ unidades de tempo, conforme definido na Equação 3.3. A formulação especifica que a trajetória precisa começar e terminar em estados diferentes, 


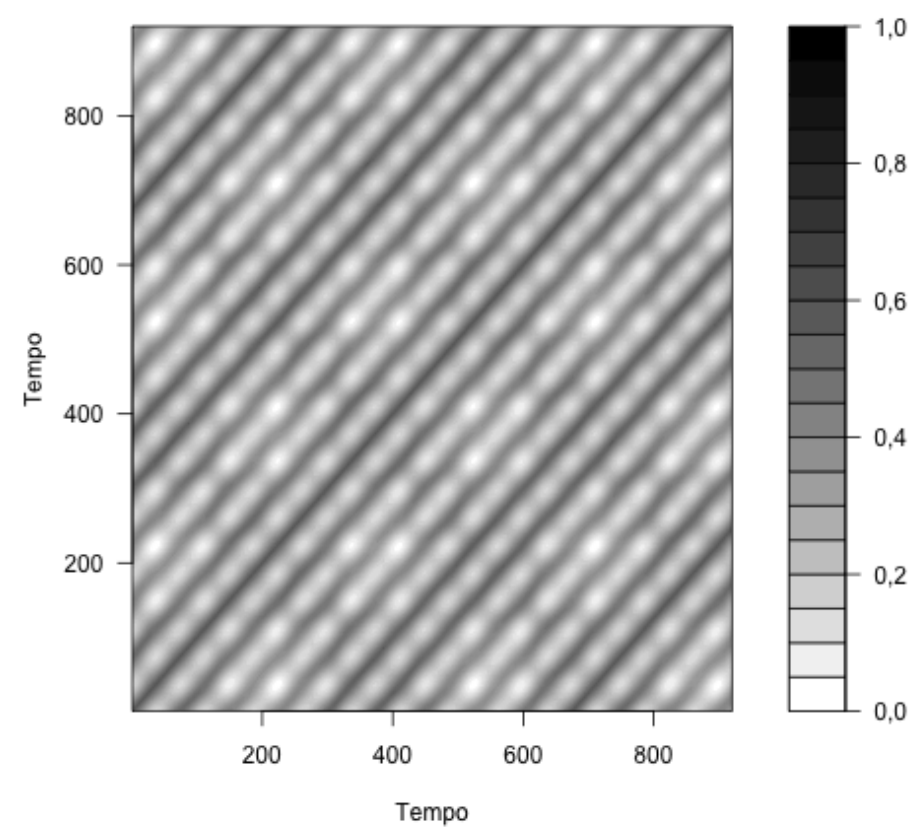

Figura 3.3: Recurrence Plot para a série determinística $S_{1}$ da Figura 3.2a. Neste gráfico, ao invés de usar a função degrau para formar a matriz de recorrência, foi utilizada uma matriz de similaridade, a qual é dada por 1 - dist Euclidiana. É possível observar que, na diagonal principal, todos os pontos são pretos, já que representam a similaridade entre estados no mesmo instante de tempo. Neste Recurrence Plot observa-se também a formação de várias estruturas diagonais, indicativas do determinismo presente na série $S_{1}$. Para a reconstrução no espaço fase deste RP foi utilizada dimensão embutida $m=5$ e de separação $\tau=20$.

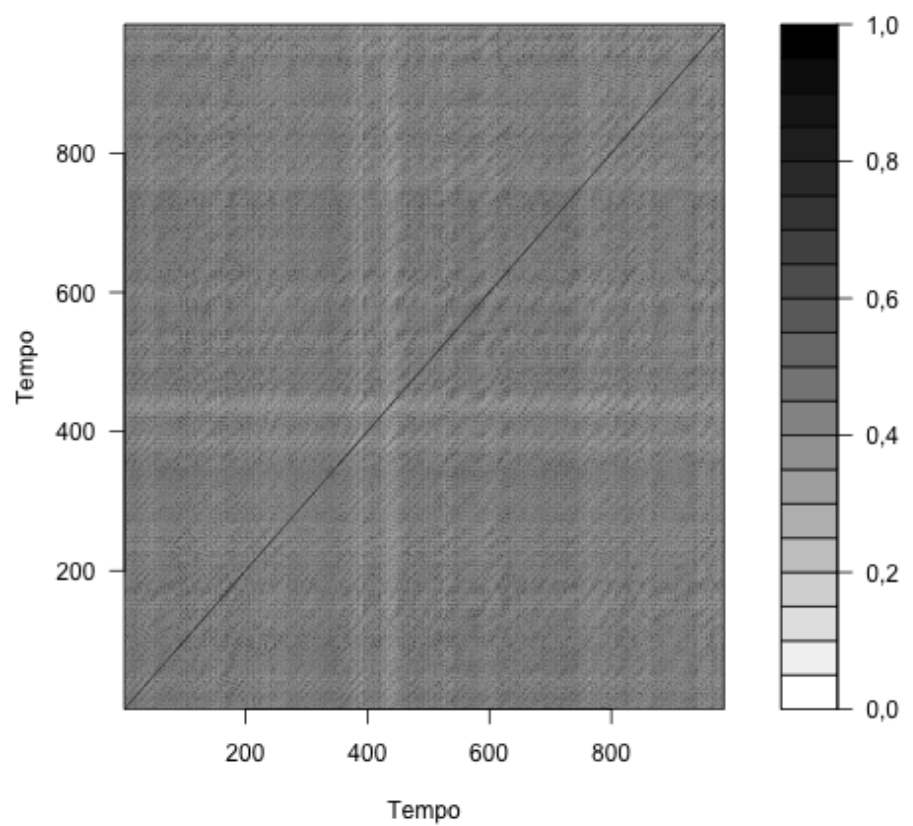

Figura 3.4: Recurrence Plot para a série estocástica $S_{2}$ da Figura 3.2b. Neste caso não se observam estruturas diagonais, o que indica a ausência de determinismo na série $S_{2}$, conforme esperado, já que a série é composta por observações independentes e determinadas de forma estocástica, seguindo uma distribuição Normal. Para a reconstrução no espaço fase deste RP foi utilizada dimensão embutida $m=4$ e de separação $\tau=5$. 
mas durante $l$ unidades de tempo deve estar contida em uma $\epsilon$-vizinhança. Da mesma maneira, existem definições para linhas verticais e horizontais.

$$
\left(1-\mathbf{R}_{i-1, j-1}\right)\left(1-\mathbf{R}_{i+l, j+l}\right) \prod_{k=0}^{l-1} \mathbf{R}_{i+k, j+k} \equiv 1
$$

Utilizando propriedades quantitativas básicas de RPs, como o comprimento médio de linhas diagonais, definições mais elaboradas podem ser feitas, levando a medidas muito úteis (Marwan, 2008). Uma delas é chamada Determinismo (DET), a qual indica o nível de previsibilidade do sistema, sendo útil para diferenciar séries temporais determinísticas de estocásticas. O Determinismo é dado pela porcentagem de pontos de recorrência que formam linhas diagonais com comprimento de pelo menos $l$ unidades, conforme a Equação 3.4. O termo $P(\epsilon, l)$ indica a probabilidade de ocorrência de uma linha diagonal de tamanho $l$, o que é calculado para uma $\epsilon$-vizinhança de acordo com a Equação 3.5.

$$
\begin{gathered}
D E T=\frac{\sum_{l=l_{\min }}^{N} l P(\epsilon, l)}{\sum_{l=1}^{N} l P(\epsilon, l)} \\
P(\epsilon, l)=\sum_{i, j=1}^{N}\left(1-\mathbf{R}_{i-1, j-1}(\epsilon)\right)\left(1-\mathbf{R}_{i+l, j+l}(\epsilon)\right) \prod_{k=0}^{l-1} \mathbf{R}_{i+k, j+k}(\epsilon)
\end{gathered}
$$

Sistemas com comportamento estocástico ou não correlacionado apresentam poucas diagonais no Recurrence Plot, enquanto sistemas determinísticos tendem a apresentar longas diagonais (Marwan et al., 2007). Assim, o valor de DET pode ajudar a determinar se o sistema tem majoritariamente um componente estocástico ou determinístico. Várias outras medidas também foram definidas na área de RQA, como a Divergência (DIV), que é o inverso do comprimento da maior diagonal no RP. Uma discussão completa de todas as medidas pode ser encontrada em Marwan et al. (2007).

\subsubsection{Expoente de Lyapunov}

Enquanto o Recurrence Plot analisa como a trajetória de um sistema é recorrente no espaço fase (ver Seção 1.1), o expoente de Lyapunov (Sandri, 1996) é uma medida de divergência de trajetórias que iniciam a partir de pontos próximos. O expoente pode ser usado para avaliar a sensibilidade a condições iniciais ${ }^{2}$ ou a presença de atratores caóticos ${ }^{3}$.

Considere duas trajetórias infinitesimalmente próximas no espaço fase com uma separação inicial $\Delta s_{0} \rightarrow 0$. O expoente de Lyapunov $\lambda$ é dado pela Equação 3.6 (Elert, 1995), em que $t$ é o instante de tempo e $\Delta s\left(s_{0}, t\right)$ é uma separação que depende da condição inicial e do tempo.

\footnotetext{
${ }^{2}$ Como pequenas variações na condição inicial do sistema, por exemplo, o valor de $s_{0}$ para uma série mapa logístico, influenciam seu comportamento.

${ }^{3} \mathrm{Um}$ atrator pode ser entendido como uma figura geométrica formada no espaço fase (ver Seção 1.1), que representa um determinado comportamento recorrente do sistema. Pontos próximos a um atrator tendem a continuar próximos mesmo com pequenas perturbações.
} 


$$
\lambda=\lim _{t \rightarrow \infty} \frac{1}{t} \ln \frac{\left|\Delta s\left(s_{0}, t\right)\right|}{\left|\Delta s_{0}\right|}
$$

A análise do sinal do expoente de Lyapunov fornece informações importantes sobre a trajetória do sistema (Elert, 1995). Quando $\lambda<0$, a trajetória é atraída a um ponto fixo estável ou a uma trajetória periódica estável, que caracteriza sistemas dissipativos ou não conservativos, como um oscilador harmônico amortecido. A Figura 3.5a ilustra a série temporal de um oscilador harmônico, juntamente com o valor de $\lambda$, o qual é negativo para a série, por se tratar de um sistema dissipativo. Para o caso em que $\lambda=0$, tem-se um sistema conservativo, e.g., uma senóide oscilando a frequência constante. A Figura 3.5b ilustra essa situação, com o valor de $\lambda$ muito próximo de zero. Finalmente, quando $\lambda>0$, a trajetória do sistema é instável ou caótica, na qual pontos próximos tenderão a divergir para uma separação arbitrária. A série da Figura 3.6, gerada segundo o modelo de Lorenz (1963) com uma parametrização tal que apresentasse características caóticas, possui um valor positivo para $\lambda$.

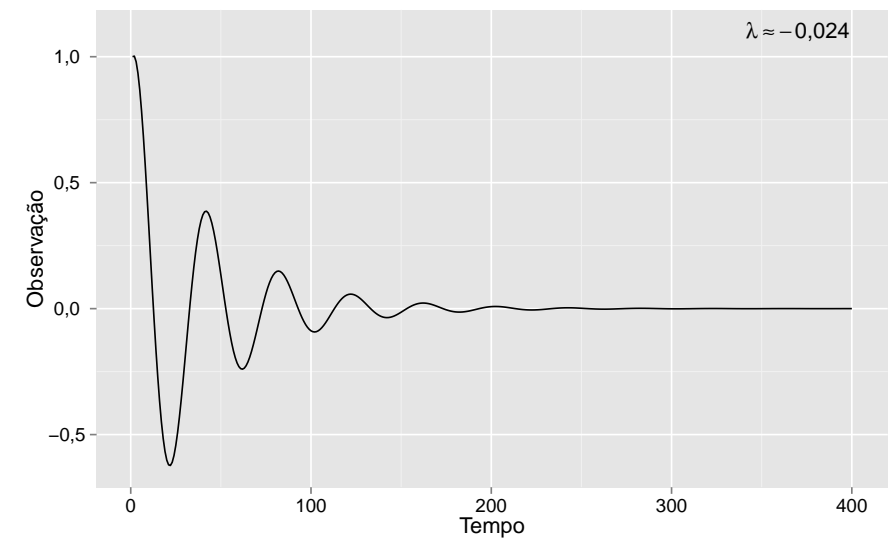

(a) Série temporal de um oscilador harmônico amortecido, o qual apresenta um valor negativo para o expoente de Lyapunov $\lambda$, caracterizando um sistema dissipativo. Apenas os primeiros 400 pontos são mostrados.

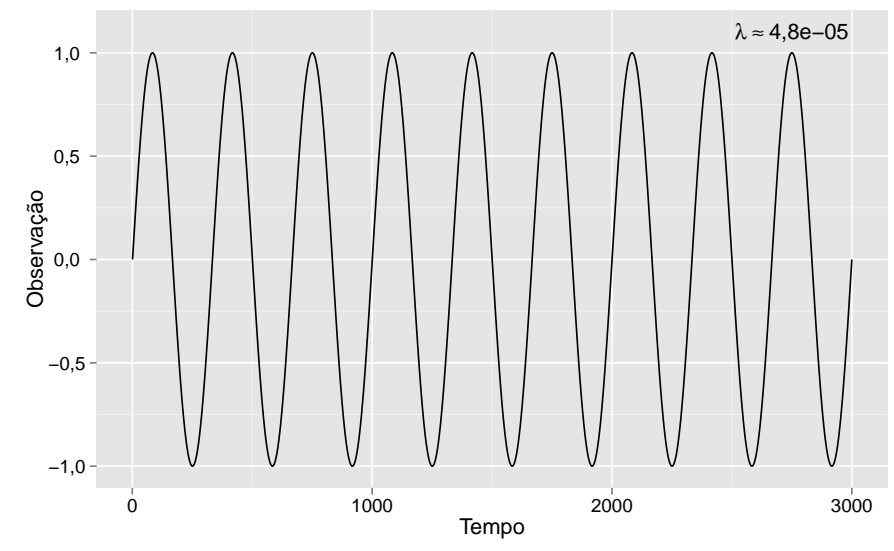

(b) Série temporal de uma senóide, a qual apresenta expoente de Lyapunov $\lambda \approx 0$, caracterizando um sistema conservativo.

Figura 3.5: Exemplos de séries com o valor do expoente de Lyapunov. 


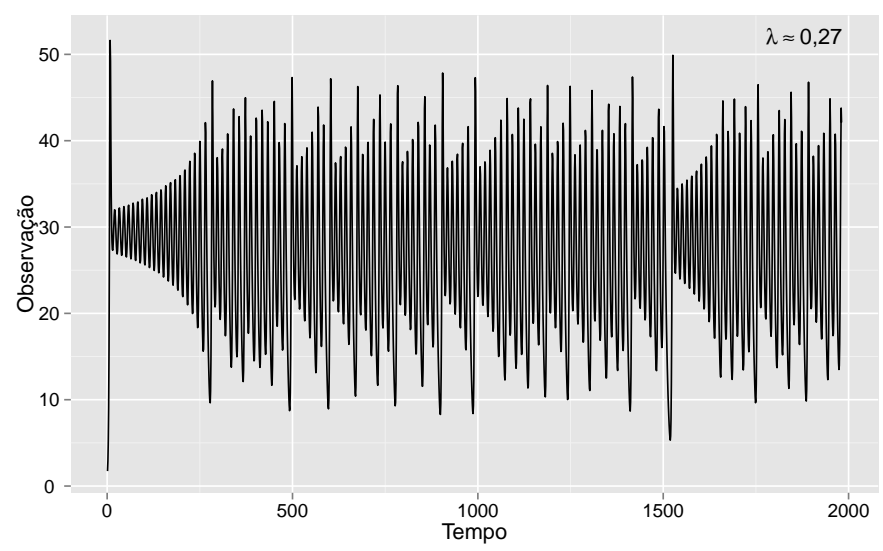

Figura 3.6: Série temporal de Lorenz, a qual apresenta expoente de Lyapunov positivo, caracterizando um sistema caótico.

\subsubsection{Expoente de Hurst}

Outra ferramenta útil para caracterizar uma série temporal é o expoente de Hurst (Kantz e Schreiber, 1997), que mede a aleatoriedade dos dados e funciona tanto para séries lineares quanto não lineares. Existem diversas maneiras de calcular esse expoente, sendo uma delas denominada Rescaled Range. Esse método funciona de maneira iterativa e mede a razão do intervalo dos dados, em vários segmentos da série, sobre seu desvio padrão.

Dada uma série $S_{x}=\left(S_{x 1}, S_{x 2}, \ldots, S_{x n}\right)$, a técnica de Rescaled Range inicia calculando a média da série $m=\frac{1}{n} \sum_{i=1}^{n} s_{x i}$ (Qian e Rasheed, 2004). A seguir, cria-se uma série de valores ajustados de acordo com a média: $y_{t}=s_{x t}-m, \quad t=1,2, \ldots, n$. Calcula-se então a série cumulativa de desvios: $z_{t}=\sum_{i=1}^{t} y_{i}, \quad t=1,2, \ldots, n$. O próximo passo consiste em criar a série de intervalos (ranges): $r_{t}=\max \left(z_{1}, z_{2}, \ldots, z_{t}\right)-\min \left(z_{1}, z_{2}, \ldots, z_{t}\right), \quad t=$ $1,2, \ldots n$. Computa-se a seguir a série de desvios $d_{t}=\sqrt{\frac{1}{t} \sum_{i=1}^{t}\left(s_{x i}-u\right)^{2}}, \quad t=1,2, \ldots, n$, em que $u=\frac{1}{t} \sum_{i=1}^{t} s_{x i}$. Finalmente, a série de rescaled ranges é calculada da seguinte forma: $(r / d)_{t}=\frac{r_{t}}{d_{t}}, \quad t=1,2, \ldots, n$.

Para estimar o expoente, plota-se o gráfico do logaritmo de $t$ versus o logaritmo da série $(r / d)_{t}$. A seguir, realiza-se uma regressão linear, sendo o expoente de Hurst o coeficiente angular da reta encontrada.

$\mathrm{O}$ valor do expoente de Hurst restringe-se ao intervalo $H \in[0,1]$. Um valor próximo de 1 indica que existe correlação positiva entre observações passadas e futuras da série. Valores próximos de 0 indicam que há correlação negativa, ou seja, se observações passadas decrescem, então observações futuras irão crescer, e vice-versa. Valores do expoente próximos a 0,5 indicam que a série foi produzida por um processo aleatório.

A Figura 3.7 ilustra uma senóide, a qual fornece um expoente próximo a 1, devido à sua periodicidade. Já a Figura 3.8 apresenta um sinal que alterna entre um valor alto e outro baixo, implicando em um expoente próximo a zero. Finalmente, a Figura 3.9 apresenta um sinal amostrado de uma distribuição Normal $(\mu=0, \sigma=1)$, a qual implica em independência e estocasticidade, produzindo um expoente próximo a 0,5. 


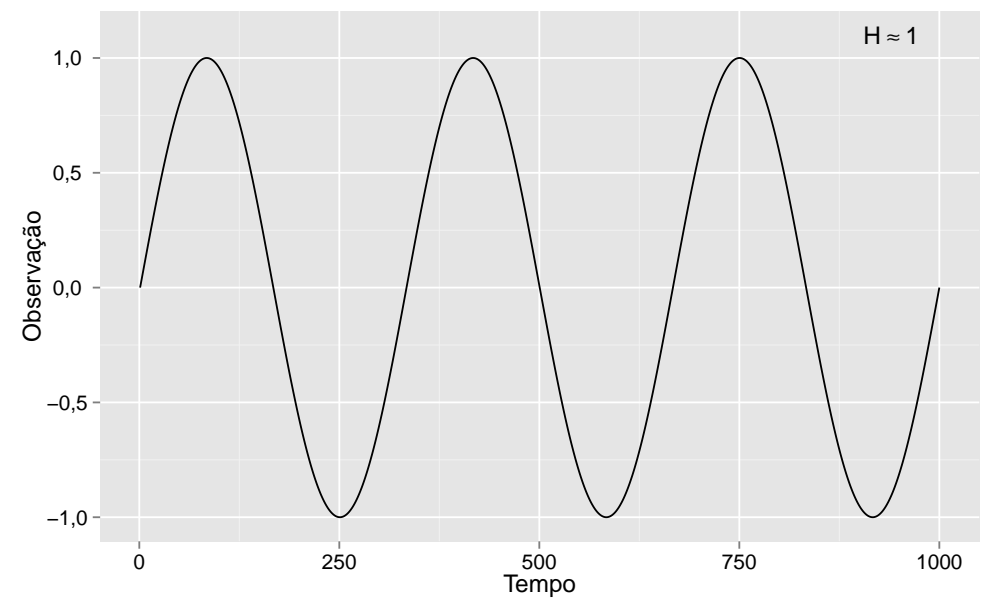

Figura 3.7: Série temporal com comportamento senoidal, que tem expoente de Hurst $H \approx 1$, caracterizando um sistema com correlação positiva.

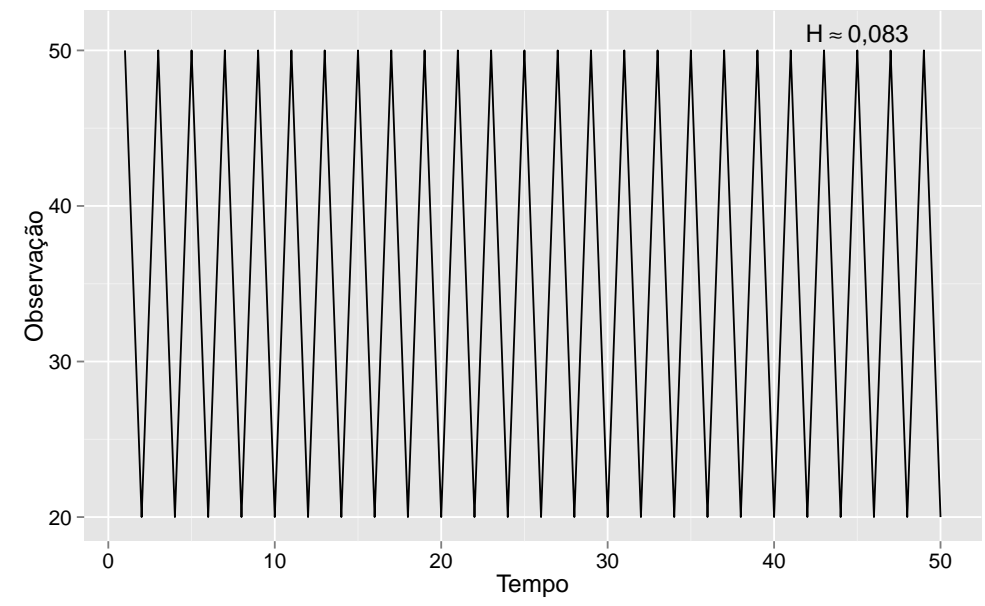

Figura 3.8: Série temporal de um sinal que alterna entre valores altos e baixos constantemente, a qual apresenta expoente de Hurst $H \approx 0$, caracterizando um sistema com correlação negativa. Apenas os primeiros 50 pontos são apresentados.

\subsubsection{Detrended Fluctuation Analysis}

Séries temporais reais geralmente apresentam tendências, as quais podem prejudicar o cálculo direto do expoente de Hurst (Kantz e Schreiber, 1997). Para superar essa limitação, a técnica Detrended Fluctuation Analysis (DFA) foi proposta por Peng et al. (1994), a qual leva em conta as tendências e retorna um expoente similar ao de Hurst. O método funciona integrando a série original $S_{x}$ para obter uma nova $S_{y}$ e então, iterativamente, a subdivide em janelas de tamanho $w$. Uma regressão linear é aplicada dentro das janelas para modelar tendências locais (Equação 3.7). A seguir, $F(w)$, a raiz quadrada do desvio médio (flutuação) é calculada para cada janela (Equação 3.8). O expoente $\alpha$ é então computado como o coeficiente angular da regressão do gráfico log-log de $w$ versus $F(w)$.

$$
\underset{a, b}{\operatorname{argmin}} E^{2}=\sum_{t=1}^{w}\left(S_{y t}-a t-b\right)^{2}
$$




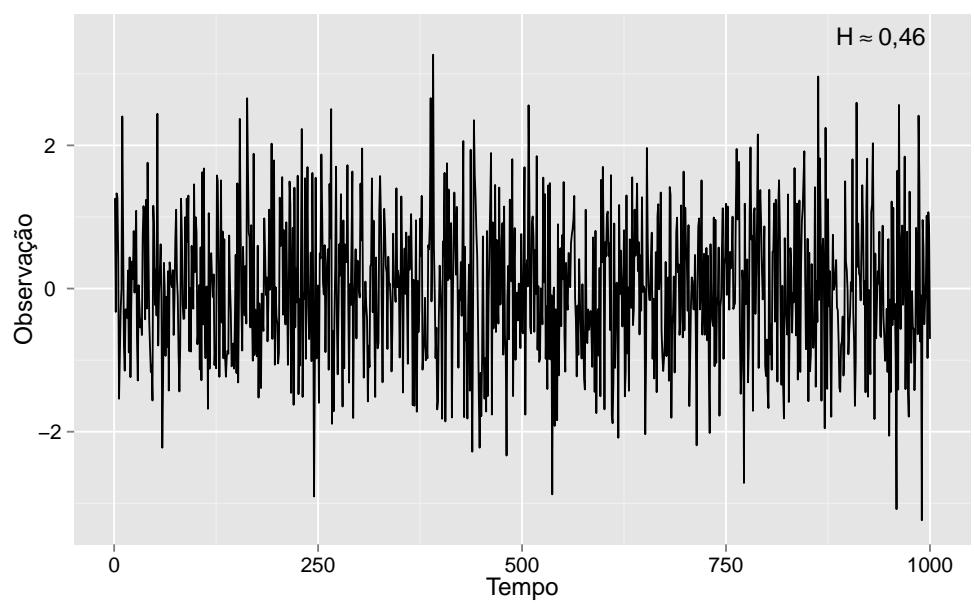

Figura 3.9: Série temporal gerada de acordo com uma Normal, a qual apresenta expoente de Hurst $H \approx 0,5$, caracterizando um sistema aleatório.

$$
F(w)=\left[\frac{1}{w} \sum_{t=1}^{w}\left(S_{y t}-a t-b\right)^{2}\right]^{\frac{1}{2}}
$$

De maneira similar ao expoente de Hurst, um valor próximo de 1 indica que existe correlação positiva entre observações passadas e futuras da série. Valores próximos de 0 indicam que há correlação negativa. Finalmente, valores próximos a 0,5 indicam que a série foi produzida por um processo aleatório.

\subsubsection{Transformada de Fourier}

Outra maneira de analisar séries temporais é no domínio das frequências, utilizando técnicas como a análise de Fourier e Wavelet. A transformada de Fourier (1888) permite a decomposição de uma série temporal em suas frequências fundamentais. A versão discreta ${ }^{4}$ da transformada recebe como entrada uma série $S_{k}, 0 \leq k \leq n-1$, sendo $n$ o número de observações, e fornece como saída uma nova série $Y_{\omega}$ de $n$ números complexos, sendo que cada um descreve uma função seno de dada frequência (Skiena, 1998).

A transformada é descrita pela Equação 3.9, em que $i$ é a unidade imaginária, $2 \pi$ refere-se à extensão em radianos do círculo de raio unitário, $n$ é o número de observações da série, $\omega$ varia de 0 a $n-1, k$ percorre os elementos da série no somatório e a função exponencial provém da fórmula de Euler (Feynman et al., 1965) $e^{i \omega}=\cos (\omega)+i \operatorname{sen}(\omega)$, que mapeia um $\omega$ real para o plano complexo utilizando o círculo unitário (Figura 3.10). $\mathrm{Na}$ análise de Fourier, sinais são descritos como combinações de senóides. Logo, a fórmula de Euler fornece uma representação interessante para isso.

$$
Y_{\omega}=\sum_{k=0}^{n-1} S_{k} e^{-\frac{2 \pi i k \omega}{n}}, \quad \omega=0, \ldots, n-1
$$

\footnotetext{
${ }^{4}$ Mais apropriada para a análise de séries temporais amostradas no tempo.
} 


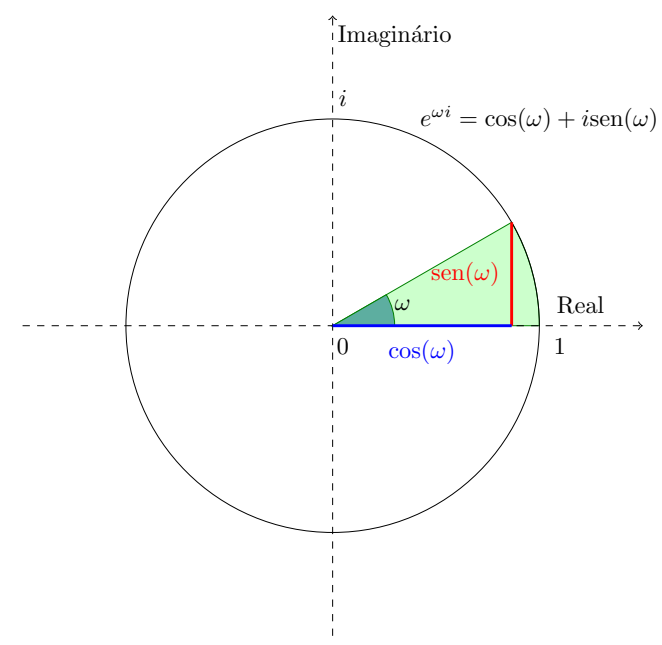

Figura 3.10: Plano complexo com o círculo unitário. A fórmula de Euler permite mapear um ângulo medido em radianos (valor real) para um ponto no plano complexo.

\subsubsection{Transformada discreta de cossenos}

Juntamente com a transformada discreta de Fourier (DFT), que especifica as séries em termos de senos e cossenos, existe também a transformada discreta de cossenos (DCT) (Ahmed et al., 1974), que tem o mesmo objetivo da DFT, porém expressa seus componentes somente em termos de funções cosseno. A transformada DCT é dada pela Equação 3.10, na qual $n$ é o número de pontos da série de entrada.

$$
Y_{\omega}=\sum_{k=0}^{n-1} S_{k} \cos \left[\frac{\pi}{n}\left(k+\frac{1}{2}\right) \omega\right], \omega=0, \ldots, N-1
$$

\subsubsection{Transformada Wavelet}

A análise com a transformada de Fourier fornece um meio intuitivo e útil para decompor um sinal em suas frequências fundamentais e compará-las às de outros sinais. Uma limitação da transformada de Fourier, entretanto, é que não há localização no tempo para as frequências. Isso significa que se deve considerar as frequências encontradas como presentes em todo o sinal, não sendo possível discriminar quais frequências ocorrem em intervalos específicos.

Para superar essa limitação e tornar possível a localização no tempo dos componentes de um sinal, a análise Wavelet (Daubechies, 1992) foi criada. Um dos primeiros desenvolvimentos foi a Wavelet de Haar (1910). Uma Wavelet pode ser entendida como uma onda que cresce e decai em um período limitado de tempo (Percival e Walden, 2006). Seja $\psi(\cdot)$ uma função real que satisfaz as propriedades das Equações 3.11 e 3.12.

$$
\begin{aligned}
& \int_{-\infty}^{\infty} \psi(u) d u=0 \\
& \int_{-\infty}^{\infty} \psi^{2}(u) d u=1
\end{aligned}
$$


A Equação 3.11 diz que $\psi(\cdot)$ deve ter suporte finito, ou seja, integrar para zero sobre toda a reta real. A Equação 3.12 diz que a energia da função deve integrar para a unidade. Se a Equação 3.12 for válida para $\psi(\cdot)$, então para qualquer $0<\epsilon<1$, deve existir um intervalo finito $[-T, T]$ na reta real tal que a Equação 3.13 é válida (Percival e Walden, 2006), ou seja, $\epsilon$ é a energia da função fora do suporte $[-T, T]$ (Figura 3.11). Caso $\epsilon \approx 0$, então $\psi(\cdot)$ só pode se desviar pouco de zero fora do intervalo $[-T, T]$. As Equações 3.11 e 3.12 levam então ao que se chama de "pequena onda", também conhecida por Wavelet.

$$
\int_{-T}^{T} \psi^{2}(u) d u>1-\epsilon
$$

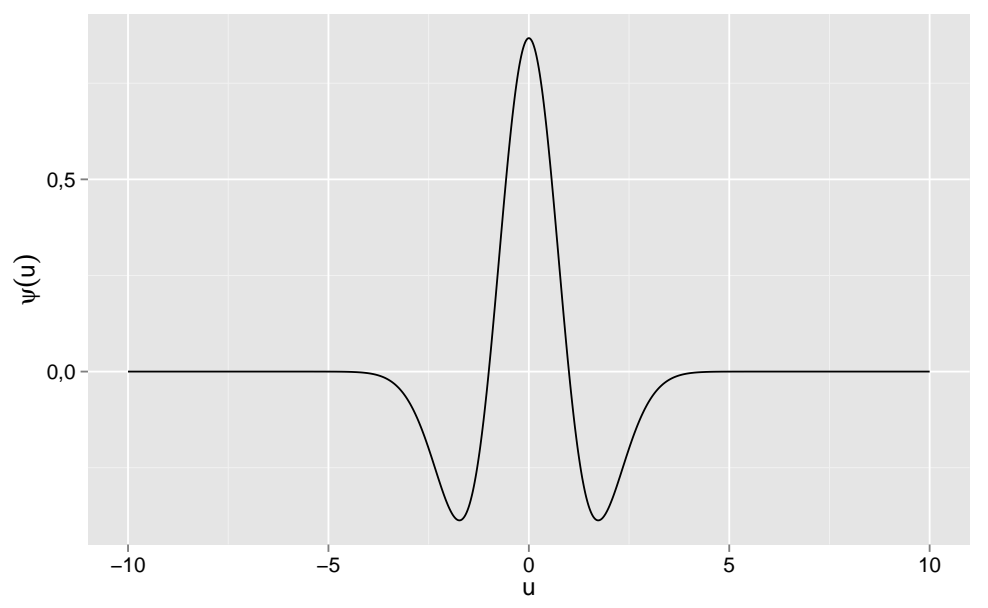

Figura 3.11: Wavelet $\psi(u)$ conhecida como "chapéu mexicano", que corresponde à derivada segunda da função Gaussiana. Nesse caso, o suporte $[-T, T]=[-5,5]$ define que fora dessa faixa a função não se desvia de zero, $\log \boldsymbol{\epsilon}=\int_{-\infty}^{5} \psi^{2}(u) d u+\int_{5}^{\infty} \psi^{2}(u) d u=0$, o que torna a energia da função no suporte $[-5,5]$ igual a $\int_{-5}^{5} \psi^{2}(u) d u=1$.

A análise Wavelet tem o importante benefício de ser localizada no tempo, ou seja, é possível distinguir quais componentes de um sinal estão presentes em segmentos específicos de tempo, ao contrário da análise de Fourier. A transformada contínua Wavelet (CWT) de um sinal contínuo $x(t)$ na escala $a$ e translação $b$ é dada pela Equação 3.14, na qual $\psi(\cdot)$ é a Wavelet $\mathrm{e} *$ é o conjugado complexo.

O parâmetro de translação (b) permite percorrer toda a extensão do sinal analisado modificando o suporte da Wavelet. O parâmetro de escala $(a)$ serve para controlar a granulosidade com que se deseja analisar o sinal. Quanto maior a escala, maior a extensão do sinal que é coberta, porém informações menos detalhadas são obtidas (baixas frequências). Por outro lado, quanto menor a escala, mais localizada é a análise, porém mais detalhes são obtidos (altas frequências). A Figura 3.12 apresenta algumas translações e escalas da Wavelet "chapéu mexicano", previamente apresentada na Figura 3.11.

Considere a série apresentada na Figura 3.13, a qual é composta pela frequência $3 \mathrm{~Hz}$ até o instante $1 s$ e $20 \mathrm{~Hz}$ após $t=1 s$. Nesse caso, as frequências são localizadas no tempo. A Figura 3.14 apresenta o periodograma ${ }^{5}$ obtido a partir da transformada de Fourier.

\footnotetext{
${ }^{5}$ Existem várias definições para o periodograma, porém ele pode ser visto como um gráfico de frequên-
} 

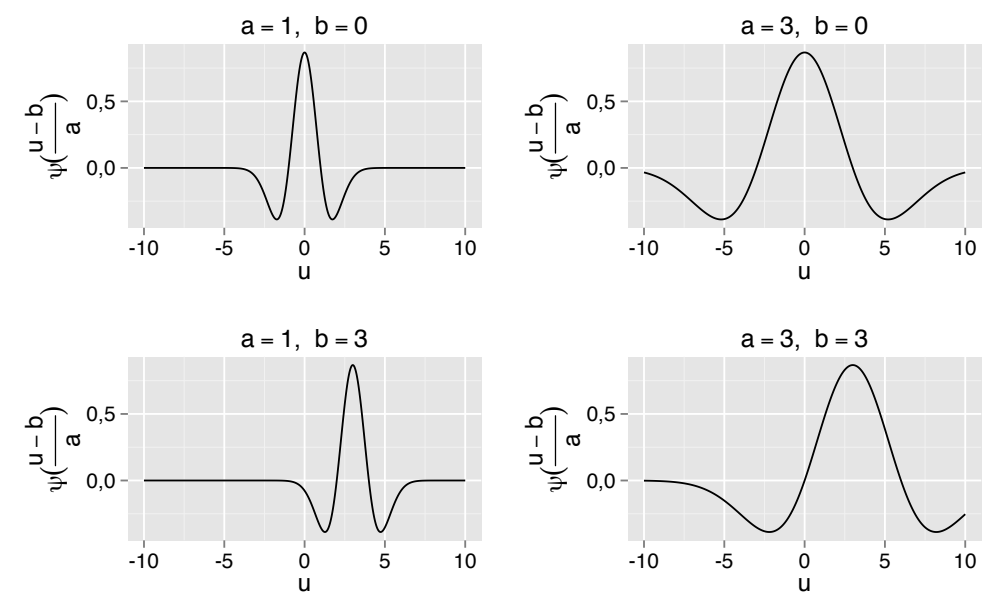

Figura 3.12: Exemplos de translações (parâmetro b) e escalas (parâmetro a) para a Wavelet "chapéu mexicano". Modificando o parâmetro b é possível alterar o suporte da Wavelet. O ajuste da escala permite modificar a extensão e, consequentemente, o nível de detalhe analisado do sinal.

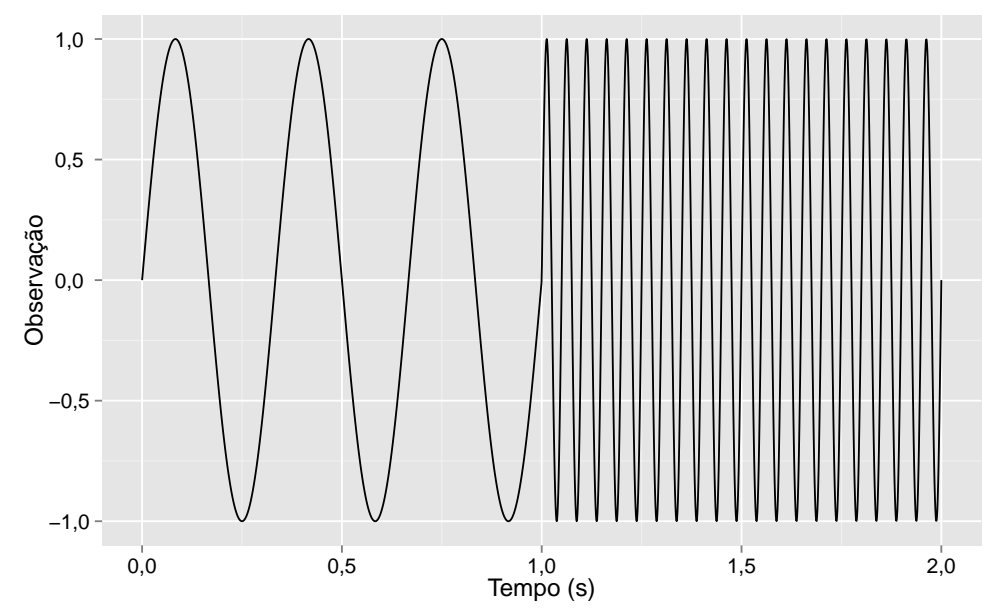

Figura 3.13: Série com duas frequências localizadas no tempo. Até o instante $t=1 \mathrm{~s}$, a série apresenta a frequência $3 \mathrm{~Hz}$ e, de $t=1 s$ a $t=2 s$, frequência $20 \mathrm{~Hz}$.

Apesar de ser possível encontrar as frequências presentes no sinal, não há como saber em que instantes de tempo elas ocorrem. Por outro lado, na Figura 3.15, que apresenta a transformada Wavelet contínua, é possível observar uma representação simultânea no tempo e frequência. Pode-se observar que, para escalas mais altas (baixas frequências), presentes no início do sinal, tem-se tonalidades mais fortes na figura. Já para as frequências altas (escalas baixas), presentes na segunda parte do sinal $(t \in[1,2])$, as tonalidades mais claras estão presentes na região inferior da figura, conforme esperado.

$$
X_{w}(a, b)=\frac{1}{\sqrt{|a|}} \int_{-\infty}^{\infty} x(t) \psi^{*}\left(\frac{t-b}{a}\right) d t
$$

A transformada discreta Wavelet (DWT) é baseada no uso de filtros passa-baixa e passa-alta sobre o sinal discreto amostrado. As saídas dos filtros são então subamostradas pela metade. Para a Wavelet de Haar (1910), o processo pode ser reduzido ao cálculo das

cias versus sua energia, ou seja, a contribuição de cada frequência para o sinal. Na prática, ele é calculado utilizando a transformada rápida de Fourier (FFT) (Ao, 2010). 
somas e diferenças dos pares de observações. Ao final, obtém-se um conjunto de coeficientes de aproximação, os quais fornecem uma versão suavizada do sinal, e coeficientes de detalhe, que contêm as frequências mais altas presentes no sinal, tais como ruído.

Considere a Figura 3.16, que apresenta na base o gráfico de uma senóide com adição de ruído. Os três gráficos do topo representam o resultado da transformada discreta da Wavelet de Haar, sendo o sinal composto pela concatenação dos coeficientes de aproximação e detalhes após a aplicação da transformada. É possível observar que, na primeira metade da série, tem-se o sinal original suavizado, enquanto na segunda metade os coeficientes de detalhe, que representam as frequências mais altas do sinal - geralmente compostas por ruído, como neste exemplo. A cada nível, calcula-se a transformada sobre os coeficientes de suavização obtidos no nível anterior. Assim, quanto mais aplicações da transformada, mais suavizado o sinal que se obtém. É possível observar que para o nível 3 uma quantidade razoável de ruído foi removida.

\subsubsection{Empirical Mode Decomposition}

Ambas as transformadas de Fourier e Wavelet são lineares, o que levou ao desenvolvimento de uma técnica para lidar com sinais não lineares e não estacionários, chamada de Empirical Mode Decomposition (EMD) (Huang et al., 1998). Ela é útil para a análise de sinais reais, comuns na natureza, que muitas vezes apresentam não estacionariedade e não linearidade.

Basicamente, a técnica EMD decompõe um sinal em suas funções de modo intrínsecas (IMFs) (Kim e Oh, 2009). Com os componentes (IMFs) obtidos a partir da técnica EMD é possível aplicar a transformada de Hilbert (1912), a qual estima amplitude e frequência instantâneas de cada componente como função do tempo.

Para obter as IMFs, primeiramente os extremos locais e cruzamentos com zero (eixo

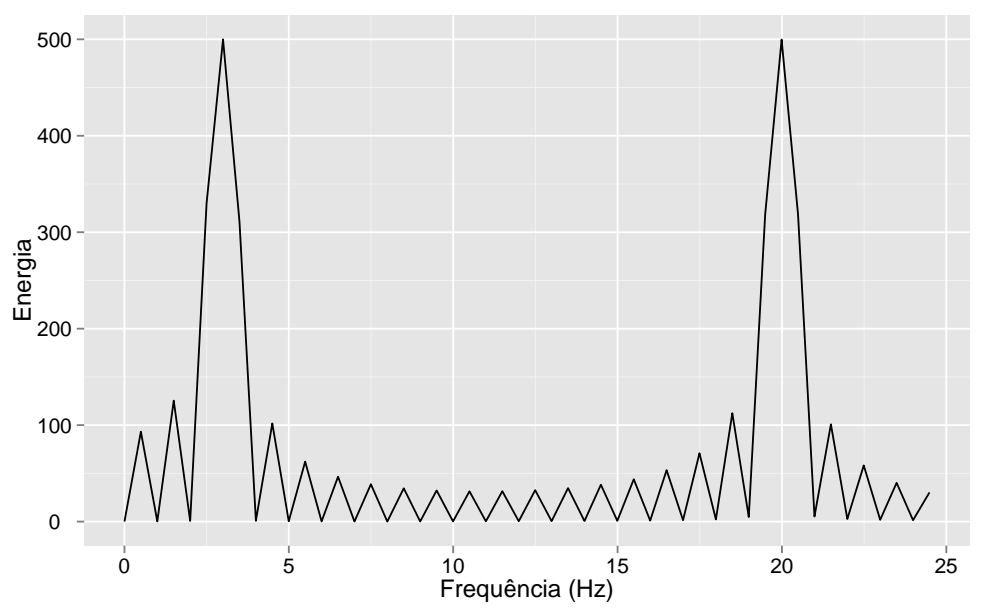

Figura 3.14: Periodograma construído a partir da transformada de Fourier para a série da Figura 3.13. É possível observar que, com a transformada de Fourier, apesar de ser possível descobrir as frequências presentes no sinal (picos em 3 e $20 \mathrm{~Hz}$ ), não há como saber em qual faixa de tempo essas frequências ocorrem. 


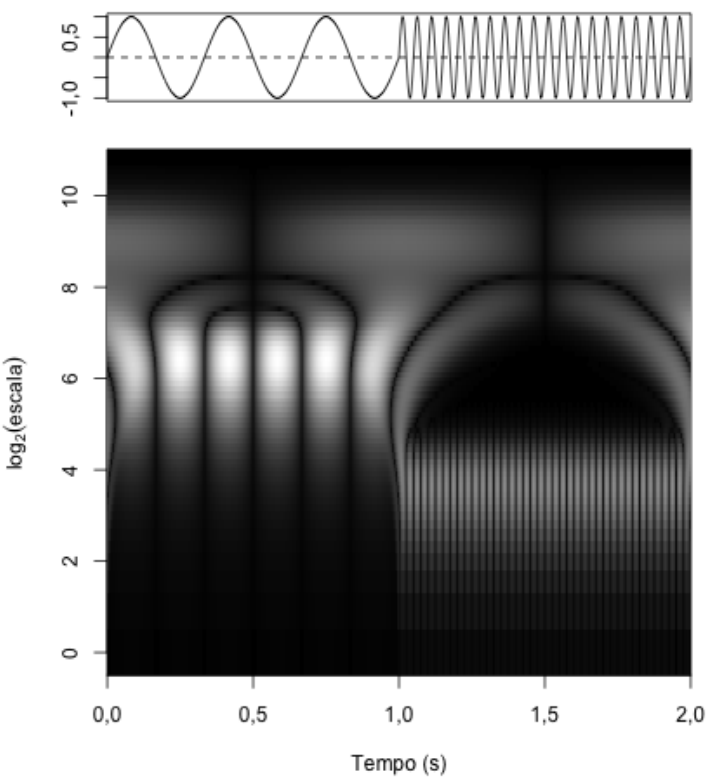

Figura 3.15: Transformada Wavelet contínua (CWT) da série da Figura 3.13, reproduzida novamente na parte superior. O eixo y é representado pelo logaritmo das escalas, que guardam uma relação inversa com as frequências do sinal, ou seja, frequências altas representam escalas baixas e vice-versa. Na figura, tonalidades mais claras representam maior energia dos coeficientes Wavelet.
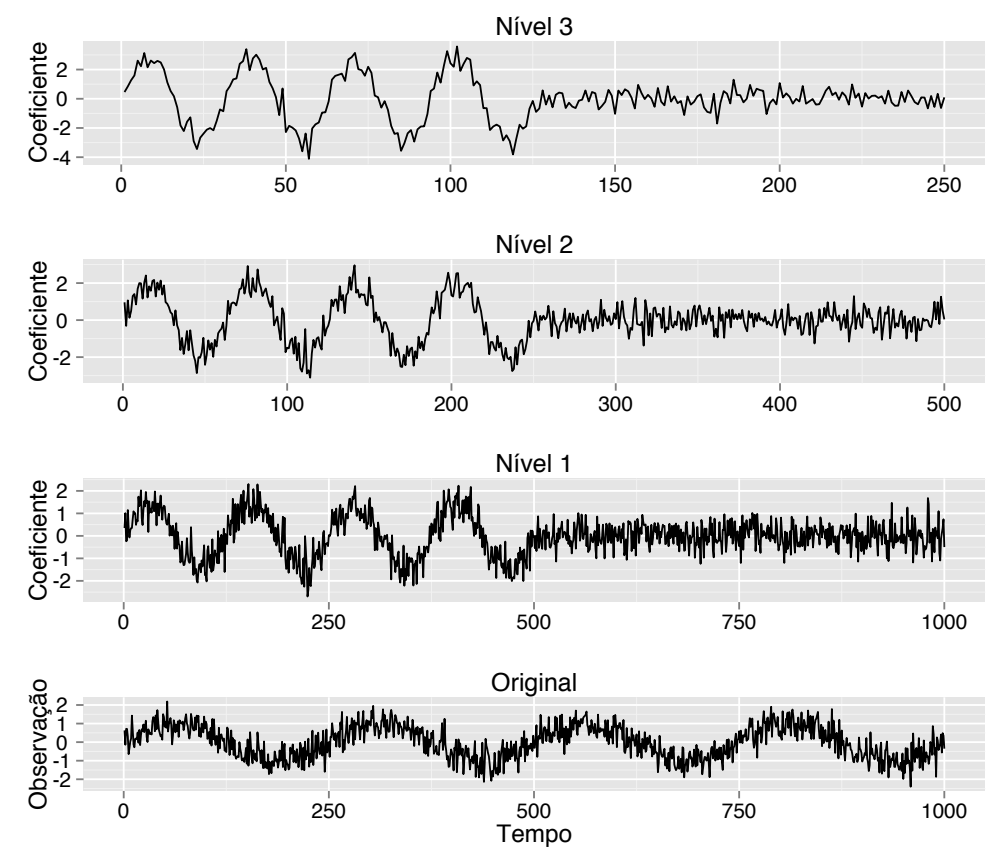

Figura 3.16: Exemplo da aplicação da transformada discreta da Wavelet de Haar em vários níveis para um seno com ruído adicionado.

x) são identificados. A seguir, a técnica calcula "envelopes" superiores e inferiores para o sinal, que são encontrados interpolando os extremos locais. No próximo passo, a técnica calcula a média dos envelopes, produzindo um componente de frequência mais baixa, o qual é subtraído do sinal original. Huang et al. (1998) definiu que esse sinal resultante é uma IMF caso duas condições sejam satisfeitas: 1) o número de extremos e de cruzamentos com zero difere somente em um; e 2) a média local é zero. Caso essas condições não sejam 
atendidas, o procedimento é repetido com o sinal residual. A série resultante é a primeira IMF. Subtraindo a IMF do sinal original, obtém-se um componente de alta frequência, geralmente denominado de sinal residual.

Huang et al. (1998) também consideram o conceito de Frequência Instantânea (IF) por meio da transformada de Hilbert (1912). Para uma série $S_{x}$, seu sinal analítico é definido como $Z=S_{x}+i Y$, em que $Y$ é a transformada de Hilbert de $S_{x}$. A fase de $Z$ ao longo do tempo é $\theta(t)=\arctan \left(Y / S_{x}\right)$. A Frequência Instantânea é então definida como $\frac{d \theta(t)}{d t}$. Por meio da extração de IMF's de um sinal e com o uso da transformada de Hilbert é possível estudar como sua frequência se altera ao longo do tempo.

\subsubsection{Modelos paramétricos de Box e Jenkins}

Outro conjunto de ferramentas para modelagem de séries temporais são os modelos paramétricos propostos por Box e Jenkins (1994). Nesse contexto, modelos Autorregressivos (AR) consideram a observação atual de uma série como uma combinação linear de valores passados mais ruído branco. A Equação 3.15 apresenta um modelo AR de ordem $p$, em que $\mu$ é a média do processo, $t$ é o instante de tempo atual, $\phi_{i}$ é o $i$-ésimo coeficiente autoregressivo e $a_{t}$ representa uma entrada proveniente de ruído branco no tempo $t$.

$$
Z_{t}=\mu+\sum_{i=1}^{p} \phi_{i} Z_{t-i}+a_{t}
$$

De maneira similar, modelos de médias móveis (MA) definem que o valor atual de uma série é uma combinação linear de entradas passadas compostas por ruído branco, conforme a Equação 3.16, em que $q$ é a ordem, $\mu$ é a média, $\theta_{i}$ é o $i$-ésimo coeficiente autoregressivo e $a_{t}$ é o ruído branco no tempo $t$.

$$
Z_{t}=\mu+\sum_{i=1}^{q} \theta_{i} a_{t-i}+a_{t}
$$

Já os modelos Autorregressivos de Médias Móveis (ARMA) combinam ambos os modelos anteriores usando um fator aditivo, conforme exposto na Equação 3.17.

$$
Z_{t}=\mu+\sum_{i=1}^{p} \phi_{i} Z_{t-i}+\sum_{i=1}^{q} \theta_{i} a_{t-i}+a_{t}
$$

Enquanto os modelos AR, MA e ARMA são capazes de representar séries temporais lineares e estacionárias, modelos Autorregressivos Integrados de Médias Móveis (ARIMA) são capazes de lidar também com séries não estacionárias. Para isso, aplica-se diferenças até que a série se torne estacionária, sendo que o número de diferenças caracteriza a ordem do termo de integração $(d)$. A Equação 3.18 apresenta o modelo $\operatorname{ARIMA(p,d,q)~de~uma~}$ série, tal que $W_{t}=\Delta^{d} Z_{t}$, em que $\Delta^{d}$ é o operador de diferença. 


$$
W_{t}=\mu+\sum_{i=1}^{p} \phi_{i} W_{t-i}+\sum_{i=1}^{q} \theta_{i} a_{t-i}+a_{t}
$$

\subsubsection{Autocorrelação}

Um ponto importante ao usar um modelo autoregressivo, como os propostos por BoxJenkins, é a ordem do modelo, ou seja, o número de observações passadas que são consideradas. Uma maneira de descobrir como a série se correlaciona com valores passados é por meio da Função de Autocorrelação (ACF) (Box e Jenkins, 1994) (Equação 3.19). O parâmetro $\tau$ é o lag ou atraso no tempo, $\mu$ é a média e $\sigma^{2}$ a variância. A função opera como uma correlação linear da série com ela mesma, dado um deslocamento no tempo.

$$
A C F(\tau)=\frac{E\left[\left(Z_{t}-\mu\right)\left(Z_{t+\tau}-\mu\right)\right]}{\sigma^{2}}
$$

Além da Autocorrelação, é possível definir também a Autocorrelação Parcial (PACF), que é simplesmente a Autocorrelação entre $Z_{t}$ e $Z_{t-\tau}$ que não leva em conta os lags 1 a $\tau-1$. Isso permite identificar com mais facilidade qual a ordem $p$ de um modelo autorregressivo.

A Figura 3.17a apresenta uma série AR(3) gerada sinteticamente, enquanto a Figura 3.17b apresenta o gráfico da Autocorrelação Parcial para essa série. Nesse último gráfico, as linhas tracejadas representam um intervalo de confiança de 95\%, ou seja, apenas as autocorrelações que extrapolam os limites são consideradas significativas. É possível observar que, de $\tau=1$ a $\tau=3$, encontram-se as autocorrelações parciais significativas, conforme esperado, devido ao modelo utilizado para gerar a série.

\subsubsection{Autoinformação Mútua}

A função de Autocorrelação, apesar de muito útil, calcula apenas relacionamentos lineares entre observações. Para avaliar se existem relacionamentos não lineares entre observações de uma série é possível utilizar a técnica de Autoinformação Mútua (AMI), já que ela é capaz de capturar tanto correlações lineares e não lineares, por se basear apenas nas probabilidades de ocorrência das observações. A Equação 3.20 apresenta a definição da AMI para o caso discreto, em que $S_{x}$ é a série e $S_{y}$ sua versão com atraso.

$$
I\left(S_{x} ; S_{y}\right)=\sum_{y \in S_{y}} \sum_{x \in S_{x}} p(x, y) \log _{2}\left(\frac{p(x, y)}{p(x) p(y)}\right)
$$

Para computar o valor da probabilidade conjunta $p(x, y)$ na versão discreta da AMI é necessário a construção de um histograma duplo que relaciona valores observados da série e de sua versão com atraso. Isso é feito discretizando os valores da série e calculando o número de ocorrências conjuntas de $s_{i}^{\prime}$ e $s_{i+\tau}^{\prime}$, em que $s_{i}^{\prime}$ indica o $i$-ésimo intervalo do histograma. A partir desse histograma calcula-se então a probabilidade conjunta. 


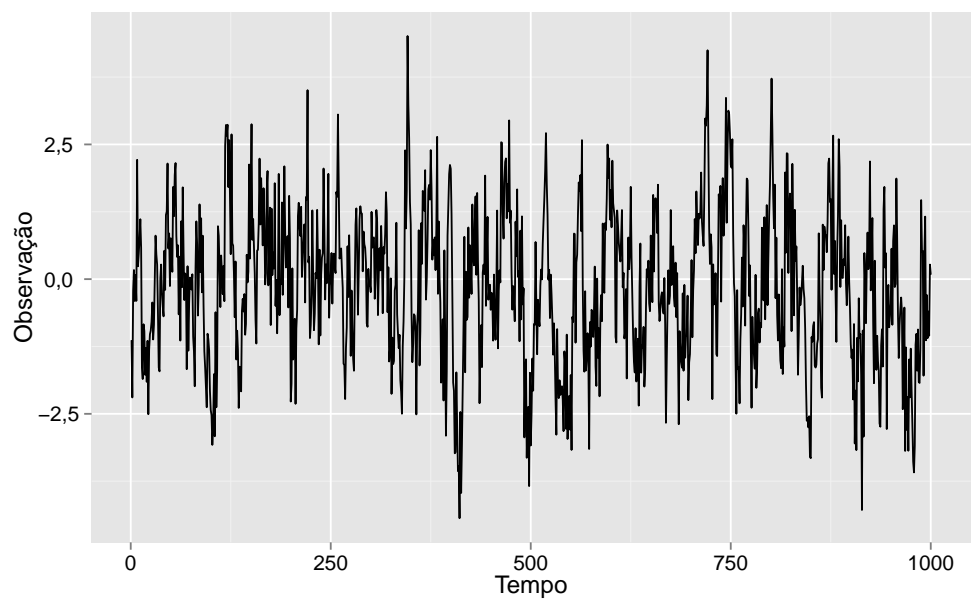

(a) Série $\operatorname{AR}(3)$ gerada sinteticamente.

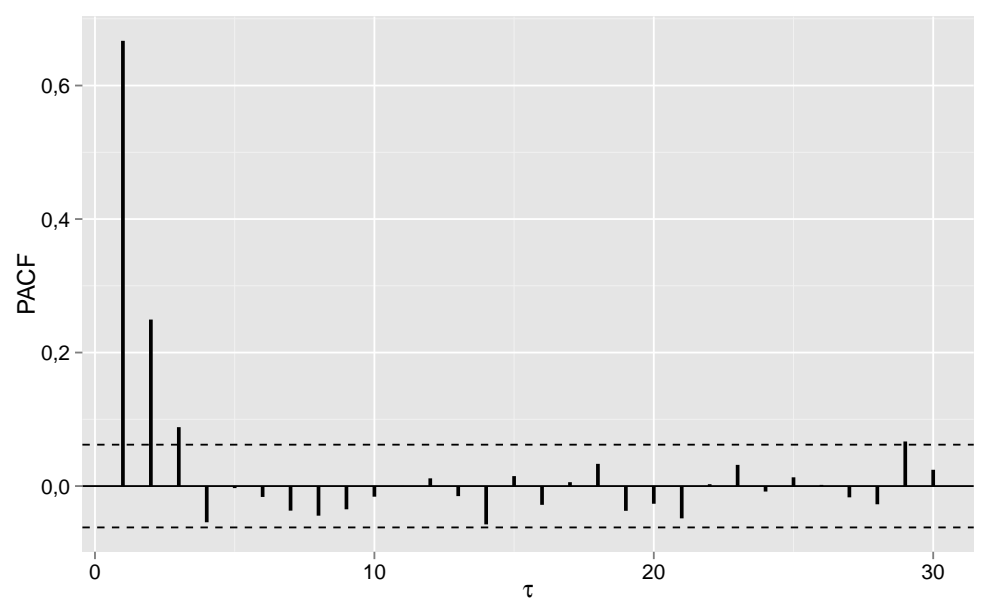

(b) Autocorrelação Parcial para a série da Figura 3.17a.

Figura 3.17: Série AR(3) juntamente com sua Autocorrelação.

A Autoinformação Mútua ainda apresenta outra utilidade. Fraser e Swinney (1986) mostraram que a seleção do primeiro mínimo da Autoinformação Mútua para uma dada série permite estimar a dimensão de separação $\tau$ quando se deseja reconstruir a série no espaço fase (ver Seção 1.1). Os autores motivam essa escolha pelo fato de nessa separação as observações apresentarem menor similaridade. Assim, a reconstrução nessa separação ressalta diferenças, facilitando a visualização do atrator ${ }^{6}$, caso ele exista.

A Figura 3.18a apresenta um trecho da série de Lorenz (1963), enquanto a Figura 3.18b traz o gráfico da Autoinformação Mútua para essa série. É possível observar que uma separação $\tau=5$ é indicada para a reconstrução, o que está de acordo com o valor recomendado nos trabalhos de Lorenz (1963) e Kennel et al. (1992).

\footnotetext{
${ }^{6}$ Conforme mencionado anteriormente, o atrator é uma figura geométrica que representa a dinâmica comportamental da série. Pontos próximos ao atrator tendem a continuar próximos mesmo na presença de leves perturbações.
} 


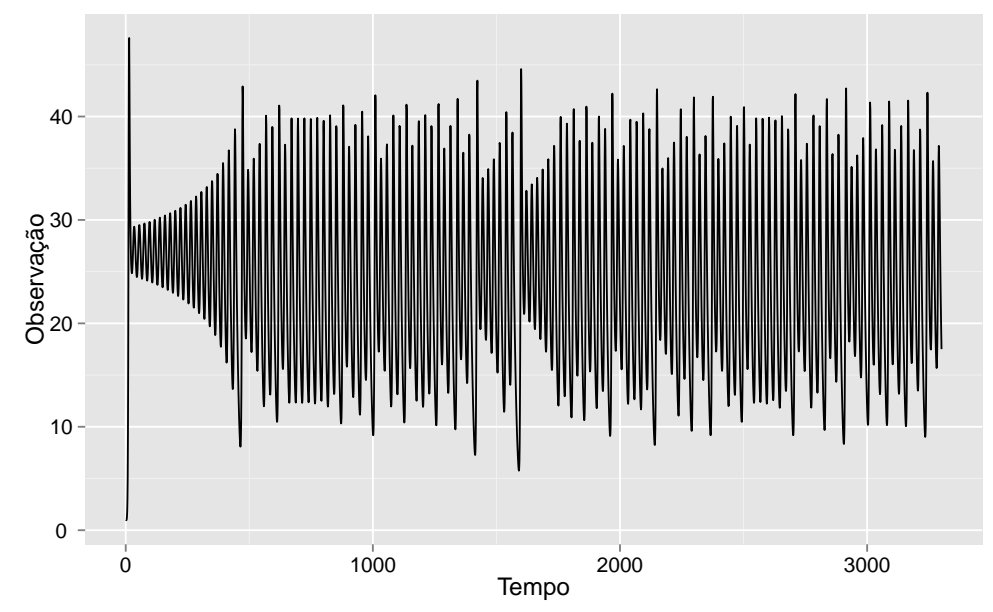

(a) Série temporal de Lorenz (1963).

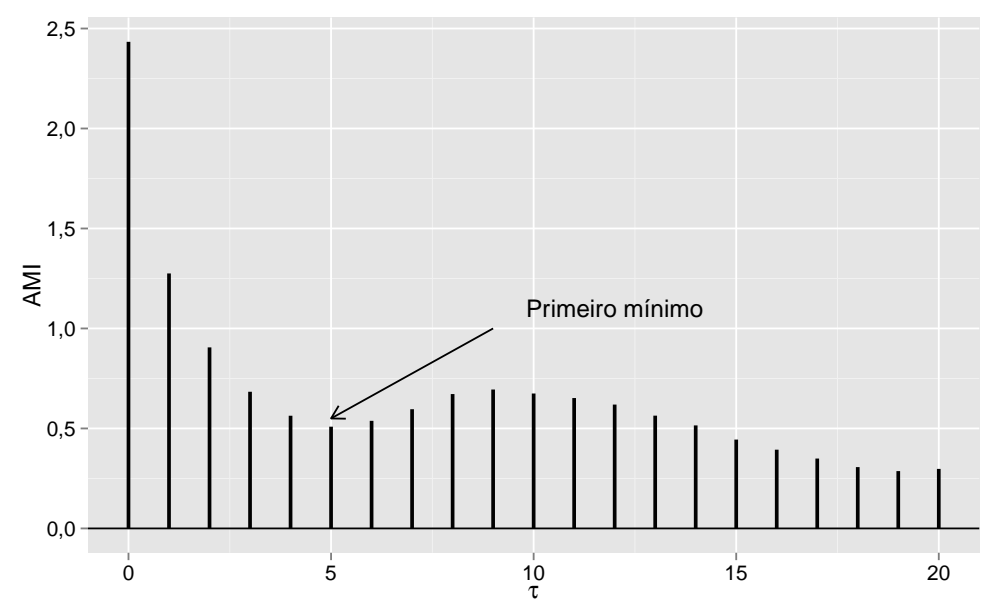

(b) Autoinformação Mútua para a série da Figura 3.18a.

Figura 3.18: Série de Lorenz juntamente com o gráfico dos valores da Autoinformação Mútua. O primeiro mínimo no gráfico do AMI pode ser utilizado como um indicativo da melhor dimensão de separação para se fazer a reconstrução da série no espaço fase (Fraser e Swinney, 1986) (ver Seção 1.1).

\subsection{Considerações finais}

Dadas as propriedades de modelos geradores, tais como estocasticidade, linearidade e estacionariedade, levantadas por Ishii et al. (2011), buscou-se neste trabalho um conjunto de medidas descritivas de séries temporais capazes de identificar e mensurar tais propriedades.

Neste capítulo, foram apresentadas as diversas medidas consideradas, tanto no domínio do tempo com modelos paramétricos, tais como os de Box-Jenkins, como no domínio das frequências, com a análise de Fourier e Wavelet. As particularidades e limitações intrínsecas de cada medida motivam seu uso em conjunto, a fim de obter uma caracterização mais ampla e precisa do modelo gerador de séries temporais.

Enquanto as técnicas apresentadas no Capítulo 2 exploraram o uso de uma ou poucas medidas descritivas, como a correlação de Pearson, este trabalho buscou avaliar um conjunto maior e mais completo de medidas, permitindo que todas as classes de séries da 
taxonomia de Ishii et al. (2011) fossem representadas.

O próximo capítulo apresenta um estudo realizado com as diversas medidas descritivas em um cenário de classificação de séries temporais, a fim de, antes de utilizá-las em agrupamento, analisar o impacto de seu uso em um cenário controlado e obter um ranking daquelas com maior poder discriminativo. 


\section{Experimentos com medidas descritivas de séries temporais}

\subsection{Considerações Iniciais}

Neste capítulo são apresentados diversos experimentos realizados com as medidas descritivas de séries temporais discutidas no capítulo anterior. Para avaliar o impacto do uso das medidas em um cenário controlado, optou-se primeiramente por realizar experimentos com classificação de séries temporais, i.e., aprendizado supervisionado, utilizando algoritmos já bem estabelecidos. Os resultados mostram que o uso das medidas apresenta um impacto significativo na acurácia da classificação, motivando seu uso para o agrupamento de séries temporais em fluxos contínuos, conforme a proposta deste trabalho de doutorado.

As avaliações foram realizadas primeiramente utilizando um conjunto de séries sintéticas e posteriormente dados reais provenientes de séries de músicas. Essa escolha deve-se à disponibilidade gratuita das músicas no Free Music Archive ${ }^{1}$, e ao fato de sua discretização fornecer um número suficiente de observações para o cálculo das medidas descritivas empregadas neste trabalho.

É importante destacar que, apesar de existir um benchmark bem conhecido para classificação de séries temporais, notadamente o UCR Time Series Archive ${ }^{2}$, optou-se por não utilizá-lo. A primeira razão se dá em função do pequeno número de observações disponíveis nas séries, conforme ilustrado no histograma da Figura 4.1, o qual considera 20 conjuntos do repositório $\mathrm{UCR}^{3}$. Esse pequeno número de observações em muitos dos con-

\footnotetext{
${ }^{1}$ http://freemusicarchive.org/. Último acesso: 11 de junho de 2012.

${ }^{2}$ http://www.cs.ucr.edu/ eamonn/time_series_data/. Último acesso: 29 de novembro de 2012.

${ }^{3}$ Conjuntos considerados: yoga, Two_Patterns, OliveOil, Gun_Point, wafer, Adiac, Beef, Coffee, CBF, synthetic_control, Trace, Lighting2, FaceFour, FaceAll, fish, SwedishLeaf, 50words, OSULeaf, Lighting7
} 


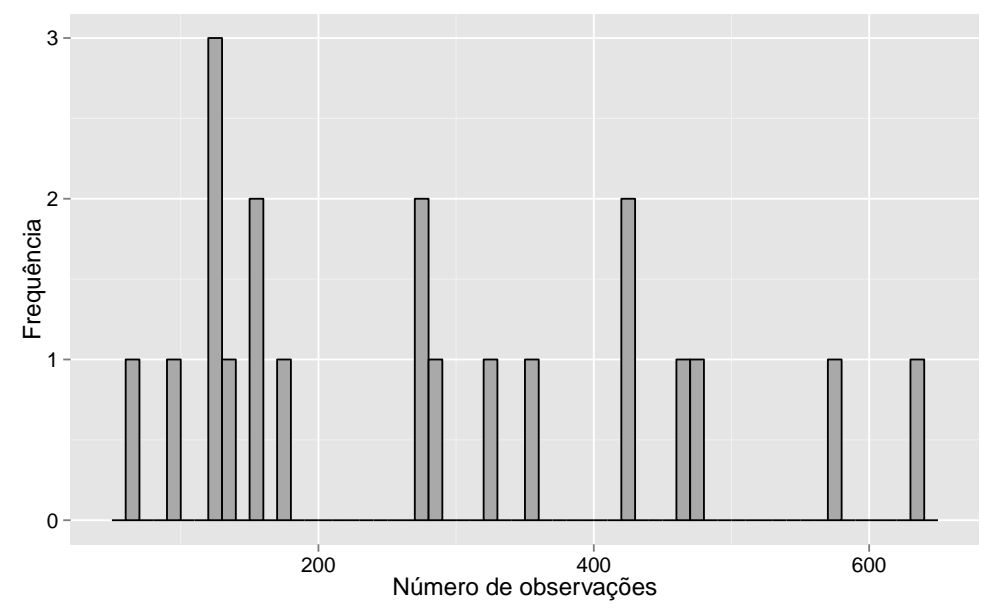

Figura 4.1: Histograma do número de observações das séries provenientes do repositório UCR.

Tabela 4.1: Classes e modelos usados para a geração das séries temporais sintéticas. A nomenclatura "+ N" em alguns modelos corresponde a não linearidade introduzida.

\begin{tabular}{ll}
\hline \multicolumn{1}{c}{ Classes } & \multicolumn{1}{c}{ Modelos } \\
\hline Determinística (D) & Logística e Lorenz \\
Estocástica Linear Estacionária (ELE) & $\operatorname{AR}(1)$ e MA $(1)$ \\
Estocástica Linear Não Estacionária (ELN) & $\operatorname{ARI}(1,1)$ e IMA $(1,1)$ \\
Estocástica Não Linear Estacionária (ENE) & $\operatorname{AR}(1)+\mathrm{N}$ e MA $(1)+\mathrm{N}$ \\
Estocástica Não Linear Não Estacionária (ENN) & $\operatorname{ARI}(1,1)+\mathrm{N}$ e IMA $(1,1)+\mathrm{N}$ \\
\hline
\end{tabular}

juntos de dados faz com que várias das medidas consideradas neste trabalho não possam ser calculadas, pois elas requerem um número maior de observações (e.g., as que realizam uma reconstrução da série no espaço fase).

Outro motivo que desencorajou o uso das séries provenientes do repositório UCR é que a supervisão das séries, ou seja, a rotulação de classe atribuída a cada série não necessariamente reflete uma estrutura de grupos nos dados, o que é desejado no contexto deste trabalho. Assim, optou-se por não se usar esse benchmark.

\subsection{Experimentos com séries sintéticas}

Em função de vários trabalhos na área de classificação de séries temporais apontarem o algoritmo 1-NN (1-Nearest Neighbor) como um dos melhores (Xi et al., 2006; Ding et al., 2008), optou-se por utilizá-lo nos experimentos como base de comparação. Também empregou-se árvores de decisão (Tan et al., 2005) para comparação, já que elas usam o Ganho de Informação (Witten e Frank, 2002), o qual auxilia a descobrir quais medidas descritivas fornecem o maior poder discriminativo de séries temporais, de forma que atributos mais relevantes encontram-se mais próximos da raiz da árvore.

Inicialmente, diversas bases sintéticas de séries temporais foram geradas, a fim de 
cobrir todos os ramos da taxonomia proposta por Ishii et al. (2011) (ver Figura 1.6 na página 10). A Tabela 4.1 apresenta os modelos usados para a geração das séries.

Para a simulação da classe Determinística, um mapa logístico da forma $x_{t+1}=r \cdot x_{t}$. $\left(1-x_{t}\right)$ foi usado, com $x_{0}$ amostrado uniformemente no intervalo [0,3;0,5], a fim de gerar várias séries com realizações diferentes, porém seguindo o mesmo modelo matemático, ou seja, apresentando as mesmas propriedades. Também foi utilizado o valor de $r=3,8$, o que faz com que a série apresente características caóticas ${ }^{4}$. O mapa logístico, originalmente proposto como um modelo demográfico, é um exemplo amplamente usado de como o comportamento caótico pode surgir a partir de equações não lineares simples.

Para a classe Determinística também foi usado o modelo de Lorenz (1963) (Equação 4.1) com condição inicial $x^{T}=\left[x_{1}, x_{2}, x_{3}\right] \in \mathbb{R}^{3}$ amostrada uniformemente no intervalo [1;5] e parâmetros $\rho=28, \sigma=10$ e $\beta=-8 / 3$. Esse modelo foi escolhido porque é um exemplo de sistema dinâmico não linear determinístico com características caóticas, além de ser um modelo importante na área de previsão climática (Ivancevic e Ivancevic, 2008).

$$
\begin{aligned}
& \frac{d x}{d t}=\sigma(y-x) \\
& \frac{d y}{d t}=x(\rho-z)-y \\
& \frac{d z}{d t}=x y-\beta z
\end{aligned}
$$

Para todas as outras classes foram usados modelos autoregressivos de Box e Jenkins (1994), com os coeficientes amostrados uniformemente no intervalo $[0,3 ; 0,5]$. Não linearidades foram introduzidas por meio da adição de senóides ao sinal original, de forma que o teste de não linearidade de White (Lee et al., 1993) permitisse aceitar a hipótese de que o sinal continha não linearidade. Os experimentos foram realizados em dois cenários: na ausência e na presença de ruído.

Foram criadas 30 bases, cada uma contendo 50 séries temporais de cada classe, sendo 5 classes no total (Tabela 4.1). Ao todo, 250 séries por base. Cada série foi composta por 1000 observações. A Figura 4.2 ilustra essa configuração. Todos os experimentos foram executados utilizando 10-fold cross validation (Tan et al., 2005). As implementações foram feitas na linguagem estatística R (R Development Core Team, 2011) em um sistema Linux.

As Figuras 4.3 a 4.12 mostram exemplos de séries utilizadas nos experimentos. Enquanto algumas séries apresentam padrões característicos, como Lorenz, outras são muito similares, como AR e MA.

Conforme mencionado anteriormente, para realizar os experimentos utilizou-se também árvores de decisão (Quinlan, 1993b), pois elas fornecem modelos interpretáveis e indicam quais são os atributos mais discriminativos. A implementação utilizada foi a

\footnotetext{
${ }^{4} \mathrm{O}$ comportamento caótico de um sistema pode ser entendido como uma alta sensibilidade a pequenas variações nas condições iniciais, as quais podem produzir realizações completamente distintas. Isso ocorre apesar do sistema ser determinístico, ou seja, determinado apenas por sua condição inicial, sem nenhum elemento estocástico envolvido.
} 


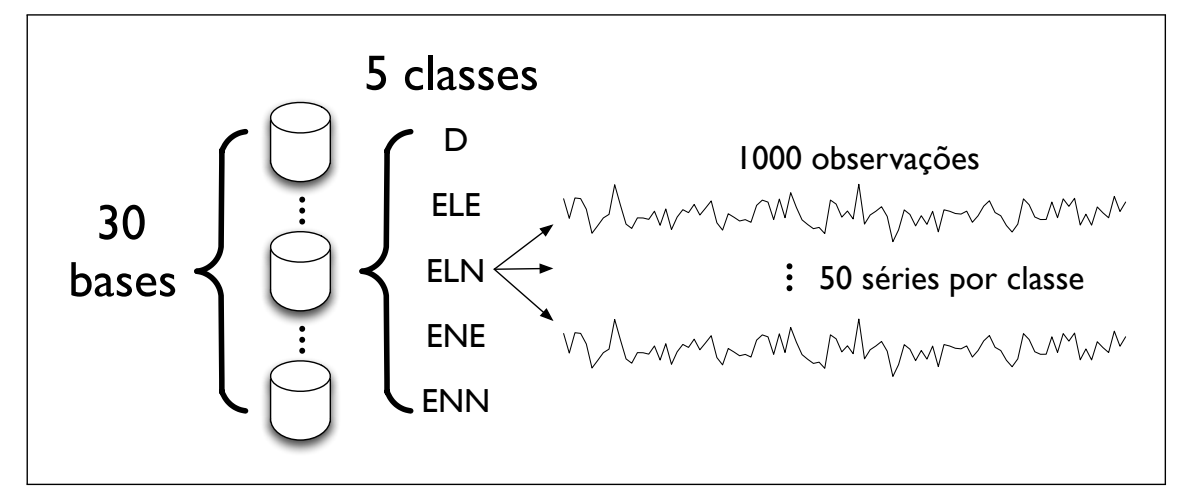

Figura 4.2: Configuração experimental no cenário utilizando séries simuladas. As classes são as definidas pela taxonomia de Ishii et al. (2011).

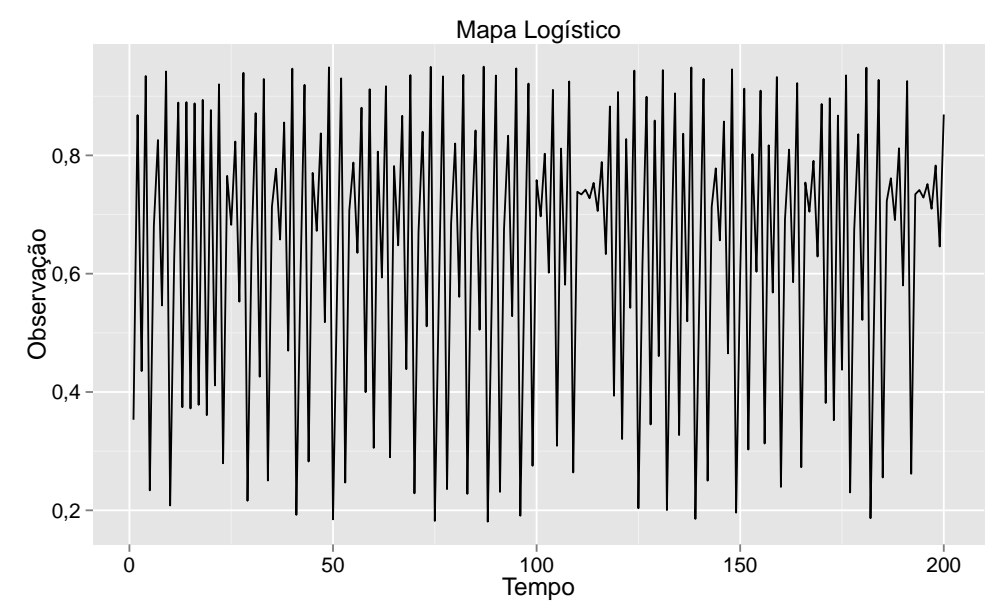

Figura 4.3: Exemplo de série mapa Logístico usada nos experimentos para a classe Determinística.

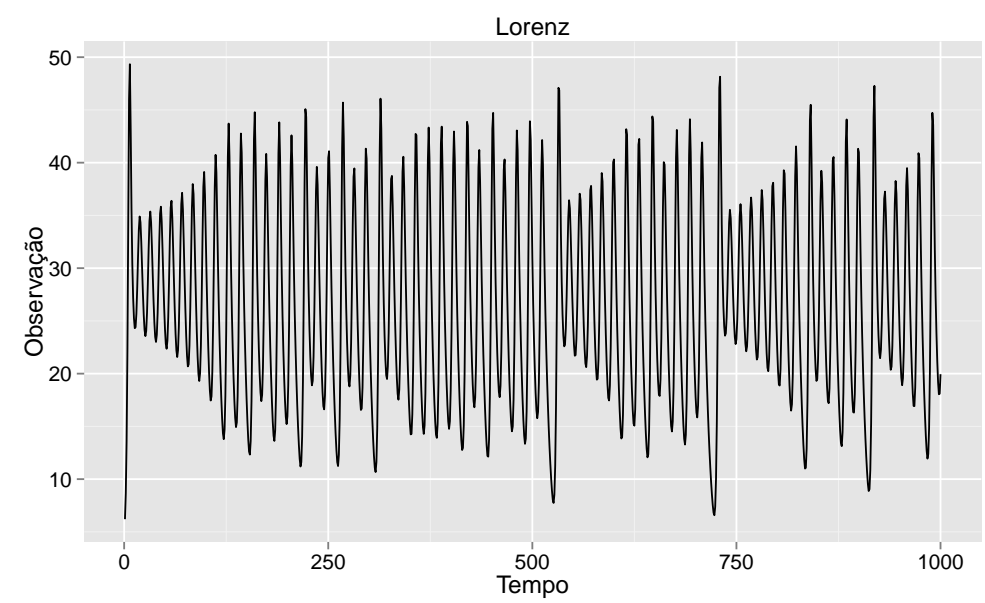

Figura 4.4: Exemplo de série de Lorenz usada nos experimentos para a classe Determinística. 


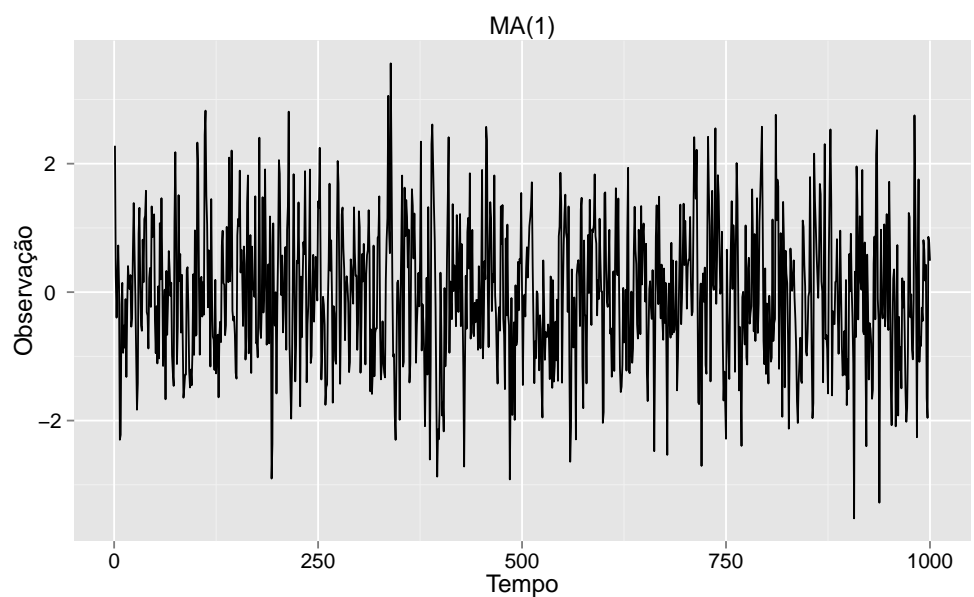

Figura 4.5: Exemplo de série MA(1) usada nos experimentos para a classe Estocástica, Linear, Estacionária.

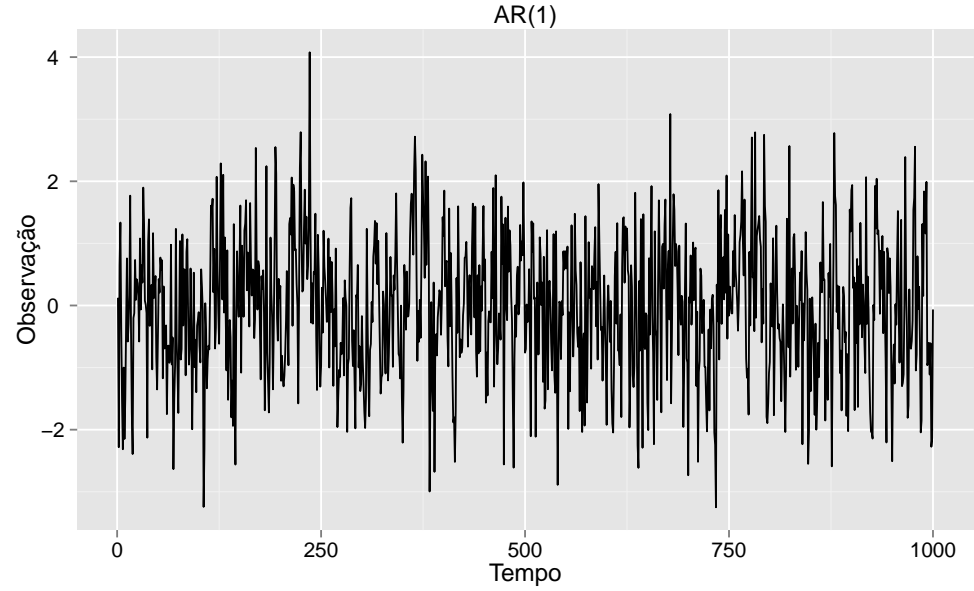

Figura 4.6: Exemplo de série $\operatorname{AR}(1)$ usada nos experimentos para a classe Estocástica, Linear, Estacionária.

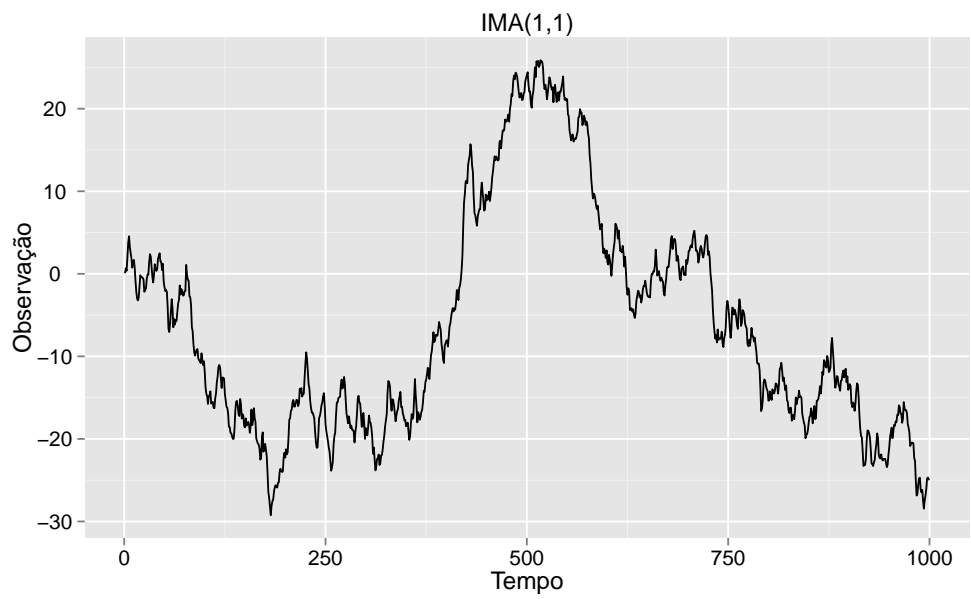

Figura 4.7: Exemplo de série IMA(1,1) usada nos experimentos para a classe Estocástica, Linear, Não Estacionária. 


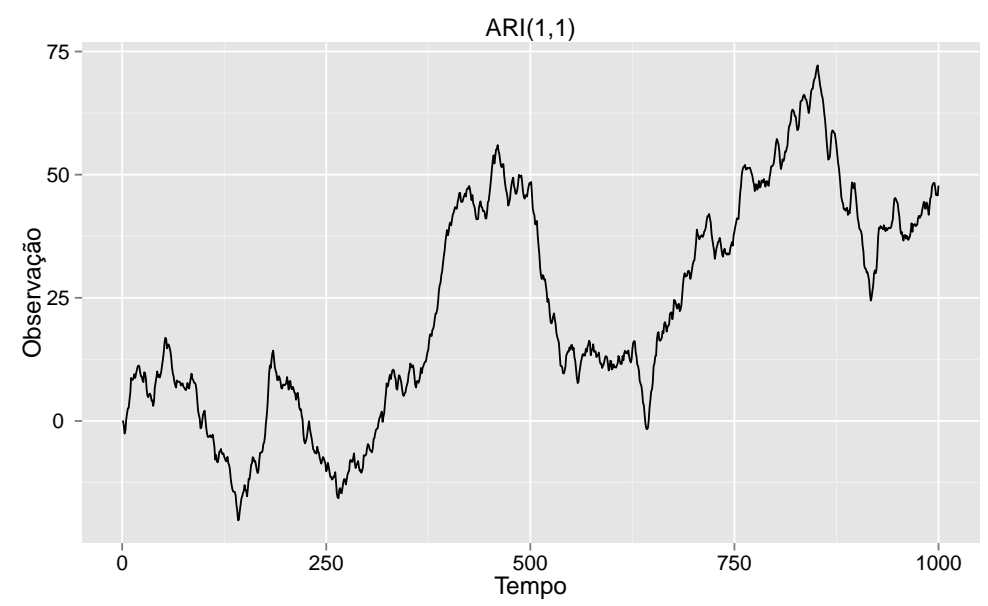

Figura 4.8: Exemplo de série ARI(1,1) usada nos experimentos para a classe Estocástica, Linear, Não Estacionária.

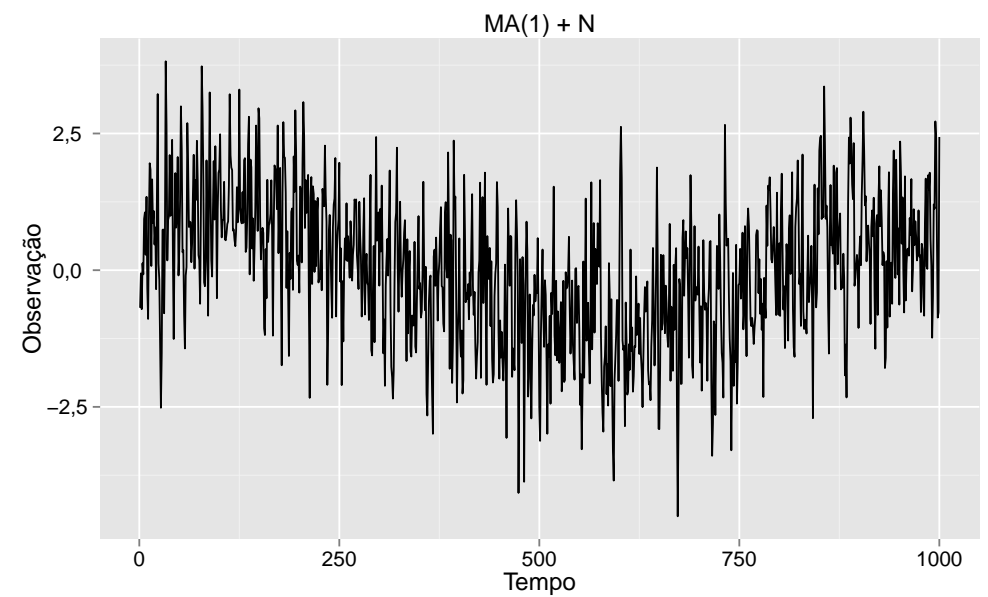

Figura 4.9: Exemplo de série MA(1) + N usada nos experimentos para a classe Estocástica, Não Linear, Estacionária.

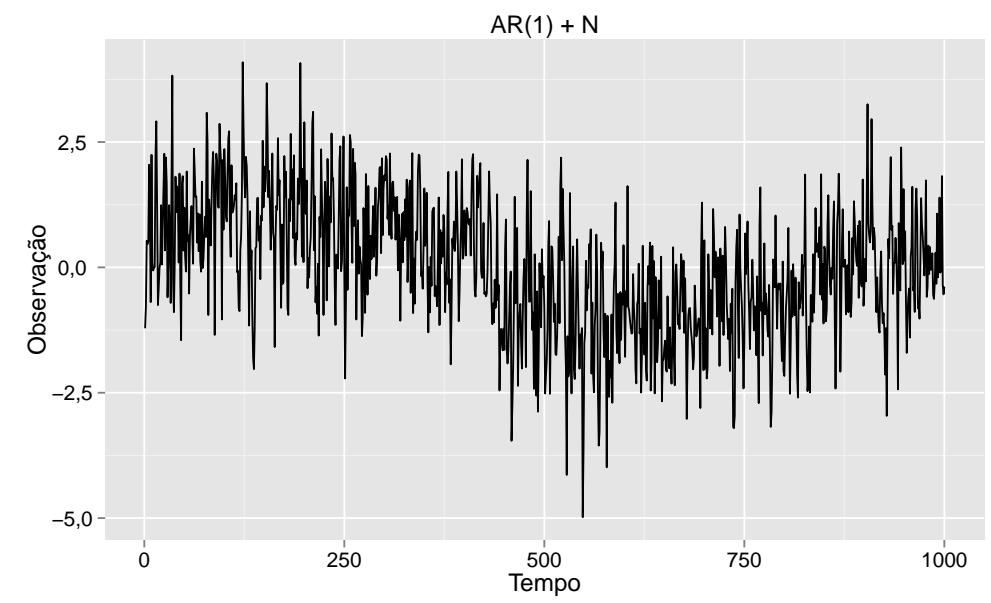

Figura 4.10: Exemplo de série AR(1) + N usada nos experimentos para a classe Estocástica, Não Linear, Estacionária. 


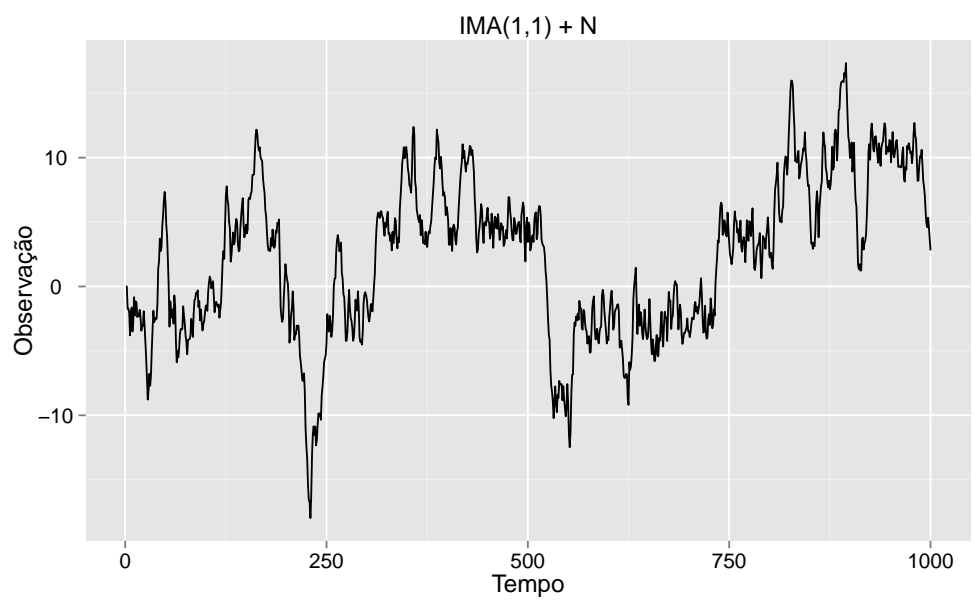

Figura 4.11: Exemplo de série IMA(1,1) + N usada nos experimentos para a classe Estocástica, Não Linear, Não Estacionária.

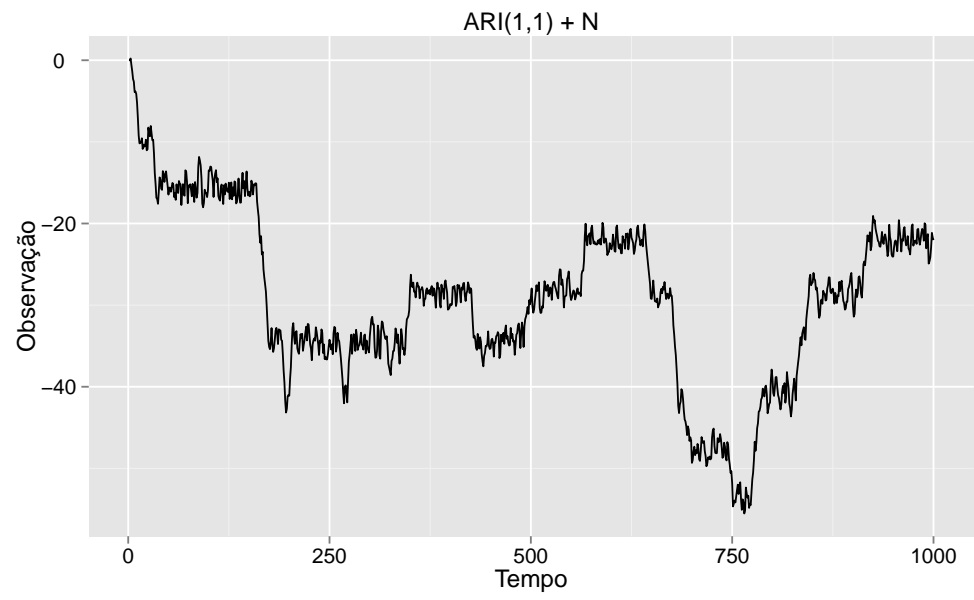

Figura 4.12: Exemplo de série ARI $(1,1)+\mathrm{N}$ usada nos experimentos para a classe Estocástica, Não Linear, Não Estacionária. 
J48 ${ }^{5}$ disponível no pacote $W e k a^{6}$ e acessada via sua interface com $\mathrm{R}$ pelo pacote RWeka ${ }^{7}$. O Algoritmo 6 apresenta os passos básicos para a indução de uma árvore de decisão (Tan et al., 2005). Após sua obtenção, a classificação de novos exemplos é feita executando os testes a partir da raiz até que uma folha seja atingida. O exemplo é então classificado com o rótulo da folha.

Para confirmar a hipótese de que as medidas descritivas estudadas de fato podem melhorar a acurácia da classificação de séries, utilizou-se como base de comparação o algoritmo 1-NN (Cover e Hart, 1967). O classificador 1-NN, por utilizar a distância Euclidiana sobre as observações das séries, torna-se muito suscetível a erros na presença de ruído e, em geral, funciona bem quando existe um padrão geométrico característico que determina cada classe. Apesar de sua simplicidade, o 1-NN é considerado por vários autores como um dos algoritmos mais difíceis de superar na tarefa de classificação de séries temporais (Xi et al., 2006; Ding et al., 2008; Ye e Keogh, 2009). O Algoritmo 7 apresenta os passos básicos para a classificação de um novo exemplo com o 1-NN, já que não há procedimento inicial para indução de um modelo.
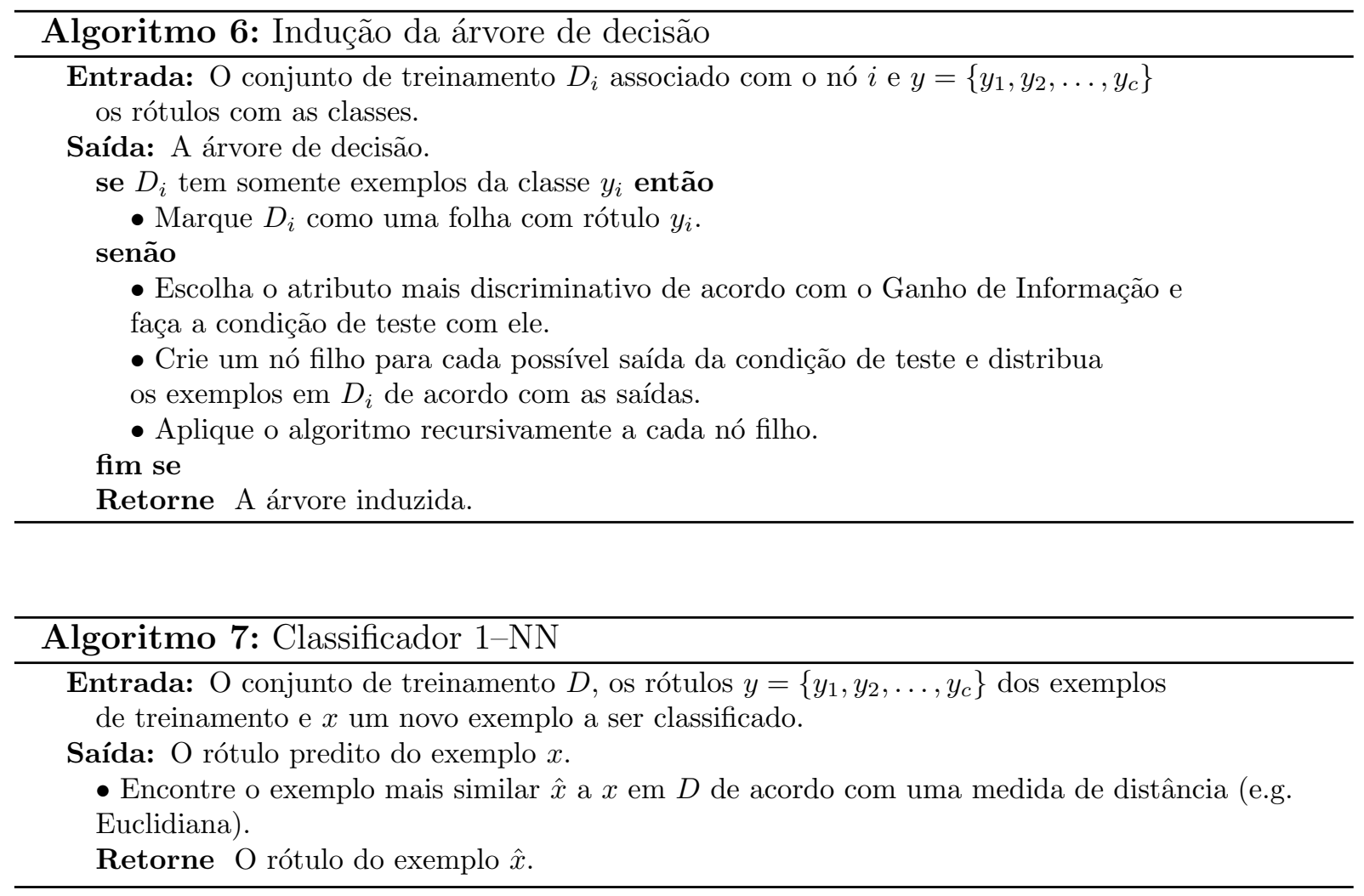

Além de analisar o impacto na acurácia da classificação após a introdução do uso das medidas descritivas de séries temporais, os experimentos também visaram avaliar quais medidas são mais úteis, ou seja, possuem maior poder para discriminar entre diferentes

\footnotetext{
${ }^{5}$ Os parâmetros utilizados para os experimentos foram: uso de árvore sem poda $U=$ Falso, confiança para poda $C=0,25$, número mínimo de instâncias por folha $M=20$. Outros parâmetros específicos da implementação foram deixados nos valores padrões.

${ }^{6}$ http://www.cs.waikato.ac.nz/ml/weka/. Último acesso: 06 de junho de 2012.

${ }^{7}$ http://cran.r-project.org/web/packages/RWeka/index.html. Último acesso: 06 de junho de 2012 .
} 
classes de séries. Com essa finalidade, optou-se pelo uso do Ganho de Informação (Tan et al., 2005). Como todas as medidas descritivas utilizadas neste trabalho fornecem saídas numéricas, não foram consideradas divisões discretas de atributos, mas apenas binárias

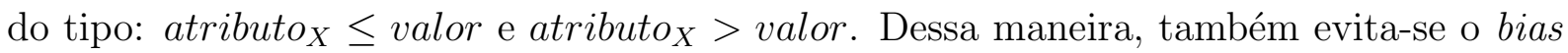
do Ganho de Informação em favor de testes com muitas saídas (Quinlan, 1993b).

O Ganho de Informação é definido de acordo com a Equação 4.2 (Tan et al., 2005), em que $I\left(v_{\text {data }}\right)$ é a Entropia de Shannon (1951) dos dados, $k$ é o número de saídas do teste (no caso deste trabalho sempre igual a 2, já que somente testes binários são considerados), $N$ é o número de exemplos, $N\left(v_{j}\right)$ é o número de exemplos no $j$-ésimo subconjunto após a divisão, e $I\left(v_{j}\right)$ corresponde à Entropia do $j$-ésimo subconjunto. A intuição por trás dessa medida é que, quanto menor a impureza (Entropia) após a divisão dos exemplos, menor será o valor do somatório, maximizando o Ganho de Informação $\Delta_{\text {info }}$.

$$
\Delta_{\text {info }}=I\left(v_{\text {data }}\right)-\sum_{j=1}^{k} \frac{N\left(v_{j}\right)}{N} I\left(v_{j}\right)
$$

\subsubsection{Resultados - Cenário sem ruído}

Os resultados para o cenário com séries sintéticas e sem adição de ruído estão ilustrados na Figura 4.14 e listados na Tabela 4.2, medidos de acordo com a Acurácia (Equação 4.4), em que $\delta_{i, j}$ é a função delta de Kronecker (Abramowitz, 1974) (Equação 4.3), $x$ é um exemplo no conjunto de teste $T, \hat{y}(x)$ é o rótulo predito para $x, y(x)$ é o rótulo real de $x$ e $|T|$ é o número de exemplos no conjunto de teste.

$$
\begin{gathered}
\delta_{i, j}= \begin{cases}1 & \text { se } i=j \\
0 & \text { se } i \neq j\end{cases} \\
\text { Acurácia }=\frac{\sum_{x \in T} \delta_{\hat{y}(x), y(x)}}{|T|}
\end{gathered}
$$

Tabela 4.2: Resultados experimentais com 10-fold Cross-validation para 30 bases no cenário sem adição de ruído.

\begin{tabular}{llcc}
\hline Classificador & \multicolumn{1}{c}{ Entrada } & Acurácia Média & Desvio Padrão \\
\hline 1-NN & Observações originais & 0,490 & 0,035 \\
1-NN & Medidas descritivas & 0,806 & 0,032 \\
Árvore & Observações originais & 0,618 & 0,035 \\
Árvore & Medidas descritivas & 0,886 & 0,027 \\
\hline
\end{tabular}

É possível observar na Tabela 4.2 que a árvore de decisão, baseada nas várias medidas descritivas de séries temporais, teve resultados superiores aos do 1-NN com as observações originais das séries. Para mostrar o impacto das medidas considerando o mesmo algoritmo 
de aprendizado, a Tabela 4.2 também apresenta os resultados para a árvore de decisão usando as observações originais e 1-NN usando as medidas.

Para avaliar a significância estatística dos resultados, executou-se um Teste-T monocaudal (Walpole et al., 1998) para confirmar se a acurácia média da árvore de decisão com as medidas descritivas é superior à média do 1-NN com as observações originais das séries. Foi possível de fato rejeitar a hipótese nula, de que as médias são iguais, com p-valor $6,6 \times 10^{-47}$ e confirmar a superioridade da árvore de decisão com as medidas descritivas.

A Figura 4.13 apresenta um exemplo de árvore induzida durante os experimentos sem adição de ruído. Cada nó arredondado representa uma condição de teste no atributo especificado. Por exemplo, a raiz testa o valor do terceiro coeficiente da Autoinformação Mútua (AMI3), que calcula a correlação da série com atraso 3. É importante observar, que quanto mais próximo da raiz o atributo está, maior seu poder discriminativo, já que a seleção é feita em termos da maximização do Ganho de Informação. No exemplo da figura, o coeficiente AMI3 é o atributo que melhor separa as classes no conjunto de dados. Isso é interessante porque confirma que uma medida de autocorrelação capaz de capturar relacionamentos não lineares é uma das melhores medidas para a caracterização de séries, considerando o conjunto de dados utilizado, o qual cobre todas as classes presentes na taxonomia proposta por Ishii et al. (2011).

Outro ponto interessante a se observar na Figura 4.13 é a interpretabilidade dos resultados. Por exemplo, o coeficiente de integração ARIMA-D, que é útil para saber se uma série temporal é estacionária ou não, discriminou com sucesso as classes não estacionárias (ENN e ELN) da determinística (D).

A seguir, na mesma linha da seleção de atributos realizada pelo algoritmo de aŕvore de decisão, foi feito um ranking das medidas descritivas de acordo com o Ganho de Informação sobre as 30 bases de séries temporais sem adição de ruído. O ranking completo encontra-se na Tabela A.1 (Apêndice A, p. 117), em que FOU representa a transformada discreta de Fourier, IF a frequência instantânea, DET Determinismo e assim por diante.

É interessante observar, na Tabela A.1, que, em média, para as 30 bases de dados, a Autoinformação Mútua foi a medida mais discriminativa. Isso é interessante porque a AMI é capaz de detectar inclusive correlações não lineares, o que ajuda a caracterizar o comportamento de séries e seu modelo gerador. Outra medida útil é a Detrended Fluctuation Analysis (DFA), que é uma versão mais robusta do expoente de Hurst. Ela auxilia na caracterização da aleatoriedade de uma série temporal. Por exemplo, valores próximos a 0,5 indicam um processo aleatório. Na Figura 4.13, observa-se que DFA foi útil para separar o comportamento não linear, que tende a ser mais imprevisível, de um comportamento linear, fazendo a divisão dos exemplos no valor 0,52 do expoente. O coeficiente de integração ARIMA-D foi especialmente útil na caracterização de comportamento não estacionário, como discutido anteriormente.

Os coeficientes de Fourier foram eficazes para separar séries lineares das não lineares, já que foi possível modelar as não linearidades por meio da combinação de senóides. 


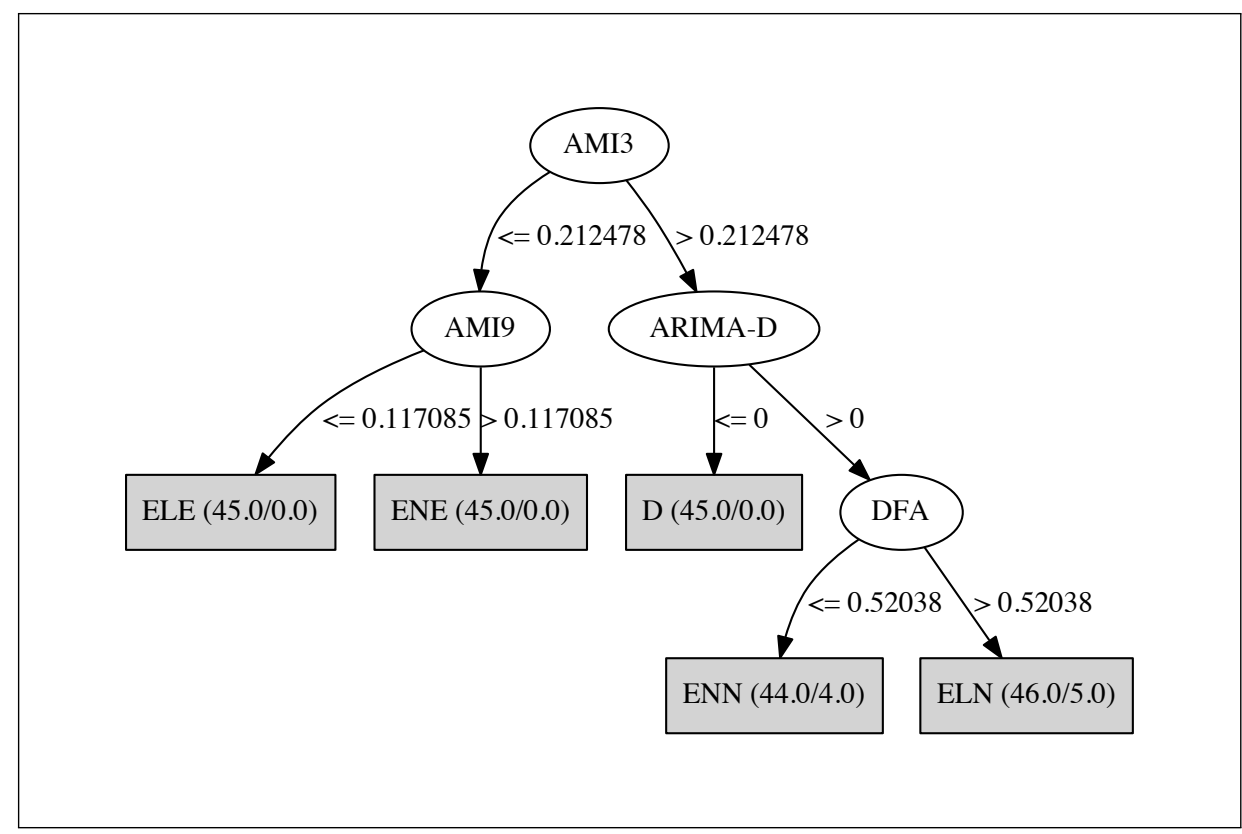

Figura 4.13: Árvore de decisão induzida nos experimentos sem adição de ruído. Os rótulos dos nós arredondados representam os coeficientes utilizados para a condição de teste. Por exemplo, no segundo nível, ARIMA-D representa o coeficiente de integração do modelo ajustado ARIMA. Os rótulos para os nós retangulares são os valores de classe preditos e, entre parênteses, são indicados os números de classificações (corretas / incorretas) no conjunto de treinamento. Os rótulos de classe têm o seguinte mapeamento: D - Determinística; ELE - Estocástica, Linear, Estacionária; ENE - Estocástica, Não Linear, Estacionária; ELN - Estocástica, Linear, Não Estacionária e ENN - Estocástica, Não Linear, Não Estacionária.

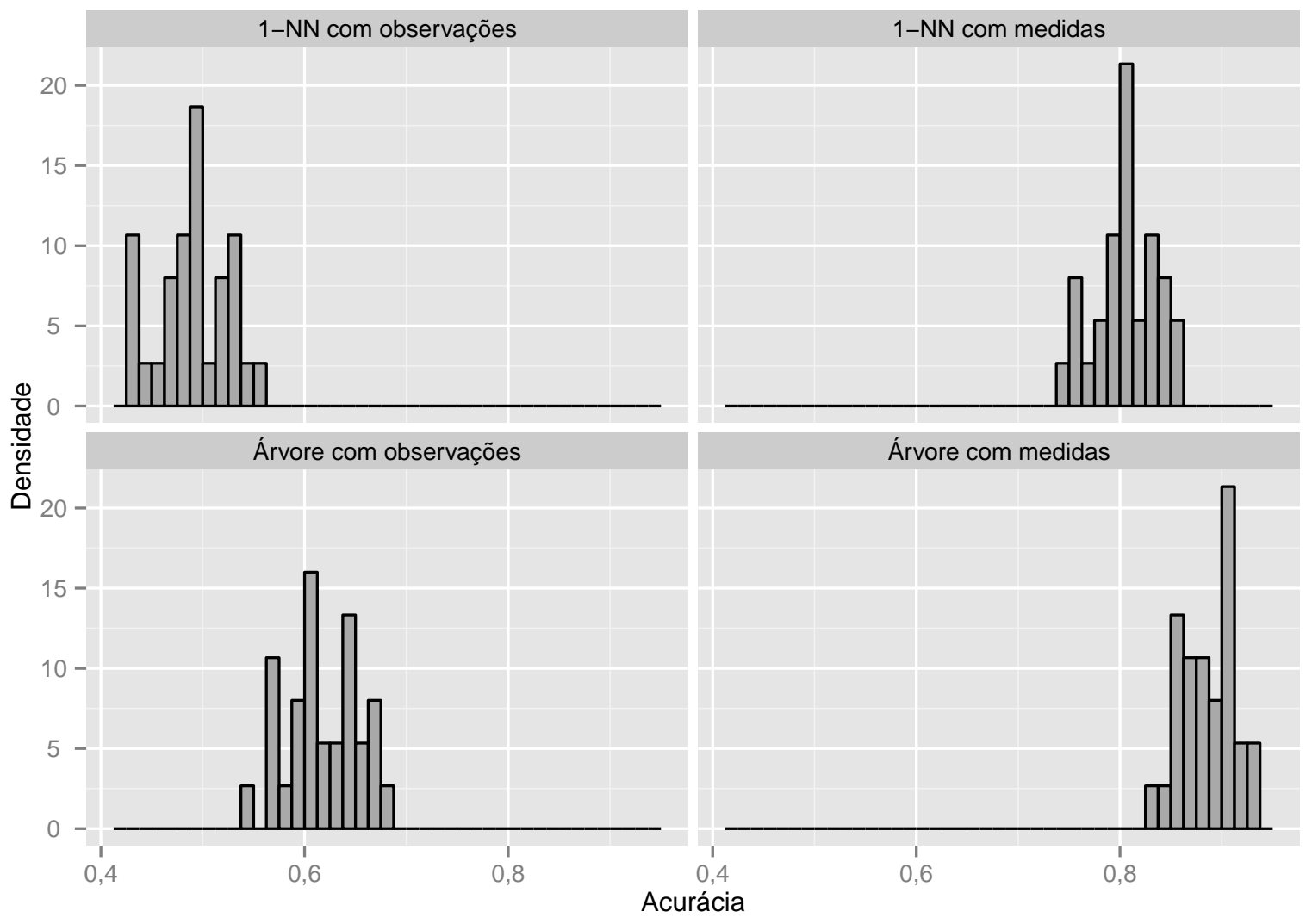

Figura 4.14: Histogramas da acurácia para experimentos com séries sintéticas sem adição de ruído. 
De fato, como as não linearidades foram introduzidas por meio da adição de senóides, a transformada de Fourier apresenta um viés favorável a encontrar tais não linearidades. Porém, conforme será apresentado nos experimentos com séries reais, os coeficientes gerados pela transforma de Fourier também apresentaram alto poder discriminativo sem a adição sintética de não linearidades.

\subsubsection{Resultados - Cenário com ruído}

Neste segundo cenário, foi adicionado ruído às séries consideradas na seção anterior. O ruído foi modelado como proveniente de uma distribuição Uniforme no intervalo média \pm três desvios padrão das observações da série: $x \sim U(\min =\mu-3 \sigma, \max =\mu+3 \sigma)$.

Os resultados são apresentados na Tabela 4.3 e na Figura 4.15. O primeiro ponto a observar é que todas as técnicas tiveram pior acurácia em média, o que era esperado na presença de ruído. O segundo ponto importante é em relação às quedas de qualidade relativas. O classificador 1-NN com as observações originais teve uma queda de $30 \%$ na acurácia e de $0,5 \%$ com as medidas. A árvore de decisão com observações originais teve uma queda de $16 \%$, enquanto a versão utilizando as medidas descritivas apresentou uma queda de acurácia de 9,6\%. É importante observar que, apesar da queda do 1-NN com as medidas ter sido menor que a da árvore, a acurácia do 1-NN para o cenário sem ruído foi aproximadamente $10 \%$ menor que a da árvore.

Mais uma vez, a utilização das medidas descritivas para determinar características globais das séries forneceu um ganho de acurácia significativo e, além disso, mostrou-se menos sensível à presença de ruído. Já o classificador 1-NN com as observações originais mostrou-se muito afetado pela presença de ruído, uma vez que suas decisões são baseadas diretamente nos valores das séries. Novamente, realizou-se um Teste-T para avaliar a confiança dos resultados, com a hipótese alternativa de que a árvore de decisão com medidas descritivas teve acurácia média superior à do $1-\mathrm{NN}$ com observações originais ${ }^{8}$. A hipótese nula pôde ser rejeitada com um p-valor $2,5 \times 10^{-55}$, permitindo aceitar a hipótese alternativa de que de fato a árvore de decisão produz resultados superiores.

Tabela 4.3: Resultados experimentais com 10-fold Cross-validation para as 30 bases no cenário com adição de ruído.

\begin{tabular}{llcc}
\hline Classificador & \multicolumn{1}{c}{ Entrada } & Acurácia Média & Desvio Padrão \\
\hline 1-NN & Observações originais & 0,342 & 0,022 \\
1-NN & Medidas descritivas & 0,802 & 0,027 \\
Árvore de decisão & Observações originais & 0,520 & 0,030 \\
Árvore de decisão & Medidas descritivas & 0,801 & 0,028 \\
\hline
\end{tabular}

\footnotetext{
${ }^{8} \mathrm{O}$ algoritmo 1-NN utilizando como entrada as observações de séries temporais e distância Euclidiana é a versão mais empregada na literatura e considerada uma das mais difíceis de se superar (Xi et al., 2006).
} 


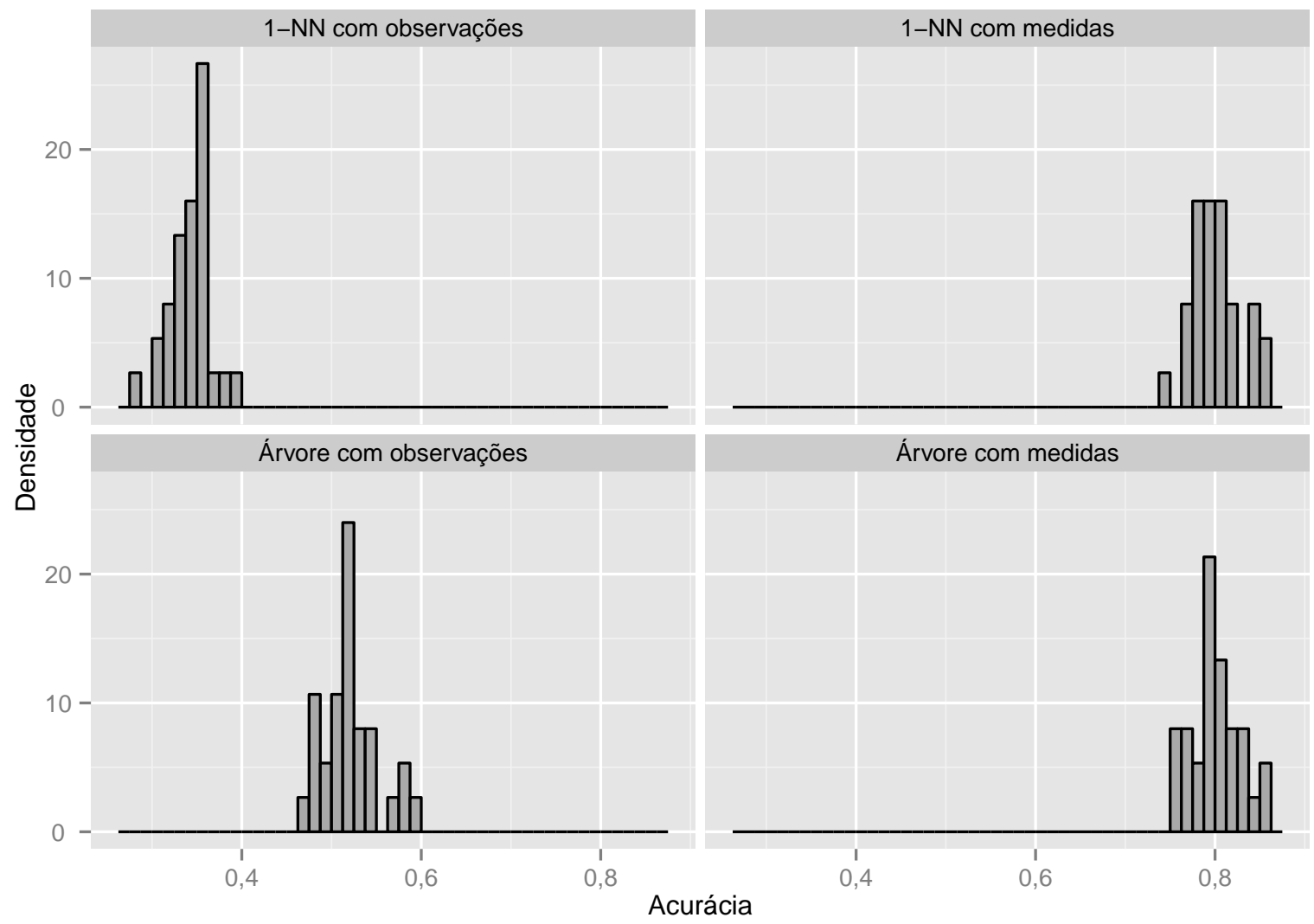

Figura 4.15: Histogramas dos resultados para o cenário com adição de ruído.

Apesar dos resultados do 1-NN com as medidas descritivas terem se mostrado próximos aos da árvore de decisão, há vários motivos para se preferir árvores de decisão neste trabalho. Primeiramente, as árvores naturalmente permitem identificar quais atributos são mais relevantes, já que eles residem mais próximos à raiz. Em segundo lugar, as árvores são mais interpretáveis, permitindo que leigos compreendam de forma mais fácil o modelo induzido. Em terceiro lugar, algoritmos baseados em vizinhos mais próximos, como 1$\mathrm{NN}$, requerem o armazenamento de toda a base de conhecimento, além da necessidade do cálculo da distância de todos os objetos entre si, o que resulta em uma complexidade de tempo quadrática.

A Figura 4.16 apresenta uma árvore de decisão induzida durante os experimentos com adição de ruído. É possível observar que desta vez a árvore usa mais testes para alcançar os nós folha, como esperado. Isso ocorre porque as observações com ruído atrapalham na diferenciação entre as classes de séries temporais. Embora o cenário seja mais difícil, a árvore de decisão usando as medidas descritivas ainda produz acurácia duas vezes maior que a do $1-\mathrm{NN}$ com observações originais (modelo mais tradicional na literatura).

A Tabela A.2 (p. 119) apresenta os rankings das medidas descritivas de séries temporais sobre as 30 bases de dados com adição de ruído. Nessa tabela, Ventr é a entropia da distribuição do comprimento de linhas diagonais, Lentr é a entropia da distribuição do comprimento de linhas verticais e $T$ representa o período de recorrência. Em resumo, todas as três são medidas de Análise de Quantificação de Recorrência (RQA) (Marwan 


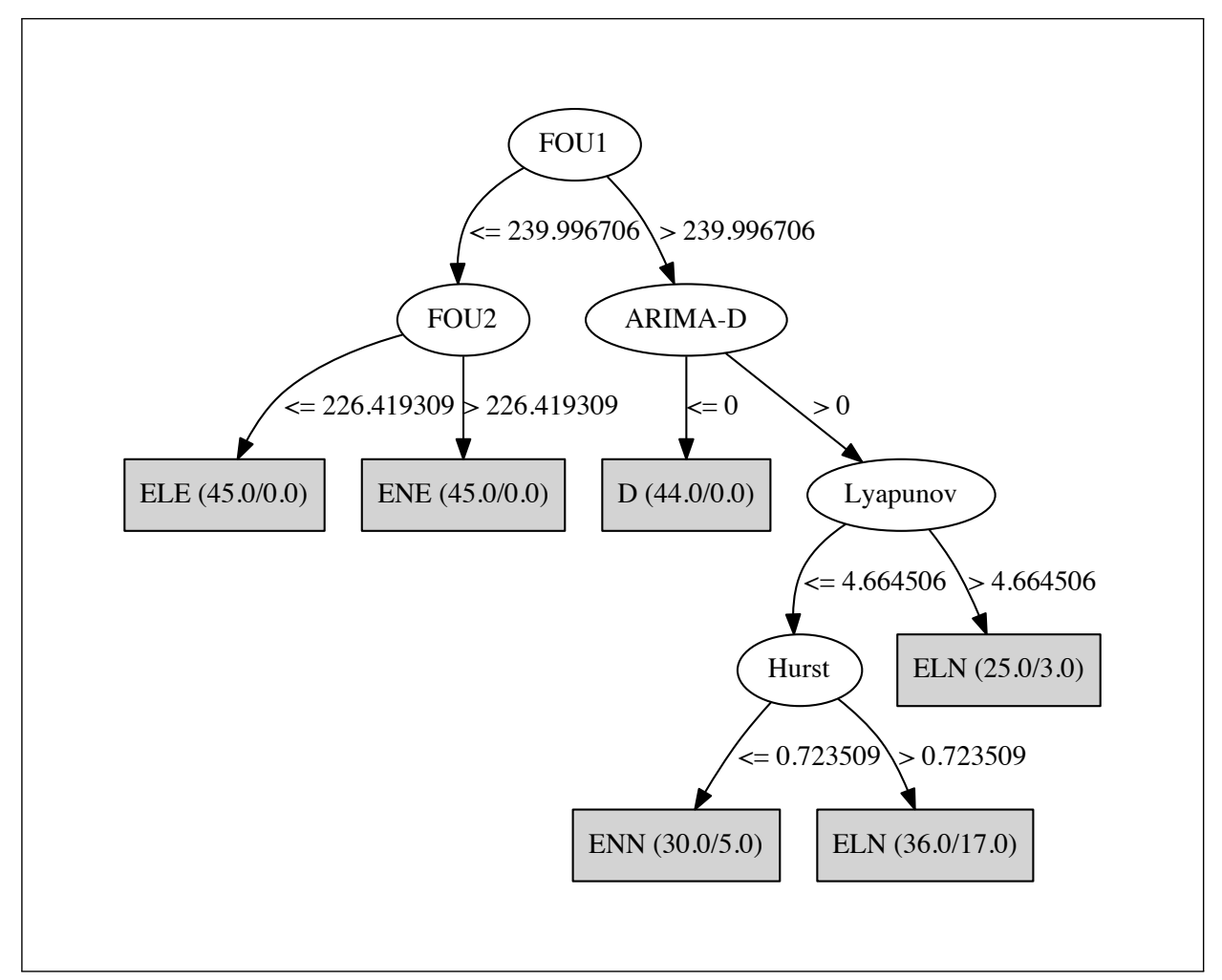

Figura 4.16: Exemplo de árvore de decisão induzida durante os experimentos com adição de ruído. Os rótulos usados são os mesmos da Figura 4.13.

et al., 2007). Observa-se ainda que a modelagem com técnicas de Box-Jenkins, como AR, MA e ARIMA apresentaram alto poder discriminativo. A Autoinformação Mútua (AMI), coeficientes de Fourier e de Lyapunov também ficaram bem posicionados em ambos os cenários, com e sem ruído. É interessante observar que o coeficiente de Hurst apresentou uma queda no ranking. Essa medida funciona calculando o nível de dependência com o passado de uma série. Como o ruído adicionado nas séries era proveniente de uma distribuição Uniforme (i.i.d.), o coeficiente de Hurst não apresentou um poder discriminativo expressivo.

\subsection{Experimentos com séries reais}

Além dos experimentos com as séries sintéticas, realizou-se também avaliações com séries temporais reais, extraídas de músicas publicamente disponíveis no Free Music Archive $^{9}$. A lista de músicas utilizadas pode ser encontrada na Tabela D.1 na página 132 (Apêndice D). Quatro gêneros musicais foram selecionados para os experimentos: Blues, Disco, Clássica e Hip-Hop, uma vez que existem diferenças claras entre eles. Para cada gênero, dez faixas foram usadas com uma frequência de downsampling de $8 \mathrm{KHz}^{10}$. Trinta

\footnotetext{
${ }^{9}$ http://www.freemusicarchive.org. Último acesso: 17 de maio de 2012.

${ }^{10} \mathrm{O}$ valor de $8 \mathrm{KHz}$ foi escolhido pois a maioria dos instrumentos musicais opera com frequências fundamentais abaixo de $4 \mathrm{KHz}$, com exceção do órgão de tubos que chega até $7.1 \mathrm{KHz}$ (conferir por exemplo http://www.independentrecording.net/irn/resources/freqchart/main_display.htm, último acesso: 03/12/2012.). Assim, optou-se por usar o dobro dessa frequência, ou seja, $8 \mathrm{KHz}$, para obter garantias do teorema de amostragem de Nyquist-Shannon (Shannon, 1949). Outro indicativo da
} 


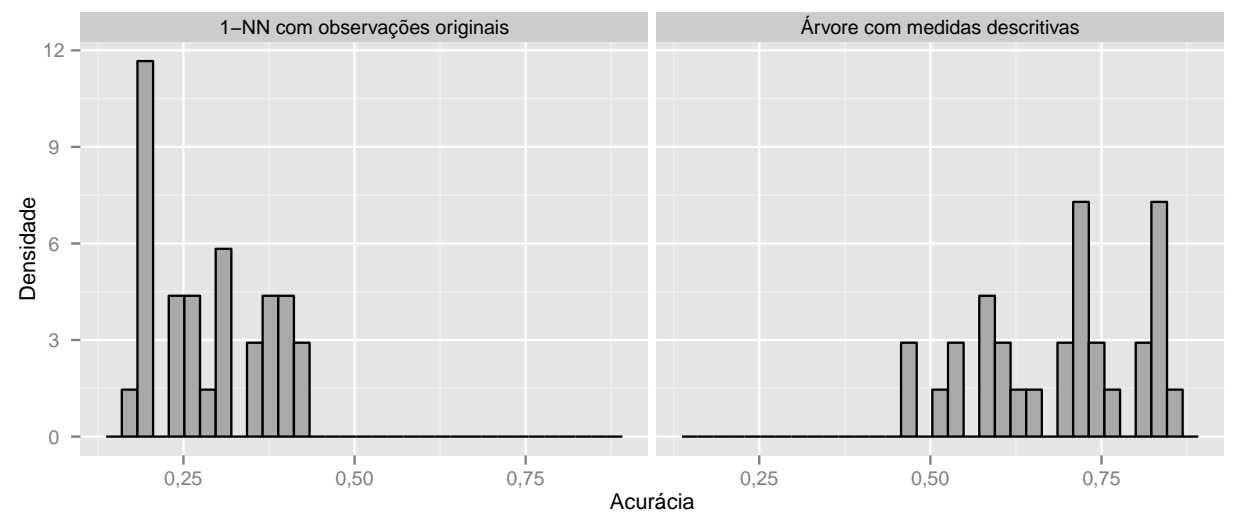

Figura 4.17: Resultados para os experimentos com séries temporais reais extraídas de músicas.

bases de dados foram criadas por meio da seleção aleatória de cinco faixas e sete séries temporais de cada uma delas. Cada série foi composta por 40000 observações de um segmento de cinco segundos de uma faixa. O rótulo de supervisão de cada série foi definido pela faixa da qual ela foi extraída.

A Tabela 4.4 apresenta os resultados para os trinta conjuntos de dados de músicas para classificação. A acurácia descrita na tabela é também ilustrada no gráfico da Figura 4.17. Observa-se que, em todos os casos, a árvore de decisão com medidas descritivas superou o 1-NN com observações originais. Em muitos casos a acurácia da árvore chegou a ser mais do que o dobro da obtida com o 1-NN.

Na Tabela 4.4, também são apresentados os valores do coeficiente Kappa de Cohen et al. (1960), que mede a concordância entre os rótulos atribuídos pelo classificador e os rótulos reais, porém com correção para a concordância esperada ao acaso. É interessante observar que na maioria dos casos o valor estimado do coeficiente Kappa para o 1-NN foi 0 , enquanto que para a árvore de decisão foi similar à sua acurácia. Isso aponta que a rotulação obtida com o 1-NN é mais próxima de uma classificação aleatória do que a obtida com a árvore.

Também foi feito um ranking das medidas descritivas para os dados reais extraídos das músicas. Os resultados estão listados na Tabela A.3 (Apêndice A, p. 119). É interessante comparar o ranking das medidas para as séries sintéticas e reais. Enquanto os coeficientes dos modelos de Box-Jenkins, AR, MA e ARIMA funcionaram bem para as séries sintéticas, eles não apresentaram um poder discriminativo expressivo para os dados reais do domínio de músicas. Por outro lado, os coeficientes obtidos pela Autoinformação Mútua (AMI) e Fourier (FOU) mostraram-se muito úteis tanto para as séries sintéticas quanto para as reais. O bom resultado da transformada de Fourier já era esperado, já que músicas são caracterizadas pelas frequências presentes. Esses resultados favorecem

adequação desse valor para amostragem é a frequência máxima adotada na implementação do software estatístico R para o cálculo dos coeficientes Mel-frequency cepstrum (MFCC), notadamente $6855.6 \mathrm{~Hz}$. Esse valor reproduz os resultados do pacote de análise de áudio de Malcolm Slaney para MATLAB. Nota-se, entretanto, que a realização do mesmo experimento com frequência de amostragem de $4 \mathrm{KHz}$ já fornece bons resultados. 
Tabela 4.4: Resultados experimentais com 10-fold Cross-validation sobre as bases do Free Music Archive.

\begin{tabular}{c|cc|cc}
\hline Conjunto & Acurácia Árvore de decisão & Kappa Árvore de decisão & Acurácia 1-NN & Kappa 1-NN \\
\hline 1 & 0,83 & 0,79 & 0,34 & 0,00 \\
2 & 0,80 & 0,75 & 0,20 & 0,00 \\
3 & 0,71 & 0,64 & 0,40 & 0,07 \\
4 & 0,69 & 0,61 & 0,43 & 0,00 \\
5 & 0,63 & 0,54 & 0,20 & 0,00 \\
6 & 0,54 & 0,43 & 0,26 & 0,07 \\
7 & 0,66 & 0,57 & 0,40 & 0,00 \\
8 & 0,83 & 0,79 & 0,23 & 0,04 \\
9 & 0,71 & 0,64 & 0,37 & 0,04 \\
10 & 0,80 & 0,75 & 0,37 & 0,00 \\
11 & 0,86 & 0,82 & 0,37 & $-0,04$ \\
12 & 0,71 & 0,64 & 0,31 & 0,00 \\
13 & 0,54 & 0,43 & 0,20 & 0,00 \\
14 & 0,77 & 0,71 & 0,23 & 0,04 \\
15 & 0,46 & 0,32 & 0,20 & 0,00 \\
16 & 0,57 & 0,46 & 0,20 & 0,00 \\
17 & 0,57 & 0,46 & 0,26 & $-0,04$ \\
18 & 0,57 & 0,46 & 0,26 & 0,04 \\
19 & 0,60 & 0,50 & 0,20 & 0,00 \\
20 & 0,60 & 0,50 & 0,20 & 0,00 \\
21 & 0,69 & 0,61 & 0,34 & 0,00 \\
22 & 0,71 & 0,64 & 0,31 & 0,00 \\
23 & 0,46 & 0,20 & $-0,04$ \\
24 & 0,83 & 0,32 & 0,23 & 0,04 \\
25 & 0,74 & 0,79 & 0,17 & -04 \\
26 & 0,51 & 0,68 & 0,43 & 0,00 \\
27 & 0,83 & 0,39 & 0,31 & 0,04 \\
28 & 0,74 & 0,79 & 0,40 & $-0,07$ \\
29 & 0,83 & 0,68 & & 0,04 \\
30 & 0,71 & 0,79 & & \\
\hline
\end{tabular}


a escolha dessas medidas (AMI e Fourier) para o uso em conjunto com o algoritmo de agrupamento proposto neste trabalho. 


\subsection{Considerações Finais}

Neste capítulo, foram apresentados os experimentos realizados para avaliar o impacto das medidas descritivas de séries temporais em um cenário de classificação. Foram utilizados dois algoritmos para a realização dos experimentos, notadamente árvores de decisão e 1-NN.

A escolha por árvores de decisão foi motivada por sua interpretabilidade, ranking natural dos atributos com maior poder discriminativo e eficiência. O algoritmo 1-NN foi escolhido por se tratar de uma das técnicas mais usadas na literatura de classificação de séries temporais, além de ser considerado um dos mais difíceis de superar nessa tarefa.

Os resultados mostraram que, de fato, o uso das medidas descritivas aumentou a acurácia da classificação. Além disso, outro ponto importante indicado pelos experimentos é o de que um classificador utilizando as medidas descritivas apresenta menor sensibilidade à presença de ruídos, com uma menor perda relativa de acurácia.

A melhora na acurácia da tarefa de classificação, a partir do uso das medidas descritivas, motivou a adoção de um subconjunto delas para a abordagem de agrupamento desenvolvida neste trabalho de doutorado. O ranking realizado também contribuiu para a seleção de medidas com maior poder discriminativo, as quais foram priorizadas nos experimentos com a abordagem de agrupamento. 
Capítulo

\subsection{Considerações iniciais}

Os capítulos anteriores mostraram como a maioria das técnicas de agrupamento de séries temporais em fluxos contínuos consideram, em geral, uma única perspectiva para calcular a similaridade entre séries. Técnicas como ODAC (Rodrigues et al., 2008) e ECM (Widiputra et al., 2011) baseiam-se somente na correlação de Pearson para a determinação de similaridade (ver Seção 1.1). Conforme demonstrado no exemplo da Figura 1.3, no Capítulo 1, séries geradas pelo mesmo modelo e com mesma parametrização podem resultar em correlação próxima a zero, refutando o uso exclusivo dessa medida.

Este trabalho busca cobrir essa lacuna por meio de uma caracterização mais completa do modelo gerador de séries temporais (Seção 1.2). Com essa finalidade, diversas medidas descritivas foram selecionadas, as quais foram apresentadas no Capítulo 3 e avaliadas no Capítulo 4. Os bons resultados obtidos em cenários controlados de classificação motivaram o emprego das medidas em uma nova abordagem de agrupamento, a qual é apresentada neste capítulo.

\subsection{Objetivo}

A limitação encontrada nas diversas abordagens de agrupamento de séries temporais em fluxos contínuos, notadamente de utilizarem apenas uma ou poucas características do 
modelo gerador no cálculo de similaridade entre séries, motivou a proposta de uma nova abordagem, que visa realizar o agrupamento baseando-se em uma caracterização mais completa de modelos geradores, por meio de diversas medidas que contemplem as propriedades levantadas na taxonomia de Ishii et al. (2011). Essas medidas foram detalhadas no Capítulo 3.

Portanto, o objetivo deste trabalho é melhorar a qualidade do agrupamento de séries temporais em fluxos contínuos por meio de uma caracterização mais completa de seu modelo gerador, para isso utilizando diversas medidas descritivas.

O principal critério de validação utilizado foi o Adjusted Rand Index ${ }^{1}$ (ARI), que se baseia na contagem de pares de objetos ${ }^{2}$ nos quais duas partições concordam ou discordam (Hubert e Arabie, 1985). Qualquer par de objetos pode ser colocado em uma de quatro categorias: i) eles estão no mesmo grupo em ambas as partições $\left(N_{11}\right)$, ii) eles estão em grupos diferentes em ambas as partições $\left(N_{00}\right)$, iii) eles estão no mesmo grupo na primeira partição, mas em grupos diferentes na segunda $\left(N_{10}\right)$ e iv) eles estão em grupos diferentes na primeira partição, mas no mesmo grupo na segunda $\left(N_{01}\right)$.

Os valores $N_{11}$ e $N_{00}$ podem ser vistos como medidas de concordância entre as duas partições, enquanto $N_{10}$ e $N_{01}$ como medidas de discordância. Dadas duas partições de um conjunto $S$ de $M$ objetos, seja $U=\left\{U_{1}, U_{2}, \ldots, U_{R}\right\}$ a primeira partição com $R$ grupos e $V=\left\{V_{1}, V_{2}, \ldots, V_{C}\right\}$ a segunda partição com $C$ grupos. Seja também $\cap_{i=1}^{R} U_{i}=\cap_{j=1}^{C} V_{j}=$ $\varnothing, \cup_{i=1}^{R} U_{i}=\cup_{j=1}^{C} V_{j}=S$. É possível criar uma matriz de contingência $R \times C$ na qual cada elemento $n_{i j}$ indica o número de objetos em comum aos grupos $U_{i}$ e $V_{j}$.

Uma das principais críticas ao Rand Index original é que ele não é corrigido para chance, ou seja, seu valor não é zero quando avalia duas partições geradas aleatoriamente (Vendramin et al., 2010). O Adjusted Rand Index corrige essa limitação por meio de uma normalização, tal que seu valor esperado é 0 para duas partições aleatórias e 1 para partições idênticas. O índice pode ser calculado conforme descrito na Equação 5.1, na qual $n_{i j}$ é um elemento da matriz de contingência, $a_{i}$ é a soma da $i$-ésima linha e $b_{j}$ a soma da $j$-ésima coluna.

$$
\mathrm{ARI}=\frac{\sum_{i j}\left(\begin{array}{c}
n_{i j} \\
2
\end{array}\right)-\left[\sum_{i}\left(\begin{array}{c}
a_{i} \\
2
\end{array}\right) \sum_{j}\left(\begin{array}{c}
b_{j} \\
2
\end{array}\right)\right] /\left(\begin{array}{c}
N \\
2
\end{array}\right)}{\frac{1}{2}\left[\sum_{i}\left(\begin{array}{c}
a_{i} \\
2
\end{array}\right)+\sum_{j}\left(\begin{array}{c}
b_{j} \\
2
\end{array}\right)\right]-\left[\sum_{i}\left(\begin{array}{c}
a_{i} \\
2
\end{array}\right) \sum_{j}\left(\begin{array}{c}
b_{j} \\
2
\end{array}\right)\right] /\left(\begin{array}{c}
N \\
2
\end{array}\right)}
$$

Não se utilizou neste trabalho critérios como Silhueta, Índice de Dunn ou DaviesBouldin (Halkidi et al., 2001), pois todos dependem das distâncias entre objetos da base. Essa decisão baseia-se no cenário abordado por este trabalho, no qual os objetos são séries temporais, e a distância Euclidiana ou a correlação de Pearson, empregadas por critérios tais como os citados, nem sempre representam de fato a similaridade entre os modelos geradores de séries temporais, como já demonstrado em vários exemplos (ver Seção 1.1).

\footnotetext{
${ }^{1}$ Trata-se de um critério externo que utiliza uma rotulação conhecida dos grupos. Enquanto é uma medida muito útil para avaliar o algoritmo, em ambientes de produção não se dispõe da rotulação externa para a aplicação do critério.

${ }^{2}$ No contexto deste trabalho, objetos são séries temporais.
} 
Além dessas limitações, não seria possível comparar os valores obtidos por esses critérios com a abordagem proposta neste trabalho e outras da literatura, já que cada uma utiliza uma medida de distância diferente. Utilizar o critério de Silhueta com a distância Euclidiana, por exemplo, favoreceria alguns algoritmos e prejudicaria outros.

\subsection{TS-Stream - Abordagem proposta}

No início deste trabalho, realizou-se uma revisão da literatura, a qual levou em conta diversos estudos de agrupamento no contexto de fluxos contínuos. Foi possível observar que poucos trabalhos abordaram o agrupamento de séries temporais, sendo que a principal técnica encontrada para esse cenário foi ODAC (Rodrigues et al., 2008). Um estudo detalhado revelou que ODAC e outras abordagens derivadas (Widiputra et al., 2011; Yang e Chen, 2011) baseiam-se somente na correlação de Pearson para a determinação de similaridade entre séries. Esse viés mostrou-se uma forte limitação, dado que o simples cálculo de correlação nem sempre é capaz de detectar séries produzidas por um mesmo modelo gerador. Essas restrições motivaram a busca por medidas descritivas que melhor caracterizassem o modelo gerador de séries temporais. Esse estudo juntamente com a avaliação realizada das medidas foram apresentados nos Capítulos 3 e 4 .

Após a identificação de medidas relevantes para a tarefa de caracterização de modelos geradores, a etapa seguinte deste trabalho consistiu na proposta de uma abordagem de agrupamento. Essa etapa resultou no algoritmo TS-Stream (Time Series Stream), listado no Algoritmo 8.

TS-Stream funciona por meio da indução de um modelo similar a uma árvore de decisão, porém sem o uso de classes. A estratégia adotada para a construção da árvore funciona no sentido top-down, iniciando com todas as séries em um mesmo grupo (raiz) e realizando sucessivas divisões e agregações. Cada nó intermediário da árvore realiza um teste binário do tipo "valor atributo $\leq x$ " sobre determinado atributo calculado pelas medidas descritivas. Quando uma folha é alcançada, a série é agrupada junto às demais pertencentes à mesma folha.

O procedimento principal recebe como entrada um conjunto $S=\left\{S_{1}, S_{2}, \ldots, S_{m}\right\}$ de $m$ séries temporais com um número de observações possivelmente infinito, as quais são analisadas em janelas de tamanho fixo de $w$ observações. Também devem ser fornecidos os parâmetros $\alpha \in[0,1], \beta \in[0, \infty)$ e $\lambda \in[0,1]$, explicados mais adiante.

O primeiro passo consiste no cálculo de medidas descritivas de séries temporais ${ }^{3}$, tais como as apresentadas no Capítulo 3. Isso gera uma matriz de entrada $m \times n$, em que $n$ corresponde ao número de atributos obtidos via as medidas ${ }^{4}$. A seguir, realiza-se a normalização dessa matriz em cada dimensão com score- $z$ : $x=(x-\mu) / \sigma$, em que $\mu$ é a média e $\sigma$ o desvio padrão da dimensão.

\footnotetext{
${ }^{3}$ É importante deixar claro que o cálculo dessas medidas não é incremental, necessitando da janela de $w$ observações armazenada em uma memória temporária.

${ }^{4}$ Uma medida pode gerar diversos coeficientes, como a transformada de Fourier por exemplo.
} 
Essa normalização é essencial, pois conforme discutido adiante, o algoritmo utiliza um critério de minimização de variância. Como diferentes medidas descritivas de séries temporais podem fornecer como saída coeficientes em escalas distintas, a normalização faz com que não seja dada maior importância a um atributo apenas em função de sua escala.

No início, o algoritmo cria a raiz da árvore supondo que todas as séries estão em um mesmo grupo, porém existem diferenças entre elas e, portanto, devem ser separadas. Para isso, o procedimento encontraAtributoSignificativo é chamado, passando como parâmetro um vetor de pertinências: membros $=[1,1, \ldots, 1]$, sendo 1 indicativo de que a i-ésima série pertence ao nó; com $m$ posições, e o bloco (matriz de entrada $m \times n$ ) atual.

O procedimento encontraAtributoSignificativo é responsável por encontrar o melhor atributo para realizar o teste de divisão do nó atual. Essa busca envolve a minimização de um critério de variância ponderada. Seja $\Lambda$ o nó atual com $n$ membros e $\Lambda_{e s q}$ e $\Lambda_{d i r}$ os nós gerados após a divisão, cada um com $n_{\text {esq }}$ e $n_{\text {dir }}$ membros, respectivamente. O critério busca o atributo que maximiza o ganho na variância ponderada após a divisão, conforme a Equação 5.2 , em que $\sigma^{2}(\cdot)$ é a função de variância ${ }^{5}$.

$$
\text { Ganho }=\sigma^{2}(\Lambda)-\frac{n_{e s q} \cdot \sigma^{2}\left(\Lambda_{e s q}\right)+n_{d i r} \cdot \sigma^{2}\left(\Lambda_{d i r}\right)}{n}
$$

A intuição por trás desse critério é que deve existir pelo menos um atributo, obtido via as medidas descritivas, capaz de separar as séries de acordo com seu modelo gerador. Isso significa que séries provenientes de um mesmo modelo apresentarão valores próximos entre si para o atributo. Assim, ao se realizar a divisão, cada nó filho possuirá séries com menor variância para o dado atributo, i.e., maior pureza. Esse conceito assemelha-se à medida de Ganho de Informação (Tan et al., 2005) usada em algoritmos como C4.5, porém não faz uso de classes, já que o cenário abordado é de agrupamento.

O procedimento encontraAtributoSignificativo utiliza o parâmetro $\beta$ como forma de penalização de atributos que apresentam uma fração alta de valores distintos ou todos os valores iguais, casos que não auxiliam na separação das séries. Isso é feito por meio do cálculo da Entropia de Shannon (1951) do atributo, conforme a Equação 5.3, em que $h$ é o número de bins em que o atributo foi discretizado. O procedimento só considera um atributo como candidato para divisão caso sua entropia seja maior que o parâmetro $\beta$. Esse conceito é ilustrado na Figura 5.1.

$$
\text { Entropia }=-\sum_{i=1}^{h} p_{i} \cdot \log _{2} p_{i}
$$

A função melhorQuebra é utilizada para realizar a minimização do critério de variância $^{6}$. Para isso, ela avalia todos os possíveis pontos de corte do atributo em questão e

\footnotetext{
${ }^{5}$ Por completude, a variância de uma sequência $X=\left(x_{1}, x_{2}, \ldots, x_{n}\right)$ é definida como $\sigma^{2}(X)=\sum_{i=1}^{n} p_{i} \cdot\left(x_{i}-\mu\right)^{2}$, em que $p_{i}$ é a probabilidade de ocorrência da observação $x_{i}$ e $\mu$ é a média da sequência.

${ }^{6} \mathrm{~A}$ minimização da variância é equivalente à maximização do Ganho após a divisão, conforme definido na Equação 5.2.
} 


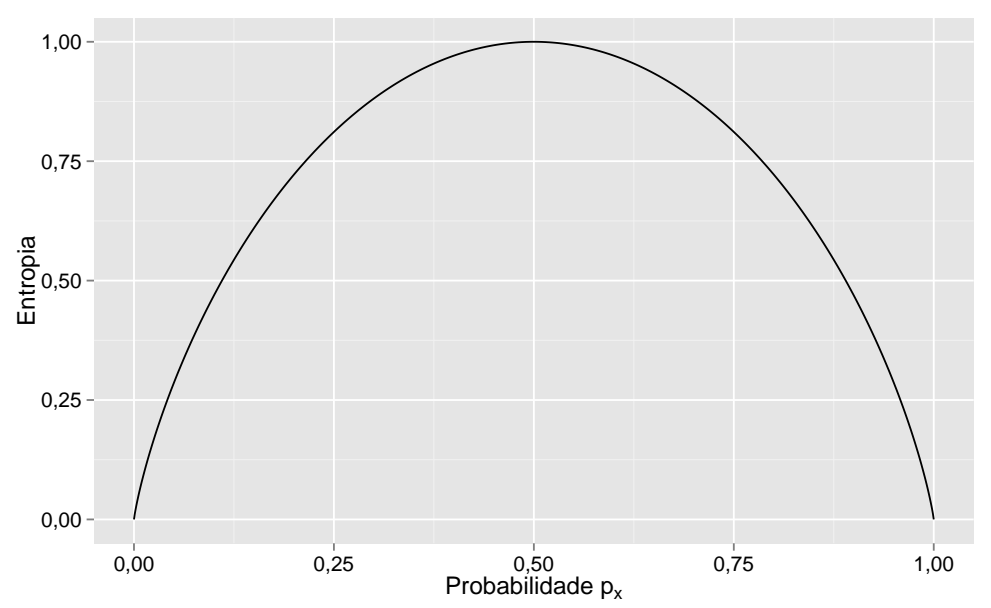

Figura 5.1: Exemplo do valor de entropia para o caso em que o atributo é segmentado em duas partições (bins): Entropia $=-\left(p_{x} \log _{2} p_{x}+p_{y} \log _{2} p_{y}\right)$. Em ambos os extremos, $p_{x} \approx 0$ e $p_{x} \approx 1$, uma das partições tem probabilidade próxima a 1 de ser observada, já que $p_{x}+p_{y}=1$. Esses cenários não são úteis, pois se quase todas as séries apresentam o mesmo valor para um dado atributo, então não é possível segmentá-las. O parâmetro $\beta$ define um corte mínimo de entropia, abaixo do qual o atributo não é considerado para divisão.

retorna o que fornece a menor variância ponderada.

O teste binário da raiz da árvore é então criado utilizando o ponto de corte do atributo selecionado, o que resulta nas primeiras folhas. Ao final da primeira iteração do algoritmo obtém-se uma árvore composta por um nó raiz e duas folhas.

$\mathrm{Na}$ próxima iteração, ao processar a segunda entrada de dados (matriz $m \times n$ de coeficientes obtidos por meio das medidas descritivas), primeiramente procede-se a uma fase de agrupamento das séries de acordo com a estrutura de árvore atual. A seguir, inicia-se a fase de atualização do modelo, na qual é avaliada a necessidade de agregação ou divisão de folhas.

Para decidir se uma folha deve ser agregada à sua irmã (i.e., aquela no mesmo nível e proveniente do mesmo nó pai), calcula-se a variância ponderada das duas e agrega-se caso ela seja maior ou igual a $\lambda$ vezes a variância do pai no atributo utilizado para divisão. Por exemplo, caso a variância ponderada dos nós filhos seja $10, \lambda=0,5$ e a variância do pai seja 12, então o algoritmo opta pela agregação, já que a variância dos filhos supera o valor mínimo de $50 \%=6$ da variância do pai. Caso ocorra agregação, então os dois nós são apagados. O nó pai é então novamente marcado como uma folha.

Caso não ocorra agregação, é avaliada a possibilidade de divisão de folhas. O procedimento encontraAtributoSignificativo é chamado e, verificado que existe um atributo que atende aos pré-requisitos para divisão, procede-se à quebra da folha caso haja uma redução de variância de pelo menos $\alpha$ vezes a atual. Isso implica na criação de duas novas folhas utilizando o teste binário definido pelo ponto de corte do atributo selecionado.

Dessa maneira, a cada iteração o algoritmo agrupa as séries de acordo com a estrutura de árvore atual e verifica se deve ocorrer uma atualização no modelo, tanto no sentido de expandir a hierarquia (com divisões) ou simplificá-la, com agregações.

A seção seguinte apresenta uma discussão sobre alguns pontos do algoritmo, como a 
opção pelo uso do modelo inspirado em árvores de decisão, as implicações e restrições causadas por isso e os parâmetros do algoritmo e como configurá-los. 


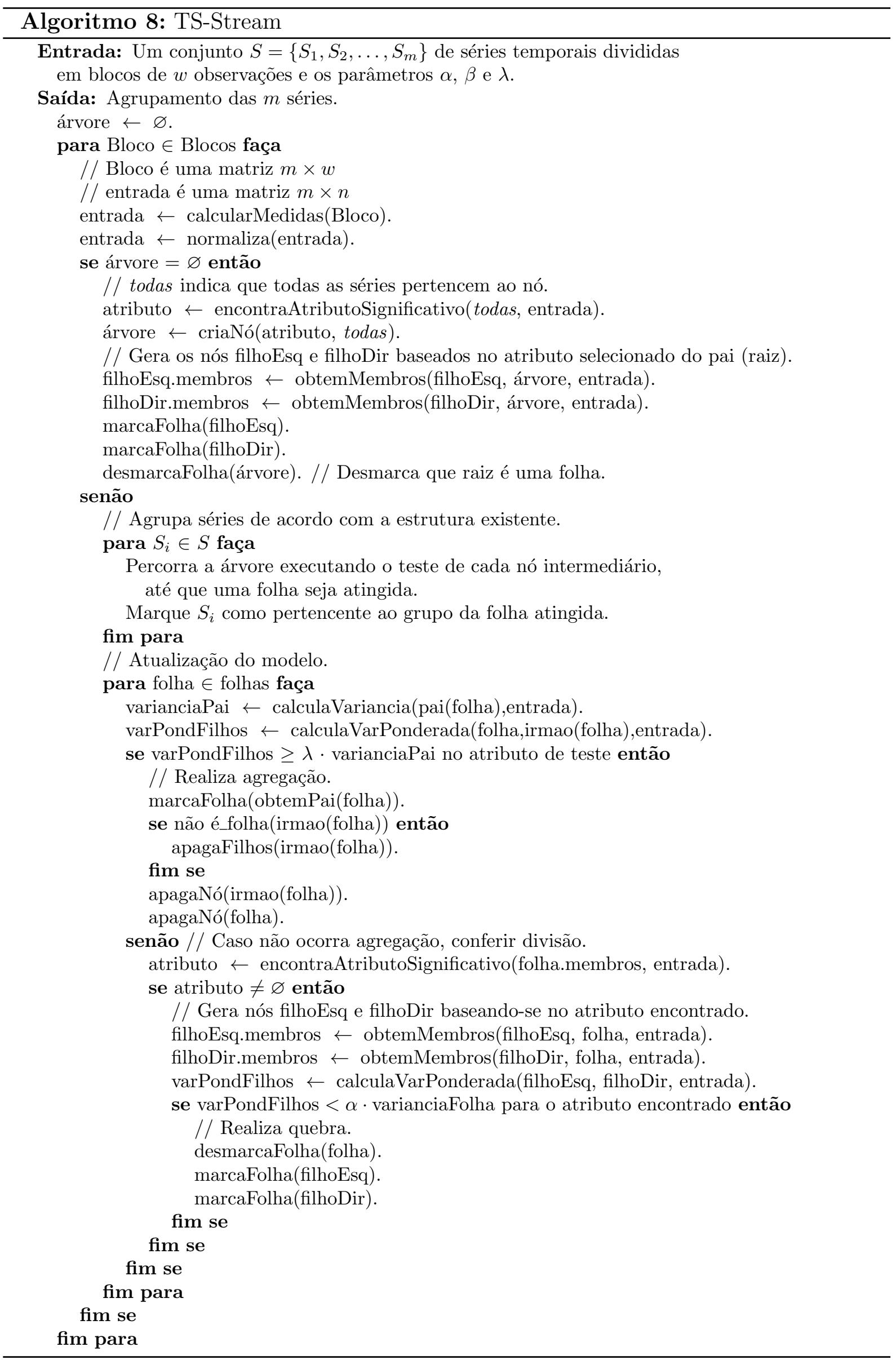



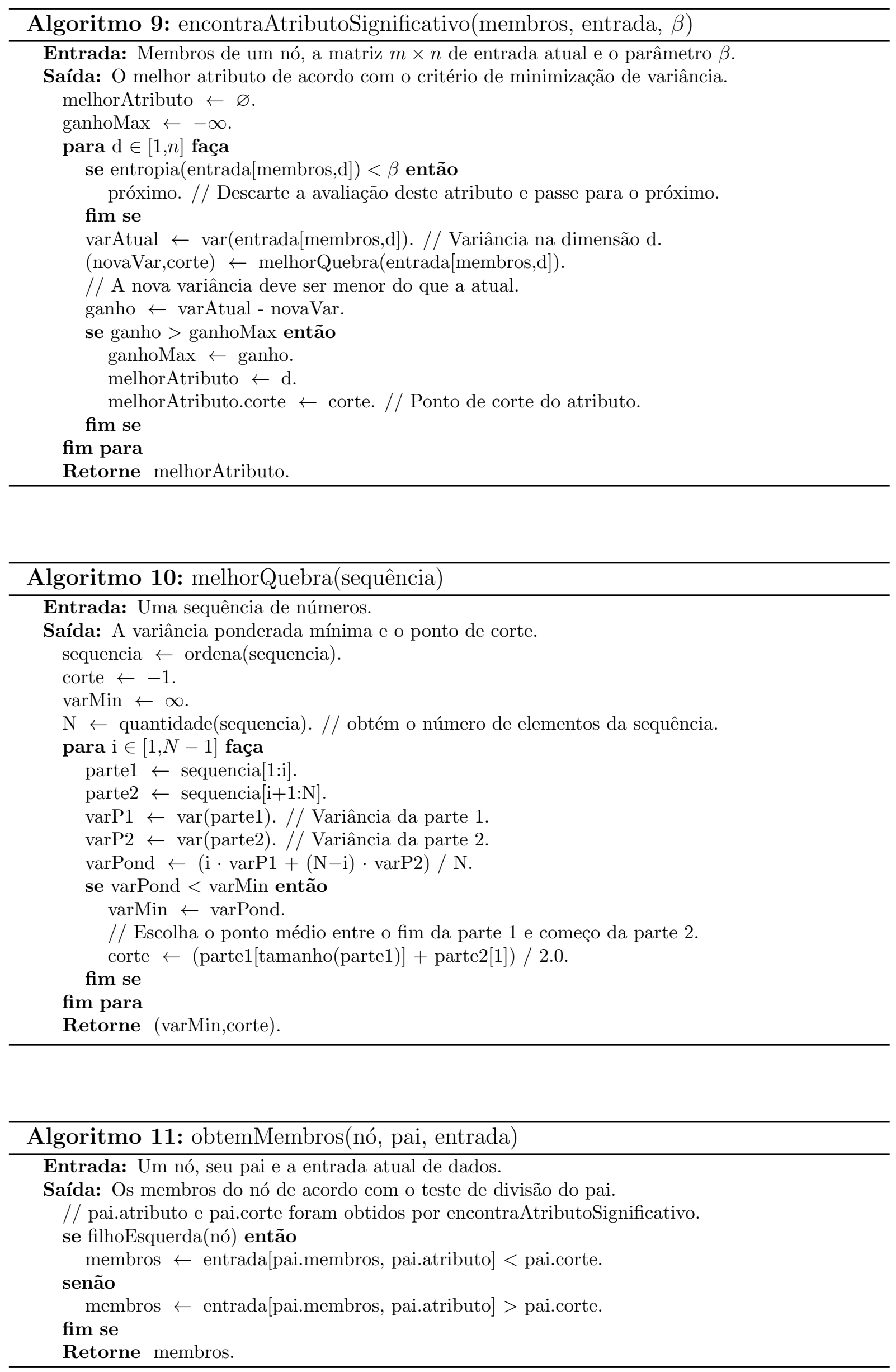

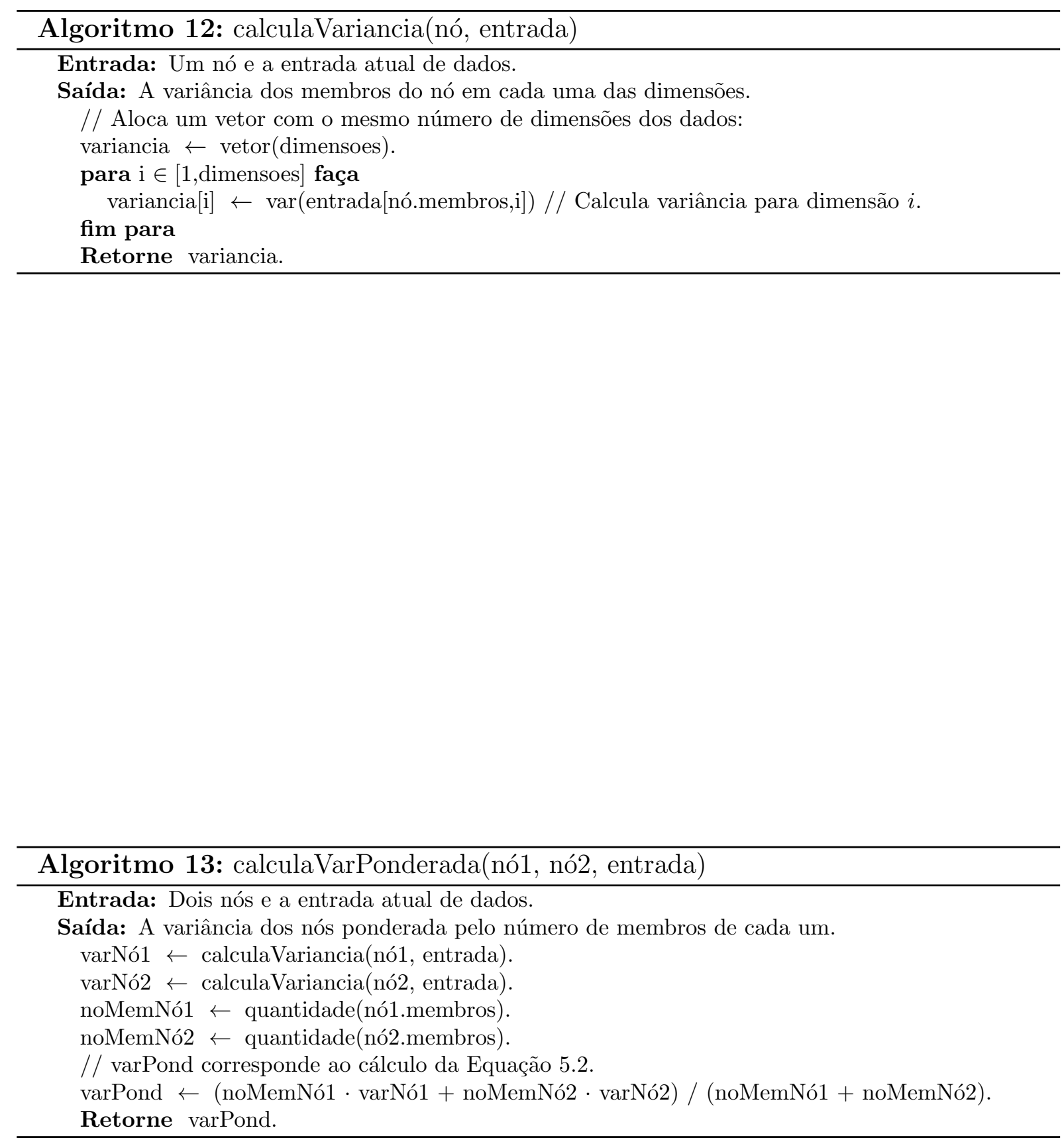


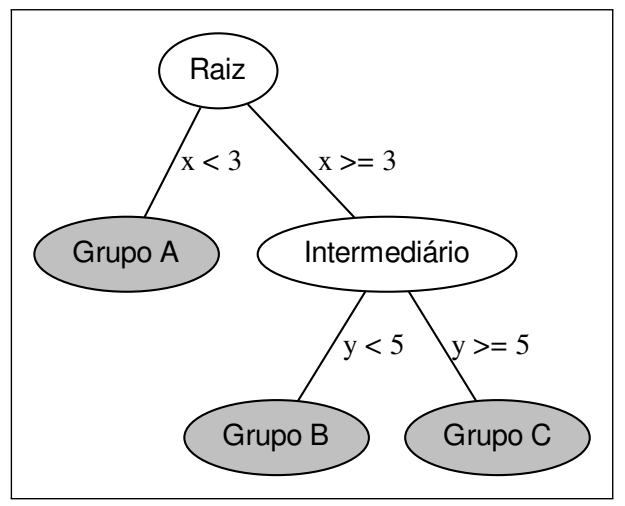

(a) Árvore hipotética.

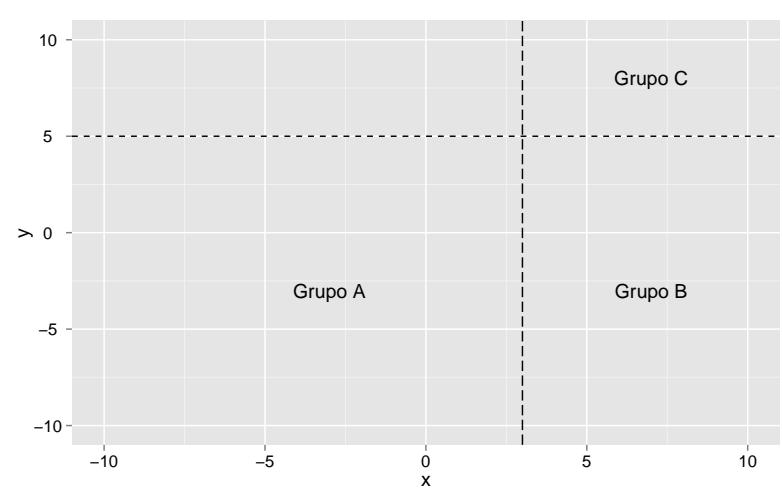

(b) Plano cartesiano com cortes ortogonais.

Figura 5.2: Exemplo de uma árvore com três folhas (em cinza), representando três grupos. Os cortes realizados são ortogonais entre si e estão projetados no plano cartesiano da figura à direita.

\subsection{Discussão sobre o algoritmo}

A opção pelo uso de um modelo de agrupamento inspirado em árvores de decisão foi motivada pelos bons resultados obtidos durante os experimentos no cenário de classificação com o algoritmo J48 (ver Capítulo 4).

Os testes binários, do tipo $a t r_{X} \leq Y$ e $a t r_{X}>Y$, baseados nos coeficientes calculados por meio das medidas descritivas de séries temporais, mostraram-se adequados para segmentar séries em suas diferentes classes.

Outra vantagem que TS-Stream compartilha com árvores de decisão tradicionais é uma certa robustez a atributos irrelevantes e ruidosos. No caso de TS-Stream, isso significa que, mesmo na presença de coeficientes extraídos de medidas descritivas que não apresentem alto grau de poder discriminativo (ou muito similar a outros coeficientes), o algoritmo é capaz de ignorar esses atributos, já que a redução de variância proporcionada por eles tende a ser menor - maior mistura no caso de atributos ruidosos - ou muito próxima a outros, no caso de atributos correlacionados (irrelevantes). TS-Stream sempre escolhe para divisão o atributo que fornece a máxima redução de variância, minimizando os problemas causados por atributos irrelevantes e ruidosos. Além disso, o parâmetro $\lambda$, que realiza uma penalização em função da entropia de um atributo, também auxilia na robustez, eliminando atributos com pouco poder discriminativo.

Também optou-se pelo modelo de árvore de decisão em função de sua interpretabilidade, já que é mais simples analisar quais coeficientes (e portanto quais características) determinaram os grupos encontrados. Esses coeficientes auxiliam na melhor caracterização do modelo gerador das séries estudadas (ver Capítulo 4). Por exemplo, caso o teste de um nó seja sobre o valor de Determinismo - DET - então se pode concluir que as séries foram segmentadas devido a algumas apresentarem modelos majoritariamente estocásticos enquanto outras modelos majoritariamente determinísticos.

É importante ressaltar algumas características provenientes da opção pelo uso de árvores e testes binários para decisão. Primeiramente, os cortes realizados são ortogonais 
entre si com relação às dimensões de separação. A Figura 5.2 apresenta uma árvore hipotética e os cortes correspondentes projetados no plano cartesiano. O fato dos cortes serem ortogonais entre si significa que não é possível obter divisões oblíquas do espaço, por meio de testes que realizam combinações lineares entre atributos. É importante ressaltar, entretanto, que TS-Stream permite o reuso do mesmo atributo em testes subsequentes na árvore. Isso possibilita a segmentação de três ou mais conjuntos de séries bem agrupadas em um mesmo atributo.

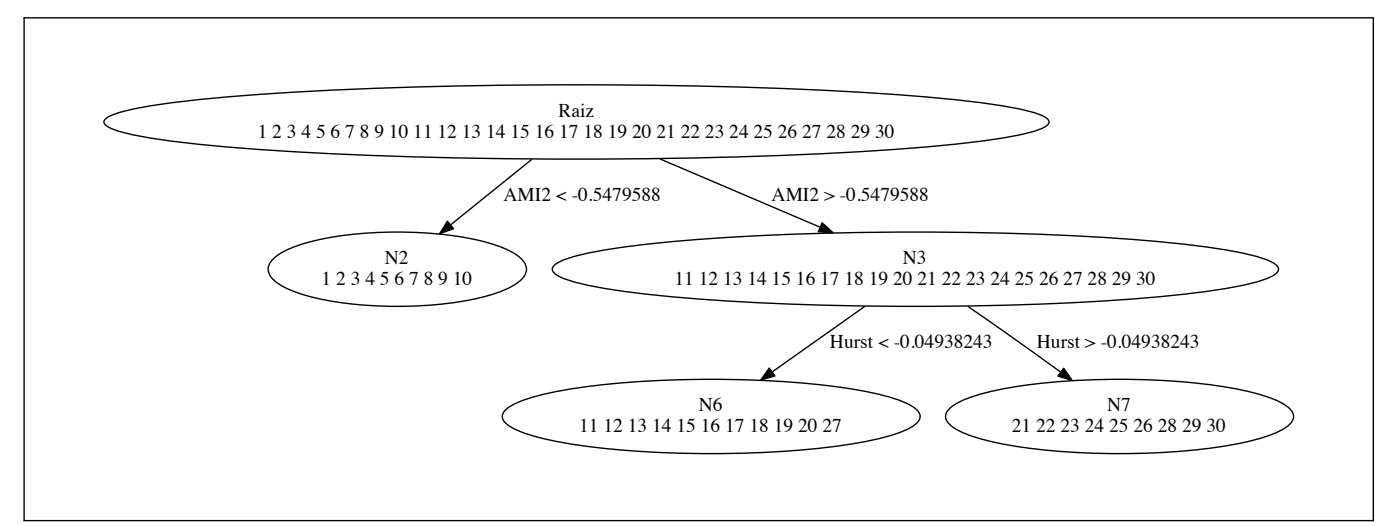

Figura 5.3: Exemplo de uma árvore induzida sobre uma base de dados sintética formada pela partição $\{\{1,2, \ldots, 10\},\{11,12, \ldots, 20\},\{21,22, \ldots, 30\}\}$. Na árvore, AMI2 indica o coeficiente obtido a partir da Autoinformação Mútua com atraso 2. Hurst indica o valor obtido para o expoente de Hurst.

A Figura 5.3 apresenta uma árvore induzida pelo algoritmo sobre uma base de dados sintética composta por 3 grupos e 30 séries. As séries de 1 a 10 constituem um grupo cujo modelo gerador foi dado por um processo Autoregressivo AR(1). As séries de 11 a 20 são oriundas de um mapa logístico, enquanto as séries de 21 a 30 foram geradas a partir de um modelo $\operatorname{ARIMA}(1,1,0)$ com não linearidade adicionada. Conforme pode ser observado na Figura 5.3, o algoritmo segmentou corretamente a maioria das séries, ficando apenas a número 27 no grupo do nó N6 enquanto deveria estar no nó N7.

TS-Stream se destaca em relação a ODAC especialmente em conjuntos de dados com características não lineares. Considere um fluxo contínuo $S=\left\{S_{1}, S_{2}, S_{3}, S_{4}, S_{5}\right\}$, com séries seguindo modelos de acordo com as Equações 5.4 a 5.7. A partir desses modelos é possível identificar três grupos naturais: $C_{A}=\left\{S_{1}, S_{2}\right\}$, dado que a diferença matemática entre $S_{1}$ e $S_{2}$ é apenas na fase da senóide $\phi=3 \pi / 2 ; C_{B}=\left\{S_{3}, S_{4}\right\}$, dado que são realizações de uma variável aleatória distribuída segundo uma Normal; e $C_{C}=\left\{S_{5}\right\}$.

$$
\begin{gathered}
S_{1 t}=\sin (14 \pi t) \\
S_{2 t}=\sin (14 \pi t+3 \pi / 2) \\
S_{3 t} \text { e } S_{4 t} \sim \mathcal{N}(0,1)
\end{gathered}
$$




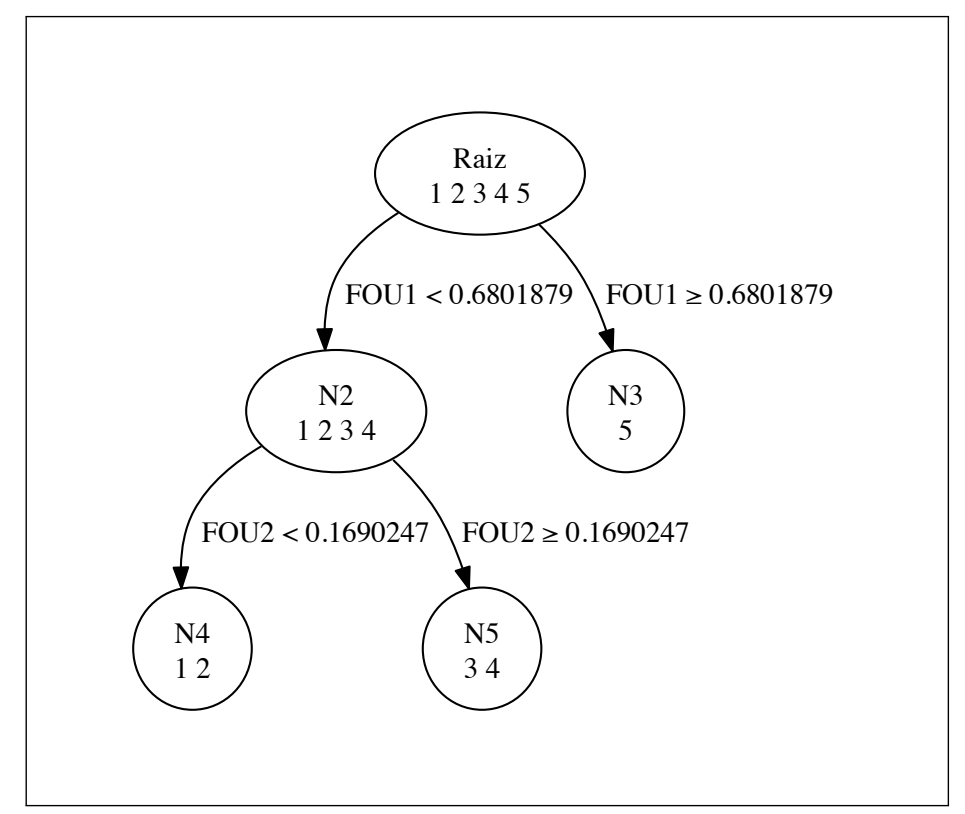

Figura 5.4: Árvore obtida por TS-Stream para o experimento com um fluxo $S=\left\{S_{1}, S_{2}, S_{3}, S_{4}, S_{5}\right\}$. As folhas $N 3, N 4, N 5$ indicam os grupos. FOU1 e FOU2 são os coeficientes de Fourier (primeiro e segundo, respectivamente) identificados pelo critério de minimização de variância de TS-Stream como os melhores para realizar a divisão.

$$
S_{5 t}= \begin{cases}1 & \text { se } t \text { é par } \\ -1 & \text { se } t \text { é ímpar }\end{cases}
$$

Gerando 10000 observações linearmente espaçadas de cada série no intervalo $t=0 \mathrm{~s}$ e $t=10 \mathrm{~s}$ e calculando a matriz $R$ de dissimilaridade RNOMC, obtém-se os valores mostrados na Equação 5.8. Observa-se que a medida RNOMC, baseada na correlação de Pearson, não é capaz de capturar a similaridade entre as séries, pois todas ficam aproximadamente equidistantes umas das outras. É interessante observar ainda que a série $S_{1}$ (senóide) ficou mais próxima de $S_{3}$ (ruído branco) do que da outra senóide, $S_{2}$.

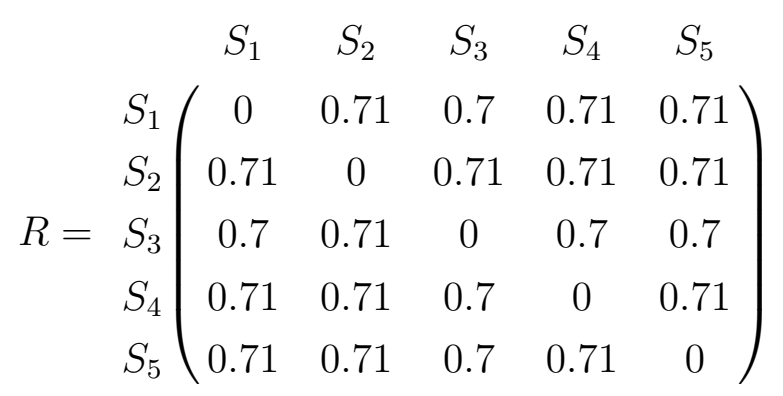

A Figura 5.4 apresenta a árvore obtida com TS-Stream usando os parâmetros $\alpha=0,3$, $\beta=0,3, \lambda=0,6$ and $w=1000$. Observa-se que TS-Stream identificou com sucesso os três grupos esperados. A Figura 5.5 apresenta os coeficientes de Fourier obtidos por TS-Stream via o critério de minimização de variância. Verifica-se que, no espaço projetado, as séries estão bem agrupadas de acordo com seu modelo matemático. Além de encontrar uma projeção adequada, os cortes ortogonais realizados por TS-Stream retornam a partição correta $\left\{\left\{S_{1}, S_{2}\right\},\left\{S_{3}, S_{4}\right\},\left\{S_{5}\right\}\right\}$. Isso realça a vantagem de TS-Stream sobre ODAC em 


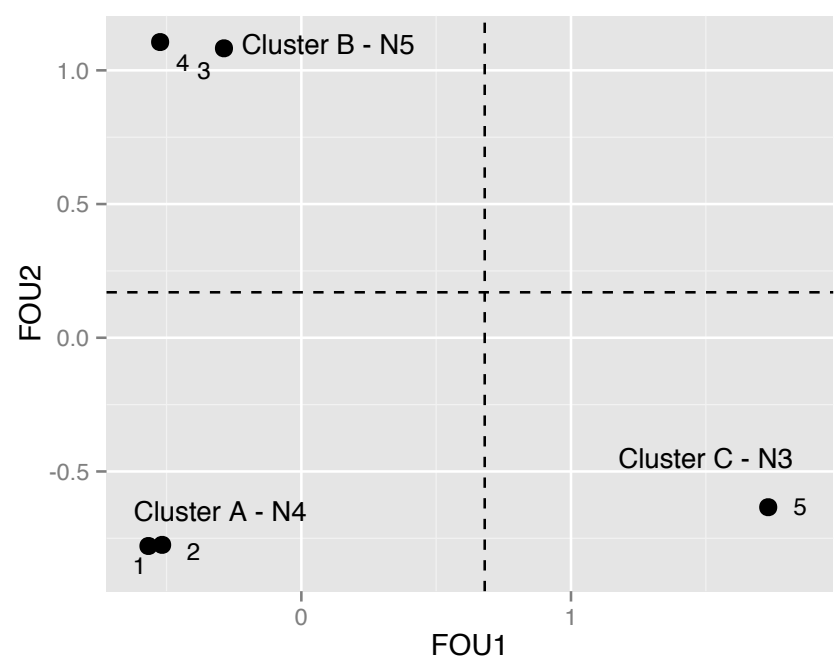

Figura 5.5: Cortes ortogonais realizados por TS-Stream no espaço projetado dos coeficientes de Fourier, separando com sucesso os grupos. As dimensões apropriadas (FOU1 e FOU2), juntamente com os pontos de corte, foram identificados pelo critério de minimização de variância de TS-Stream. Os números de 1 a 5 indicam os pontos correspondentes às séries do fluxo.

conjuntos de dados com características não lineares, as quais não são adequadamente capturadas pela correlação de Pearson.

Outra característica importante é que, diferentemente da estratégia gulosa de algoritmos como ID3 (Quinlan, 1986) e C4.5 (Quinlan, 1993a), TS-Stream permite backtracking por meio das operações de agregação e divisão. Essa característica é especialmente importante dado o cenário de fluxos contínuos, já que os grupos podem se alterar ao longo do tempo e decisões prévias podem não ser mais válidas.

Outro ponto relevante é a parametrização do algoritmo. O primeiro parâmetro, $\alpha \in$ [0,1], controla qual a porcentagem mínima da variância de um atributo do nó pai que precisa ser reduzida para que haja uma divisão. Assim, quanto maior o valor de $\alpha$, menor será a redução de variância necessária para realizar a divisão. O segundo parâmetro, $\beta \in[0, \infty)$, controla a entropia mínima que um atributo deve ter para ser um candidato à divisão. Atributos com todos os valores iguais ou todos os valores muito diferentes auxiliam pouco na segmentação de séries. Quanto maior o valor de $\beta$, maior deverá ser o nível de diferenciação do atributo a fim de que ele seja considerado para divisão. Já o parâmetro $\lambda \in[0,1]$ controla o momento de agregação. Caso a variância ponderada de duas folhas irmãs supere $\lambda$ vezes a do pai é executada a operação de agregação. Dessa forma, quanto maior o valor de $\lambda$, mais raramente a operação de agregação é executada.

É importante também indicar as atuais limitações de TS-Stream. Em um cenário no qual o usuário deseja encontrar grupos de séries com formato (shape) similar, as medidas estudadas neste trabalho, especialmente Fourier, Hurst e AMI, não são adequadas. Para esse propósito, o uso da correlação de Pearson, em geral, tende a funcionar melhor. Entretanto, cenários como esse podem ser englobados por TS-Stream por meio da adição de medidas descritivas adequadas. Considere uma medida que enumera subestruturas das séries em um conjunto de coeficientes binários $C_{1}, C_{2}, \ldots, C_{i}, \ldots, C_{n}$. Para o $i$-ésimo 
coeficiente, um valor igual a 1 para uma série indica a presença da $i$-ésima subestrutura nessa série, enquanto o valor 0 indica a ausência. Essa medida forneceria ao critério de minimização de variância de TS-Stream um método para segmentar as séries em termos de seus formatos, assim como ODAC tende a fazer com a correlação de Pearson.

A seção seguinte continua a discussão sobre o algoritmo apresentando a análise de sua complexidade assintótica, considerando também o custo para o cálculo das medidas descritivas utilizadas nos experimentos.

\subsection{Análise de complexidade}

Nesta seção, é apresentada a análise de complexidade assintótica do algoritmo TSStream para o pior caso. Como descrito anteriormente, o algoritmo utiliza diversas medidas descritivas de séries temporais para realizar o agrupamento. O custo para o cálculo dessas medidas não pode ser desprezado, porém como ele depende de quais são usadas, inicialmente apresenta-se apenas a análise assintótica do algoritmo. Posteriormente, o custo das medidas também é apresentado.

Para iniciar a análise, faz-se necessário definir as variáveis envolvidas no custo de complexidade do algoritmo. Seja $m$ o número de séries que compõem o fluxo, $w$ o tamanho da janela observada a cada iteração e $n$ o número de atributos obtidos por meio das

medidas descritivas e que foram selecionados para uso. É importante ressaltar que o algoritmo não opera diretamente sobre as observações das séries de entrada, mas sim sobre os atributos obtidos via as medidas. Assim, a entrada do algoritmo, a cada iteração, é uma matriz de $m$ por $n$ dimensões.

Considere inicialmente o Algoritmo 8 que traz os passos de TS-Stream. Atribuições simples, como "árvore $\leftarrow \varnothing$ ", resultam em um custo constante da ordem $O(1)$. O custo do procedimento calcularMedidas será analisado posteriormente, já que é influenciado por quais medidas descritivas são utilizadas. A seguir, o procedimento normaliza é chamado, o qual transforma os atributos obtidos via calcularMedidas para que tenham média 0 e desvio padrão 1. Isso requer os cálculos de média e desvio padrão para cada uma das dimensões, as quais são compostas por $m$ séries. No total, isso resulta em um custo da ordem $O(m \cdot n)$.

Inicialmente, todas as séries estão agrupadas na raiz da árvore. Para que seja realizada a primeira divisão, chama-se o procedimento encontraAtributoSignificativo, o qual busca por um atributo e seu ponto de corte, a fim de minimizar a variância ponderada.

Essa operação necessita que todas as $n$ dimensões sejam percorridas, avaliando as possíveis candidatas para segmentação. Uma dimensão só é considerada candidata caso sua entropia seja maior que o parâmetro $\beta$. O cálculo da entropia, dado um histograma com um número fixo de bins $h$, tem custo de $O(m \log m)$, já que é necessário ordenar as observações para encontrar os pontos de divisão do histograma. O cálculo da entropia em si, após a obtenção do histograma, tem custo $O(h)$, já que basta percorrer o vetor de 


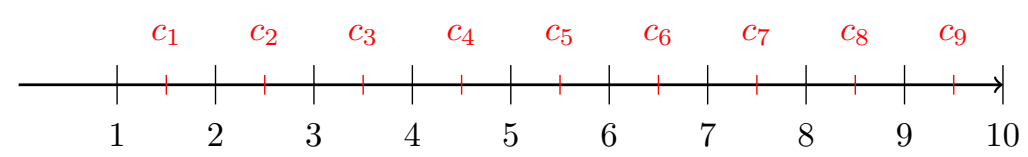

Figura 5.6: Pontos de corte. Dada uma sequência ordenada de $x$ números, existem $x-1$ pontos de corte a serem considerados. No exemplo, $x=10$. Para o ponto de corte $c_{1}$ obtém-se a partição: $\{\{1\},\{2, \ldots, 10\}\}$, para $c_{2}:\{\{1,2\},\{3, \ldots, 10\}\}$, e assim por diante.

probabilidades obtido computando o somatório.

Para o pior caso do procedimento encontraAtributoSignificativo, pode-se considerar um nó folha que tenha todas as $m$ séries como membros (e.g. a raiz no passo inicial) e todas as $n$ dimensões com entropia maior que $\beta$.

A avaliação das dimensões é feita por meio de um laço que chama o procedimento melhorQuebra, no qual se ordena a sequência de $m$ pontos para uma dimensão $d$ e avaliase todos os possíveis pontos de corte. Para uma sequência ordenada de $m$ números, existem $m-1$ pontos de corte a serem considerados, conforme ilustrado na Figura 5.6. No interior do procedimento melhorQuebra é necessário calcular a variância de cada subconjunto produzido pela quebra, o que tem custo $O(m)$ no pior caso. Assim, o procedimento todo apresenta custo $O\left(\mathrm{~m}^{2}\right)$. Como isso é feito para cada uma das $n$ dimensões, a complexidade de encontraAtributoSignificativo é de $O\left(m^{2} \cdot n\right)$.

Uma maneira de substituir o termo quadrático por um linear na complexidade do procedimento encontraAtributoSignificativo é não avaliar todos os possíveis pontos de corte, mas tomar diretamente a média ou mediana. Enquanto isso reduz a complexidade assintótica, na prática os cálculos de variância são eficientes, e a qualidade obtida por se procurar o melhor ponto de corte mostrou-se vantajosa.

Retomando a análise de custo do procedimento principal de TS-Stream, após a chamada de encontraAtributoSignificativo, cria-se a raiz da árvore contendo todas as séries, o que tem custo constante $O(1)$. Em seguida, chama-se o procedimento obtemMembros, que retorna quais séries de um determinado nó pai devem ser integrantes de um nó filho, dado que se trata do filho da esquerda ou da direita. No pior caso, devem ser feitas $m$ comparações, resultando em um custo $O(m)$.

As atribuições para marcar e desmarcar nós como folhas apresentam custo constante $O(1)$, já que simplesmente alteram um bit no vetor de máscara de folhas.

Na segunda iteração do algoritmo, TS-Stream recebe o próximo bloco de dados e agrupa as séries de acordo com a estrutura de árvore criada. Isso é feito por meio de um laço tal que para cada série a árvore é percorrida, executando os testes em cada nó, até que uma folha seja atingida. A série é então agrupada juntamente com as outras que também foram atribuídas àquela folha. O custo de percorrer a árvore no pior caso (degeneração em uma lista) é de $O(m)$. Como isso deve ser feito para todas as $m$ séries, o custo total resulta em $O\left(m^{2}\right)$.

A fase seguinte do algoritmo consiste na atualização do modelo. Para isso as folhas são percorridas, a fim de avaliar a necessidade de agregação ou divisão. O primeiro procedi- 
mento chamado nessa fase é calculaVariancia, o qual recebe um nó e calcula a variância de seus membros em cada uma das dimensões. No pior caso, quando existem $m$ membros e $n$ dimensões, o custo total é da ordem de $O(m \cdot n)$. De maneira semelhante, o procedimento calculaVarPonderada computa a variância para dois nós separadamente e as pondera pelo número de membros de cada um, resultando também em uma complexidade $O(m \cdot n)$.

Os outros procedimentos chamados nos passos seguintes da fase de atualização do modelo já foram apresentados, juntamente com sua complexidade. É possível concluir com essa análise que a complexidade dominante do algoritmo TS-Stream é $O\left(m^{2} \cdot n\right)$, que decorre diretamente de encontraAtributoSignificativo, a função mais custosa.

É importante ressaltar que, apesar da complexidade assintótica do algoritmo apresentar um termo quadrático no pior caso, esse termo refere-se ao número $m$ de séries que compõem o fluxo. Tipicamente esse número é pequeno e constante, da ordem de dezenas. Por exemplo, Rodrigues et al. (2008) utilizam 10 séries temporais para realizar experimentos, enquanto Díaz e Vilar (2010) utilizam 12 séries.

Ainda assim, caso uma garantia assintótica forte seja desejada, com uma simples modificação no procedimento melhorQuebra, de forma a retornar diretamente o ponto de corte como a média ou mediana, sem procurar pelo corte ótimo, reduz-se a complexidade de encontraAtributoSignificativo para $O(m \cdot n)$. A complexidade de TS-Stream continua sendo $O\left(m^{2}\right)$ para o pior caso, no qual a árvore se degenera em uma lista (aproximadamente um grupo por série). Nesse caso, o laço responsável por percorrer a árvore e agrupar as séries tem custo $O\left(m^{2}\right)$. É importante ressaltar, entretanto, que em geral o número de grupos $k \ll m$, portanto não se verifica na prática o crescimento quadrático do tempo de execução conforme o número de séries cresce. Isso pode ser observado nos gráficos de tempo de execução da Figura 5.7.

Tendo a complexidade do algoritmo sido definida, é importante também apresentar a complexidade para o cálculo de medidas descritivas empregadas. Utilizou-se coeficientes obtidos por meio de três medidas, notadamente a Transformada de Fourier, a Autoinformação Mútua e o Expoente de Hurst (ver Capítulo 3), já que elas forneceram bons resultados nos experimentos desta tese. Assim, a análise de complexidade concentra-se nessas três medidas.

Os coeficientes da Transformada de Fourier podem ser obtidos por meio da Fast Fourier Transform (FFT) (Skiena, 1998), apresentando custo da ordem $O(w \cdot \log w)$, sendo $w$ o tamanho da janela de observações. Como a transformada precisa ser computada para as $m$ séries, obtém-se um custo total $O(m \cdot w \cdot \log w)$.

O custo da Autoinformação Mútua (Pompe, 1993) depende, além do tamanho da janela $(w)$, também do número de lags (ou deslocamentos no tempo) para os quais ela deve ser avaliada e do número de partições usadas para compor o histograma das séries. Isso resulta em um custo total, para as $m$ séries, de $O\left(m \cdot w \cdot\right.$ lagmax partições $\left.^{2}\right)$. Como lagmax e o número de partições são constantes, a complexidade do método é $O(m \cdot w)$. 


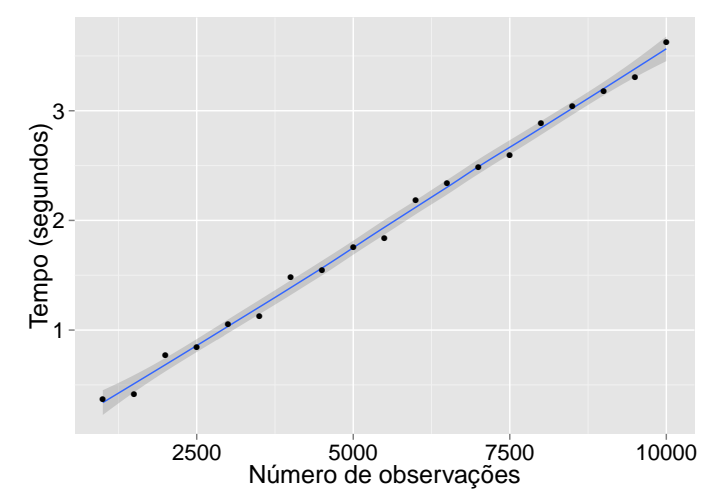

(a) Avaliação de desempenho para a variação no número de observações.

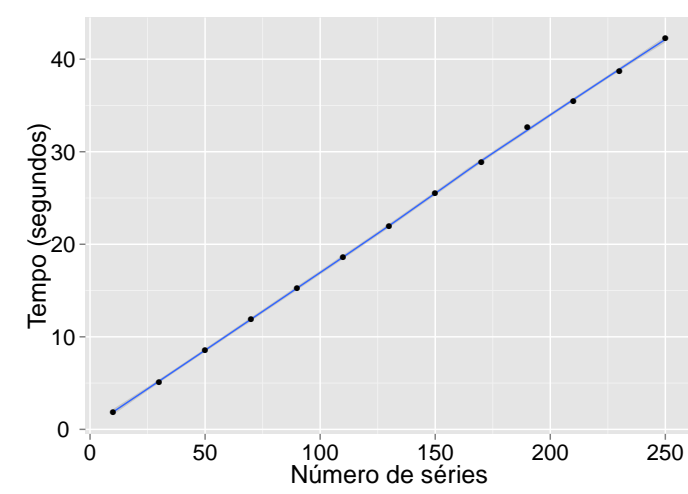

(b) Avaliação de desempenho para a variação no número de séries.

Figura 5.7: Avaliação de desempenho da implementação de TS-Stream em R. O código foi executado na versão 2.15 .1 do $\mathrm{R}$ em uma máquina com processador Intel Core(TM) i7 @2.80Hz, 6 GB de RAM e sistema GNU/Linux com kernel 3.4.6. Para ambos os experimentos foram utilizados conjuntos de dados seguindo modelos AR e AR com não linearidade adicionada. O tamanho da janela de processamento foi $w=400$. O gráfico da esquerda apresenta o desempenho do algoritmo sobre um conjunto com 20 séries temporais e variando o número de observações. O gráfico da direita apresenta o desempenho do algoritmo para um número fixo de 10000 observações e variado de séries temporais. É possível observar que para ambas as variáveis críticas, notadamente o número de observações e o número de séries, o tempo de processamento de TS-Stream cresce de forma linear em cenários práticos.

O Expoente de Hurst (Kantz e Schreiber, 1997) tem como custo dominante a solução de um problema de mínimos quadrados. Assumindo que a solução será dada por meio da inversão de uma matriz (Tan et al., 2005), seu custo é de $O\left(C^{3}\right)$, em que $C$ é o número de atributos. Porém, o problema de mínimos quadrados colocado para o cálculo do Expoente de Hurst apresenta apenas $C=1$ atributo, o que reduz a ordem assintótica para $O(1)$. O custo das operações para o cálculo do expoente, utilizando o método rescaled range (Kantz e Schreiber, 1997) resultam em um custo final de $O(m \cdot w \cdot \log w)$.

Finalmente, em termos assintóticos, a complexidade para o cálculo da Transformada Rápida de Fourier e Expoente de Hurst resultam em $O(m \cdot w \cdot \log w)$. Somando esse custo ao do algoritmo TS-Stream, obtém-se um custo final de $O\left(m^{2} \cdot n+m \cdot w \cdot \log w\right)$.

\subsection{Análise de sensibilidade dos parâmetros}

Esta seção apresenta uma análise de sensibilidade dos parâmetros do algoritmo, notadamente $\alpha, \beta, \lambda$ e também o tamanho de janela $w$. Para todos os experimentos apresentados nesta seção foram geradas 30 bases contendo 3 grupos formados por séries seguindo modelos $\operatorname{AR}(1)$, mapa logístico e $\operatorname{ARIMA}(1,1,0)$ com não linearidade adicionada. As séries foram geradas com 2000 observações, 10 séries por modelo e sem adição de ruído. A avaliação foi feita utilizando o Adjusted Rand Index.

Primeiramente, avaliou-se o efeito causado pela variação do parâmetro $\alpha$, o qual controla a redução de variância necessária para a divisão de folhas. Utilizou-se nesta configuração os parâmetros $\beta=0,3, \lambda=0,6$ e $w=400$. Os resultados são apresentados na Figura 5.8. É possível observar que para a maioria dos valores de $\alpha$ a variação nos 
resultados não é drástica.

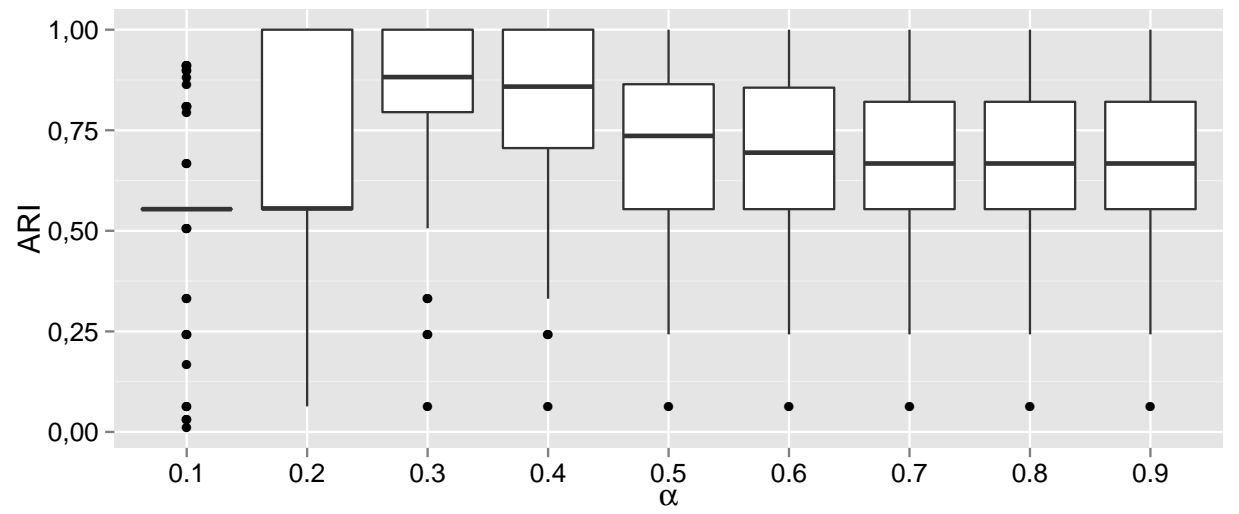

Figura 5.8: Resultados dos experimentos de sensibilidade variando o parâmetro $\alpha$, considerando 30 bases para cada valor testado.

O segundo conjunto de testes avaliou a sensibilidade do parâmetro $\beta$, que determina a entropia mínima de uma dimensão para que ela seja considerada para divisão. Nestes experimentos utilizou-se a mesma configuração anterior, porém com $\alpha=0,3$ fixo. Observou-se que a variação dos resultados, considerando diferentes valores de $\beta$, é mínima. Isso pode ser explicado porque basta um valor $\beta>0$ para que os casos extremos sejam evitados, como dimensões com um único valor ou todos os valores diferentes.

O terceiro conjunto de experimentos avaliou a sensibilidade ao parâmetro $\lambda$, que controla a variação necessária para que duas folhas sejam agregadas em seu nó pai. A mesma configuração do experimento anterior foi utilizada, porém fixando $\beta=0,3$. Os resultados obtidos com a variação de $\lambda$ são ilustrados na Figura 5.9. Conforme esperado, observou-se que os resultados para valores até $\lambda=0,4$ foram inferiores, já que não são valores adequados de configuração para um parâmetro que controla agregação. Para valores mais adequados, tais como a partir de 0,5 , os resultados são bons e apresentam pouca variação.

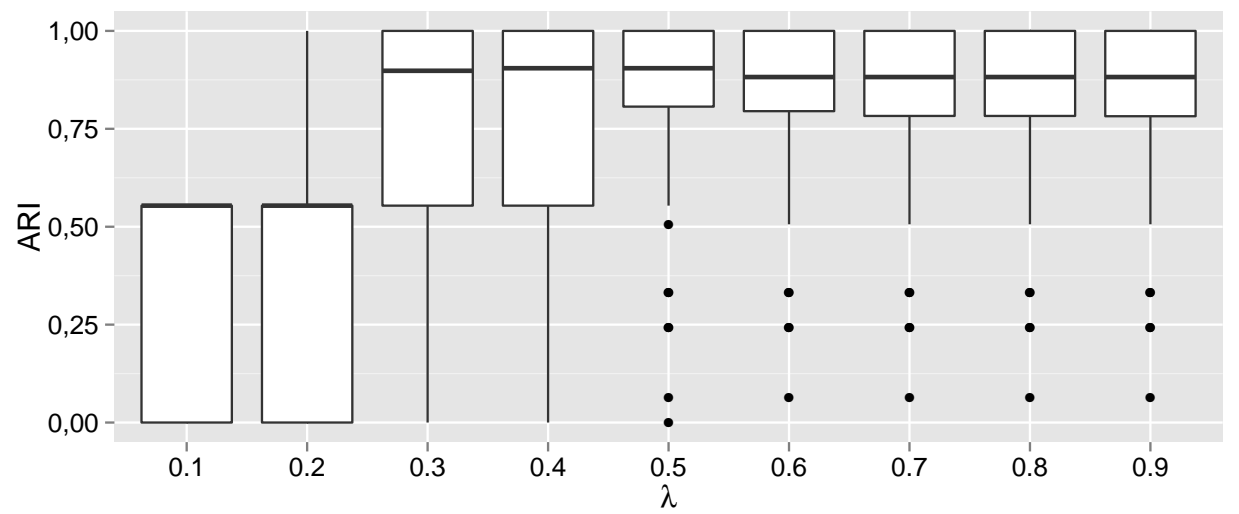

Figura 5.9: Resultados dos experimentos de sensibilidade variando o parâmetro $\lambda$, considerando 30 bases para cada valor testado.

Finalmente, o quarto conjunto de experimentos avaliou a sensibilidade à escolha do tamanho da janela $w$. A configuração foi a mesma do experimento anterior, porém com 
$\lambda=0,6$ fixo. Os resultados são apresentados na Figura 5.10. É possível observar que a escolha do tamanho da janela pouco afetou os resultados, o que é um ponto interessante, já que não há um método direto para a escolha do tamanho de janela ideal.

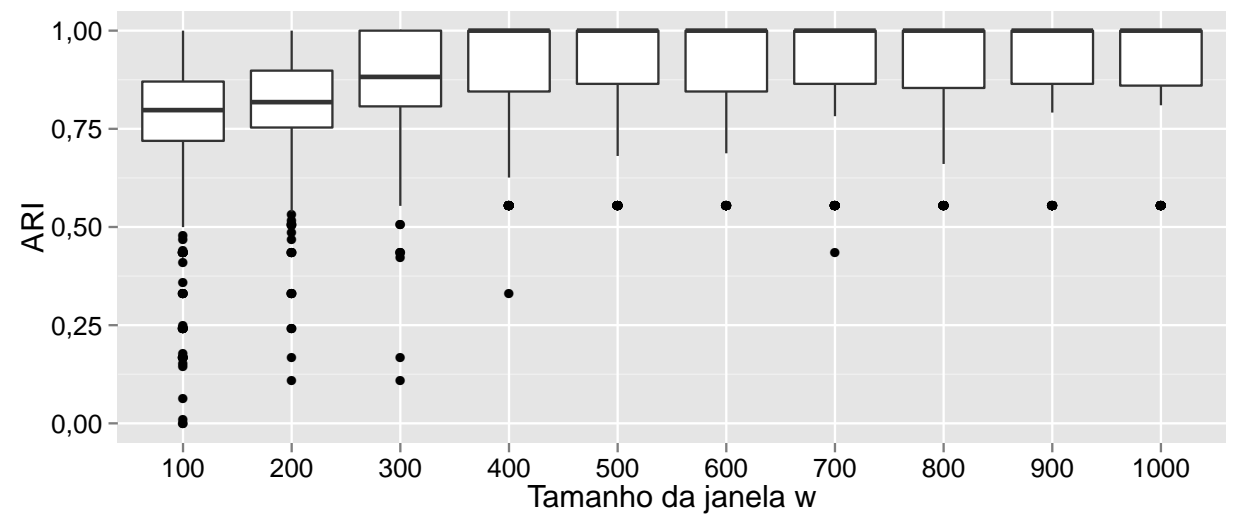

Figura 5.10: Resultados dos experimentos de sensibilidade variando o tamanho da janela $w$, considerando 30 bases para cada valor testado.

A seção seguinte apresenta experimentos com o algoritmo proposto em diversos cenários simulados.

\subsection{Experimentos com TS-Stream}

Foram realizados diversos experimentos com TS-Stream para avaliar a qualidade do agrupamento obtido. A técnica ODAC (Rodrigues et al., 2008), previamente descrita na Seção 2.3 (p. 19), foi utilizada para fins de comparação, já que é a principal proposta concorrente na literatura. As implementações de ambas as técnicas foram feitas em $\mathrm{R}$ ( $\mathrm{R}$ Development Core Team, 2011) utilizando uma máquina com processador Intel Core(TM) i7 @2.80Hz, 6 GB de RAM e sistema GNU/Linux com kernel 3.4.6. Os modelos utilizados para geração das séries sintéticas foram os descritos na Seção 4.2 (p. 52). Todos os experimentos foram realizados utilizando 10 séries temporais por modelo e 10000 observações para cada série. Também foram feitas 30 execuções para cada experimento, a fim de garantir relevância estatística. A qualidade das partições foi avaliada por meio do Adjusted Rand Index, sendo que a medição foi feita a cada janela de $w=400$ observações.

Os parâmetros de TS-Stream foram configurados manualmente com os valores $\alpha=$ $0,2, \beta=0,5$ e $\lambda=0,8$, exceto quando mencionado diferentemente. Para o algoritmo ODAC, os parâmetros foram selecionados utilizando duas técnicas de otimização sobre um subconjunto de $10 \%$ dos dados com função objetivo retornando o Adjusted Rand Index. Os valores iniciais dos parâmetros foram configurados de acordo com os utilizados pelos autores, $\tau=0,02$ e $\delta=0,05$ (Rodrigues et al., 2008). A primeira técnica utilizada para otimização foi Simulated Annealing (Bélisle, 1992), porém não foi possível obter resultados melhores do que aqueles com a parametrização sugerida pelos autores. A segunda técnica de otimização utilizada foi Evolução Diferencial (Ardia et al., 2011). Nesse caso, foi 
possível melhorar os resultados, assim optou-se pela parametrização $\tau=0,039$ e $\delta=0,05$.

\subsubsection{Experimentos com modelos $A R$ e $A R$ com não linearidade adicionada}

Nestes experimentos foram utilizados modelos AR com coeficiente autorregressivo $\phi=$ 0,5 considerando versões com e sem a adição de não linearidade por meio de senóides. O intuito foi verificar se TS-Stream era capaz de distinguir entre modelos lineares e não lineares. TS-Stream foi configurado com $\alpha=0,35, \beta=1,0, \lambda=0,45, w=2000 \mathrm{e}$ utilizando apenas coeficientes da transformada de Fourier. Os resultados são apresentados na Figura 5.11.

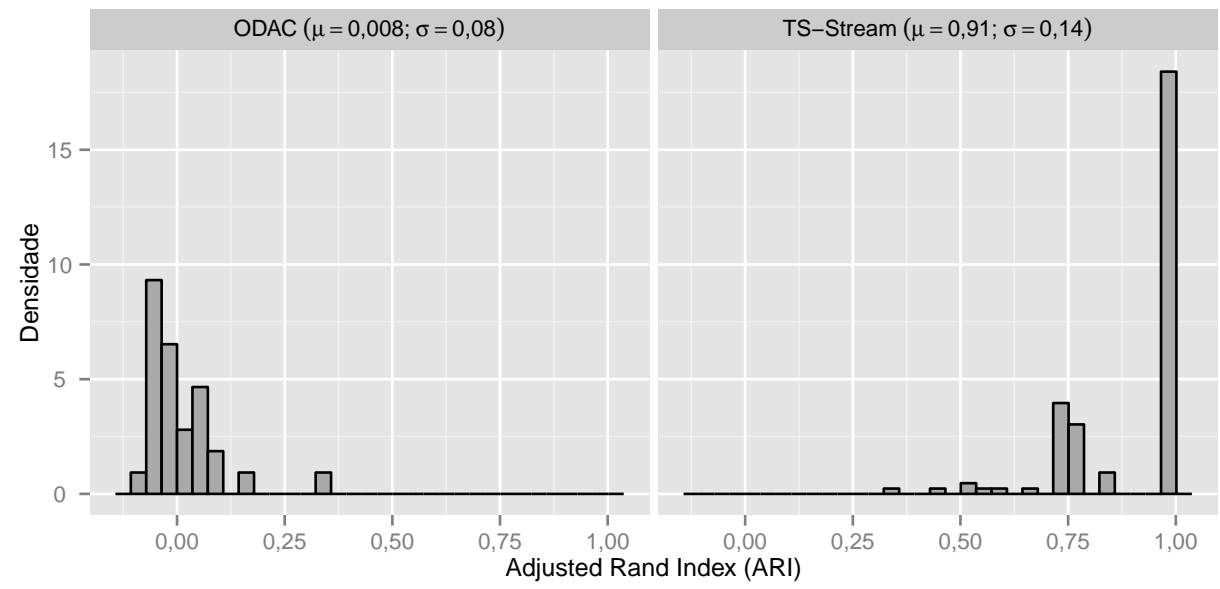

Figura 5.11: Resultados dos experimentos com modelos AR e AR com não linearidade adicionada, considerando as 30 execuções.

É possível observar que a maioria dos resultados de ODAC, em termos de ARI, concentra-se em torno de zero, o que equivale a um agrupamento aleatório. Já os resultados de TS-Stream concentram-se majoritariamente próximos a 1, um agrupamento em total concordância com os grupos reais ${ }^{7}$.

Realizou-se um teste estatístico não paramétrico, o Wilcoxon Rank-Sum Test (Walpole et al., 1998) para confirmar que os resultados de TS-Stream superam os de ODAC de forma estatisticamente significativa. A hipótese alternativa do teste foi de que a média de ARI de TS-Stream é superior à média de ODAC. O $p$-valor obtido pelo teste foi $1,9 \times 10^{-69}$, confirmando que existem evidências suficientes para aceitar a hipótese alternativa.

\subsubsection{Experimentos com modelos $A R$ e $\operatorname{ARIMA}(1,1,0)$, ambos com não line- aridade adicionada}

Neste conjunto de experimentos foi avaliada a capacidade de TS-Stream de separar modelos não estacionários de estacionários, porém considerando que ambos são não lineares. Para isso foram utilizados os modelos AR e $\operatorname{ARIMA}(1,1,0)$, ambos com coeficiente

\footnotetext{
${ }^{7}$ A rotulação dos grupos reais, também chamada de golden truth, é conhecida devido à geração sintética das séries. Cada série foi colocada no grupo correspondente ao modelo utilizado para gerá-la, assim os grupos correspondem de fato às propriedades matemáticas que caracterizam cada uma das séries.
} 
autorregressivo $\phi=0,5$ e não linearidade adicionada por meio de senóides. Os resultados obtidos são ilustrados na Figura 5.12.

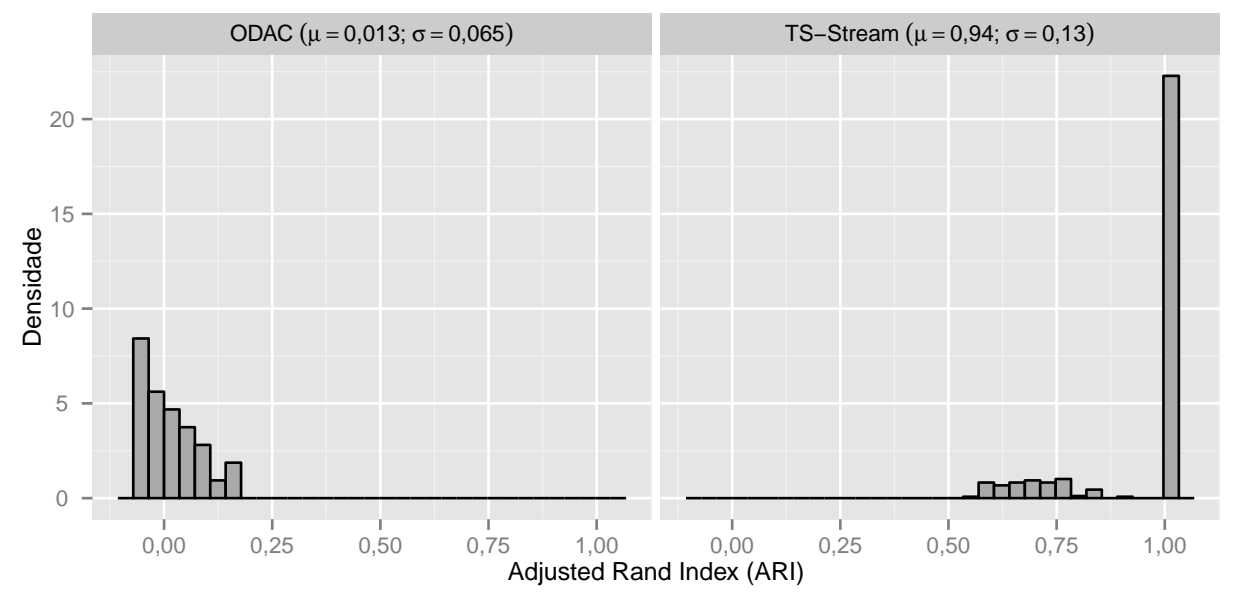

Figura 5.12: Resultados dos experimentos com modelos $\operatorname{AR}$ e $\operatorname{ARIMA}(1,1,0)$ ambos com não linearidade adicionada, considerando as 30 execuções.

É possível observar novamente que a maioria dos resultados de ODAC estão em torno de zero enquanto os de TS-Stream concentram-se em 1. Novamente foi realizado um Teste de Wilcoxon para avaliar a hipótese de que os resultados de TS-Stream são superiores e o $p$-valor obtido foi $7,7 \times 10^{-259}$, confirmando o esperado.

\subsubsection{Experimentos com modelos $A R$ e mapas logísticos}

Neste conjunto de experimentos avaliou-se a capacidade de TS-Stream distinguir entre modelos estocásticos (AR) e determinísticos (mapa logístico). Os modelos AR foram parametrizados com coeficiente autorregressivo $\phi=0,5$ e os mapas com $r=3,8$. Os resultados estão ilustrados na Figura 5.13.

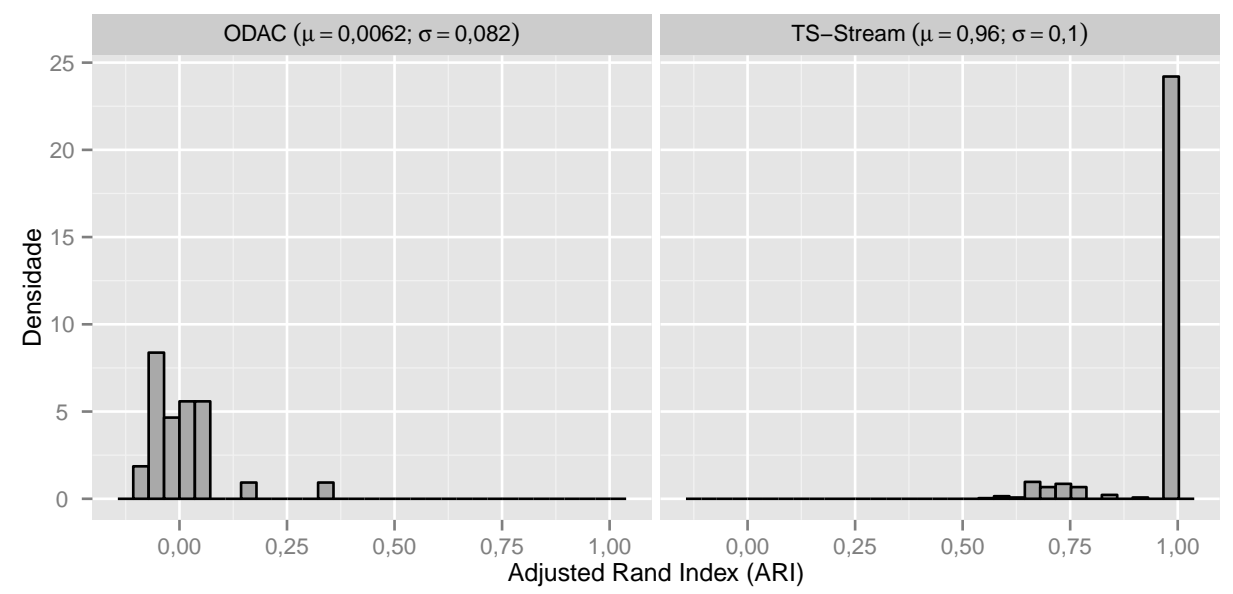

Figura 5.13: Resultados dos experimentos com modelos AR e mapa logístico, considerando as 30 execuções.

O $p$-valor obtido no teste estatístico foi $1,7 \times 10^{-264}$, novamente confirmando que a média de ARI para TS-Stream superou a de ODAC. 


\subsubsection{Experimentos com modelos $A R$ e $\operatorname{ARIMA}(1,1,0)$}

Nestes experimentos foram considerados modelos AR e $\operatorname{ARIMA}(1,1,0)$, ambos com coeficiente autorregressivo $\phi=0,5$. O intuito foi avaliar a capacidade de TS-Stream de separar modelos estacionários e não estacionários, sendo ambos lineares. Os resultados obtidos são apresentados na Figura 5.14.

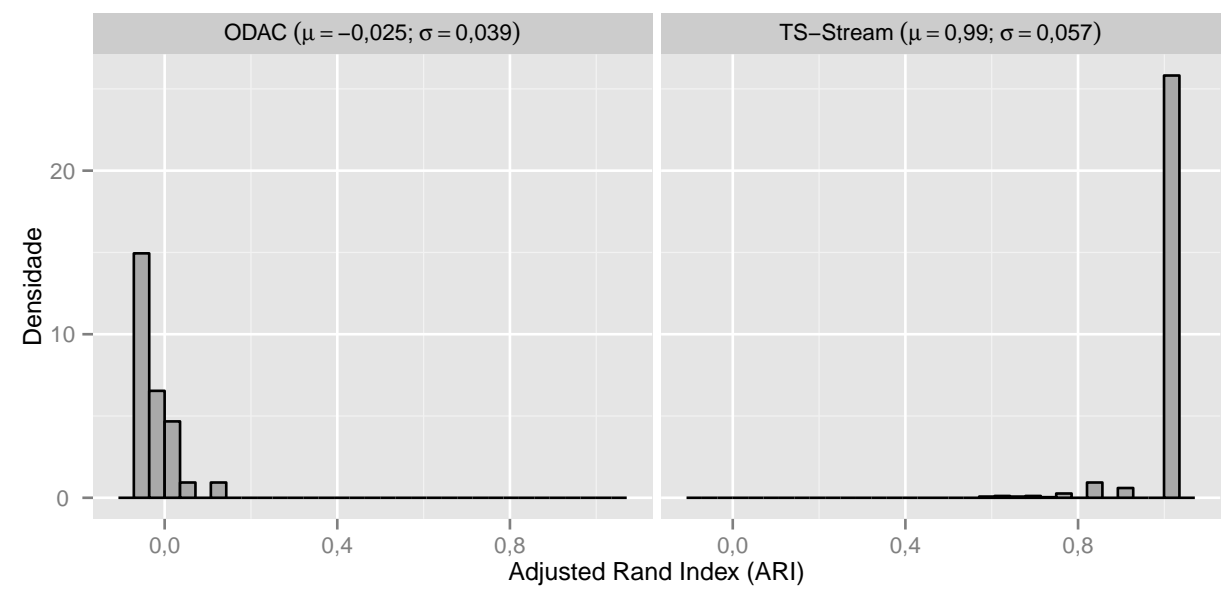

Figura 5.14: Resultados dos experimentos com modelos AR e ARIMA(1,1,0), considerando as 30 execuções.

Novamente os resultados são favoráveis a TS-Stream, sendo que o Teste de Wilcoxon retorna o $p$-valor $1,3 \times 10^{-269}$ considerando a hipótese alternativa de que a média de ARI de TS-Stream é maior que a de ODAC.

\subsubsection{Experimentos com evolução de grupos}

Uma das características mais importantes na área de fluxos contínuos é o que se denomina de evolução de grupos, ou seja, grupos podem aparecer, desaparecer, fundir-se, separar-se ou modificar-se ao longo do tempo. Este conjunto de experimentos visou avaliar TS-Stream quanto à sua capacidade de adaptação na presença da evolução de grupos.

Para modelar essa evolução utilizou-se a proposta de Bifet e Kirby (2009), a qual emprega uma função sigmoidal, conforme a Equação 5.9, em que $t$ indica o instante de tempo atual, $s$ é um parâmetro de suavização e $t_{c}$ é o instante de mudança. Um exemplo dessa função é ilustrado na Figura 5.15. A evolução se deu como a mudança de um determinado modelo de série temporal para outro, sendo os pesos dos modelos governados pela função sigmoidal.

$$
\operatorname{peso}\left(t, s, t_{c}\right)=\frac{1}{1+e^{-s\left(t-t_{c}\right)}}
$$

É instrutivo analisar o comportamento do algoritmo em um exemplo com poucas séries, a fim de acompanhar as partições geradas a cada iteração. Nesta seção, a notação de um fluxo foi levemente alterada, a fim de facilitar a compreensão de como as partições 


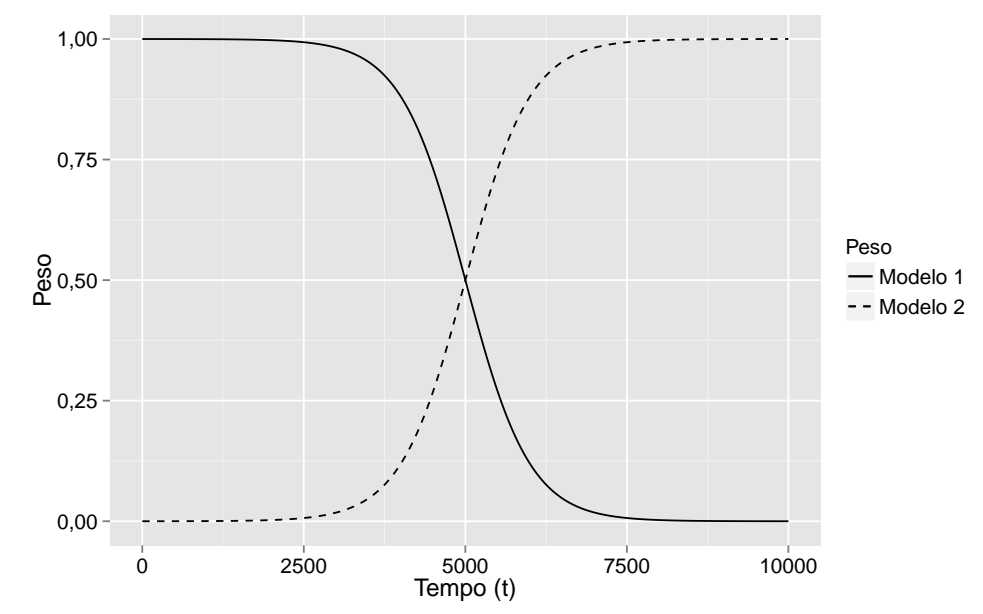

Figura 5.15: Função sigmoidal utilizada para a modelagem de evolução de grupos ao longo do tempo.

se alteram ao longo do tempo. Assim, um fluxo $S$ composto por $m$ séries é denotado por $S=\left[S_{1} S_{2} \ldots S_{m}\right]$. Uma partição de $S$ é denotada por $P=\left[g_{1} g_{2} \ldots g_{m}\right]$ em que $g_{i} \in\{1,2, \ldots, k\}$ é o grupo da $i$-ésima série do fluxo, sendo $k$ o número de grupos.

Para este experimento foi gerado um conjunto de dados composto por 4 séries temporais: $\left[S_{1} S_{2} S_{3} S_{4}\right]$, cada uma com 10000 observações. Os grupos foram construídos da seguinte forma: no tempo $t=1$ a partição correta das séries é $\left[\begin{array}{llll}1 & 1 & 2 & 2\end{array}\right]$, ou seja, séries $S_{1}$ e $S_{2}$ no grupo 1 e $S_{3}$ e $S_{4}$ no grupo 2 . No instante final $t=10000$ a partição correta

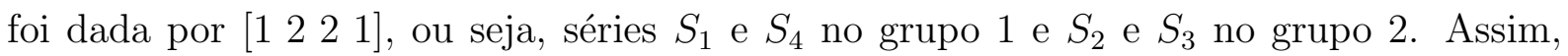
as séries $S_{2}$ e $S_{4}$ migraram de um modelo para outro. A Figura 5.16 apresenta o trecho inicial, imediatamente antes e depois do ponto de mudança e o trecho final da série $S_{2}$, mostrando como o modelo se alterou de Lorenz para $\mathrm{AR}(1)$. O ponto de mudança do modelo foi configurado como $t_{c}=5000$ e o parâmetro de suavização como $s=0,002$.

A observação atual da $i$-ésima série foi determinada de acordo com a equação $s_{i t}=$ $w_{1}(t) \cdot \mathcal{M}_{1}(t)+w_{2}(t) \cdot \mathcal{M}_{2}(t)$, em que $w_{1}(t)$ é o peso do modelo $\mathcal{M}_{1}$ no instante $t$ e $w_{2}(t)=1-w_{1}(t)$ é o peso do modelo $\mathcal{M}_{2}$ no instante $t$.

Para analisar como as partições produzidas por TS-Stream e ODAC evoluíram ao longo do tempo foi construída a Tabela 5.1. É possível observar que tanto TS-Stream quanto ODAC conseguem identificar corretamente os grupos iniciais. Entretanto, ODAC não foi capaz de detectar e nem de se adaptar à evolução dos grupos. A partição final de ODAC, denotada por 0000 ocorre pois ODAC calcula a diferença de primeira ordem das séries, assim não chega a processar o tamanho de janela suficiente para determinação da última partição. Já TS-Stream conseguiu adaptar-se ao segundo cenário, em que as séries $S_{2}$ e $S_{4}$ migram de grupo. É importante ressaltar que as partições 1221 e 2112 são equivalentes.

TS-Stream teve dificuldades em determinar os grupos da janela 5200 a 5600 em função de ser o período em que ocorre maior mistura entre os modelos, impedindo a clara distinção entre eles. Isso pode ser observado no gráfico da função peso (Figura 5.15), em que a maior mistura dos modelos ocorre justamente nesse período. 

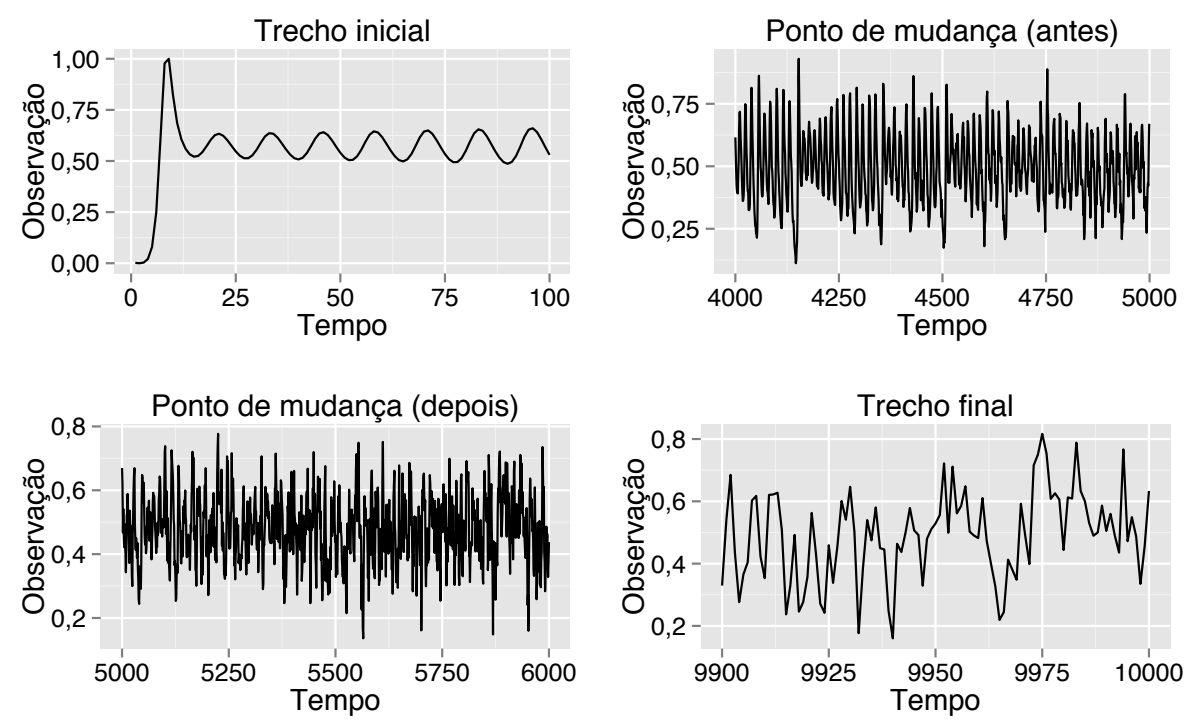

Figura 5.16: Exemplos de trechos da série $S_{2}$ do conjunto de dados criado para testar TS-Stream quanto à sua capacidade de adaptação na presença de evolução de grupos. A figura no canto superior direito representa as 1000 observações antes do ponto de mudança, enquanto a do canto inferior esquerdo as 1000 observações após o ponto de mudança.

Tabela 5.1: Partições encontradas a cada iteração de TS-Stream e ODAC para o conjunto de dados com evolução de grupos ao longo do tempo. As linhas em negrito indicam as iterações (13-25) em que o Modelo 2 apresentava maior peso do que o Modelo 1. Observa-se que na iteração 15 TS-Stream já está adaptado à nova estrutura de grupos.

\begin{tabular}{|c|c|c|c|}
\hline Iteração & Janela & TS-Stream & ODAC \\
\hline 1 & 400 & 1122 & 1122 \\
\hline 2 & 800 & 1122 & 1122 \\
\hline 3 & 1200 & 1122 & 1122 \\
\hline 4 & 1600 & 1122 & 1122 \\
\hline 5 & 2000 & 1122 & 1122 \\
\hline 6 & 2400 & 1122 & 1122 \\
\hline 7 & 2800 & 1122 & 1122 \\
\hline 8 & 3200 & 1122 & 1122 \\
\hline 9 & 3600 & 1122 & 1122 \\
\hline 10 & 4000 & 1122 & 1122 \\
\hline 11 & 4400 & 1122 & 1122 \\
\hline 12 & 4800 & 1122 & 1122 \\
\hline 13 & 5200 & 1112 & $\begin{array}{lll}1122 \\
\end{array}$ \\
\hline 14 & 5600 & 1112 & 1122 \\
\hline 15 & 6000 & 21112 & $\begin{array}{lll}1 & 1 & 2 \\
2\end{array}$ \\
\hline 16 & 6400 & 21112 & $\begin{array}{lll}1 & 1 & 2 \\
2\end{array}$ \\
\hline 17 & 6800 & 2112 & 1122 \\
\hline 18 & 7200 & 2112 & 1122 \\
\hline 19 & 7600 & 21112 & $\begin{array}{lll}1122 \\
\end{array}$ \\
\hline 20 & 8000 & 21112 & $\begin{array}{lll}1122 \\
\end{array}$ \\
\hline 21 & 8400 & $\begin{array}{llll}2 & 1 & 1 & 2\end{array}$ & $\begin{array}{lll}1 & 122\end{array}$ \\
\hline 22 & 8800 & 21112 & $\begin{array}{lll}1 & 1 & 2 \\
2\end{array}$ \\
\hline 23 & 9200 & 21112 & $\begin{array}{llll}1 & 1 & 2 & 2\end{array}$ \\
\hline 24 & 9600 & 2112 & 1122 \\
\hline 25 & 10000 & 21112 & $\begin{array}{llll}0 & 0 & 0 & 0\end{array}$ \\
\hline
\end{tabular}


A fim de obter relevância estatística, esse experimento foi ampliado para 10 séries por modelo e 10000 observações, sendo executado sobre 30 bases. Os resultados obtidos estão ilustrados na Figura 5.17. Para determinar as partições de referência (golden truth) utilizou-se o critério de que a partição correta em determinado instante $t$ corresponde àquela em que os grupos são definidos pelo modelo com maior peso nesse instante.

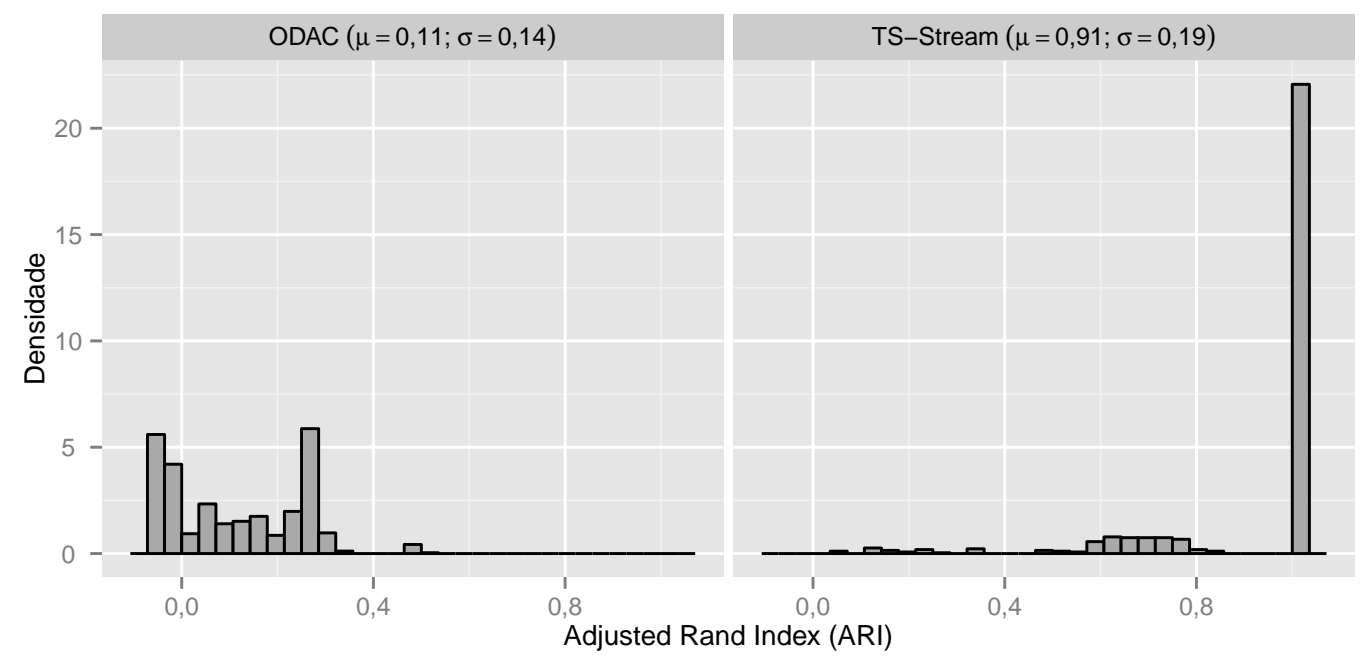

Figura 5.17: Resultados dos experimentos com conjuntos de dados contendo evolução de grupos ao longo do tempo, considerando as 30 execuções.

É possível observar que TS-Stream superou ODAC fortemente. Realizando um Teste de Wilcoxon obteve-se o $p$-valor $5,8 \times 10^{-246}$, confirmando que a média de ARI para TSStream supera a de ODAC para o cenário de evolução de grupos testado.

\subsubsection{Experimentos com dados reais do setor financeiro}

Este conjunto de experimentos teve por objetivo mostrar uma aplicação de TS-Stream em um cenário real. Para isso foi escolhida uma aplicação do setor financeiro, notadamente de ações de bolsa de valores. Essa escolha se deu devido à livre disponibilidade dos dados em diversas fontes ${ }^{8}$ e a possibilidade de avaliar o impacto do algoritmo em termos de uma medida de sucesso externa, como o ganho de capital.

Um total de 270 ações foram escolhidas aleatoriamente das bolsas NYSE (New York Stock Exchange) e NASDAQ (National Association of Securities Dealers Automated Quotations) durante um período de 9 anos, de 2003 a 2011. Foram geradas 30 bases, cada uma com uma subseleção de 20 séries históricas de preços, sendo cada série composta por 2266 observações.

Foi implementado um simulador baseado em eventos discretos guiado pelo indicador econômico MACD (Moving Average Convergence Divergence) (Appel, 2005). O simulador foi usado para gerar eventos de compra e venda de ações, os quais foram consumidos por

\footnotetext{
${ }^{8}$ Tais como Yahoo Finance (http://finance.yahoo.com/) e Google Finance (http://www.google. com/finance). Último acesso: 19 de agosto de 2013.
} 
políticas de negociação que implementavam diferentes estratégias na escolha de quanto e quais ações comprar ou vender.

O indicador MACD, utilizado para gerar eventos de compra e venda pelo simulador, é um indicador de análise técnica, o qual é usado para identificar mudanças na força, direção e duração da tendência do preço de uma ação (Appel, 2005). Basicamente, o MACD pode ser visto como um gráfico composto por três componentes baseados no preço de fechamento de uma ação. O primeiro componente, a linha MACD, é a diferença entre uma média móvel exponencial curta ${ }^{9}$ e outra longa ${ }^{10}$ do preço de fechamento. O segundo componente, também chamado de "sinal", representa uma média móvel exponencial do primeiro componente ${ }^{11}$. Finalmente, o terceiro componente, também conhecido por "histograma", é o resultado da diferença (divergência) entre a linha do MACD e do sinal. O gráfico da Figura 5.18 ilustra o MACD para uma série de ações da empresa Google Inc.

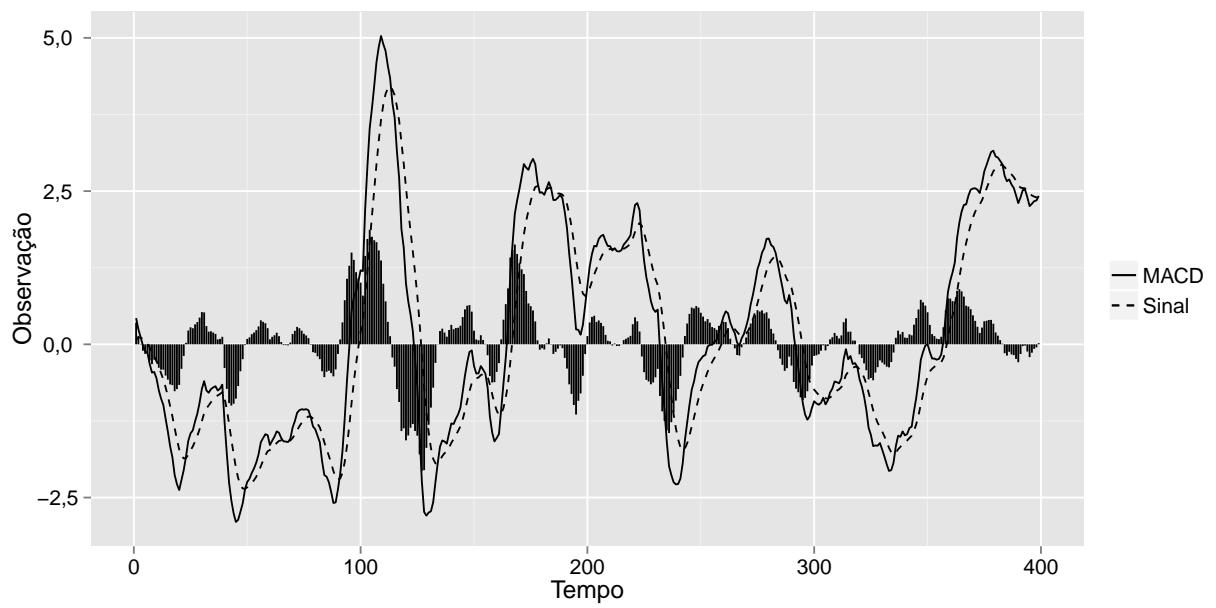

Figura 5.18: Exemplo do MACD para uma série de preços de fechamento do Google.

A interpretação básica é que se deve comprar a ação quando a linha do MACD cruza a do sinal para cima (movimento conhecido por bullish) e vender quando o cruzamento é para baixo (movimento conhecido por bearish). Ambos os movimentos indicam que a tendência da ação é de aceleração na direção do cruzamento. A linha do histograma indica quando os cruzamentos ocorrem, já que ela representa a diferença (divergência) entre MACD e sinal. Assim, quando o histograma atinge zero, significa que houve um cruzamento.

O simulador implementado utiliza os eventos descritos pelo MACD, tanto de compra quanto de venda, para empregar políticas de negociação, que por sua vez escolhem as ações que serão compradas ou vendidas, além da quantidade. A fim de simular o comportamento de pequenos e médios investidores, foram implementadas quatro políticas de negociação.

A primeira, denominada Top-1, compra a ação com indicação de venda que apresenta a maior divergência naquele momento. Essa política simula o comportamento de um pequeno investidor que compra papéis de uma única empresa (e.g., Petrobrás).

\footnotetext{
${ }^{9}$ Tipicamente de 12 dias (Appel, 2005), valor também adotado neste trabalho.

${ }^{10}$ Tipicamente de 26 dias (Appel, 2005), valor também adotado neste trabalho.

${ }^{11}$ Tipicamente é adotado o valor de 9 dias do MACD (Appel, 2005).
} 
A segunda política, denominada TS-Stream, utiliza o algoritmo de agrupamento proposto neste trabalho para encontrar relacionamentos entre diferentes ações a partir de seus modelos geradores. A intuição é que montando uma carteira diversificada, com ações de diversos grupos encontrados pelo algoritmo, é possível maximizar os ganhos e minimizar as perdas. Dessa forma, após a etapa de agrupamento, a política seleciona a ação com maior divergência de cada grupo para compra.

A terceira política, denominada Top-K, simula o comportamento de um médio investidor, o qual monta uma carteira de ações. Essa política seleciona as $K$ ações com maior divergência para compra, sendo $K$ dado pelo número de grupos encontrados por TS-Stream. É importante ressaltar que essa política não usa TS-Stream diretamente, mas apenas o número $K$ de grupos encontrados pelo algoritmo. Isso permite avaliar se o agrupamento de fato auxilia na maximização de ganhos.

A quarta política, denominada ODAC, funciona da mesma maneira que a política baseada em TS-Stream, porém utilizando o algoritmo ODAC para a fase de agrupamento. Isso permite comparar TS-Stream a ODAC em um cenário real.

Cada política recebeu no início da simulação um valor de US\$20000 dólares para investir de acordo com sua estratégia de negociação. A medida de avaliação usada para determinar o sucesso das políticas foi o resgate total, que representa o capital disponível não usado naquele momento, somado ao capital obtido caso todas as ações previamente adquiridas fossem vendidas.

A Figura 5.19 apresenta os resultados para as quatro políticas de negociação na primeira base de dados. É possível observar que os resgates totais de TS-Stream e ODAC são bastante superiores aos obtidos com Top-1 e Top-K. Isso confirma que 1) investir em uma única ação é perigoso, pois fortes alterações de preço podem comprometer todo o capital investido (vide Figura 5.20); 2) o agrupamento retornado por TS-Stream de fato possibilitou a construção de uma carteira de investimento mais rentável do que a simples compra de um conjunto de ações com base no MACD.

A Tabela 5.2 apresenta um comparativo entre as políticas TS-Stream e Top-1 para as 30 bases de dados. Para cada técnica são mostrados os valores da média $(\mu)$, desvio padrão $(\sigma)$ e valor máximo. A coluna "Score" indica se a média de TS-Stream foi superior à de Top-1 para a base da $i$-ésima linha. A coluna "P-valor" indica o p-valor obtido executando o teste de Wilcoxon (Walpole et al., 1998) com hipótese alternativa $H_{a}$ : a distribuição de resgate total da técnica com maior média para a base da i-ésima linha está deslocada à direita da distribuição da outra técnica. O teste não paramétrico foi utilizado porque as distribuições de resgate total não se aproximam de Normais, conforme pode ser observado na Figura 5.21.

É possível notar, na Tabela 5.2, que TS-Stream supera Top-1 em todas as bases de dados. Observa-se ainda que o desvio padrão para as políticas é alto. Esse fato pode ser facilmente explicado considerando novamente a Figura 5.19. Observa-se que para uma política obter maiores ganhos de capital demanda-se tempo, o que de fato é esperado 

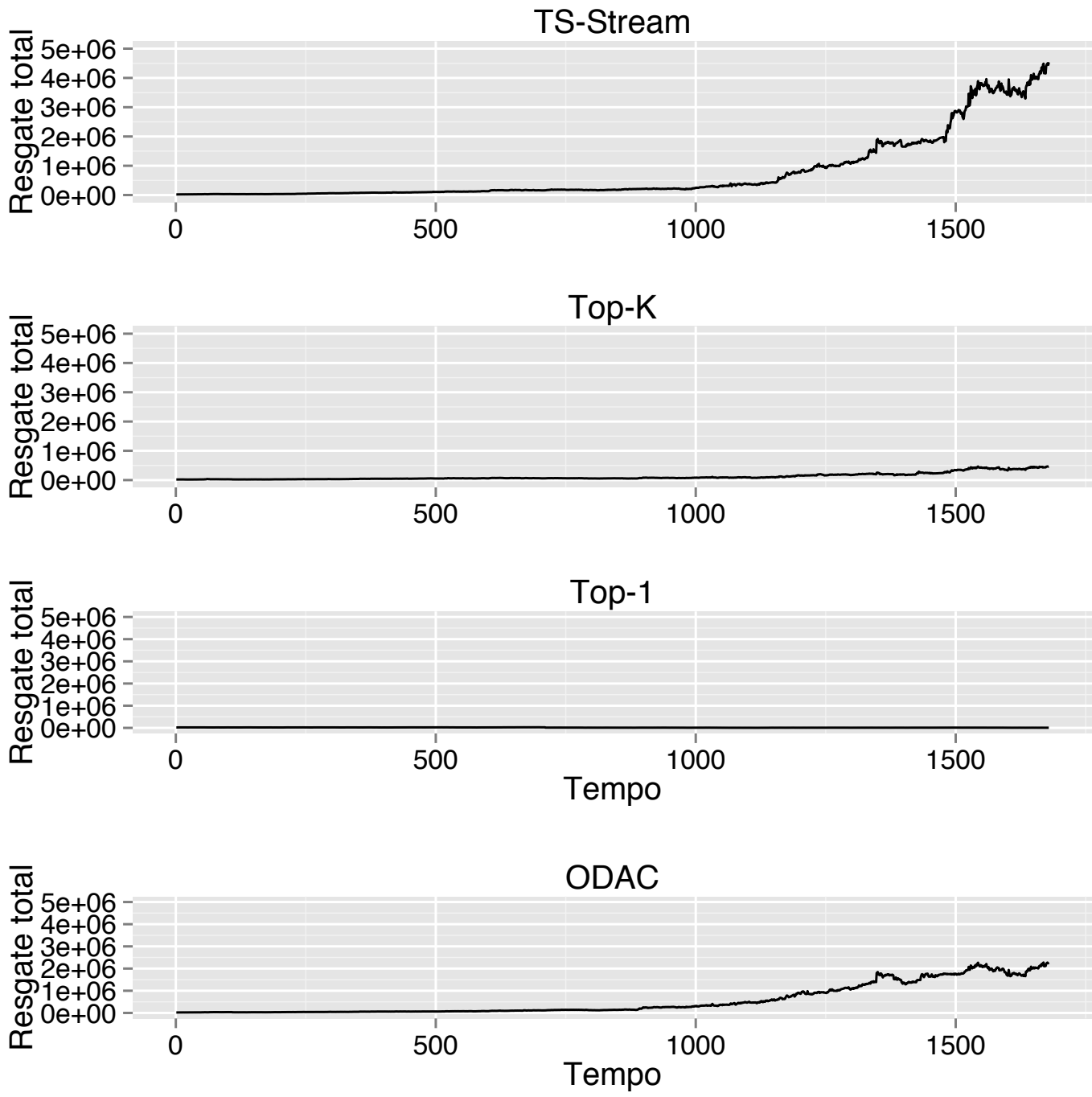

Figura 5.19: Resultados das quatro políticas de negociação para a primeira base de dados do setor financeiro.

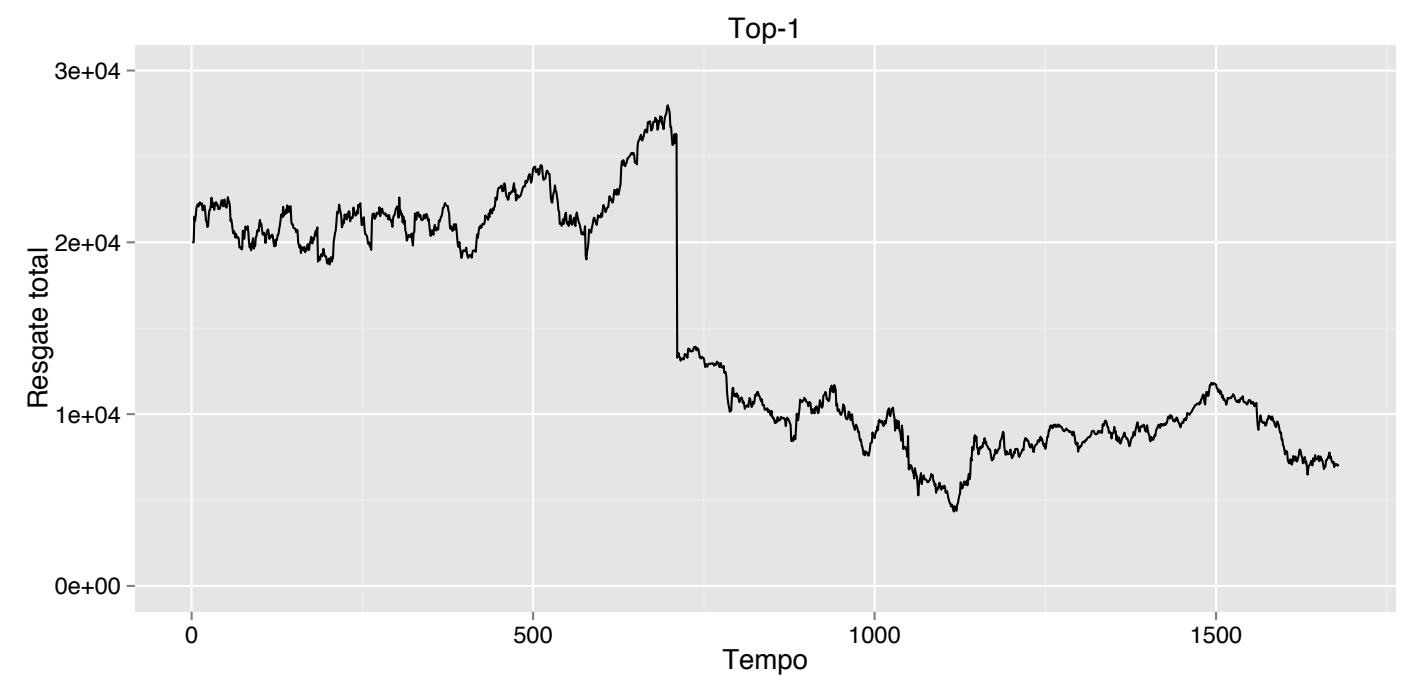

Figura 5.20: Resultados da política de negociação Top-1 para a primeira base de dados do setor financeiro. Observa-se que, entre os instantes 500 e 1000, há uma queda brusca do capital resgatado. A diversificação do investimento visa justamente evitar situações como essa, fazendo com que eventuais perdas com uma ação sejam compensadas por ganhos com outras. 
por muitos investidores. Para que as ações de uma empresa sejam muito valorizadas, afora fatos extraordinários, é necessário que ela cresça e a economia do país se desenvolva, fatores que demandam tempo. No entanto, analisando a porcentagem de tempo em que o resgate total de cada política ficou acima do capital inicial investido, conforme apresentado na Tabela 5.4, é possível observar que tanto para TS-Stream como Top-K e ODAC, em quase $100 \%$ do tempo houve ganhos acima do valor inicial investido.

A Tabela 5.3 apresenta a comparação entre TS-Stream e Top-K. Observa-se que, em 27 das 30 bases, TS-Stream obteve uma média de resgate total maior do que Top-K. $\mathrm{Na}$ maioria delas foi detectada uma diferença significativa pelo teste estatístico. Para a maioria das bases, o valor máximo de resgate total de TS-Stream também foi maior (e várias ordens de grandeza) do que o alcançado por Top-K.

Tabela 5.2: Resultados para as 30 bases do setor financeiro, considerando TS-Stream e Top-1. A coluna Score indica se a média $(\mu)$ de TS-Stream superou a de Top-1 (+) ou não (-). A coluna P-valor indica o resultado do teste de Wilcoxon com hipótese alternativa de que a distribuição de resgate total da técnica com maior média da linha é deslocada à direita da distribuição da outra técnica. P-valores menores do que 0,05 indicam que há uma diferença estatisticamente significativa entre as distribuições.

\begin{tabular}{|c|c|c|c|c|c|c|c|c|}
\hline Base \# & $\mu \mathrm{TS}$ & $\sigma \mathrm{TS}$ & $\max \mathrm{TS}$ & $\mu$ Top-1 & $\sigma$ Top-1 & $\max$ Top-1 & Score & P-valor \\
\hline 1 & $7,695 \times 10^{5}$ & $1,137 \times 10^{6}$ & $4,533 \times 10^{6}$ & $1,459 \times 10^{4}$ & $6,536 \times 10^{3}$ & $2,798 \times 10^{4}$ & + & 0,000 \\
\hline 2 & $1,096 \times 10^{6}$ & $1,688 \times 10^{6}$ & $8,874 \times 10^{6}$ & $2,092 \times 10^{4}$ & $7,736 \times 10^{3}$ & $4,114 \times 10^{4}$ & + & 0,000 \\
\hline 3 & $1,801 \times 10^{6}$ & $3,241 \times 10^{6}$ & $2,509 \times 10^{7}$ & $1,918 \times 10^{4}$ & $1,058 \times 10^{4}$ & $9,304 \times 10^{4}$ & + & 0,000 \\
\hline 4 & $2,36 \times 10^{6}$ & $4,65 \times 10^{6}$ & $3,187 \times 10^{7}$ & $1,902 \times 10^{4}$ & $1,031 \times 10^{4}$ & $8,297 \times 10^{4}$ & + & 0,000 \\
\hline 5 & $2,104 \times 10^{6}$ & $4,266 \times 10^{6}$ & $3,187 \times 10^{7}$ & $1,17 \times 10^{5}$ & $1,065 \times 10^{5}$ & $4,228 \times 10^{5}$ & + & 0,000 \\
\hline 6 & $7,053 \times 10^{6}$ & $2,201 \times 10^{7}$ & $1,484 \times 10^{8}$ & $3,263 \times 10^{4}$ & $9,68 \times 10^{3}$ & $6,642 \times 10^{4}$ & + & 0,000 \\
\hline 7 & $6,075 \times 10^{6}$ & $2,051 \times 10^{7}$ & $1,484 \times 10^{8}$ & $2,158 \times 10^{4}$ & $7,305 \times 10^{3}$ & $3,763 \times 10^{4}$ & + & 0,000 \\
\hline 8 & $5,48 \times 10^{6}$ & $1,923 \times 10^{7}$ & $1,484 \times 10^{8}$ & $1,107 \times 10^{5}$ & $5,478 \times 10^{4}$ & $3,37 \times 10^{5}$ & + & 0,000 \\
\hline 9 & $4,911 \times 10^{6}$ & $1.82 \times 10^{7}$ & $1,484 \times 10^{8}$ & $1.09 \times 10^{5}$ & $5,442 \times 10^{4}$ & $3.37 \times 10^{5}$ & + & 0.000 \\
\hline 10 & $4,764 \times 10^{6}$ & $1,736 \times 10^{7}$ & $1,484 \times 10^{8}$ & $2,298 \times 10^{4}$ & $3,637 \times 10^{3}$ & $3,113 \times 10^{4}$ & + & 0,000 \\
\hline 11 & $4,381 \times 10^{6}$ & $1,66 \times 10^{7}$ & $1,484 \times 10^{8}$ & $1,568 \times 10^{4}$ & $4,533 \times 10^{3}$ & $2,612 \times 10^{4}$ & + & 0,000 \\
\hline 12 & $4,268 \times 10^{6}$ & $1,597 \times 10^{7}$ & $1,484 \times 10^{8}$ & $4,162 \times 10^{4}$ & $1,269 \times 10^{4}$ & $9,255 \times 10^{4}$ & + & 0,000 \\
\hline 13 & $4,143 \times 10^{6}$ & $1,541 \times 10^{7}$ & $1,484 \times 10^{8}$ & $1,024 \times 10^{5}$ & $4,801 \times 10^{4}$ & $2,171 \times 10^{5}$ & + & 0,000 \\
\hline 14 & $3,946 \times 10^{6}$ & $1,489 \times 10^{7}$ & $1,484 \times 10^{8}$ & $2,225 \times 10^{4}$ & $1,087 \times 10^{4}$ & $4,95 \times 10^{4}$ & + & 0,000 \\
\hline 15 & $3,746 \times 10^{6}$ & $1,442 \times 10^{7}$ & $1,484 \times 10^{8}$ & $1,929 \times 10^{4}$ & $9,075 \times 10^{3}$ & $4,255 \times 10^{4}$ & + & 0,000 \\
\hline 16 & $3,615 \times 10^{6}$ & $1,399 \times 10^{7}$ & $1,484 \times 10^{8}$ & $2,117 \times 10^{4}$ & $5,837 \times 10^{3}$ & $3,805 \times 10^{4}$ & + & 0,000 \\
\hline 17 & $3,535 \times 10^{6}$ & $1,362 \times 10^{7}$ & $1,484 \times 10^{8}$ & $2,996 \times 10^{4}$ & $2,793 \times 10^{4}$ & $1,33 \times 10^{5}$ & + & 0,000 \\
\hline 18 & $3,109 \times 10^{7}$ & $2,641 \times 10^{8}$ & $3,999 \times 10^{9}$ & $3,082 \times 10^{4}$ & $2,834 \times 10^{4}$ & $1,345 \times 10^{5}$ & + & 0,000 \\
\hline 19 & $2,952 \times 10^{7}$ & $2,572 \times 10^{8}$ & $3,999 \times 10^{9}$ & $3,586 \times 10^{4}$ & $1,135 \times 10^{4}$ & $7,038 \times 10^{4}$ & + & 0,000 \\
\hline 20 & $2,882 \times 10^{7}$ & $2,507 \times 10^{8}$ & $3,999 \times 10^{9}$ & $7,874 \times 10^{3}$ & $7,377 \times 10^{3}$ & $3,445 \times 10^{4}$ & + & 0,000 \\
\hline 21 & $2,802 \times 10^{7}$ & $2,447 \times 10^{8}$ & $3,999 \times 10^{9}$ & $1,204 \times 10^{5}$ & $1,075 \times 10^{5}$ & $4,228 \times 10^{5}$ & + & 0,000 \\
\hline 22 & $2,735 \times 10^{7}$ & $2,393 \times 10^{8}$ & $3,999 \times 10^{9}$ & $2,344 \times 10^{4}$ & $1,156 \times 10^{4}$ & $4,973 \times 10^{4}$ & + & 0,000 \\
\hline 23 & $2,624 \times 10^{7}$ & $2,342 \times 10^{8}$ & $3,999 \times 10^{9}$ & $4,173 \times 10^{4}$ & $1,273 \times 10^{4}$ & $9,255 \times 10^{4}$ & + & 0,000 \\
\hline 24 & $2,529 \times 10^{7}$ & $2,294 \times 10^{8}$ & $3,999 \times 10^{9}$ & $2,083 \times 10^{4}$ & $7,757 \times 10^{3}$ & $4,198 \times 10^{4}$ & + & 0,000 \\
\hline 25 & $2,435 \times 10^{7}$ & $2,248 \times 10^{8}$ & $3,999 \times 10^{9}$ & $1,463 \times 10^{4}$ & $5,539 \times 10^{3}$ & $2,631 \times 10^{4}$ & + & 0,000 \\
\hline 26 & $2,343 \times 10^{7}$ & $2,205 \times 10^{8}$ & $3,999 \times 10^{9}$ & $1,201 \times 10^{5}$ & $1,077 \times 10^{5}$ & $4,228 \times 10^{5}$ & + & 0,000 \\
\hline 27 & $2,274 \times 10^{7}$ & $2,165 \times 10^{8}$ & $3,999 \times 10^{9}$ & $1,346 \times 10^{5}$ & $1,008 \times 10^{5}$ & $4,4 \times 10^{5}$ & + & 0,000 \\
\hline 28 & $2,354 \times 10^{7}$ & $2,129 \times 10^{8}$ & $3,999 \times 10^{9}$ & $2,81 \times 10^{4}$ & $1,722 \times 10^{4}$ & $9,302 \times 10^{4}$ & + & 0,000 \\
\hline 29 & $2,889 \times 10^{7}$ & $2,187 \times 10^{8}$ & $3,999 \times 10^{9}$ & $3,008 \times 10^{4}$ & $2,78 \times 10^{4}$ & $1,324 \times 10^{5}$ & + & 0,000 \\
\hline 30 & $2,795 \times 10^{7}$ & $2,15 \times 10^{8}$ & $3,999 \times 10^{9}$ & $2,814 \times 10^{4}$ & $1,697 \times 10^{4}$ & $9,187 \times 10^{4}$ & + & 0,000 \\
\hline
\end{tabular}

É importante comparar também os resultados de TS-Stream com os de ODAC. Observase na Tabela 5.5 que, para 28 das 30 bases, TS-Stream obteve uma média de resgate total maior do que ODAC. Em aproximadamente metade dessas bases foi detectada uma diferença estatisticamente significativa. Para as duas bases em que ODAC teve uma média geral maior do que TS-Stream (bases \#2 e \#3) não se detectou uma diferença significativa (p-valor menor do que 0,05). Em 28 das 30 bases, o valor máximo obtido por TS-Stream 
Tabela 5.3: Resultados para as 30 bases do setor financeiro, considerando TS-Stream e Top-k. A coluna Score indica se a média $(\mu)$ de TS-Stream superou a de Top-k $(+)$ ou não (-). A coluna P-valor indica o resultado do teste de Wilcoxon com hipótese alternativa de que a distribuição de resgate total da técnica com maior média da linha é deslocada à direita da distribuição da outra técnica. P-valores menores do que 0,05 indicam que há uma diferença estatisticamente significativa entre as distribuições.

\begin{tabular}{|c|c|c|c|c|c|c|c|c|}
\hline Base \# & $\mu \mathrm{TS}$ & $\sigma \mathrm{TS}$ & $\max \mathrm{TS}$ & $\mu$ Top-k & $\sigma$ Top-k & $\max$ Top-k & Score & P-valor \\
\hline 1 & $7,695 \times 10^{5}$ & $1,137 \times 10^{6}$ & $4,533 \times 10^{6}$ & $1,199 \times 10^{5}$ & $1,154 \times 10^{5}$ & $4,661 \times 10^{5}$ & + & 0,000 \\
\hline 2 & $1,096 \times 10^{6}$ & $1,688 \times 10^{6}$ & $8,874 \times 10^{6}$ & $3,794 \times 10^{6}$ & $5,598 \times 10^{6}$ & $2,119 \times 10^{7}$ & - & 0,000 \\
\hline 3 & $1,801 \times 10^{6}$ & $3,241 \times 10^{6}$ & $2,509 \times 10^{7}$ & $5,899 \times 10^{5}$ & $7,306 \times 10^{5}$ & $2,27 \times 10^{6}$ & + & 0,000 \\
\hline 4 & $2,36 \times 10^{6}$ & $4,65 \times 10^{6}$ & $3,187 \times 10^{7}$ & $7,896 \times 10^{5}$ & $1,071 \times 10^{6}$ & $3,732 \times 10^{6}$ & + & 0,002 \\
\hline 5 & $2,104 \times 10^{6}$ & $4,266 \times 10^{6}$ & $3,187 \times 10^{7}$ & $1,149 \times 10^{6}$ & $1,876 \times 10^{6}$ & $7,719 \times 10^{6}$ & + & 0,000 \\
\hline 6 & $7,053 \times 10^{6}$ & $2,201 \times 10^{7}$ & $1,484 \times 10^{8}$ & $1,477 \times 10^{6}$ & $2,103 \times 10^{6}$ & $6,848 \times 10^{6}$ & + & 0,000 \\
\hline 7 & $6,075 \times 10^{6}$ & $2,051 \times 10^{7}$ & $1,484 \times 10^{8}$ & $1,729 \times 10^{5}$ & $1,751 \times 10^{5}$ & $6,663 \times 10^{5}$ & + & 0,000 \\
\hline 8 & $5,48 \times 10^{6}$ & $1,923 \times 10^{7}$ & $1,484 \times 10^{8}$ & $2,253 \times 10^{5}$ & $2,295 \times 10^{5}$ & $1,231 \times 10^{6}$ & + & 0,000 \\
\hline 9 & $4,911 \times 10^{6}$ & $1,82 \times 10^{7}$ & $1,484 \times 10^{8}$ & $1,235 \times 10^{5}$ & $1,264 \times 10^{5}$ & $5,889 \times 10^{5}$ & + & 0,000 \\
\hline 10 & $4,764 \times 10^{6}$ & $1,736 \times 10^{7}$ & $1,484 \times 10^{8}$ & $3,599 \times 10^{6}$ & $5,051 \times 10^{6}$ & $1,75 \times 10^{7}$ & + & 1,000 \\
\hline 11 & $4,381 \times 10^{6}$ & $1,66 \times 10^{7}$ & $1,484 \times 10^{8}$ & $2,263 \times 10^{5}$ & $2,086 \times 10^{5}$ & $7,421 \times 10^{5}$ & + & 0,000 \\
\hline 12 & $4,268 \times 10^{6}$ & $1,597 \times 10^{7}$ & $1,484 \times 10^{8}$ & $5,856 \times 10^{5}$ & $5,978 \times 10^{5}$ & $2,286 \times 10^{6}$ & + & 0,137 \\
\hline 13 & $4,143 \times 10^{6}$ & $1,541 \times 10^{7}$ & $1,484 \times 10^{8}$ & $1,185 \times 10^{6}$ & $2,005 \times 10^{6}$ & $6,934 \times 10^{6}$ & + & 0,931 \\
\hline 14 & $3,946 \times 10^{6}$ & $1,489 \times 10^{7}$ & $1,484 \times 10^{8}$ & $4,12 \times 10^{5}$ & $6,559 \times 10^{5}$ & $2,407 \times 10^{6}$ & + & 0,000 \\
\hline 15 & $3,746 \times 10^{6}$ & $1,442 \times 10^{7}$ & $1,484 \times 10^{8}$ & $4,368 \times 10^{5}$ & $5,806 \times 10^{5}$ & $2,306 \times 10^{6}$ & + & 0,000 \\
\hline 16 & $3,615 \times 10^{6}$ & $1,399 \times 10^{7}$ & $1,484 \times 10^{8}$ & $2,006 \times 10^{6}$ & $3,042 \times 10^{6}$ & $1,037 \times 10^{7}$ & + & 1,000 \\
\hline 17 & $3,535 \times 10^{6}$ & $1,362 \times 10^{7}$ & $1,484 \times 10^{8}$ & $5,405 \times 10^{5}$ & $4,654 \times 10^{5}$ & $1,966 \times 10^{6}$ & + & 0,292 \\
\hline 18 & $3,109 \times 10^{7}$ & $2,641 \times 10^{8}$ & $3,999 \times 10^{9}$ & $1,902 \times 10^{8}$ & $3,452 \times 10^{8}$ & $1,179 \times 10^{9}$ & - & 0,000 \\
\hline 19 & $2,952 \times 10^{7}$ & $2,572 \times 10^{8}$ & $3,999 \times 10^{9}$ & $1,692 \times 10^{5}$ & $1,522 \times 10^{5}$ & $5,517 \times 10^{5}$ & + & 0,000 \\
\hline 20 & $2,882 \times 10^{7}$ & $2,507 \times 10^{8}$ & $3,999 \times 10^{9}$ & $3,092 \times 10^{5}$ & $4,697 \times 10^{5}$ & $1,663 \times 10^{6}$ & + & 0,000 \\
\hline 21 & $2,802 \times 10^{7}$ & $2,447 \times 10^{8}$ & $3,999 \times 10^{9}$ & $6,988 \times 10^{6}$ & $1,141 \times 10^{7}$ & $3,629 \times 10^{7}$ & + & 0,667 \\
\hline 22 & $2,735 \times 10^{7}$ & $2,393 \times 10^{8}$ & $3,999 \times 10^{9}$ & $6,405 \times 10^{5}$ & $7,356 \times 10^{5}$ & $2,879 \times 10^{6}$ & + & 0,000 \\
\hline 23 & $2,624 \times 10^{7}$ & $2,342 \times 10^{8}$ & $3,999 \times 10^{9}$ & $1,696 \times 10^{5}$ & $1,809 \times 10^{5}$ & $7,103 \times 10^{5}$ & + & 0,000 \\
\hline 24 & $2,529 \times 10^{7}$ & $2,294 \times 10^{8}$ & $3,999 \times 10^{9}$ & $1,711 \times 10^{6}$ & $2,263 \times 10^{6}$ & $7,361 \times 10^{6}$ & + & 0,204 \\
\hline 25 & $2,435 \times 10^{7}$ & $2,248 \times 10^{8}$ & $3,999 \times 10^{9}$ & $1,01 \times 10^{6}$ & $1,399 \times 10^{6}$ & $4,93 \times 10^{6}$ & + & 0,000 \\
\hline 26 & $2,343 \times 10^{7}$ & $2,205 \times 10^{8}$ & $3,999 \times 10^{9}$ & $1,781 \times 10^{6}$ & $2,812 \times 10^{6}$ & $1,491 \times 10^{7}$ & + & 1,000 \\
\hline 27 & $2,274 \times 10^{7}$ & $2,165 \times 10^{8}$ & $3,999 \times 10^{9}$ & $4,174 \times 10^{6}$ & $6,594 \times 10^{6}$ & $2,4 \times 10^{7}$ & + & 1,000 \\
\hline 28 & $2,354 \times 10^{7}$ & $2,129 \times 10^{8}$ & $3,999 \times 10^{9}$ & $4,292 \times 10^{5}$ & $4,039 \times 10^{5}$ & $1,324 \times 10^{6}$ & + & 0,000 \\
\hline 29 & $2,889 \times 10^{7}$ & $2,187 \times 10^{8}$ & $3,999 \times 10^{9}$ & $7,321 \times 10^{7}$ & $1,053 \times 10^{8}$ & $3,98 \times 10^{8}$ & - & 0,000 \\
\hline 30 & $2,795 \times 10^{7}$ & $2,15 \times 10^{8}$ & $3,999 \times 10^{9}$ & $5,651 \times 10^{5}$ & $6,249 \times 10^{5}$ & $2,251 \times 10^{6}$ & + & 0,000 \\
\hline
\end{tabular}

Tabela 5.4: Porcentagem de tempo em que o resgate total ficou acima do capital inicial investido.

\begin{tabular}{lc}
\hline \multicolumn{1}{c}{ Política } & \% de tempo acima do capital inicial investido. \\
\hline TS-Stream & 98,82 \\
Top-K & 98,93 \\
Top-1 & 65,11 \\
ODAC & 99,00 \\
\hline
\end{tabular}



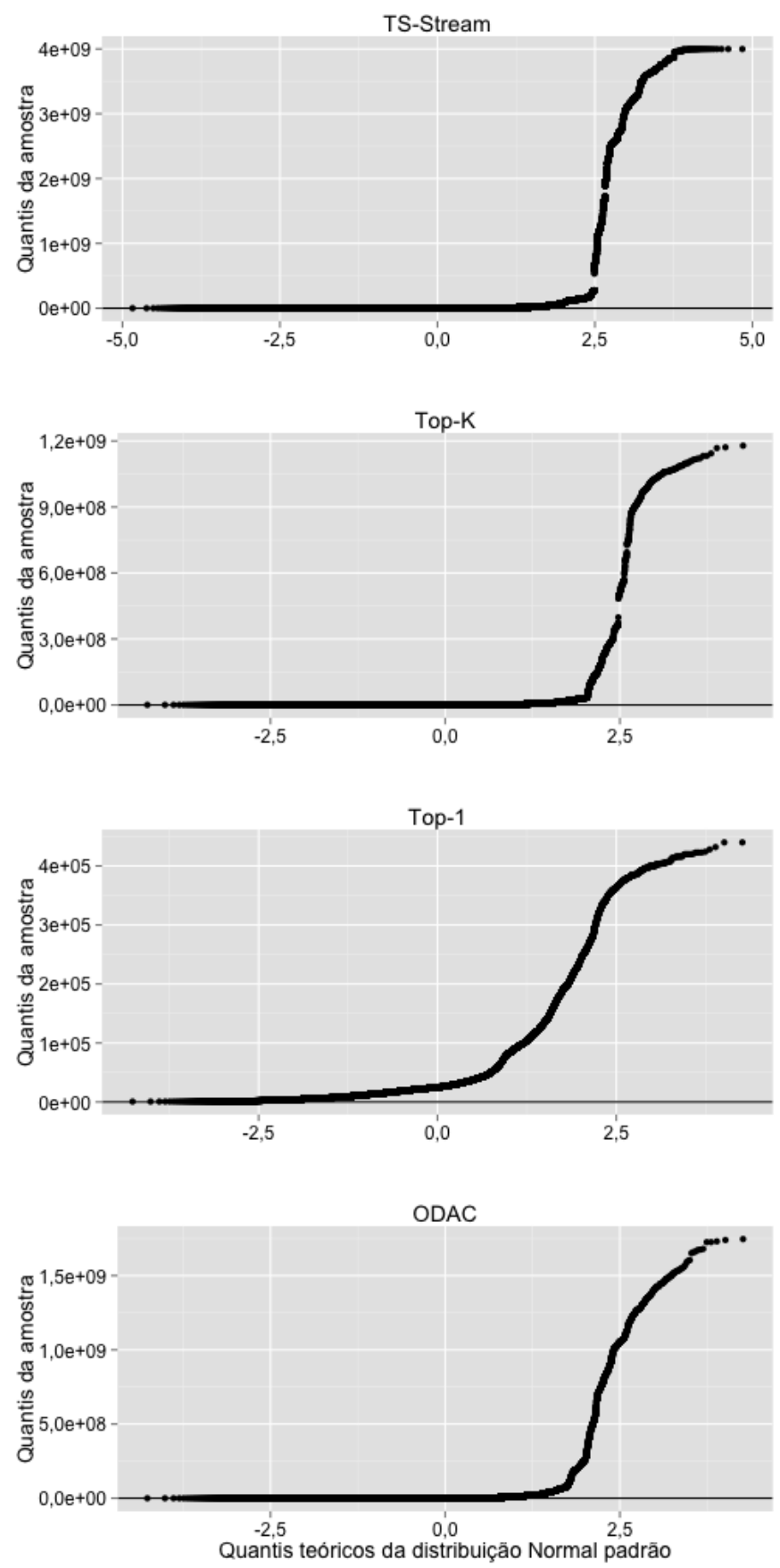

Figura 5.21: Gráficos quantil-quantil para as quatro políticas de negociação: TS-Stream, Top-K, Top-1 e ODAC, considerando as 30 bases de dados do setor financeiro. 
também foi maior do que o de ODAC.

Tabela 5.5: Resultados para as 30 bases do setor financeiro, considerando TS-Stream e ODAC. A coluna Score indica se a média $(\mu)$ de TS-Stream superou a de ODAC $(+)$ ou não (-). A coluna P-valor indica o resultado do teste de Wilcoxon com hipótese alternativa de que a distribuição de resgate total da técnica com maior média da linha é deslocada à direita da distribuição da outra técnica. P-valores menores do que 0,05 indicam que há uma diferença estatisticamente significativa entre as distribuições.

\begin{tabular}{|c|c|c|c|c|c|c|c|c|}
\hline Base \# & $\mu \mathrm{TS}$ & $\sigma \mathrm{TS}$ & $\max \mathrm{TS}$ & $\mu \mathrm{ODAC}$ & $\sigma \mathrm{ODAC}$ & $\max$ ODAC & Score & P-valor \\
\hline 1 & $7,695 \times 10^{5}$ & $1,137 \times 10^{6}$ & $4,533 \times 10^{6}$ & $5,633 \times 10^{5}$ & $6,884 \times 10^{5}$ & $2,271 \times 10^{6}$ & + & 0,000 \\
\hline 2 & $1,096 \times 10^{6}$ & $1,688 \times 10^{6}$ & $8,874 \times 10^{6}$ & $2,338 \times 10^{6}$ & $4,956 \times 10^{6}$ & $2,78 \times 10^{7}$ & - & 0,100 \\
\hline 3 & $1,801 \times 10^{6}$ & $3,241 \times 10^{6}$ & $2,509 \times 10^{7}$ & $2,171 \times 10^{6}$ & $4,304 \times 10^{6}$ & $2,78 \times 10^{7}$ & - & 0,998 \\
\hline 4 & $2,36 \times 10^{6}$ & $4,65 \times 10^{6}$ & $3,187 \times 10^{7}$ & $2,058 \times 10^{6}$ & $4,016 \times 10^{6}$ & $2,78 \times 10^{7}$ & + & 0,000 \\
\hline 5 & $2,104 \times 10^{6}$ & $4,266 \times 10^{6}$ & $3,187 \times 10^{7}$ & $1,752 \times 10^{6}$ & $3,665 \times 10^{6}$ & $2,78 \times 10^{7}$ & + & 0,000 \\
\hline 6 & $7,053 \times 10^{6}$ & $2,201 \times 10^{7}$ & $1,484 \times 10^{8}$ & $3,016 \times 10^{6}$ & $7,715 \times 10^{6}$ & $5,903 \times 10^{7}$ & + & 0,000 \\
\hline 7 & $6,075 \times 10^{6}$ & $2,051 \times 10^{7}$ & $1,484 \times 10^{8}$ & $2,769 \times 10^{6}$ & $7,195 \times 10^{6}$ & $5,903 \times 10^{7}$ & + & 0,003 \\
\hline 8 & $5,48 \times 10^{6}$ & $1,923 \times 10^{7}$ & $1,484 \times 10^{8}$ & $2,526 \times 10^{6}$ & $6,768 \times 10^{6}$ & $5,903 \times 10^{7}$ & + & 0,000 \\
\hline 9 & $4,911 \times 10^{6}$ & $1,82 \times 10^{7}$ & $1,484 \times 10^{8}$ & $2,272 \times 10^{6}$ & $6,421 \times 10^{6}$ & $5,903 \times 10^{7}$ & + & 0,000 \\
\hline 10 & $4,764 \times 10^{6}$ & $1,736 \times 10^{7}$ & $1,484 \times 10^{8}$ & $2,689 \times 10^{6}$ & $6,865 \times 10^{6}$ & $5,903 \times 10^{7}$ & + & 0,000 \\
\hline 11 & $4,381 \times 10^{6}$ & $1,66 \times 10^{7}$ & $1,484 \times 10^{8}$ & $2,54 \times 10^{6}$ & $6,58 \times 10^{6}$ & $5,903 \times 10^{7}$ & + & 0,013 \\
\hline 12 & $4,268 \times 10^{6}$ & $1,597 \times 10^{7}$ & $1,484 \times 10^{8}$ & $2,499 \times 10^{6}$ & $6,391 \times 10^{6}$ & $5,903 \times 10^{7}$ & + & 0,000 \\
\hline 13 & $4,143 \times 10^{6}$ & $1,541 \times 10^{7}$ & $1,484 \times 10^{8}$ & $2,471 \times 10^{6}$ & $6,236 \times 10^{6}$ & $5,903 \times 10^{7}$ & + & 0,000 \\
\hline 14 & $3,946 \times 10^{6}$ & $1,489 \times 10^{7}$ & $1,484 \times 10^{8}$ & $2,398 \times 10^{6}$ & $6,045 \times 10^{6}$ & $5,903 \times 10^{7}$ & + & 0,008 \\
\hline 15 & $3,746 \times 10^{6}$ & $1,442 \times 10^{7}$ & $1,484 \times 10^{8}$ & $2,368 \times 10^{6}$ & $5,904 \times 10^{6}$ & $5,903 \times 10^{7}$ & + & 0,062 \\
\hline 16 & $3,615 \times 10^{6}$ & $1,399 \times 10^{7}$ & $1,484 \times 10^{8}$ & $2,972 \times 10^{6}$ & $8,086 \times 10^{6}$ & $7,376 \times 10^{7}$ & + & 0,931 \\
\hline 17 & $3,535 \times 10^{6}$ & $1,362 \times 10^{7}$ & $1,484 \times 10^{8}$ & $2,874 \times 10^{6}$ & $7,868 \times 10^{6}$ & $7,376 \times 10^{7}$ & + & 0,973 \\
\hline 18 & $3,109 \times 10^{7}$ & $2,641 \times 10^{8}$ & $3,999 \times 10^{9}$ & $1,362 \times 10^{7}$ & $1,028 \times 10^{8}$ & $1,604 \times 10^{9}$ & + & 0,980 \\
\hline 19 & $2,952 \times 10^{7}$ & $2,572 \times 10^{8}$ & $3,999 \times 10^{9}$ & $1,296 \times 10^{7}$ & $1,001 \times 10^{8}$ & $1,604 \times 10^{9}$ & + & 0,987 \\
\hline 20 & $2,882 \times 10^{7}$ & $2,507 \times 10^{8}$ & $3,999 \times 10^{9}$ & $1,436 \times 10^{7}$ & $9,912 \times 10^{7}$ & $1,604 \times 10^{9}$ & + & 1,000 \\
\hline 21 & $2,802 \times 10^{7}$ & $2,447 \times 10^{8}$ & $3,999 \times 10^{9}$ & $1,596 \times 10^{7}$ & $9,829 \times 10^{7}$ & $1,604 \times 10^{9}$ & + & 1,000 \\
\hline 22 & $2,735 \times 10^{7}$ & $2,393 \times 10^{8}$ & $3,999 \times 10^{9}$ & $2,624 \times 10^{7}$ & $1,437 \times 10^{8}$ & $1,746 \times 10^{9}$ & + & 1,000 \\
\hline 23 & $2,624 \times 10^{7}$ & $2,342 \times 10^{8}$ & $3,999 \times 10^{9}$ & $2,55 \times 10^{7}$ & $1,407 \times 10^{8}$ & $1,746 \times 10^{9}$ & + & 1,000 \\
\hline 24 & $2,529 \times 10^{7}$ & $2,294 \times 10^{8}$ & $3,999 \times 10^{9}$ & $2,5 \times 10^{7}$ & $1,379 \times 10^{8}$ & $1,746 \times 10^{9}$ & + & 1,000 \\
\hline 25 & $2,435 \times 10^{7}$ & $2,248 \times 10^{8}$ & $3,999 \times 10^{9}$ & $2,416 \times 10^{7}$ & $1,352 \times 10^{8}$ & $1,746 \times 10^{9}$ & + & 1,000 \\
\hline 26 & $2,343 \times 10^{7}$ & $2,205 \times 10^{8}$ & $3,999 \times 10^{9}$ & $2,326 \times 10^{7}$ & $1,326 \times 10^{8}$ & $1,746 \times 10^{9}$ & + & 1,000 \\
\hline 27 & $2,274 \times 10^{7}$ & $2,165 \times 10^{8}$ & $3,999 \times 10^{9}$ & $2,251 \times 10^{7}$ & $1,302 \times 10^{8}$ & $1,746 \times 10^{9}$ & + & 1,000 \\
\hline 28 & $2,354 \times 10^{7}$ & $2,129 \times 10^{8}$ & $3,999 \times 10^{9}$ & $2,227 \times 10^{7}$ & $1,279 \times 10^{8}$ & $1,746 \times 10^{9}$ & + & 1,000 \\
\hline 29 & $2,889 \times 10^{7}$ & $2,187 \times 10^{8}$ & $3,999 \times 10^{9}$ & $2,719 \times 10^{7}$ & $1,378 \times 10^{8}$ & $1,746 \times 10^{9}$ & + & 1,000 \\
\hline 30 & $2,795 \times 10^{7}$ & $2,15 \times 10^{8}$ & $3,999 \times 10^{9}$ & $2,635 \times 10^{7}$ & $1,356 \times 10^{8}$ & $1,746 \times 10^{9}$ & + & 1,000 \\
\hline
\end{tabular}




\subsubsection{Experimento com dados reais de áudio}

Este experimento teve por objetivo mostrar a eficácia de TS-Stream em outro cenário real, utilizando uma base de dados de áudio. Empregou-se o corpus 100 Nonspeech Sounds, coletado por Guoning $\mathrm{Hu}$ da Ohio State University ${ }^{12}$. A base consiste em 100 arquivos de áudio no formato WAV, amostrados a uma taxa de $20 \mathrm{kHz}$ e provenientes de diversas fontes, tais como alarmes, sinos, tráfego de veículos e outros.

Para o experimento realizado selecionou-se um subconjunto de 15 arquivos, divididos em três grupos, conforme listado na Tabela 5.6. Esses arquivos específicos foram selecionados por dois motivos: havia pelo menos cinco deles em cada grupo e cada arquivo apresentava ao menos dois segundos de duração. Utilizou-se no experimento 2 segundos por arquivo, o que produziu 40000 observações para cada série temporal de áudio.

Tabela 5.6: Sons utilizados no experimento com a base de dados reais de áudio.

\begin{tabular}{cc}
\hline Grupo & Identificador dos arquivos utilizados \\
\hline Alarmes e sirenes & $\mathrm{N} 30, \mathrm{~N} 31, \mathrm{~N} 32, \mathrm{~N} 33, \mathrm{~N} 34$ \\
Água & $\mathrm{N} 56, \mathrm{~N} 57, \mathrm{~N} 58, \mathrm{~N} 59, \mathrm{~N} 62$ \\
Aglomerações de pessoas & $\mathrm{N} 1, \mathrm{~N} 2, \mathrm{~N} 5, \mathrm{~N} 6, \mathrm{~N} 7$ \\
\hline
\end{tabular}

\section{Periodograma do arquivo N30.wav do grupo Alarmes e Sirenes}

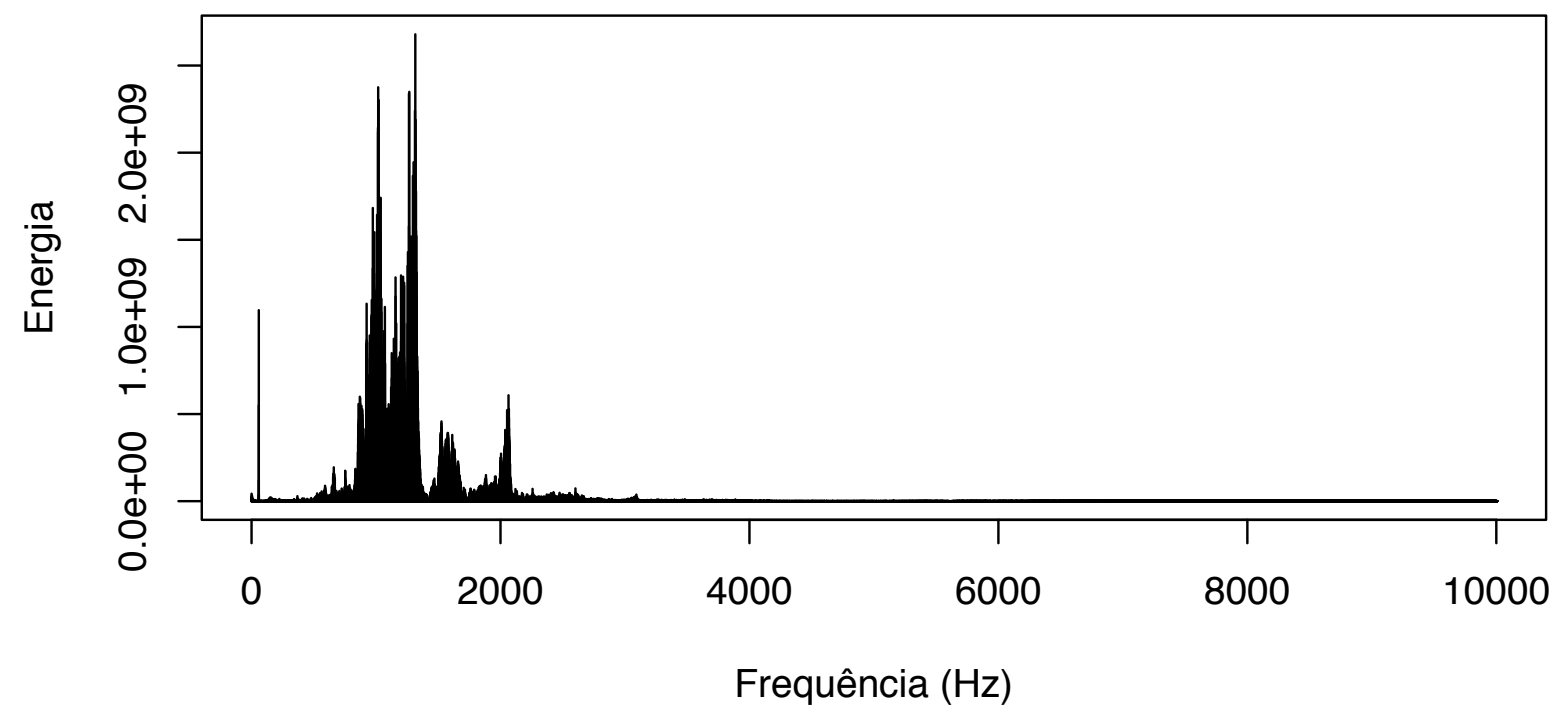

Figura 5.22: Periodograma para arquivo N30.wav, do grupo Alarmes e sirenes.

TS-Stream utilizou uma única medida descritiva, uma heurística simples, denominada MFREQ, que seleciona as $f$ frequências com maior energia do periodograma calculado a partir da Transformada de Fourier. Essa heurística é similar a técnicas de detecção

\footnotetext{
${ }^{12} \mathrm{~A}$ base pode ser obtida em http://www.cse. ohio-state.edu/pnl/corpus/HuCorpus.html. Último acesso: 23 de agosto de 2013.
} 
Periodograma do arquivo N56.wav do grupo Água

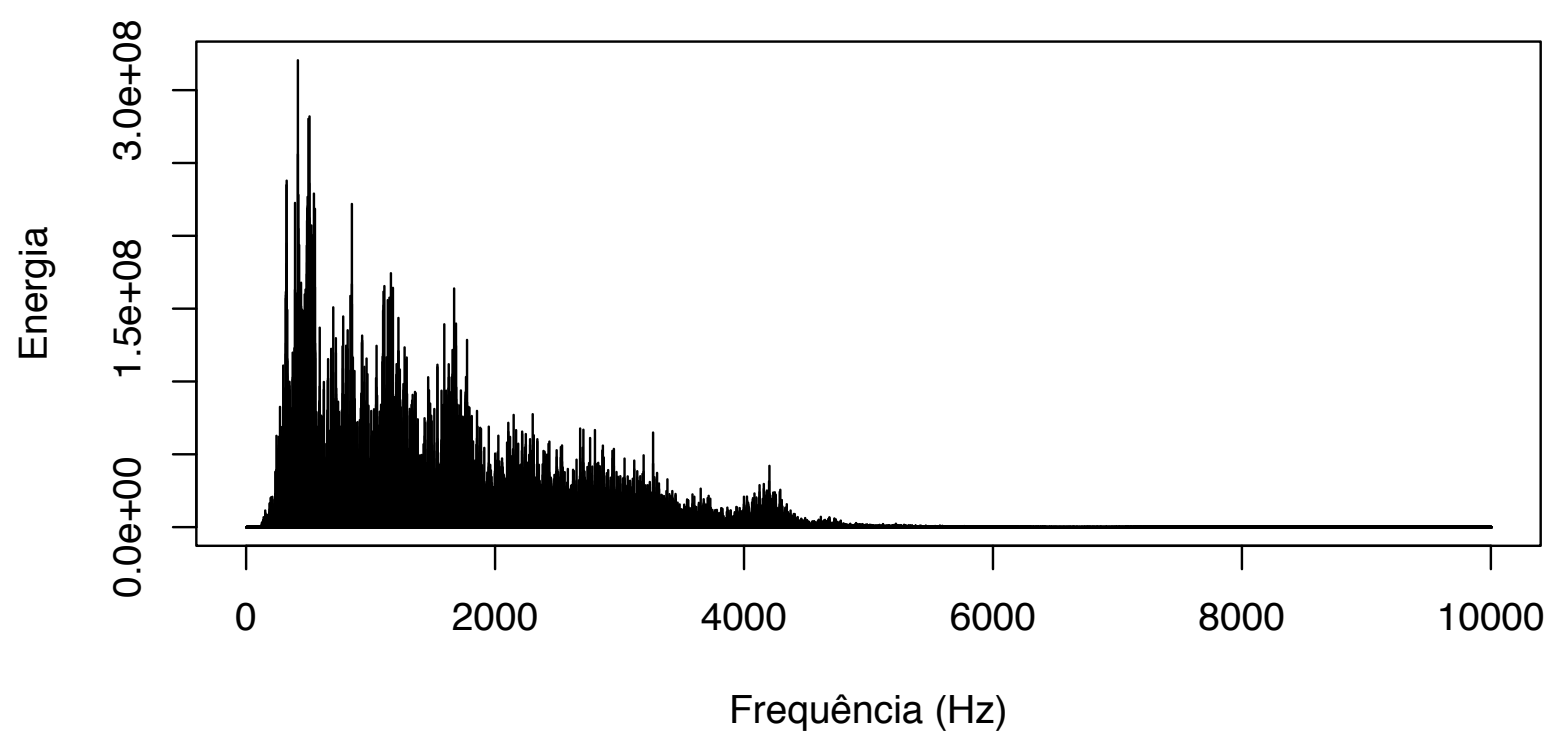

Figura 5.23: Periodograma para arquivo N56.wav, do grupo Água.

Periodograma do arquivo N1.wav do grupo Aglomerações de pessoas

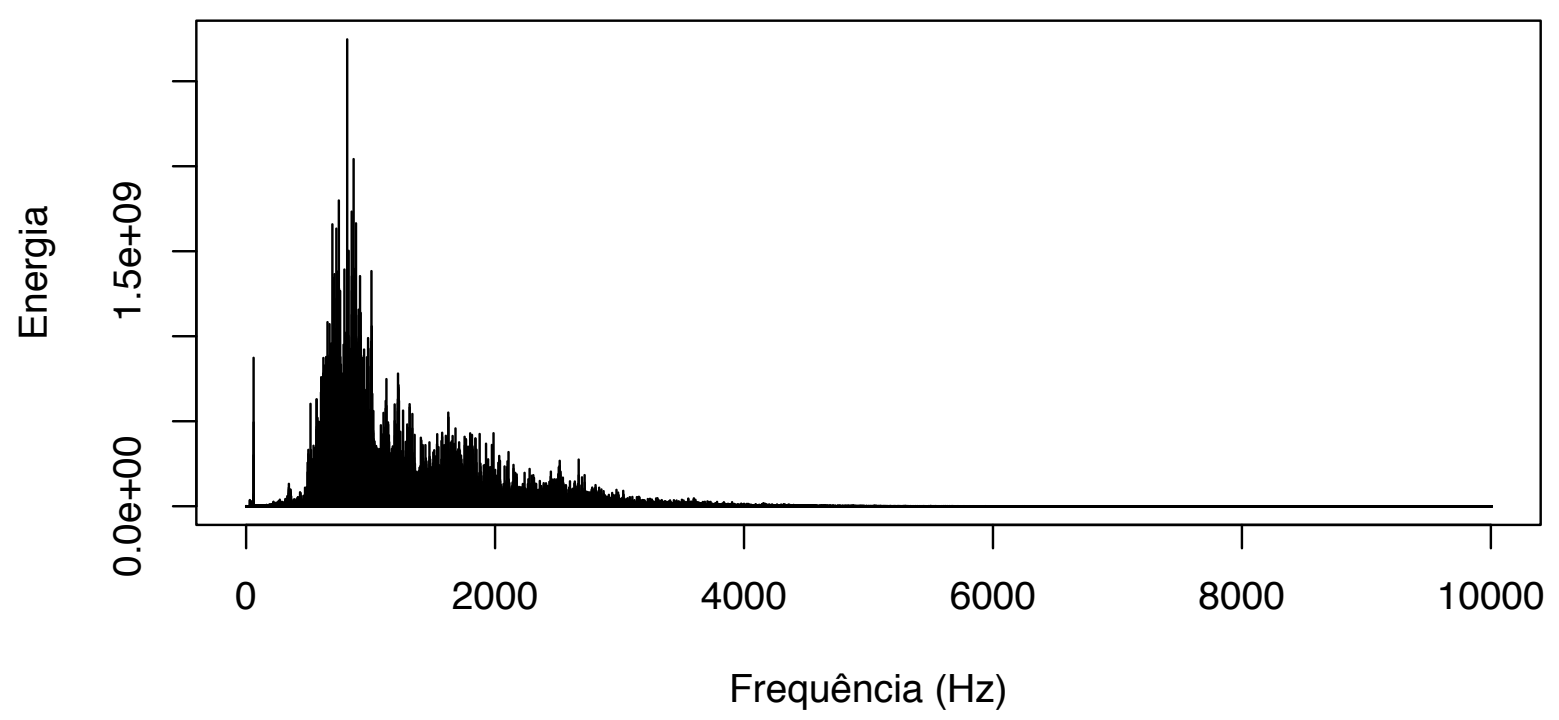

Figura 5.24: Periodograma para arquivo N1.wav, do grupo Aglomerações de pessoas. 
de frequências fundamentais, baseadas na detecção de picos no periodograma. Nesse experimento, utilizou-se o parâmetro $f=2$, o qual forneceu bons resultados. Os outros parâmetros de TS-Stream foram configurados como $W=20000, \alpha=0,5$, beta $=0,3$ e $\lambda=0,7$. O tamanho da janela de TS-Stream foi configurado com o valor da taxa de amostragem dos dados, enquanto os outros parâmetros foram determinados empiricamente. Para ODAC, utilizou-se os parâmetros $\tau=0,02$ e $\delta=0,05$, valores padrões propostos por seus autores (Rodrigues et al., 2008).

Os resultados obtidos são listados na Tabela 5.7, a qual mostra a partição obtida no cenário ideal, com TS-Stream e com ODAC, além dos valores de Adjusted Rand Index obtidos. A partição deve ser interpretada como um vetor $\left[g_{1} g_{2} \ldots g_{i} \ldots g_{n}\right]$, em que $g_{i}$ indica o grupo do $i$-ésimo objeto. Lembra-se também que um valor de ARI próximo a zero indica um resultado similar ao obtido com uma partição gerada aleatoriamente.

Tabela 5.7: Resultados do experimentos com a base de dados reais de áudio.

\begin{tabular}{|c|c|c|}
\hline Técnica & Partição obtida & ARI \\
\hline Ideal & 1111122222333333 & 1 \\
\hline TS-Stream & 1111122232333313 & 0,6 \\
\hline ODAC & 564218183317961 & 0,025 \\
\hline
\end{tabular}

É possível observar na Tabela 5.7 que a partição obtida por TS-Stream aproxima-se bastante da ideal, conforme pode ser visto também na árvore ilustrada na Figura 5.25. Os nós folhas indicam os grupos obtidos por TS-Stream. Observa-se que apenas as séries 9 e 14 foram associadas a grupos incorretos.

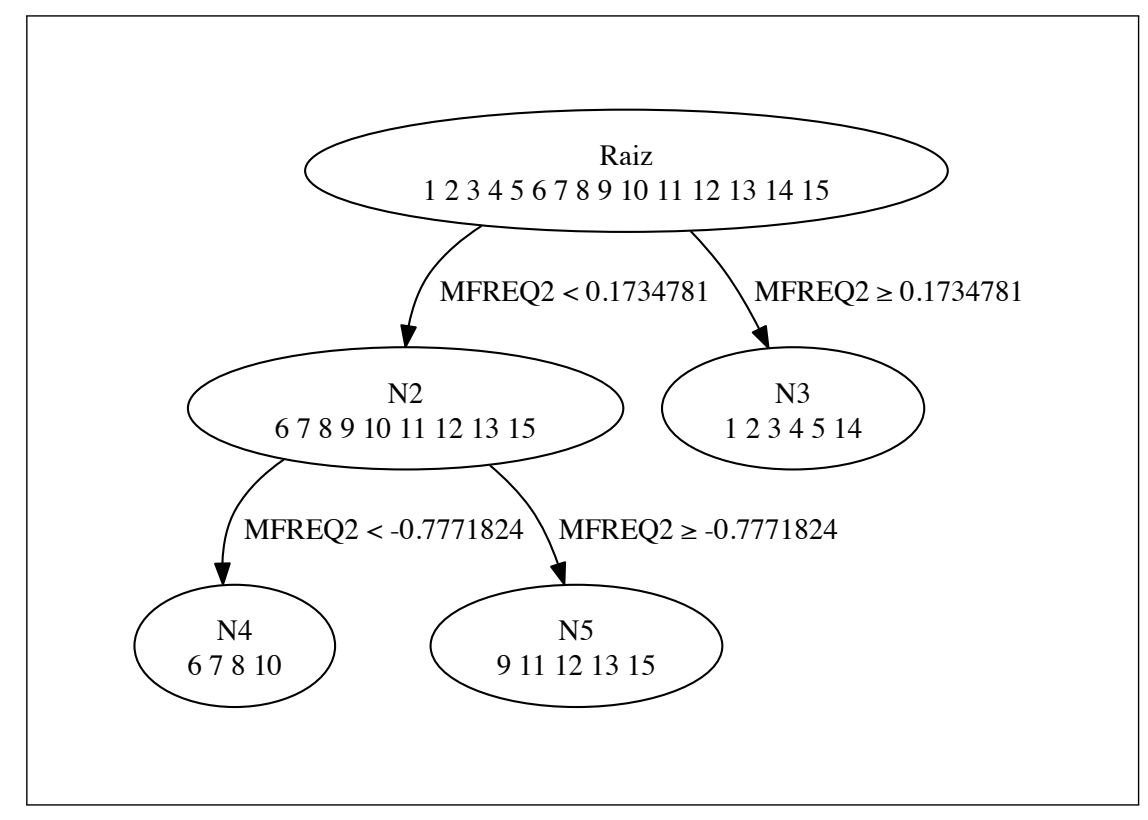

Figura 5.25: Árvore obtida por TS-Stream no experimento com a base de dados reais de áudio. MFREQ2 representa um atributo calculado a partir da heurística utilizada. Concretamente, a segunda frequência com maior energia do periodograma.

Os resultados ruins de ODAC podem ser explicados observando-se a matriz de simi- 


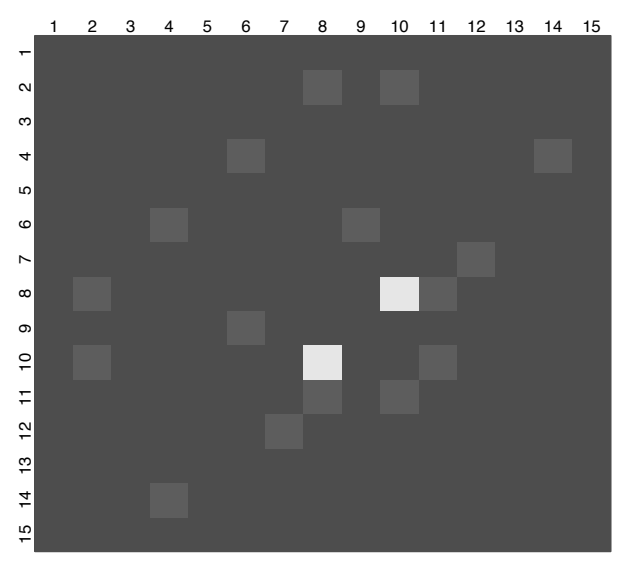

(a) Matriz de similaridade obtida pela correlação de Pearson.

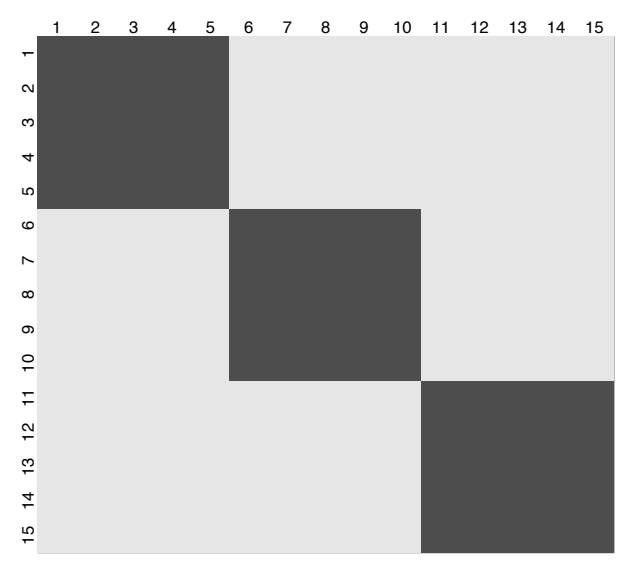

(b) Matriz de similaridade ideal.

Figura 5.26: Matrizes de similaridade para experimento com base de dados reais de áudio. Valores próximos a 1 são representados por tons mais escuros de cinza (alta similaridade). Valores próximos a 0 correspondem a tons mais claros (baixa similaridade). Observa-se que a correlação de Pearson (a) não consegue extrair de maneira satisfatória a estrutura de grupos existente nos dados (b).

laridade das séries, ao calcular-se a correlação de Pearson entre elas, conforme ilustrado na Figura 5.26. A medida de dissimilaridade de ODAC, denominada RNOMC, a qual se baseia na correlação de Pearson, não é capaz de extrair a estrutura de grupos dos dados, prejudicando a qualidade do agrupamento obtido com ODAC.

\subsection{Adaptação automática de parâmetros}

Os experimentos realizados mostraram que TS-Stream obtém bons resultados em diversos cenários, tanto simulados quanto reais, inclusive na presença de evolução de grupos, cenário em que séries migram de um modelo (grupo) para outro. Entretanto, em função da natureza volátil de fluxos contínuos, é possível que outro tipo de mudança ocorra no fluxo, de forma que a configuração inicial de parâmetros torne-se inadequada ao longo do tempo. Por exemplo, o parâmetro multiplicador $\alpha$, que determina a redução de variância necessária para a divisão de uma folha, pode precisar de ajuste com o tempo, para que o algoritmo possa acompanhar mudanças no fluxo e continue a permitir que divisões ocorram. Com o intuito de fornecer a TS-Stream ferramentas para lidar com esse cenário, realizou-se um estudo sobre a adaptação automática de seus parâmetros.

O primeiro método testado para a adaptação automática foi inspirado no algoritmo proposto por Darbellay e Vajda (2006) para a estimação da Autoinformação Mútua em uma amostra de dados. O método funciona recebendo um conjunto de dados em um espaço multidimensional e avaliando se sua distribuição é independente. Caso ela não seja, são realizados particionamentos recursivos até que a condição de independência se verifique. A adoção dessa estratégia permitiria a TS-Stream determinar se um nó deve 
continuar a ser dividido ou não sem depender do parâmetro $\alpha$.

O método consiste em particionar cada dimensão do espaço em sua mediana, gerando hiper-retângulos disjuntos e não uniformes, ou seja, sem sobreposição e de tamanhos variados. Executa-se então um teste de hipótese usando o valor $\chi^{2}$ da distribuição Chiquadrado. Para isso, conta-se o número $N_{i}$ de pontos em cada hiper-retângulo. Por exemplo, caso se tenha um espaço unidimensional, como ocorre com TS-Stream para um dado nó, a divisão será em duas regiões. O teste é então aplicado de acordo com a Equação 5.10, na qual $\chi_{95 \%}^{2}(1)$ é o valor crítico, considerando 1 grau de liberdade e $95 \%$ de confiança. Caso o valor de $T$ seja menor ou igual a 3,841, então se detecta que os dados contidos no nó pai apresentam dependência e continua-se a particionar recursivamente o espaço, até que $T$ seja maior que o valor crítico esperado.

$$
T=\sum_{i=1}^{2}\left(\frac{\sum N_{i}}{2}-N_{i}\right)^{2} \leq \chi_{95 \%}^{2}(1)=3,841
$$

Para testar esse método, criou-se um conjunto de dados artificiais com dois grupos, o primeiro consistindo de uma sequência de dez zeros e o outro de dez uns, para verificar se o algoritmo geraria a partição correta. A árvore gerada pelo método é apresentada na Figura 5.27, a qual mostra que os dois grupos foram separados corretamente.

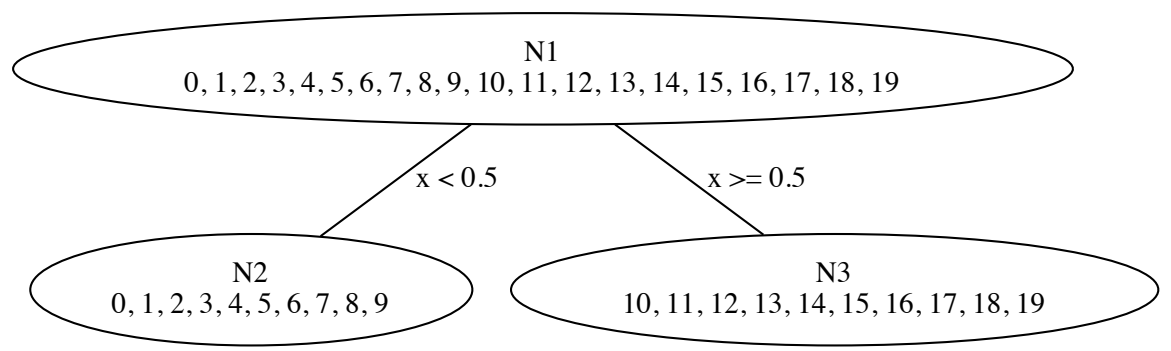

Figura 5.27: Exemplo de árvore gerada pelo método de cortes inspirado no algoritmo de Darbellay e Vajda (2006). Nesse teste uma sequência $(0, \ldots, 0,1, \ldots, 1)$, composta por dez zeros e dez uns foi fornecida ao método de divisão. Os índices abaixo do identificador do nó indicam seus membros. É possível observar que a separação correta foi feita.

O segundo teste foi realizado com séries temporais, usando o mesmo cenário apresentado na Figura 5.3 (p. 79), dado por uma base de dados sintética constituída por séries temporais formando a partição $\{\{0,1, \ldots, 9\},\{10,11, \ldots, 19\},\{20,21, \ldots, 29\}\}$. Conforme observado na Figura 5.3, o melhor atributo para realização do primeiro corte na árvore é o AMI2 (coeficiente da Autoinformação Mútua com atraso 2), portanto ele foi fornecido como entrada para o método de divisão. A árvore produzida está ilustrada na Figura 5.28. É possível observar que o método não foi bem sucedido ao realizar as divisões, particionando o espaço até a obtenção de grupos com apenas uma série.

Em face aos resultados insatisfatórios obtidos por meio dessa primeira metodologia, mesmo em um cenário simples com três grupos, buscou-se um novo método para adaptar 


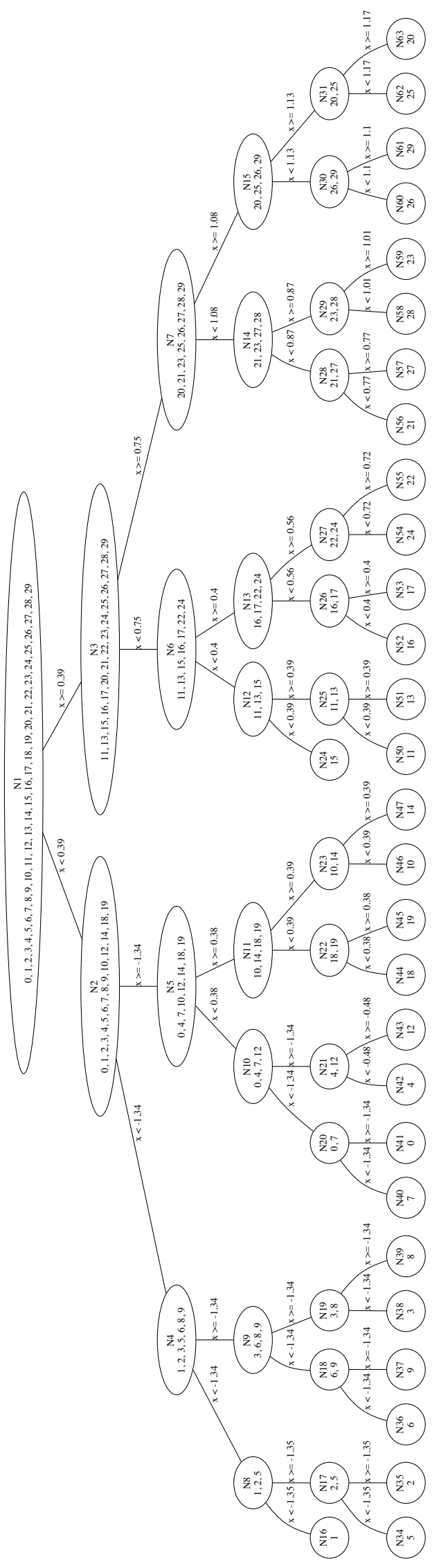

Figura 5.28: Exemplo de árvore gerada pelo método de cortes inspirado no algoritmo de Darbellay e Vajda (2006). Nesse teste o mesmo cenário apresentado na Figura 5.3 (p. 79) foi utilizado, sendo a base de dados composta pela partição $\{\{0,1, \ldots, 9\},\{10,11, \ldots, 19\},\{20,21, \ldots, 29\}\}$. É possível observar que o método não foi bem sucedido ao realizar as divisões. 
os parâmetros existentes em TS-Stream ao longo do tempo. Nesse sentido, iniciou-se um estudo visando primeiramente a adaptação do parâmetro $\alpha$, que controla a divisão em TS-Stream.

Seja $\alpha_{N}$ o valor novo atribuído ao parâmetro $\alpha$, enquanto $\alpha_{A}$ seu valor antigo. A adaptação é dada pela Equação 5.11, na qual $V_{i}$ indica um valor de variância, que faz parte de um conjunto $V=\left\{V_{i}: V_{i} \%<\alpha_{A}\right.$ ou $\left.V_{i} \%<\alpha_{A}+t o l\right\}$. Tal conjunto envolve valores de variâncias reduzidas em divisões realizadas e também daquelas que não foram realizadas, porém ficaram próximas ao limite para o serem. O valor $V_{i} \%$ corresponde à porcentagem de variância reduzida, ou que seria reduzida, na $i$-ésima divisão. O parâmetro tol indica uma tolerância a mais para o valor inicial de $\alpha$, de forma que se permita que $\alpha$ seja influenciado por divisões que ocorreriam caso ele fosse levemente maior, fazendo com que seu valor também possa aumentar ao longo da execução.

$$
\alpha_{N}=\eta \frac{\sum_{i} V_{i} \cdot V_{i} \%}{\sum_{i} V_{i}}+(1-\eta) \alpha_{A}
$$

A intuição por trás desse método é que $\alpha$ deve se mover majoritariamente na direção em que houve maior redução de variância. Isso é feito na Equação 5.11 por meio dos pesos $V_{i}$, que influenciam na direção das porcentagens $V_{i} \%$, as quais correspondem conjuntamente ao novo valor ideal de $\alpha$. Um peso $\eta$ é adotado para que se possa controlar a velocidade da movimentação de $\alpha$ para a nova direção.

Por exemplo, suponha que $\alpha=0,3$. Para calcular o conjunto $V$ deve-se levar em conta as variâncias reduzidas nas divisões concretizadas, as quais ocorrem sempre que $V_{i} \%<0,3$. Também deve-se considerar as variâncias que seriam reduzidas caso o valor de $\alpha$ fosse somado a uma tolerância, ou seja, $V_{i} \%<\alpha+$ tol. Se tol $=0,05$, então os elementos $V_{i} \%<0,305$ também são adicionados a $V$, apesar das divisões não terem sido realizadas. Isso é importante para que o valor de $\alpha$ também possa aumentar, caso observe-se que muitas divisões deixaram de ocorrer por necessitarem de um $\alpha$ levemente maior.

De maneira similar, foi idealizada a adaptação para o parâmetro $\lambda$, o qual controla a agregação em TS-Stream. Sua adaptação é feita segundo a Equação 5.12 na qual $V_{i}$ indica um valor de variância, que faz parte de um conjunto $V=\left\{V_{i}: V_{i} \% \geq \lambda_{A}\right.$ ou $V_{i} \% \geq$ $\left.\lambda_{A}-t o l\right\}$. Tal conjunto envolve valores de variâncias em agregações realizadas e também daquelas que não foram realizadas, porém ficaram próximas de o serem caso $\lambda$ fosse levemente menor. O parâmetro tol permite que $\lambda$ diminua com o tempo.

$$
\lambda_{N}=\eta \frac{\sum_{i} V_{i} \cdot V_{i} \%}{\sum_{i} V_{i}}+(1-\eta) \lambda_{A}
$$

A seguir, o conceito de estabilidade do fluxo foi usado para determinar o método de adaptação do tamanho da janela $w$. Caso nenhuma divisão ou agregação tenha ocorrido na janela atual de dados, então se assume que o fluxo encontra-se em um período estável e, portanto, a janela $w$ é incrementada em $10 \%$ de seu tamanho atual. Por outro lado, caso tenha ocorrido divisão ou agregação, identifica-se um período de mudanças e a janela é 


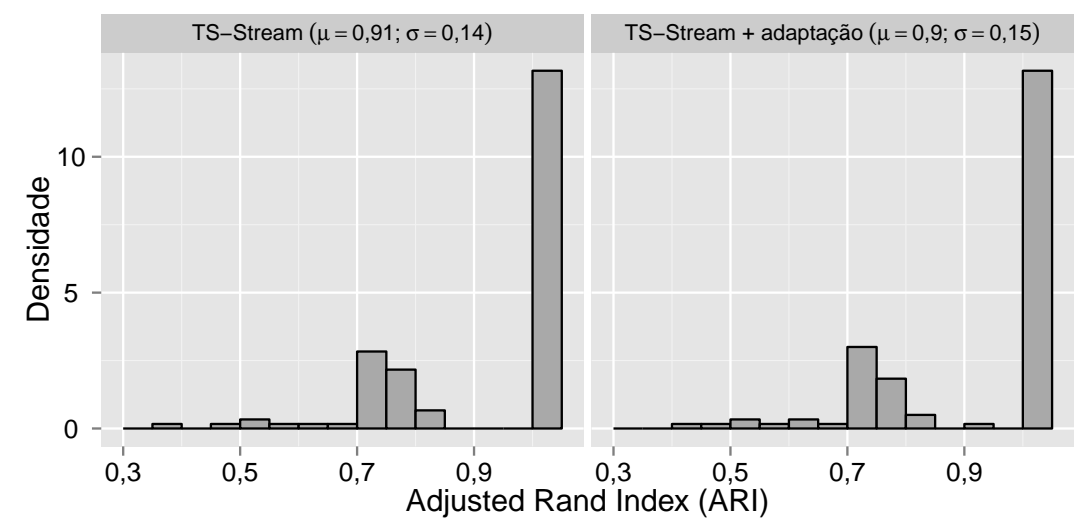

Figura 5.29: Histograma dos resultados de TS-Stream com adaptação para o cenário AR e AR com não linearidade adicionada.

reduzida em $10 \%$ de seu tamanho atual, permitindo que mudanças mais sutis sejam detectadas. O valor de $10 \%$ foi determinado empiricamente para os experimentos conduzidos. O tamanho de janela inicialmente fornecido pelo usuário é respeitado como o tamanho mínimo durante toda a execução do algoritmo. Espera-se também que o procedimento de adaptação seja capaz de fazer com que $w$ tenda a um valor mais adequado, especialmente para séries com características sazonais, as quais podem não ser adequadamente capturadas com o valor inicial estipulado para $w$.

Finalmente, não se buscou adaptar o parâmetro $\beta$, já que ele apresenta pouca variância e cumpre seu objetivo assumindo um valor maior do que zero, conforme discutido na Seção 5.6.

Para avaliar a qualidade dessa segunda metodologia para adaptação dos parâmetros de TS-Stream, realizou-se novamente quatro experimentos apresentados anteriormente na Seção 5.7. Os resultados estão ilustrados nas Figuras 5.29 a 5.32. Todos os experimentos foram executados utilizando os mesmos parâmetros descritos na Seção 5.7, porém com a adição de $\eta=0,5$ e tol $=0,05$. É possível observar que, para a maioria dos casos, houve um pequeno aumento no ARI médio e uma pequena diminuição no desvio padrão. Apesar das diferenças não serem estatisticamente significativas, elas apontam que esse mecanismo de adaptação tem o potencial de melhorar a qualidade de soluções encontradas por TSStream. 


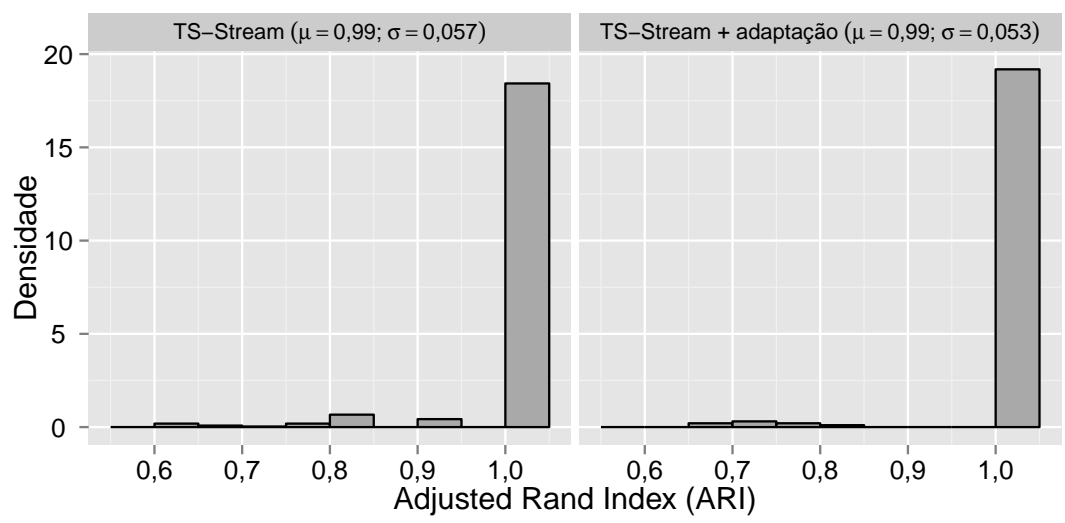

Figura 5.30: Histograma dos resultados de TS-Stream com adaptação para o cenário AR e ARIMA $(1,1,0)$.

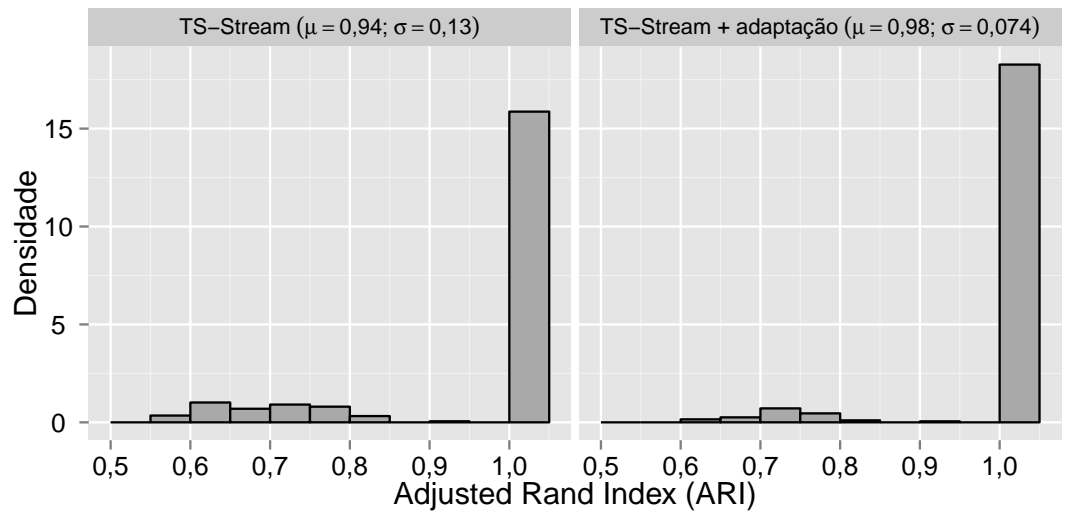

Figura 5.31: Histograma dos resultados de TS-Stream com adaptação para o cenário AR e ARIMA $(1,1,0)$, ambos com não linearidade adicionada.

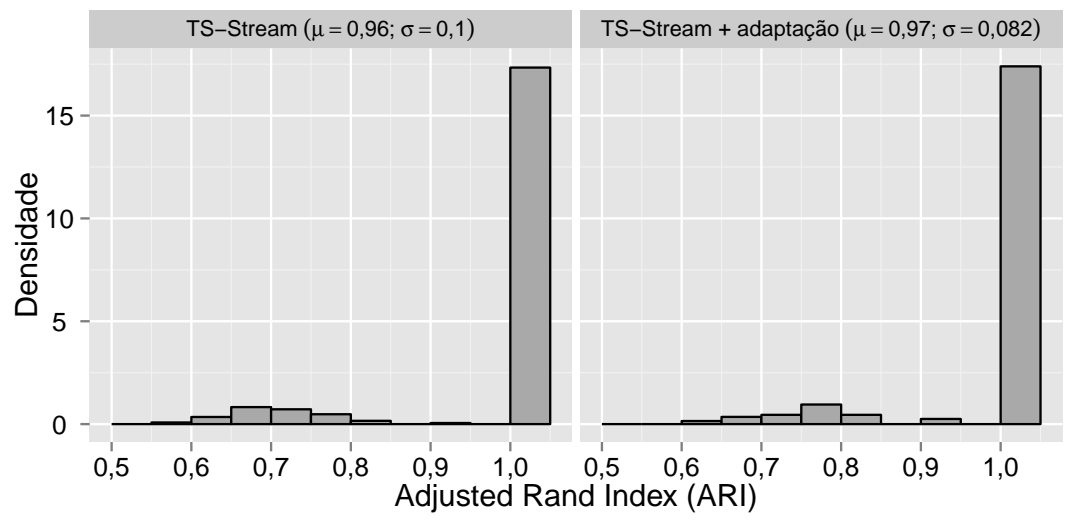

Figura 5.32: Histograma dos resultados de TS-Stream com adaptação automática de parâmetros para o cenário mapa logístico e AR. 


\subsection{Análise dos resultados}

Os resultados obtidos nos diversos experimentos realizados mostraram, com confiança estatística, que a qualidade do agrupamento de TS-Stream supera a de ODAC para os cenários analisados. É importante ressaltar as razões para as diferenças entre os resultados.

Primeiramente é importante explicar o motivo de TS-Stream apresentar baixos valores de ARI em algumas de suas iterações, apesar de seu ARI médio ser alto e com baixo desvio padrão. Considere as Figuras 5.33a a 5.33d, as quais apresentam árvores produzidas por TS-Stream durante uma execução sobre uma base de dados contendo a partição $\{\{1,2, \ldots, 10\},\{11,12, \ldots, 20\}\}$, composta por um grupo de séries geradas por um modelo $\mathrm{AR}(1)$ e um grupo de séries geradas por um modelo $\mathrm{AR}(1)$ com não linearidade adicionada.

Observa-se que, na Figura 5.33a, a partição gerada por TS-Stream divide corretamente as séries nos dois grupos existentes. Já na Figura 5.33b, nota-se que o valor do coeficiente FOU1 (o primeiro coeficiente obtido pela Transformada de Fourier) não mais permite uma divisão correta, ficando a série 1 no grupo incorreto. TS-Stream é capaz de perceber que a divisão não é mais adequada e realiza a agregação dos nós filhos de volta à raiz da árvore - Figura 5.33c. Nesse momento, a qualidade da partição, medida segundo o ARI, retorna zero, já que todas as séries estão no mesmo grupo. Entretanto, três iterações à frente, TS-Stream consegue novamente realizar a partição correta dos dados, conforme ilustrado na Figura 5.33d. Assim, resultados ruins podem ocorrer durante algumas iterações de TS-Stream devido à necessidade de agregação e nova divisão, quando o atributo de corte usado em um nó torna-se inadequado. É importante ressaltar que tais cenários não são frequentes, o que pode ser observado no alto valor médio de ARI e baixo desvio padrão que TS-Stream obteve nos experimentos realizados.

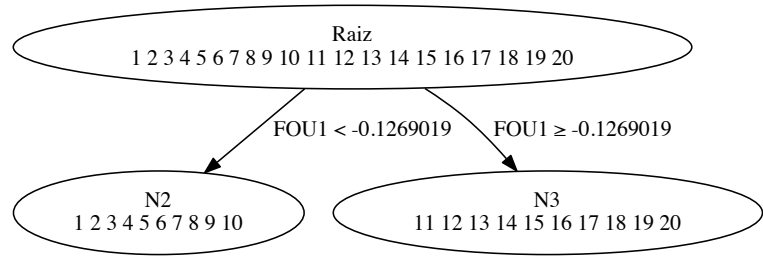

(a) Iteração 8.

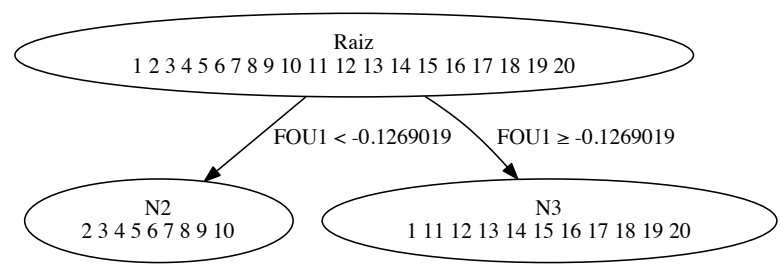

(b) Iteração 9.

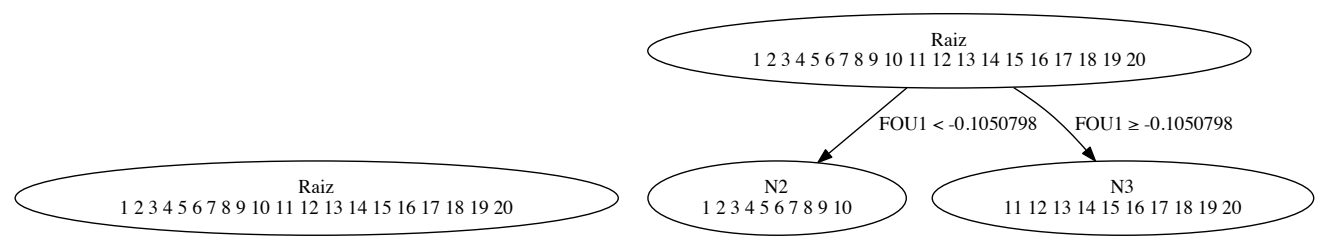

(c) Iteração 10.

(d) Iteração 13.

Figura 5.33: Análise de resultados do TS-Stream durante uma execução sobre uma base de dados com grupos formados por séries $\mathrm{AR}(1)$ e $\mathrm{AR}(1)$ com não linearidade adicionada. FOU1 indica o primeiro coeficiente obtida pela Transformada de Fourier.

Em segundo lugar é importante destacar as fortes diferenças de resultados entre TSStream e ODAC. A medida de dissimilaridade utilizada por ODAC, denominada de Rooted 

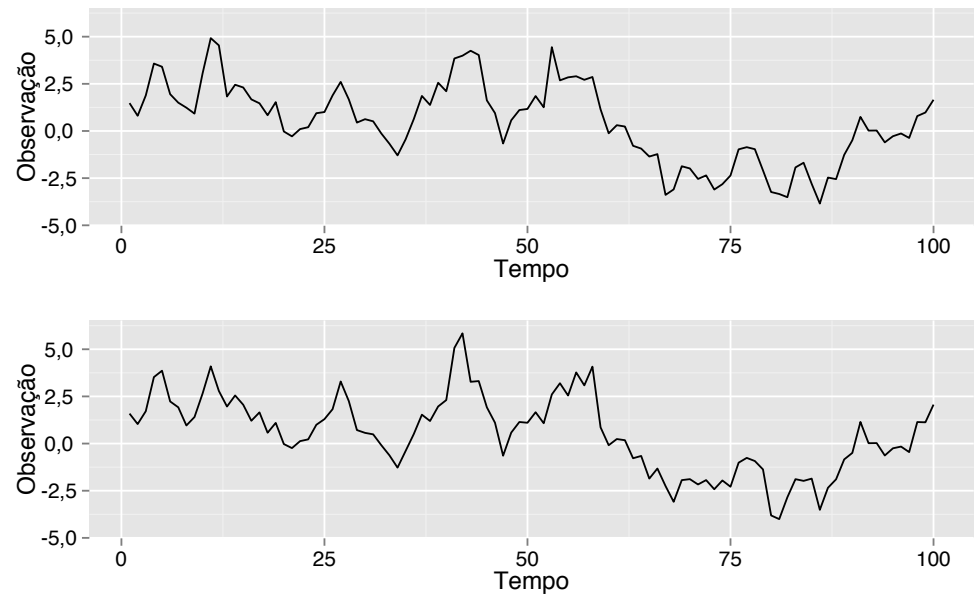

Figura 5.34: Exemplo de duas séries geradas segundo o modelo proposto por ODAC - Equação 5.13 com parâmetro $\beta=0,3$.

Normalized One Minus Correlation (RNOMC) é baseada exclusivamente na correlação de Pearson, medida sobre as observações das séries. A principal vantagem nessa escolha é que a correlação de Pearson pode ser facilmente calculada de forma incremental, apenas com o armazenamento e atualização de poucas variáveis. Isso é especialmente interessante no cenário de fluxos contínuos, no qual não se pode armazenar todas as observações. Porém, como demonstrado nos experimentos em diversos cenários, a correlação de Pearson falha na detecção de similaridade entre séries geradas por um mesmo modelo.

Os autores de ODAC (Rodrigues et al., 2008) analisaram seu comportamento utilizando um modelo que, para um dado grupo $c_{k}$, uma série pivô $p$ é gerada seguindo uma caminhada aleatória. Cada série adicional, $p_{i}$, do grupo, é gerada segundo a Equação 5.13, em que $U(-\beta p, \beta p)$ é um ruído amostrado de uma distribuição Uniforme, parametrizada por uma constante $\beta$ e a série pivô $p$.

$$
p_{i}=p+U(-\beta p, \beta p)
$$

A Figura 5.34 apresenta um exemplo de duas séries geradas seguindo o modelo proposto por ODAC e com parâmetro $\beta=0,3$. É possível observar que o comportamento das duas séries é muito similar, apesar de $30 \%$ de ruído adicionado. Calculando a correlação de Pearson entre as duas séries obtém-se o valor 0,97 , indicando que existe alta correlação entre ambas.

Para o modelo de séries temporais proposto por ODAC, a medida de dissimilaridade utilizada (RNOMC) mostra-se adequada, permitindo que o algoritmo encontre corretamente os grupos. Entretanto, para vários modelos de séries temporais, tais como AR e ARIMA, a correlação de Pearson nem sempre consegue detectar a similaridade entre as séries, apesar de terem sido geradas a partir de um mesmo modelo e com mesma parametrização (ver exemplo da Figura 1.3).

Essa limitação, inerente à correlação de Pearson, quando executada diretamente sobre as observações das séries, faz com que a qualidade do agrupamento de ODAC seja muito 
prejudicada nos cenários apresentados.

TS-Stream é capaz de sanar as limitações de ODAC nesses cenários por meio do uso de diversas medidas para a caracterização dos modelos geradores das séries. Essa caracterização permite identificar melhor quais os relacionamentos entre as séries, e consequentemente sua proximidade. O critério de minimização de variância adotado por TS-Stream contribui para a seleção dos coeficientes mais significativos obtidos pelas medidas, a fim de obter uma melhor segmentação.

A partir dos coeficientes calculados pelas medidas descritivas, TS-Stream segmenta as séries em grupos que refletem as propriedades matemáticas de seus modelos geradores, consequentemente resultando em um agrupamento de maior qualidade segundo o Adjusted Rand Index.

\subsection{Considerações finais}

Este capítulo apresentou o algoritmo proposto neste trabalho de doutorado, o qual utiliza as medidas descritivas de séries temporais para realizar um agrupamento baseado em características do modelo gerador de séries. Resultados experimentais em diversas bases de dados mostraram, com relevância estatística, que a qualidade do agrupamento de TS-Stream, medida pelo Adjusted Rand Index, supera a de ODAC. A seguir, as conclusões são apresentadas. 


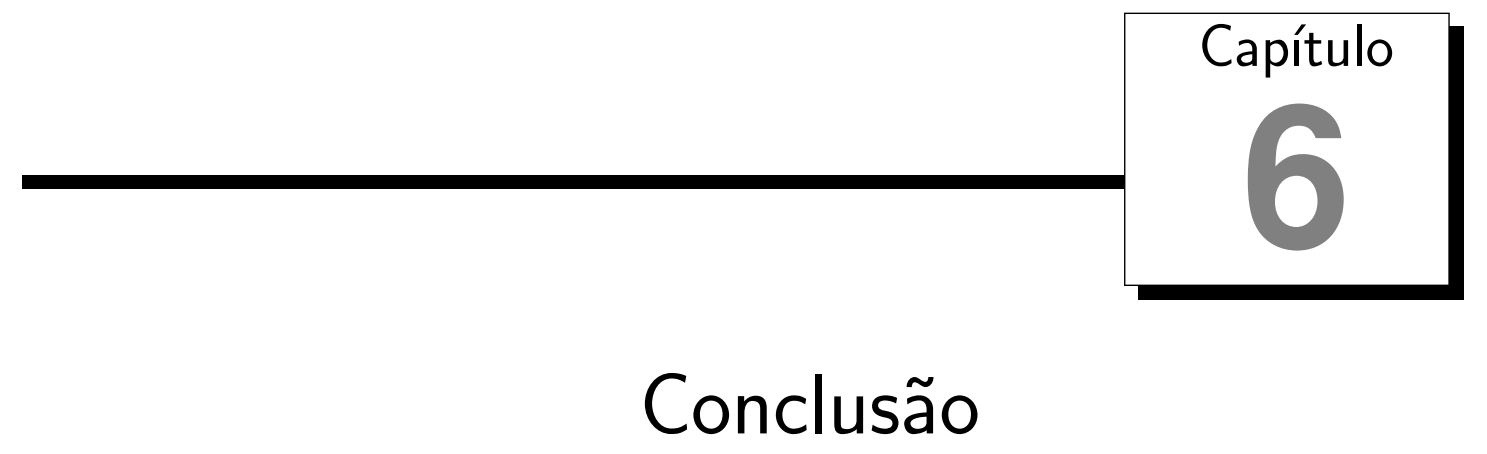

\subsection{Conclusões}

Este trabalho de doutorado iniciou-se com a investigação de propostas para o agrupamento de séries temporais em fluxos contínuos de dados. Foi possível observar que poucas abordagens para esse cenário existem na literatura. A principal abordagem encontrada, e da qual outras derivaram, é ODAC (Rodrigues et al., 2008), que utiliza a correlação de Pearson como base para o cálculo de dissimilaridade.

Conforme mostrado no Capítulo 1, existem vários casos para os quais a correlação de Pearson não se mostra adequada, pois não é capaz de identificar a similaridade entre séries geradas segundo um mesmo modelo e com mesma parametrização. Essa limitação ressalta a falta de uma melhor caracterização do modelo gerador de séries, não apenas tomando como base suas observações, mas diversas propriedades matemáticas.

Essa lacuna motivou o estudo de diversas medidas descritivas de séries temporais, tais como a Autoinformação Mútua, os expoentes de Hurst e Lyapunov, medidas de quantificação de recorrência, e outras, a fim de melhor caracterizar o modelo gerador de séries temporais (ver Capítulos 3 e 4). Nesse sentido, a taxonomia proposta por Ishii et al. (2011) auxiliou na identificação de propriedades importantes de modelos geradores, tais como estocasticidade, linearidade e estacionariedade.

O estudo com as diversas medidas envolveu a realização de experimentos em um cenário controlado de classificação, a fim de avaliar a capacidade discriminativa das medidas considerando diferentes classes de séries temporais. Esses estudos levaram a um ranking das diversas medidas de acordo com o Ganho de Informação (Tan et al., 2005) de cada uma (Capítulo 4).

Os bons resultados obtidos com as medidas no cenário de classificação motivaram 
a proposta de uma abordagem de agrupamento que as tomasse por base. Isso levou à proposta do algoritmo TS-Stream, que funciona tomando como entrada vários coeficientes calculados a partir das medidas descritivas de séries temporais.

Com uma abordagem inspirada em árvores de decisão e uma estratégia top-down, iniciando com todas as séries em um mesmo grupo, o algoritmo avalia quais atributos são mais relevantes para sucessivas divisões dos nós. A avaliação se dá por meio de um critério de minimização de variância, similar ao Ganho de Informação, porém sem o uso da informação de classes.

Experimentos com TS-Stream mostraram que o algoritmo supera ODAC (Rodrigues et al., 2008) quanto à qualidade de agrupamento segundo o Adjusted Rand Index em diversos cenários. TS-Stream também obteve sucesso em um cenário com evolução de grupos, no qual séries migravam de um modelo gerador para outro, consequentemente alterando a estrutura dos grupos. O algoritmo mostrou-se eficaz em adaptar-se ao novo cenário, característica importante para fluxos contínuos.

As contribuições deste trabalho podem ser sumarizadas da seguinte forma. Em primeiro lugar, a avaliação e ranking de diversas medidas descritivas quanto ao seu poder discriminativo, considerando vários modelos e classes de séries temporais. Em segundo lugar, a proposta de um critério de minimização de variância que funciona de maneira similar ao Ganho de Informação. Em terceiro lugar, a proposta e avaliação de um algoritmo de agrupamento que leva em conta as medidas estudadas para uma melhor caracterização do modelo gerador de séries temporais, consequentemente obtendo um agrupamento de maior qualidade em cenários em que outras técnicas da literatura atualmente falham.

Como resultado deste trabalho, foi submetido um artigo científico que encontra-se em fase de avaliação:

- PEREIRA, C. M. M.; Rodrigo F. de Mello. On relevant features for time series classification. 2013. Journal of Artificial Intelligence Research. p. 1-28.

Dois artigos foram publicados até o momento:

- PEREIRA, C. M. M.; Rodrigo F. de Mello. Common Dissimilarity Measures are Inappropriate for Time Series Clustering. Revista de Informática Teórica e Aplicada: RITA, v. 20, p. 25-48, 2013.

- PEREIRA, C. M. M.; Rodrigo F. de Mello. A Comparison of Clustering Algorithms for Data Streams. In: First International Conference on Integrated Computing Technology, 2011, São Carlos. Communications in Computer and Information Science. New York: Springer Verlag, 2011. v. 165. p. 59-74.

Um artigo foi aceito e ainda não publicado:

- PEREIRA, C. M. M.; Rodrigo F. de Mello. TS-Stream: Clustering Time Series on Data Streams. 2013. Journal of Intelligent Information Systems. p. 1-28. 


\subsection{Atividades futuras}

Trabalhos futuros podem explorar diferentes componentes da abordagem proposta nesta tese. Uma possível continuação se dá pela adaptação de medidas descritivas para que seu cálculo possa ser realizado de forma incremental, assim como a correlação de Pearson. Outra possibilidade é o estudo de mecanismos para determinar se um nó deve continuar a ser particionado ou não, sem o uso de parametrização, mas avaliando apenas a distribuição dos coeficientes das séries. Uma terceira linha de estudo pode ser a paralelização das etapas do algoritmo, já que diversas delas são independentes, como os cálculos dos coeficientes das medidas descritivas, os cálculos de variância e a busca pelo melhor ponto de corte. Outra linha de pesquisa pode avaliar estratégias de poda para a árvore, por exemplo, caso seja desejada maior eficiência de TS-Stream. Isso pode ser feito reduzindo-se a altura da árvore por meio de estratégias de poda, ao custo de se obter uma partição com maior granulosidade. 


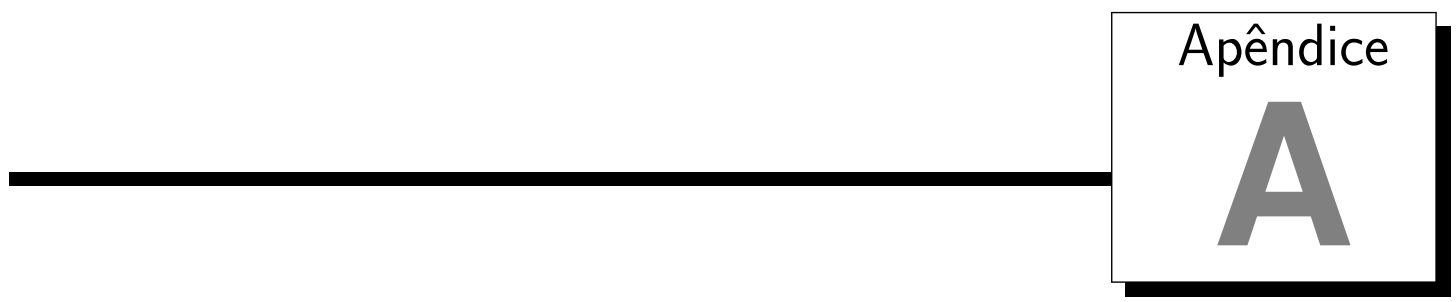

\section{Ranking das medidas descritivas de séries} temporais

Este apêndice apresenta as tabelas completas com o Ganho de Informação calculado para as diversas medidas descritivas, discutidas nos Capítulos 3 e 4 . Como várias medidas fornecem diversos coeficientes (e.g. Fourier), foram selecionados apenas os 20 primeiros dessas medidas. Para o cálculo do Ganho, foi calculada uma média desses coeficientes e depois a média sobre as 30 bases. O desvio padrão para cada medida também é apresentado. 
Tabela A.1: Ranking das medidas descritivas de séries temporais de acordo com Ganho de Informação para as 30 bases no cenário sem adição de ruído.

\begin{tabular}{cccc}
\hline Rank & Medida & Ganho de Informação & Desvio \\
\hline 1 & AMI & 0,971 & 0,000 \\
2 & DFA & 0,971 & 0,000 \\
3 & ARIMA-D & 0,968 & 0,008 \\
4 & FOU & 0,964 & 0,012 \\
5 & Hurst & 0,924 & 0,027 \\
6 & AR & 0,919 & 0,030 \\
7 & MA & 0,861 & 0,020 \\
8 & Lyapunov & 0,850 & 0,038 \\
9 & IF & 0,753 & 0,024 \\
10 & DET & 0,714 & 0,013 \\
11 & L & 0,706 & 0,018 \\
12 & Lentr & 0,680 & 0,031 \\
13 & Lmax & 0,669 & 0,033 \\
14 & DCT & 0,578 & 0,014 \\
15 & WAV & 0,565 & 0,016 \\
16 & CWT & 0,550 & 0,059 \\
17 & X.RR & 0,523 & 0,044 \\
18 & T & 0,434 & 0,036 \\
19 & Ventr & 0,357 & 0,024 \\
20 & Fmin & 0,346 & 0,029 \\
21 & LAM & 0,289 & 0,024 \\
22 & TT & 0,289 & 0,024 \\
23 & Vmax & 0,272 & 0,010 \\
\hline
\end{tabular}


Tabela A.2: Ranking das medidas descritivas de séries temporais de acordo com Ganho de Informação para as 30 bases no cenário com adição de ruído.

\begin{tabular}{cccc}
\hline Rank & Medida & Ganho de Informação & Desvio \\
\hline 1 & ARIMA-D & 0,966 & 0,012 \\
2 & FOU & 0,962 & 0,012 \\
3 & MA & 0,946 & 0,032 \\
4 & AR & 0,896 & 0,026 \\
5 & Lyapunov & 0,800 & 0,000 \\
6 & AMI & 0,732 & 0,051 \\
7 & Ventr & 0,665 & 0,024 \\
8 & Lentr & 0,653 & 0,032 \\
9 & T & 0,619 & 0,064 \\
10 & DET & 0,587 & 0,014 \\
11 & L & 0,587 & 0,014 \\
12 & LAM & 0,585 & 0,013 \\
13 & TT & 0,585 & 0,013 \\
14 & DCT & 0,578 & 0,013 \\
15 & WAV & 0,572 & 0,012 \\
16 & X.RR & 0,548 & 0,052 \\
17 & CWT & 0,482 & 0,051 \\
18 & Lmax & 0,380 & 0,041 \\
19 & Vmax & 0,379 & 0,042 \\
20 & Fmin & 0,370 & 0,050 \\
21 & Hurst & 0,291 & 0,056 \\
22 & DFA & 0,231 & 0,021 \\
23 & IF & 0,188 & 0,032 \\
\hline & & &
\end{tabular}

Tabela A.3: Ranking das medidas descritivas de séries temporais de acordo com Ganho de Informação para as 30 bases de músicas.

\begin{tabular}{cccc}
\hline Rank & Medida & Ganho de Informação & Desvio \\
\hline 1 & AMI & 0,971 & 0,000 \\
2 & FOU & 0,971 & 0,000 \\
3 & LAM & 0,964 & 0,026 \\
4 & Lmax & 0,964 & 0,026 \\
5 & Lentr & 0,964 & 0,026 \\
6 & Vmax & 0,964 & 0,026 \\
7 & Ventr & 0,964 & 0,026 \\
8 & T & 0,964 & 0,026 \\
9 & DFA & 0,939 & 0,061 \\
10 & L & 0,727 & 0,197 \\
11 & TT & 0,727 & 0,197 \\
12 & DET & 0,724 & 0,200 \\
13 & Fmin & 0,722 & 0,196 \\
14 & WAV & 0,720 & 0,199 \\
15 & ARIMA-D & 0,672 & 0,171 \\
16 & Hurst & 0,639 & 0,151 \\
17 & AR & 0,618 & 0,157 \\
18 & X.RR & 0,523 & 0,184 \\
19 & CWT & 0,510 & 0,169 \\
20 & MA & 0,472 & 0,165 \\
\hline
\end{tabular}




\section{Apêndice
0
0
0 \\ Execuções de ODAC utilizando as medidas descritivas}

Este apêndice apresenta as execuções de ODAC para os cenários apresentados no Capítulo 5, porém com as medidas descritivas de séries temporais como entrada. O objetivo dos resultados aqui apresentados é o de mostrar que a simples alteração na entrada de ODAC, fornecendo as medidas ao invés das séries temporais, não permite um ganho significativo de acurácia, indicando que a conjunção de TS-Stream com as medidas descritivas fornece um ganho real de acurácia.

Conforme pode ser observado nos gráficos das Figuras B.1, B.2, B.3 e B.4, os resultados em termos de Adjusted Rand Index mostram que TS-Stream supera fortemente ODAC, enquanto se verifica apenas uma pequena melhora ao se comparar a versão original de ODAC e sua versão modificada, que recebe como entrada as medidas descritivas.

O pequeno ganho obtido em acurácia pela simples modificação na entrada de ODAC deve-se à medida de similaridade RNOMC utilizada pelo algoritmo. Como ela só é capaz de detectar relacionamentos lineares simples, a substituição das séries originais pelas medidas descritivas já fornece um ganho, pois facilita a identificação das similaridades por RNOMC. Entretanto, mesmo com essa mudança, ODAC ainda explora de maneira precária as informações contidas nas medidas, o que justifica o uso de TS-Stream para obter um ganho significativo de acurácia. 


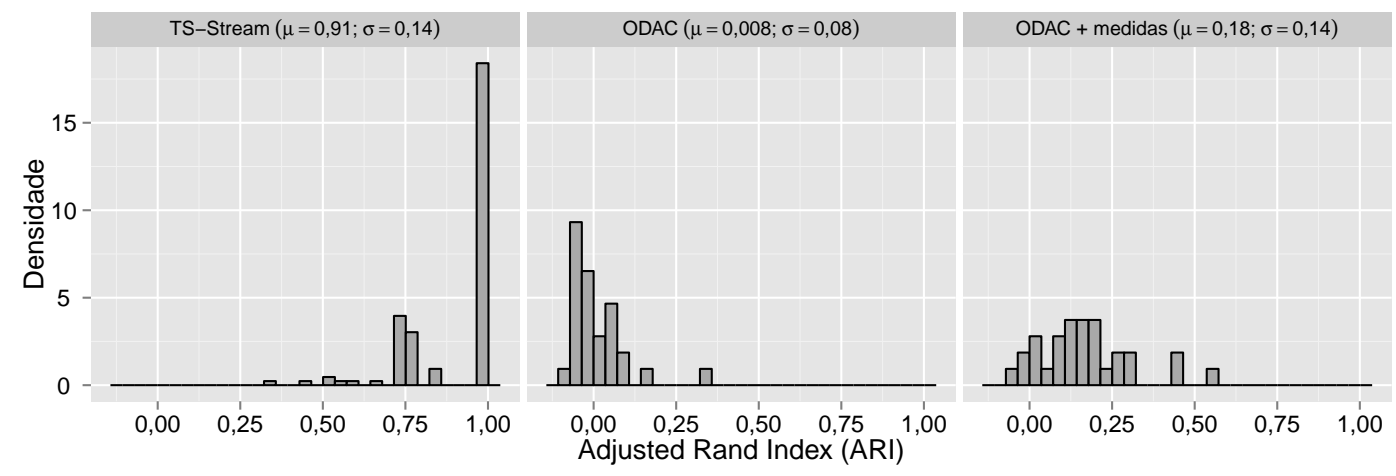

Figura B.1: Histograma dos resultados de ODAC usando as medidas descritivas como entrada para o cenário AR e AR com não linearidade adicionada.
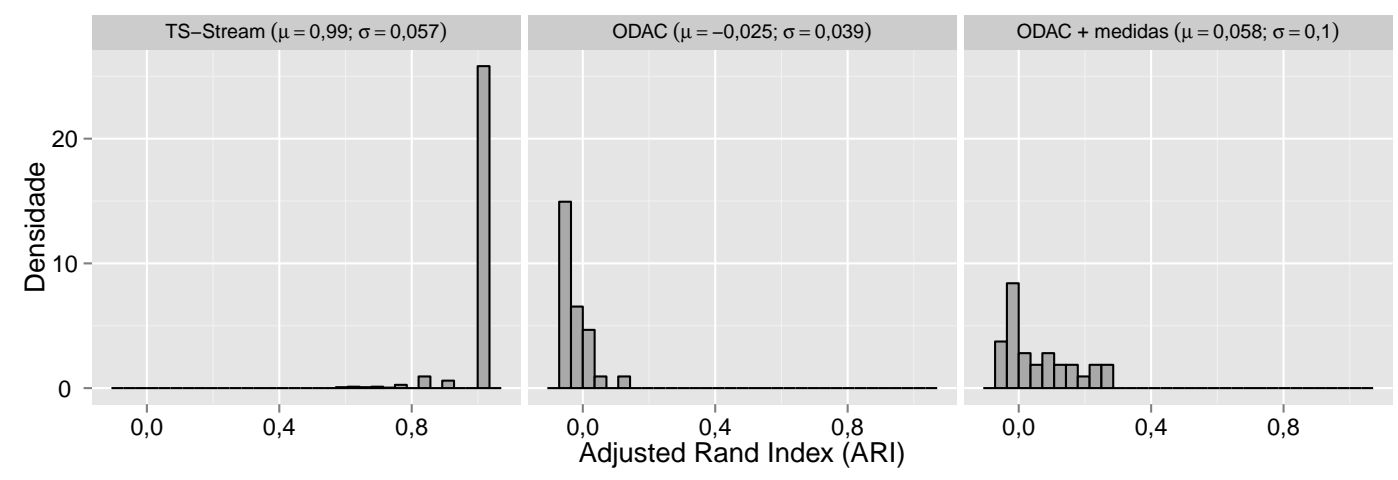

Figura B.2: Histograma dos resultados de ODAC usando as medidas descritivas como entrada para o cenário AR e ARIMA $(1,1,0)$.

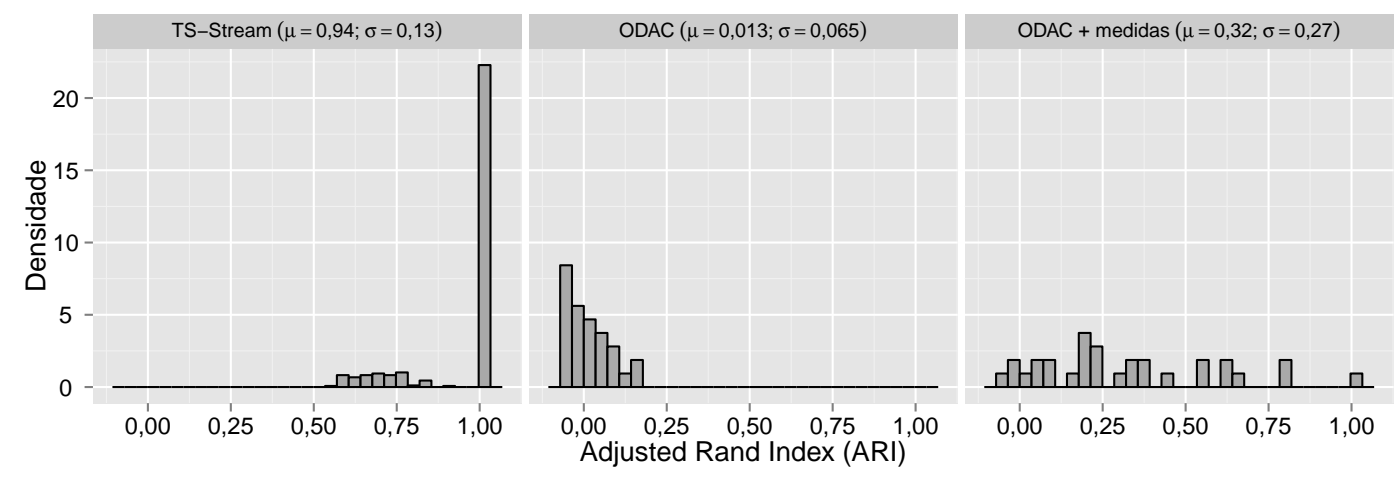

Figura B.3: Histograma dos resultados de ODAC usando as medidas descritivas como entrada para o cenário AR e $\operatorname{ARIMA}(1,1,0)$ ambos com não linearidade adicionada. 

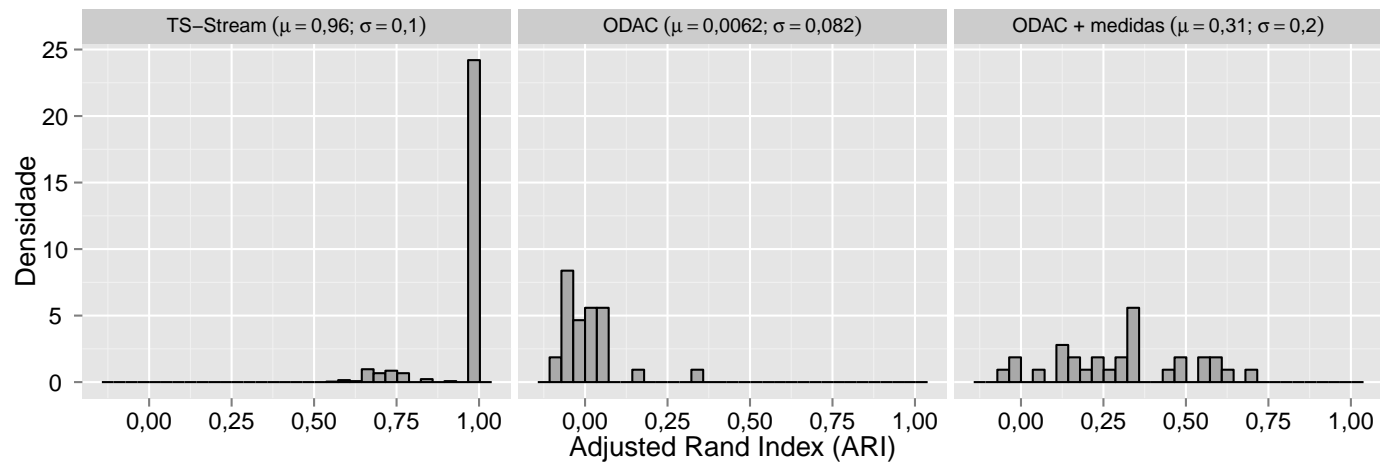

Figura B.4: Histograma dos resultados de ODAC usando as medidas descritivas como entrada para o cenário mapa logístico e AR. 
Apêndice

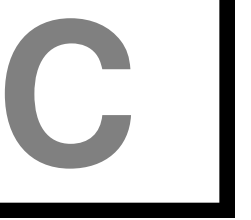

\section{Análise do comportamento da correlação de Pearson}

Este apêndice apresenta uma análise do comportamento da correlação de Pearson quando utilizada para comparar séries temporais provenientes de modelos Autorregressivos de Box e Jenkins (1994). O objetivo deste estudo, tanto analítica quanto experimentalmente, é de mostrar que a correlação de Pearson não é uma medida adequada para comparar a semelhança entre os modelos matemáticos de duas séries temporais provenientes de modelos Autorregressivos, devido à sua sensibilidade a ruído e outliers.

Considera-se aqui o cálculo da correlação de Pearson para duas séries temporais: $X=\left(x_{1}, \ldots, x_{n}\right)$ e $Y=\left(y_{1}, \ldots, y_{n}\right)$, provenientes de modelos $\mathrm{AR}(1)$, estacionárias e com mesma observação inicial $y_{1}=x_{1}$. Seja a correlação de Pearson dada pela Equação C.1, em que $\bar{X}$ é a média da série $X$ e $\bar{Y}$ é a média da série $Y$.

$$
\operatorname{corr}(X, Y)=\frac{\sum_{i=1}^{n}\left(x_{i}-\bar{X}\right) \cdot\left(y_{i}-\bar{Y}\right)}{\sqrt{\sum_{i=1}^{n}\left(x_{i}-\bar{X}\right)^{2}} \cdot \sqrt{\sum_{i=1}^{n}\left(y_{i}-\bar{Y}\right)^{2}}}
$$

Seja um modelo Autorregressivo de ordem 1 dado pela Equação C.2, na qual $a_{t}$ é distribuído de acordo com uma Normal de média $\mu$ e desvio padrão $\sigma: a_{t} \sim N(\mu, \sigma)$ e $c$ é uma constante.

$$
x_{t}=\phi_{X} \cdot x_{t-1}+a_{t}+c
$$

Primeiramente, ao analisar o comportamento esperado de uma série $\mathrm{AR}(1)$, pode-se obter sua média $\bar{X}$, conforme mostrado na Equação C.3. Considera-se aqui uma série estacionária, portanto seu valor esperado é $E\left[x_{t}\right]=E\left[x_{t-1}\right]=\bar{X}$ e $|\phi|<1$. Considerase também que $a_{t} \sim N(0, \sigma)$ e portanto $E\left[a_{t}\right]=0$. Assume-se que $c=0$ e, portanto, 
$E[c]=c=0$.

$$
\begin{aligned}
E\left[x_{t}\right] & =E\left[\phi \cdot x_{t-1}\right]+E\left[a_{t}\right]+E[c] \\
\bar{X} & =\phi E\left[x_{t-1}\right]+0+c \\
\bar{X} & =\phi \bar{X}+0+c \\
\bar{X}-\phi \bar{X} & =c \\
\bar{X}(1-\phi) & =c \\
\bar{X} & =\frac{c}{1-\phi} \\
\bar{X} & =\frac{0}{1-\phi} \\
\bar{X} & =0
\end{aligned}
$$

Para simplificar a exposição, supõe-se que $X$ e $Y$ apresentam o mesmo valor inicial, portanto $y_{1}=x_{1}$. Supõe-se também que $\phi_{Y}=\phi_{X}=\phi$ e ambas utilizam $a_{t} \sim N(0, \sigma)$. Com isso, pode-se substituir $\bar{X}$ e $\bar{Y}$ na Equação C.1 por 0, obtendo a Equação C.4.

$$
\operatorname{corr}(X, Y)=\frac{\sum_{i=1}^{n} x_{i} \cdot y_{i}}{\sqrt{\sum_{i=1}^{n}\left(x_{i}\right)^{2}} \cdot \sqrt{\sum_{i=1}^{n}\left(y_{i}\right)^{2}}}
$$

A partir da Equação C.4, a qual simplifica o cálculo para séries com média 0, procede-se à análise de estabilidade da correlação de Pearson. É instrutivo estudar seu comportamento conforme o valor do desvio padrão $\sigma$ varia, utilizado para a geração do ruído branco presente em modelos Autorregressivos.

Considere duas séries com mesma observação inicial $x_{1}$ e compostas por apenas duas observações, conforme mostrado na Equação C.5 e com $N_{1} \sim N(0, \sigma)$ e $N_{2} \sim N(0, \sigma)$.

$$
\begin{aligned}
& X=\left(x_{1}, \phi x_{1}+N_{1}\right) \\
& Y=\left(x_{1}, \phi x_{1}+N_{2}\right)
\end{aligned}
$$

Substituindo os termos na Equação C.4 pelas observações das séries obtém-se a Equação C.6.

$$
\operatorname{corr}(X, Y)=\frac{x_{1}^{2}+\left(\phi x_{1}+N_{1}\right)\left(\phi x_{1}+N_{2}\right)}{\sqrt{x_{1}^{2}+\left(\phi x_{1}+N_{1}\right)^{2}} \sqrt{x_{1}^{2}+\left(\phi x_{1}+N_{2}\right)^{2}}}
$$

Neste ponto é importante observar que, na Equação C.6, seu denominador é estritamente positivo, pois apesar das amostras da distribuição Normal poderem assumir valores negativos, eles são elevados ao quadrado antes da extração da raiz. Expandindo o numerador e denominador, obtém-se a Equação C.8 com denominador $d$, mostrado na Equação C.7. 


$$
\begin{aligned}
d_{1}= & N_{1}^{2} N_{2}^{2}+N_{1}^{2} x_{1}^{2}+N_{2}^{2} x_{1}^{2}+x_{1}^{4}+2 N_{1}^{2} N_{2} x_{1} \phi+2 N_{1} N_{2}^{2} x_{1} \phi \\
d_{2}= & 2 N_{1} x_{1}^{3} \phi+2 N_{2} x_{1}^{3} \phi+N_{1}^{2} x_{1}^{2} \phi^{2}+4 N_{1} N_{2} x_{1}^{2} \phi^{2}+N_{2}^{2} x_{1}^{2} \phi^{2} \\
d_{3}= & 2 x_{1}^{4} \phi^{2}+2 N_{1} x_{1}^{3} \phi^{3}+2 N_{2} x_{1}^{3} \phi^{3}+x_{1}^{4} \phi^{4} \\
d= & \sqrt{d_{1}+d_{2}+d_{3}} \\
& \operatorname{corr}(X, Y)=\frac{x_{1}^{2}+x_{1}^{2} \phi^{2}+N_{2} x_{1} \phi+N_{1} x_{1} \phi+N_{1} N_{2}}{d}
\end{aligned}
$$

Analisando separadamente cada termo, tem-se para o primeiro:

$$
\frac{x_{1}^{2}}{\sqrt{\ldots+x_{1}^{4}+\ldots}}
$$

Pode-se notar que caso a fração consistisse em $x_{1}^{2} / \sqrt{x_{1}^{4}}$ o resultado seria 1 , porém o denominador contém a adição de vários outros termos, muitos dos quais dependem dos valores amostrados a partir da distribuição $N(0, \sigma)$. Ora, conforme $\sigma$ aumenta, os valores obtidos da distribuição tendem a divergir cada vez mais de zero, fazendo com que esses elementos tornem-se dominantes. Nesse caso, o termo $N_{1}^{2} N_{2}^{2}$ domina os outros, considerando que $0<x_{1}<1$ e $|\phi|<1$. Esse primeiro termo tende, portanto, a zero.

Continuando a análise, para o segundo termo tem-se a fração:

$$
\frac{x_{1}^{2} \phi^{2}}{\sqrt{\ldots+x_{1}^{4} \phi^{4}+\ldots}}
$$

A mesma argumentação aplicada para o primeiro termo pode ser utilizada para o segundo, observando os termos destacados. Para o terceiro termo obtém-se:

$$
\frac{N_{2} x_{1} \phi}{\sqrt{\ldots+N_{2}^{2} x_{1}^{2} \phi^{2}+\ldots}}
$$

Para o quarto termo obtém-se:

$$
\frac{N_{1} x_{1} \phi}{\sqrt{\ldots+N_{1}^{2} x_{1}^{2} \phi^{2}+\ldots}}
$$

Finalmente, para o quinto termo:

$$
\frac{N_{1} N_{2}}{\sqrt{\ldots+N_{1}^{2} N_{2}^{2}+\ldots}}
$$

Essa análise evidencia que, conforme $\sigma$ aumenta, o termo mais relevante é $N_{1} N_{2}$, especialmente considerando-se que $0<x_{1}<1$ e $|\phi|<1$ e que todos os termos no denominador, com exceção de $N_{1}^{2} N_{2}^{2}$ são multiplicados por pelo menos $x_{1}$ ou $\phi$, fazendo com que sejam substancialmente reduzidos. Caso $\sigma$ seja alto, $N_{1} N_{2}$ também tende a produzir grandes valores. Isso faz com que toda a fração se aproxime de 1 , conforme o limite descrito na Equação C.9, em que $\psi, \epsilon \ll N_{1} N_{2}$. Esse resultado é surpreendente, já 
que se espera que conforme o ruído aumente, menor seja a similaridade entre as séries. Porém, como os termos dependentes do ruído dominam a correlação de Pearson para séries provenientes de modelos Autorregressivos, o resultado tende a 1. Para valores relativamente pequenos de $\sigma$, a magnitude de $N_{1} N_{2}$ é comparável à dos outros termos da equação, fazendo com que a correlação torne-se próxima a zero, já que os termos somados no denominador superam o numerador.

$$
\lim _{\sigma \rightarrow+\infty} \frac{\psi+N_{1} N_{2}}{\sqrt{\epsilon+N_{1}^{2} N_{2}^{2}}} \approx 1
$$

Para mostrar essa instabilidade da correlação de Pearson utiliza-se aqui a desigualdade de McDiarmid (1989):

"Sejam $X_{1}, \ldots, X_{n}$ variáveis aleatórias independentes que assumem valores no conjunto $\mathcal{X}$. Seja $f: \mathcal{X}^{n} \mapsto \mathbb{R}$ uma função de $X_{1}, \ldots, X_{n}$ que satisfaz $\forall i, \forall x_{1}, \ldots, x_{n}, x_{i}^{\prime} \in \mathcal{X} \operatorname{com}\left|f\left(x_{1}, \ldots, x_{i}, \ldots, x_{n}\right)-f\left(x_{1}, \ldots, x_{i}^{\prime}, \ldots, x_{n}\right)\right| \leq c_{i}$. Então, para todo $\epsilon>0: \operatorname{Pr}[f-\mathbb{E}[f] \geq \epsilon] \leq \exp \left(\frac{-2 \epsilon^{2}}{\sum_{i=1}^{n} c_{i}^{2}}\right)$."

A desigualdade indica que, para uma dada função $f$, caso sua entrada seja alterada em apenas um elemento $x_{i}$, seu resultado deve diferir de no máximo $c_{i}$ do valor original e a probabilidade de divergência é limitada por uma função exponencial dos valores de $c_{i}$ e da divergência $\epsilon$. Assim, para uma função estável, espera-se baixos valores de $c_{i}$ e baixas probabilidades de alta divergência.

Um primeiro experimento mostra como a divergência de McDiarmid cresce com a correlação de Pearson conforme cresce o valor de $\sigma$. A Figura C.1 apresenta os resultados com uma série temporal $X$ seguindo uma distribuição Normal com média zero, desvio padrão um e composta por 1000 observações. Utilizou-se uma série seguindo uma distribuição Normal e não um modelo Autorregressivo porque a desigualdade de McDiarmid requer séries compostas por observações aleatórias e independentes. Entretanto, modelos Autorregressivos usam como entrada justamente observações geradas a partir de uma distribuição Normal para compor os termos $a_{t}$, assim a análise é relevante. Cada boxplot apresenta os valores da divergência $\left|f\left(x_{1}, \ldots, x_{i}, \ldots, x_{n}\right)-f\left(x_{1}, \ldots, x_{i}^{\prime}, \ldots, x_{n}\right)\right|$ obtidos ao se alterar cada observação da série $X$ por um ruído amostrado de uma distribuição Normal com média zero e desvio $\sigma$. É possível observar uma tendência de crescimento da divergência conforme $\sigma$ aumenta, indicando a sensibilidade de Pearson à alteração de um único valor em uma série de 1000 observações.

Um segundo experimento visou mostrar que a correlação de Pearson tende a 1 quando o ruído torna-se dominante em uma série que segue um modelo Autorregressivo, o que foi mostrado anteriormente via o equacionamento. A Figura C.2 apresenta a correlação de Pearson média para valores crescentes de $\sigma$. Cada ponto da curva indica a média de 30 execuções experimentais, gerando duas séries AR(1) com 1000 observações, $x_{1}=y_{1}=0,5$ e $\phi=0,5$. A Figura C.3 apresenta a curva do desvio padrão. É possível observar que a 


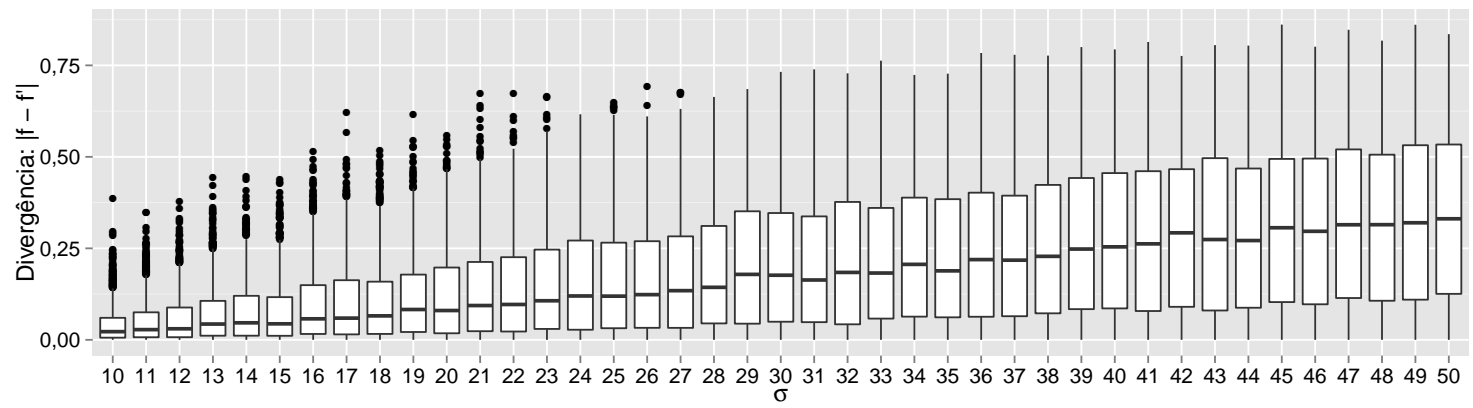

Figura C.1: Resultados dos experimentos da divergência de McDiarmid para a correlação de Pearson, alterando um único valor $x_{i}^{\prime}$ da série a cada iteração.

correlação média tende a crescer conforme a magnitude do ruído aumenta, o que é feito por meio do incremento de $\sigma$.

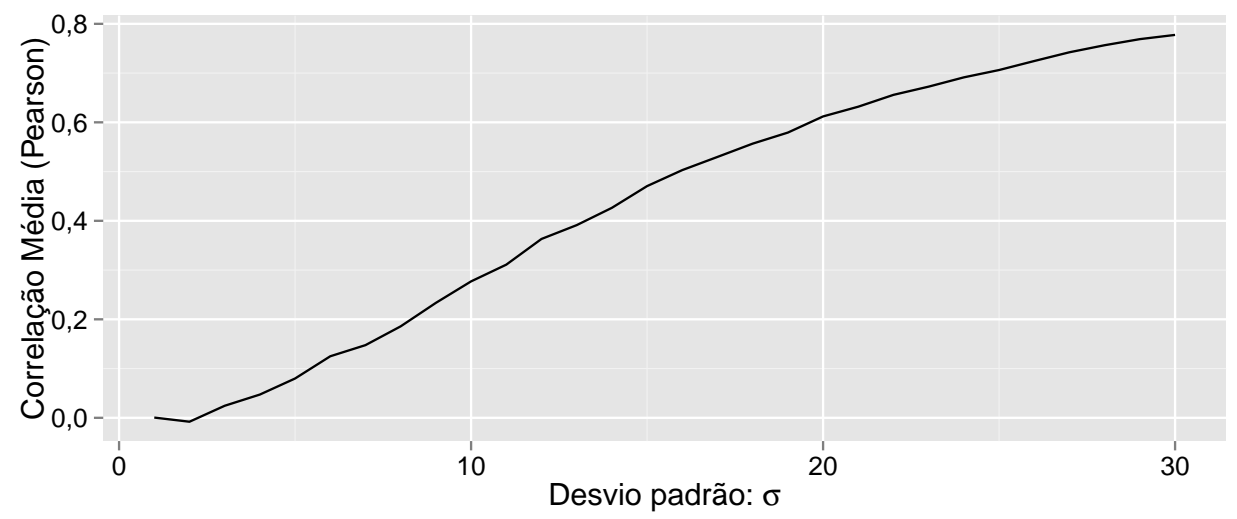

Figura C.2: Correlação de Pearson entre duas séries $\operatorname{AR}(1)$ conforme o valor de $\sigma$ aumenta.

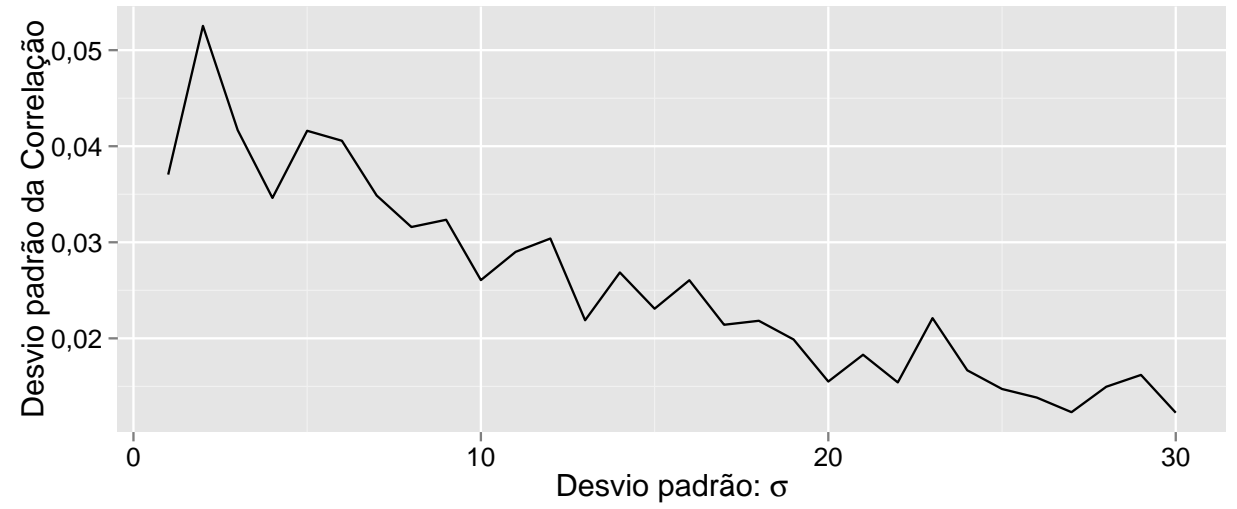

Figura C.3: Desvio padrão da Correlação de Pearson entre duas séries $\operatorname{AR}(1)$ conforme o valor de $\sigma$ aumenta.

Um terceiro experimento visou mostrar que a probabilidade da desigualdade de McDiarmid ser maior do que $\epsilon$ para a correlação de Pearson é alta, o que indica sua instabilidade. O experimento foi realizado variando o tamanho $n$ de uma série $\mathrm{X}$ amostrada de uma distribuição Normal com média $\mu=0$ e desvio padrão $\sigma=1$. A cada iteração foi alterado um valor da série pelo valor 1000000 e o tamanho da série foi incrementado em uma 
unidade. O lado direito da desigualdade de McDiarmid foi então calculado, notadamente por $\exp \left(\frac{-2 \epsilon^{2}}{\sum_{i=1}^{n} c_{i}^{2}}\right)$. Observa-se que o valor máximo de $\epsilon$, ou seja, da divergência esperada é 2, já que a correlação de Pearson está entre -1 e 1. A Figura C.4 apresenta as curvas para diferentes valores de $\epsilon$.

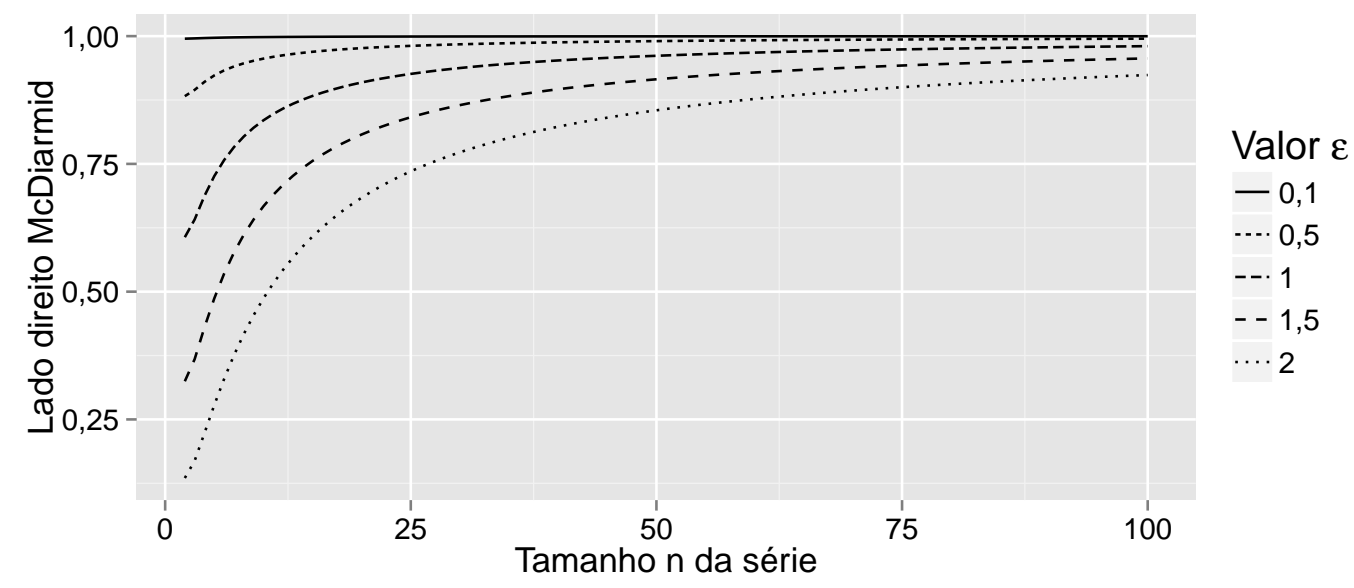

Figura C.4: Lado direito da desigualdade de McDiarmid para vários valores de $\epsilon$.

Por meio dos resultados é possível observar que, quanto maior a divergência permitida, dada por $\epsilon$, menor a probabilidade inicial de que a alteração de um único valor na série provoque uma mudança maior do que $\epsilon$ na correlação de Pearson. Entretanto, observa-se que a probabilidade de divergência cresce rapidamente, chegando próxima a $100 \%$ em vários cenários. Segundo a desigualdade de McDiarmid, isso indica a instabilidade da correlação de Pearson com a alteração de apenas uma única observação.

O estudo analítico e os experimentos apresentados neste apêndice evidenciam que a correlação de Pearson é uma medida instável para ser usada como similaridade entre séries temporais. Essa análise confirma os resultados experimentais obtidos ao longo desta tese, os quais mostram as deficiências que o algoritmo ODAC (Rodrigues et al., 2008) sofre, muitas das quais se originam no uso exclusivo da correlação de Pearson como medida de similaridade entre séries temporais. 


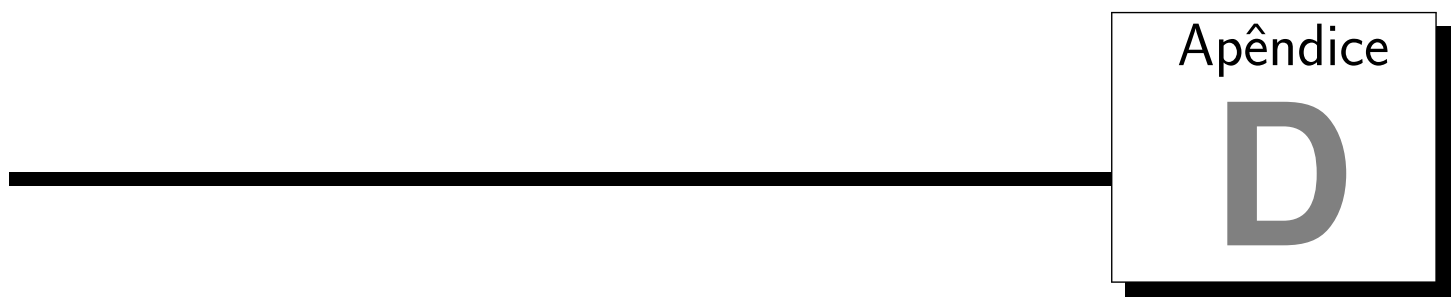

\section{Lista de músicas utilizadas}

As músicas listadas na Tabela D.1 foram extraídas do Free Music Archive e podem ser obtidas no sítio http://freemusicarchive.org/. A Seção 4.3 apresenta os resultados dos experimentos de classificação utilizando as músicas. 
Tabela D.1: Músicas utilizadas nos experimentos de classificação com séries temporais reais.

\begin{tabular}{|c|c|}
\hline Gênero & Músicas \\
\hline Blues & $\begin{array}{l}\text { The_Rope_River_Blues_Band-Capulet } \\
\text { Steve_Gunn-Improvisation_2 } \\
\text { Cian_Nugent-Double_Horse } \\
\text { My_Bubba_\&_Mi-Nothing_Much } \\
\text { The_Rope_River_Blues_Band-Dance! } \\
\text { Cooper-Moore-h_Banjo_Arba_Minch_Garden } \\
\text { Black_Rebel_Motorcycle_Club-Beat_The_Devil's_Tattoo_Live_@_KEXP } \\
\text { My_Bubba_\&_Mi-Oh_Kiss_No } \\
\text { Kevin_MacLeod-Slow_Burn } \\
\text { Cian_Nugent-My_War_Blues }\end{array}$ \\
\hline Classical & $\begin{array}{l}\text { Alastair_Cameron-gentle_marimba } \\
\text { Lee_Maddeford-Le_petit_jardin_with_Les_Gauchers_Orchestra } \\
\text { Fabrizio_Paterlini-Veloma } \\
\text { Jason_Weinberger_\&_the_WCFSO-Mahler_-_Symphony_no._5,_I._Trauermarsch } \\
\text { Alastair_Cameron-spooky } \\
\text { Kevin_MacLeod-Gagool } \\
\text { Lee_Maddeford-Wheel_of_fortune_with_Les_Gauchers_Orchestra } \\
\text { Victor_Herbert_Orchestra-1910_-_The_Prima_Donna } \\
\text { Lee_Maddeford-Ouverture } \\
\text { Lee_Maddeford-Tom's_Lullaby_with_Les_Gauchers_Orchestra }\end{array}$ \\
\hline Disco & $\begin{array}{l}\text { Kevin_MacLeod-Presenterator } \\
\text { YACHT-Utopia_instrumental } \\
\text { YACHT-Shangri-La_instrumental } \\
\text { Nambavan-Gorodskoy_Paren } \\
\text { YACHT-Dystopia_instrumental } \\
\text { YACHT-Tripped_\&_Fell_In_Love_instrumental } \\
\text { YACHT-Paradise_Engineering_instrumental } \\
\text { YACHT-Beam_Me_Up_instrumental } \\
\text { YACHT-I_Walked_Alone_instrumental } \\
\text { YACHT-One_Step_instrumental }\end{array}$ \\
\hline Hip-Hop & $\begin{array}{l}\text { Daddy_Scrabble-Flying_pea_v.1 } \\
\text { Morphamish-Another_Position_original_mix } \\
\text { Broke_For_Free-Calm_The_Fuck_Down } \\
\text { M.W.D.-Singing_Forest } \\
\text { Black_Ant-Fater_Lee } \\
\text { Daddy_Scrabble-05_CherryBlossom } \\
\text { Morphamish_+_MAKO-Ooo } \\
\text { Daddy_Scrabble-LordDa_Mercy } \\
\text { Morphamish_remixes_Full_Blush-Engine_\#3_Morphamish_Remix } \\
\text { Morphamish-Lookatcha }\end{array}$ \\
\hline
\end{tabular}




\section{Referências}

Abramowitz, M. Handbook of mathematical functions, with formulas, graphs, and mathematical tables. Dover Publications, Incorporated, 1974. Citado nas páginas 32 e 59 .

Aggarwal, C. C. Data streams: Models and algorithms (advances in database systems). Secaucus, NJ, USA: Springer-Verlag New York, Inc., 2006. Citado na página 1.

Aggarwal, C. C.; Han, J.; Wang, J.; Yu, P. S. A framework for clustering evolving data streams. In: VLDB '2003: Proceedings of the 29th international conference on Very large data bases, VLDB Endowment, p. 81-92, 2003. Citado nas páginas 2 e 17.

Aggarwal, C. C.; Han, J.; Wang, J.; Yu, P. S. A framework for projected clustering of high dimensional data streams. In: VLDB '04: Proceedings of the Thirtieth international conference on Very large data bases, VLDB Endowment, p. 852-863, 2004. Citado na página 2.

Ahmed, N.; Natarajan, T.; RaO, K. R. Discrete cosine transfom. IEEE Transactions on Computers, v. 23, p. 90-93, 1974. Citado na página 40.

Alligood, K.; Sauer, T.; Yorke, J. Chaos: an introduction to dynamical systems. Springer, 1997. Citado nas páginas 8, 10, e 11.

Ao, S.-I. Applied time series analysis and innovative computing, v. 59. Springer Verlag, 2010. Citado na página 42.

APPEL, G. Technical analysis: power tools for active investors. First ed. FT Press, 2005. Citado nas páginas 93 e 94.

Ardia, D.; Boudt, K.; Carl, P.; Mullen, K. M.; Peterson, B. G. Differential Evolution with DEoptim: An application to non-convex portfolio optimization. The R Journal, v. 3, n. 1, p. 27-34, 2011. Citado na página 87.

Athanassiou, P. Research handbook on hedge funds, private equity and alternative investments. Edward Elgar Pub, 2012. Citado na página 4. 
BAldi, P.; Brunak, S. Bioinformatics: the machine learning approach. Bradford Book, 2001. Citado na página 1.

BÉLisle, C. Convergence theorems for a class of simulated annealing algorithms on rd. Journal of Applied Probability, p. 885-895, 1992. Citado na página 87.

Beringer, J.; Hüllermeier, E. Online clustering of parallel data streams. Data Knowl. Eng., v. 58, p. 180-204, 2006. Citado nas páginas 5, 17, 18, 19, e 29.

Bifet, A.; Kirby, R. Data stream mining: A practical approach. Relatório Técnico, The University of Waikato, 2009. Citado nas páginas 2, 19, e 90.

Black, F.; Scholes, M. The pricing of options and corporate liabilities. The journal of political economy, p. 637-654, 1973. Citado na página 13.

Box, G.; Jenkins, G. Time series analysis: forecasting and control. Prentice Hall PTR, 1994. Citado nas páginas 5, 6, 12, 13, 21, 22, 45, 46, 53, e 125.

CAo, F. Density-based clustering over an evolving data stream with noise. In: Proc. Sixth SIAM Intl Conf. Data Mining, 2006. Citado na página 2.

Chaovalit, P. Clustering transient data streams by example and by variable. Tese de Doutoramento, University of Maryland, 2009. Citado nas páginas 5, 22, 23, e 29.

Chatfield, C. Time-series forecasting. CRC Press, 2001. Citado na página 3.

Chen, W.; Chang, S. Motion trajectory matching of video objects. In: Society of Photo-Optical Instrumentation Engineers (SPIE) Conference Series, p. 544-553, 1999. Citado nas páginas 6 e 26.

Cohen, J.; ET AL. A coefficient of agreement for nominal scales. Educational and psychological measurement, v. 20, n. 1, p. 37-46, 1960. Citado na página 65.

Cover, T.; HART, P. Nearest neighbor pattern classification. Information Theory, IEEE Transactions on, v. 13, n. 1, p. 21-27, 1967. Citado nas páginas 2 e 58.

Darbellay, G. A.; VAJdA, I. Estimation of the information by an adaptive partitioning of the observation space. IEEE Trans. Inf. Theor., v. 45, n. 4, p. 1315-1321, 2006.

Disponível em http://dx.doi.org/10.1109/18.761290 Citado nas páginas xvii, 104, 105 , e 106.

Daubechies, I. Ten lectures on wavelets. Philadelphia, PA, USA: Society for Industrial and Applied Mathematics, 1992. Citado na página 40. 
Ding, H.; Trajcevski, G.; Scheuermann, P.; Wang, X.; Keogh, E. Querying and mining of time series data: experimental comparison of representations and distance measures. Proceedings of the VLDB Endowment, v. 1, p. 1542-1552, 2008. Citado nas páginas 52 e 58 .

Dodonov, E. Uma abordagem de predição da dinâmica comportamental de processos para prover autonomia a ambientes distribuidos. Tese de Doutoramento, Universidade de São Paulo, São Carlos, 2009. Citado na página 9.

DíAz, S. P.; Vilar, J. A. Comparing several parametric and nonparametric approaches to time series clustering: A simulation study. J. Classif., v. 27, p. 333-362, 2010. Disponível em http://dx.doi.org/10.1007/s00357-010-9064-6 Citado na página 84 .

Eckmann, J.; Kamphorst, S.; Ruelle, D. Recurrence plots of dynamical systems. EPL (Europhysics Letters), v. 4, p. 973, 1987. Citado na página 32.

EleRT, G. The chaos hypertextbook. 1995.

Disponível em http://hypertextbook.com/chaos/ Citado nas páginas 35 e 36.

Feynman, R.; Leighton, R.; Sands, M.; Hafner, E. The feynman lectures on physics; vol. i. American Journal of Physics, v. 33, p. 750, 1965. Citado nas páginas 13 e 39 .

FOURIER, J. Théorie analytique de la chaleur, v. 1. Gauthier-Villars et fils, 1888. Citado nas páginas 5, 12, 13, 26, e 39 .

Fraser, A.; Swinney, H. Independent coordinates for strange attractors from mutual information. Physical Review A, v. 33, n. 2, p. 1134-1140, 1986. Citado nas páginas $12,32,47$, e 48 .

Fujita, A.; Sato, J.; Demasi, M.; Sogayar, M.; Ferreira, C.; Miyano, S. Comparing Pearson, Spearman and Hoeffding's D measure for gene expression association analysis. Journal of Bioinformatics and Computational Biology, v. 7, n. 4, p. 663-84, 2009. Citado nas páginas 5, 8, e 22.

Gaber, M. M.; Zaslavsky, A.; Krishnaswamy, S. Mining data streams: a review. SIGMOD Rec., v. 34, n. 2, p. 18-26, 2005. Citado na página 1.

Gama, J. Knowledge discovery from data streams. 1st ed. Chapman \& Hall/CRC, 2010. Citado nas páginas 1, 2, e 4.

Gama, J.; Rodrigues, P. Stream-based electricity load forecast. Knowledge Discovery in Databases: PKDD 2007, p. 446-453, 2007. Citado na página 3.

Graps, A. An introduction to wavelets. IEEE Comput. Sci. Eng., v. 2, n. 2, p. 50-61, 1995. Citado na página 5. 
HAAR, A. Zur theorie der orthogonalen funktionensysteme. Mathematische Annalen, v. 69, n. 3, p. 331-371, 1910. Citado nas páginas 40 e 42.

Halkidi, M.; Batistakis, Y.; Vazirgiannis, M. On clustering validation techniques. J. Intell. Inf. Syst., v. 17, p. 107-145, 2001. Citado nas páginas 6, 27, e 70.

HILBERT, D. Grundzüge einer allgemeinen theorie der linearen integralgleichungen. BG Teubner, 1912. Citado nas páginas 13, 43, e 45.

Hoeffoing, W. Probability inequalities for sums of bounded random variables. Journal of the American Statistical Association, p. 13-30, 1963. Citado nas páginas 5 e 20 .

Huang, N.; Shen, Z.; Long, S.; Wu, M.; Shih, H.; Zheng, Q.; Yen, N.; Tung, C.; LiU, H. The empirical mode decomposition and the hilbert spectrum for nonlinear and non-stationary time series analysis. Proceedings of the Royal Society of London. Series A: Mathematical, Physical and Engineering Sciences, v. 454, n. 1971, p. 903, 1998. Citado nas páginas 43, 44, e 45.

Hubert, L.; Arabie, P. Comparing partitions. Journal of Classification, v. 2, p. 193-218, 10.1007/BF01908075, 1985. Citado nas páginas 14 e 70.

Ishis, R. P.; Rios, R. A.; De Mello, R. F. Classification of time series generation processes using experimental tools: a survey and proposal of an automatic and systematic approach. International Journal of Computational Science and Engineering, v. 1, p. 1-21, 2011. Citado nas páginas 10, 12, 14, 29, 31, 32, 48, 49, 53, 54, 60, 70, e 113 .

IVAnCEVIC, V.; IVAnCEvic, T. Complex nonlinearity: chaos, phase transitions, topology change, and path integrals. Springer Verlag, 2008. Citado na página 53.

Jain, A. K.; Dubes, R. C. Algorithms for clustering data. Upper Saddle River, NJ, USA: Prentice-Hall, Inc., 1988. Citado na página 2.

Kantz, H.; SchreIBer, T. Nonlinear time series analysis. New York, NY, USA: Cambridge University Press, 1997. Citado nas páginas 37, 38, e 85.

Kennel, M.; Brown, R.; Abarbanel, H. Determining embedding dimension for phase-space reconstruction using a geometrical construction. Physical review A, v. 45, n. 6, p. 3403, 1992. Citado nas páginas 32 e 47.

Keogh, E.; Ratanamahatana, C. A. Exact indexing of dynamic time warping. Knowledge and Information Systems, v. 7, p. 358-386, 10.1007/s10115-004-0154-9, 2005. Citado na página 19.

KIM, D.; OH, H.-S. EMD: A Package for Empirical Mode Decomposition and Hilbert Spectrum. The $R$ Journal, v. 1, n. 1, p. 40-46, 2009. Citado na página 43. 
Kumar, M.; Patel, N. R. Clustering data with measurement errors. Comput. Stat. Data Anal., v. 51, p. 6084-6101, 2007. Citado na página 23.

Lee, T.; White, H.; Granger, C. Testing for neglected nonlinearity in time series models: a comparison of neural network methods and alternative tests. Journal of Econometrics, v. 56, n. 3, p. 269-290, 1993. Citado na página 53.

Lorenz, E. N. Deterministic Nonperiodic Flow. Journal of the Atmospheric Sciences, v. 20, n. 2, p. 130-141, 1963. Citado nas páginas 36, 47, 48, e 53.

Marwan, N. A historical review of recurrence plots. The European Physical Journal - Special Topics, v. 164, p. 3-12, 2008. Citado nas páginas 32 e 35.

Marwan, N.; Romano, M. C.; Thiel, M.; Kurths, J. Recurrence plots for the analysis of complex systems. Physics Reports, v. 438, n. 5-6, p. 237 -329, 2007. Citado nas páginas 8, 12, 32, 33, 35, e 63 .

McDiarmid, C. On the method of bounded differences. Surveys in combinatorics, v. 141, n. 1, p. 148-188, 1989. Citado na página 128.

O’Callaghan, L.; Meyerson, A.; Motwani, R.; Mishra, N.; Guha, S. Streaming-data algorithms for high-quality clustering. Data Engineering, International Conference on, v. 0, p. 0685, 2002. Citado nas páginas 2 e 17.

Pang, B.; Lee, L.; Vaithyanathan, S. Thumbs up?: sentiment classification using machine learning techniques. In: Proceedings of the ACL-02 conference on Empirical methods in natural language processing-Volume 10, Association for Computational Linguistics, p. 79-86, 2002. Citado na página 1.

Pearson, K. Contributions to the mathematical theory of evolution. Philosophical Transactions of the Royal Society of London. A, v. 185, p. 71-110, 1894. Citado nas páginas 5 e 19 .

Peng, C.; Buldyrev, S.; Havlin, S.; Simons, M.; Stanley, H.; Goldberger, A. On the mosaic organization of DNA sequences. Phys. Rev. E, v. 49, p. 1685-1689, 1994. Citado na página 38.

Percival, D.; Walden, A. Wavelet methods for time series analysis, v. 4 . Cambridge University Press, 2006. Citado nas páginas 40 e 41.

Pereira, C. M. M. Deteç̧ão de faltas: uma abordagem baseada no comportamento de processos. Dissertação de Mestrado, Universidade de São Paulo, 2011. Citado na página 9.

Pompe, B. Measuring statistical dependences in a time series. Journal of Statistical Physics, v. 73, n. 3, p. 587-610, 1993. Citado na página 84. 
QiAn, B.; RASHEED, K. Hurst exponent and financial market predictability. In: Proceedings of The 2nd IASTED international conference on financial engineering and applications, p. 203-209, 2004. Citado na página 37.

Quinlan, J. Induction of decision trees. Machine learning, v. 1, n. 1, p. 81-106, 1986. Citado na página 81.

Quinlan, J. C4. 5: programs for machine learning. Morgan Kaufmann, 1993a. Citado na página 81.

Quinlan, J. R. C4.5: programs for machine learning. San Francisco, CA, USA: Morgan Kaufmann Publishers Inc., 1993b. Citado nas páginas 1, 53, e 59.

R Development Core Team $R$ : A language and environment for statistical computing. R Foundation for Statistical Computing, Vienna, Austria, ISBN 3-900051-07-0, 2011.

Disponível em http://www.R-project.org Citado nas páginas 53 e 87.

Ren, J.; CAI, B.; Hu, C. Clustering over data streams based on grid density and index tree. Journal of Convergence Information Technology, v. 6, n. 1, 2011. Citado na página 2 .

Rodrigues, P. P.; Gama, J. A.; Pedroso, J. Hierarchical clustering of time-series data streams. IEEE Trans. on Knowl. and Data Eng., v. 20, p. 615-627, 2008. Citado nas páginas 5, 6, 19, 24, 25, 28, 29, 69, 71, 84, 87, 103, 111, 113, 114, e 130.

Royston, J. Algorithm as 181: The w test for normality. Journal of the Royal Statistical Society. Series C (Applied Statistics), v. 31, n. 2, p. 176-180, 1982. Citado nas páginas 21 e 22 .

Sammon, J. W. A nonlinear mapping for data structure analysis. IEEE Transactions on Computers., v. 18, n. 5, p. 401-409, 1969. Citado na página 26.

SANDRI, M. Numerical calculation of lyapunov exponents. The Mathematical Journal, v. 6 , n. 3, p. 78-84, 1996. Citado na página 35.

Shannon, C. Prediction and entropy of printed english. Bell System Technical Journal, v. 30, n. 1, p. 50-64, 1951. Citado nas páginas 59 e 72 .

Shannon, C. E. Communication in the presence of noise. Proceedings of the IRE, v. 37, n. 1, p. 10-21, 1949. Citado na página 64.

SkIEnA, S. S. The algorithm design manual. New York, NY, USA: Springer-Verlag New York, Inc., 1998. Citado nas páginas 39 e 84. 
Strehl, A.; Ghosh, J. Cluster ensembles - a knowledge reuse framework for combining multiple partitions. J. Mach. Learn. Res., v. 3, p. 583-617, 2003. Citado nas páginas 6 e 27.

TAKens, F. Detecting strange attractors in turbulence. Dynamical systems and turbulence, Warwick 1980, p. 366-381, 1981. Citado nas páginas 9, 10, 11, 13, e 32.

Tan, P.-N.; Steinbach, M.; Kumar, V. Introduction to data mining. Boston, MA, USA: Addison-Wesley Longman Publishing Co., Inc., 2005. Citado nas páginas 52, 53, $58,59,72,85$, e 113.

Tong, S.; Koller, D. Support vector machine active learning with applications to text classification. In: Journal of Machine Learning Research, Citeseer, 2000. Citado na página 1.

Vendramin, L.; Campello, R.; Hruschka, E. Relative clustering validity criteria: A comparative overview. Statistical Analysis and Data Mining, v. 3, n. 4, p. 209-235, 2010. Citado na página 70.

Walpole, R.; Myers, R.; Myers, S.; Ye, K. Probability and statistics for engineers and scientists. Prentice Hall Upper Saddle River, NJ:, 1998. Citado nas páginas 25, 60,88 , e 95 .

Wan, L.; NG, W. K.; Dang, X. H.; Yu, P. S.; Zhang, K. Density-based clustering of data streams at multiple resolutions. ACM Trans. Knowl. Discov. Data, v. 3, n. 3, p. 1-28, 2009. Citado na página 2.

Whitney, H. Differentiable manifolds. Annals of Mathematics, v. 37, n. 3, p. 645-680, 1936. Citado nas páginas 9, 10, 11, e 13.

Widiputra, H.; Pears, R.; Kasabov, N. Multiple time-series prediction through multiple time-series relationships profiling and clustered recurring trends. In: Proceedings of the 15th Pacific-Asia conference on Advances in knowledge discovery and data mining, Berlin, Heidelberg: Springer-Verlag, p. 161-172, 2011. Citado nas páginas 5, $22,24,25,29,69$, e 71 .

Witten, I. H.; Frank, E. Data mining: practical machine learning tools and techniques with java implementations, v. 31. New York, NY, USA: ACM, 76-77 p., 2002. Citado na página 52.

Xi, X.; Keogh, E.; Shelton, C.; Wei, L.; Ratanamahatana, C. A. Fast time series classification using numerosity reduction. In: Proceedings of the 23rd international conference on Machine learning, New York, NY, USA: ACM, p. 1033-1040, 2006 (ICML '06, v.1).

Disponível em http://doi.acm.org/10.1145/1143844.1143974 Citado nas páginas 52,58 , e 62 . 
Xie, X.; Beni, G. A validity measure for fuzzy clustering. Pattern Analysis and Machine Intelligence, IEEE Transactions on, v. 13, n. 8, p. 841-847, 1991. Citado na página 19.

YAng, Y.; Chen, K. Combining competitive learning networks on various representations for temporal data clustering. Trends in Neural Computation, p. 315-336, 2007. Citado nas páginas 25, 26, 27, e 28.

Yang, Y.; Chen, K. Temporal data clustering via weighted clustering ensemble with different representations. IEEE Trans. on Knowl. and Data Eng., v. 23, p. 307-320, 2011. Citado nas páginas 6, 25, 26, 28, 29, e 71 .

Ye, L.; Keogh, E. Time series shapelets: a new primitive for data mining. In: Proceedings of the 15th ACM SIGKDD international conference on Knowledge discovery and data mining, New York, NY, USA: ACM, p. 947-956, 2009 (KDD '09, v.1). Citado na página 58. 